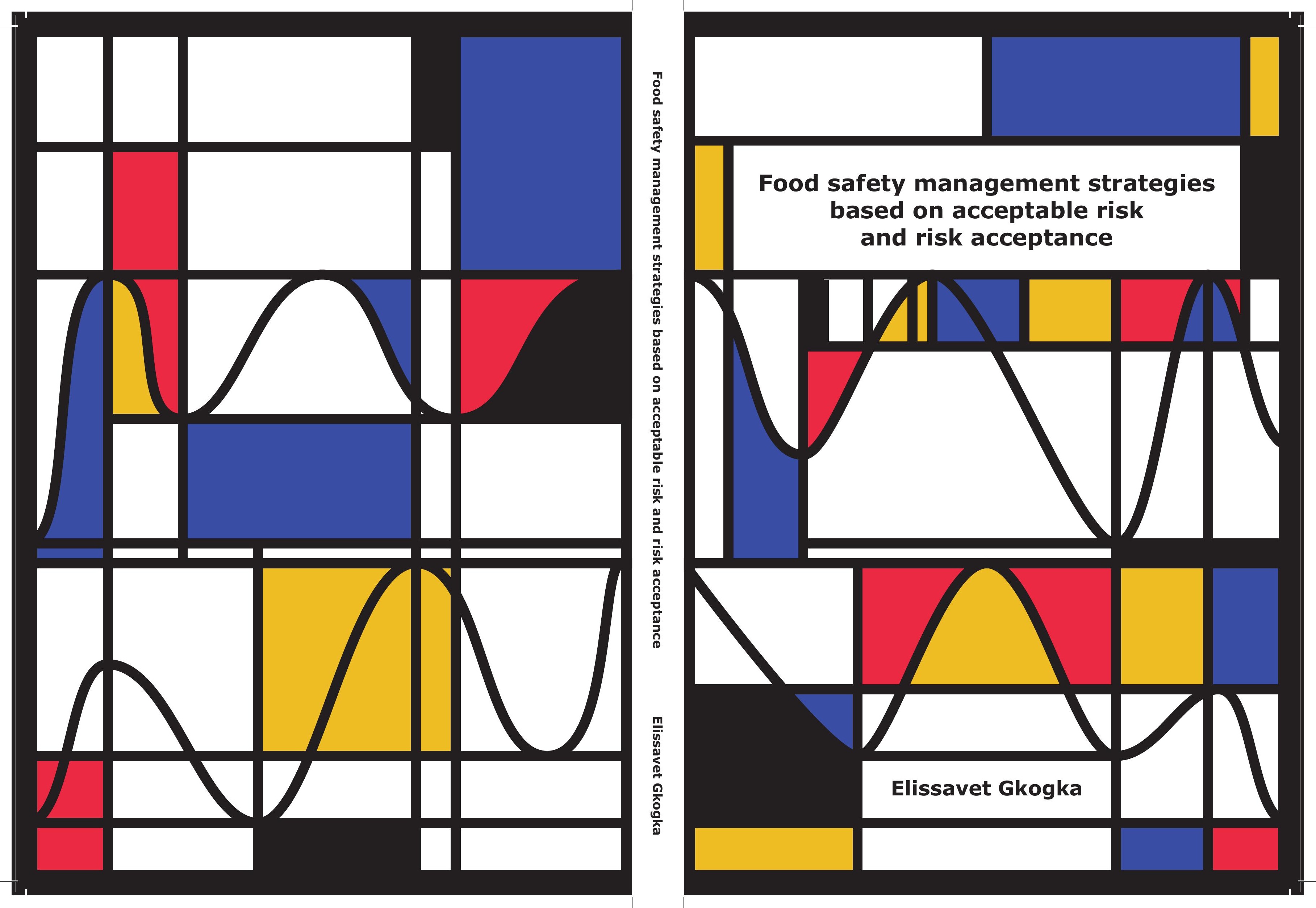




\section{Propositions}

1. The population risk is a better measure than the risk per serving to decide on an appropriate level of protection against foodborne illnesses.

(this thesis)

2. Assessing the appropriate level of protection against foodborne illnesses is a matter of defining both what is an 'acceptable risk' and the timespan of 'current'.

(this thesis)

3. Overconfidence or optimism is a factor biasing risk perception that has more negative impact for the beholder than pessimism.

4. The term food security needs to be replaced by nutrition security.

5. A good researcher is optimistic in the face of uncertainty and keeps a good balance between exploration (digging shallow) and exploitation (digging deep).

6. Similar to bread and wine being symbols of civilization in ancient times, equitable access to food, education and health care should nowadays be viewed as key performance indicators of civilized societies.

7. Fairly sharing $\mathrm{CO}_{2}$ emissions and refugees requires widespread adoption of basic human rights and values rather than just buying into scientific facts and numbers.

Propositions belonging to the thesis, entitled

Food safety management strategies based on acceptable risk and risk acceptance.

\section{Elissavet Gkogka}

Wageningen, $13^{\text {th }}$ September 2019 
Food safety management strategies based on acceptable risk and risk acceptance 


\section{Thesis committee}

\section{Promotors}

Prof. Dr M.H. Zwietering

Professor of Food Microbiology

Wageningen University \& Research

Prof. Dr L.G.M. Gorris

Professor in food safety, risk assessment and risk management

China Agricultural University, Shanghai Ocean University, University of Shanghai for Science and Technology

\section{Co-promotor}

Dr M.W. Reij

Assistant Professor, Laboratory of Food Microbiology

Wageningen University \& Research

\section{Other members}

Prof. Dr J.M. Membré, SECALIM, INRA, Oniris, Université Bretagne Loire, France

Prof. Dr B.H. ter Kuile, University of Amsterdam

Prof. Dr A.C.M. van Hooijdonk, Wageningen University \& Research

Dr J.A. Haagsma, Erasmus MC, University Medical Center Rotterdam

This research was conducted under the auspices of the Graduate School of VLAG (Voeding, Levensmiddelentechnologie, Agrobiotechnologie en Gezondheid; Nutrition, Food Technology, Agrobiotechnology and Health) 


\title{
Food safety management strategies based on acceptable risk and risk acceptance
}

\author{
Elissavet Gkogka
}

\author{
Thesis \\ submitted in fulfilment of the requirements for the degree of doctor \\ at Wageningen University \\ by the authority of the Rector Magnificus, \\ Prof. Dr A.P.J. Mol, \\ in the presence of the \\ Thesis Committee appointed by the Academic Board \\ to be defended in public \\ on Friday 13 September 2019 \\ at 1.30 p.m. in the Aula
}




\section{Elissavet Gkogka}

Food safety management strategies based on acceptable risk and risk acceptance, 284 pages.

PhD thesis, Wageningen University, Wageningen, The Netherlands (2019) With references, with summaries in English and Greek

ISBN 978-94-6395-036-7

DOI https://doi.org/10.18174/496132 


\section{Table of contents}

$\begin{array}{ll}\text { Abbreviation list } & 8\end{array}$

$\begin{array}{lll}\text { Chapter } 1 & \text { Introduction and thesis outline }\end{array}$

$\begin{array}{lll}\text { Chapter } 2 & \text { Risk-based estimate of effect of foodborne }\end{array}$

Chapter 3 The Application of the Appropriate Level of

103

Protection (ALOP) and Food Safety Objective

(FSO) concepts in food safety management,

using Listeria monocytogenes in deli meats as

a case study.

Chapter 4 Risk assessment strategies as a tool in the

139

application of the Appropriate Level of

Protection (ALOP) and Food Safety Objective

(FSO) by risk managers.

Chapter 5 Risk assessment of Clostridium perfringens in

Cornish pasties in the UK.

Chapter $6 \quad$ General discussion

Addenda

Summary (in English)

271

Summary (in Greek)

273

Overview of completed training activities

275

List of publications and presentations

277

Acknowledgements

280

About the author 


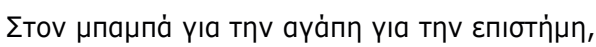

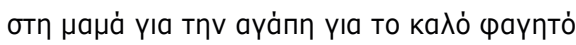




\section{Abbreviation list}

\begin{tabular}{|c|c|}
\hline ALOP & Appropriate Level of Protection \\
\hline CFU & Colony Forming Unit \\
\hline CM & Control Measure \\
\hline DALY & Disability Adjusted Life Year \\
\hline ECDC & European Centre for Disease Prevention and Control \\
\hline EFSA & European Food Safety Authority \\
\hline EHEC & Enterohemorrhagic Escherichia coli \\
\hline EU & European Union \\
\hline FDA & Food and Drug Administration \\
\hline FSO & Food Safety Objective \\
\hline GAP & Good Agricultural Practices \\
\hline GBS & Guillain-Barré Syndrome \\
\hline GMP & Good Manufacturing Practices \\
\hline GHP & Good Hygienic Practices \\
\hline HACCP & Hazard Analysis Critical Control Points \\
\hline HCIDC & Hellenic Center for Infectious Diseases Control \\
\hline HUS & Haemolytic Uraemic Syndrome \\
\hline IBD & Inflammatory Bowel Disease \\
\hline IBS & Irritable Bowel Syndrome \\
\hline LOP & Level of Protection \\
\hline MC & Microbiological Criterion \\
\hline MRA & Microbiological Risk Assessment \\
\hline NSSG & National Statistical Service of Greece \\
\hline PC & Performance Criterion \\
\hline PGI & Protected Geographical Indication \\
\hline PO & Performance Objective \\
\hline PrPs & Prerequisite Programs \\
\hline QALY & Quality Adjusted Life Year \\
\hline QMRA & Quantitative Microbiological Risk Assessment \\
\hline so & Safety Objective \\
\hline WHO & World Heath Organization \\
\hline WTO & World Trade Organization \\
\hline YLD & Years Lived with Disability \\
\hline YLL & Years of Life Lost \\
\hline YOPI & Young Old Pregnant Immunocompromised \\
\hline
\end{tabular}




\section{Chapter 1}

Introduction and thesis outline 


\section{Food, relation to illness and impact on society}

Food is an essential part of our everyday life. Indispensable for our health and wellbeing, a defining characteristic of our identity and culture, and an important element, if not the centre, of many of our social activities. As such, it is no wonder that food security (i.e. the availability of food to people) has played and continues to play a fundamental role in shaping the economy, politics and history of nations. Food can also be the cause of different types of illness, when insufficient or imbalanced amounts are consumed to cover our nutritional requirements (under-nutrition, malnutrition)[1], when our energy intake exceeds our energy expenditure (overweight/obesity) [2] or when food contains hazards rendering it unsafe for consumption [3]. In the latter context, the term hazard refers to a chemical, biological or physical agent present in the food, or a condition of the food, that has the potential to cause an adverse health effect [3]. Despite great technological achievements rendering our food safer than ever, we have not reached a situation where the consumption of food is free of risk [4], and we may never will. Around the world, food related illnesses continue to take a great toll on human health $[5,6]$. Developing countries bear the brunt of the problem, with the death of over half a million children every year due to gastrointestinal illnesses caused by the lack of safe water, sanitation or hygiene, often coinciding with poorer health and nutrition status of the consumers [7]. However, even in developed countries, where the situation is less severe, several hundred cases of food related illness per million inhabitants are reported each year (Figure 1)[8]. Most commonly these illnesses manifest as syndromes of diarrhoea and/or vomiting caused by bacteria, viruses or parasites (infectious gastroenteritis) but besides direct clinical symptoms, they may also result in long term conditions that occur independently or accompany the acute phase response to the pathogenic agents (chronic sequelae) $[9,10]$. Chronic sequelae occur in only a very small fraction of infectious gastroenteritis cases but can be severe with long term consequences on human health, having thus potentially a more detrimental impact on the health of the population than the acute incidents of the disease $[10,11]$.

Globally the exact dimension of the public health burden of food related illness is not precisely known because the reported cases generally constitute only a small fraction of the actual number of cases occurring in a country. For a disease to catch the attention of public health authorities, a series of events need to take place (Figure 2) [12]. More specifically, an individual has to become infected, develop symptoms of the disease and seek medical attention; then the physician needs to decide on a suitable diagnostic test and send a specimen that is not compromised (e.g. by antibiotic use) to a laboratory, which in turn must be able to correctly identify the pathogen and report the findings to the public health authorities. The difference between the number of cases reported to the public health authorities and the cases that actually occur in a community is known as under- 
estimation or undercount or under-reporting [13-15]. In studies providing estimates of the impact of unsafe food consumption in a community, a correction is often made for underestimation of disease incidence, together with adjusting the estimates for the percentage of cases that are transmitted via food [14-16]. The latter is known as food attribution and is necessary for knowing how many of the illnesses are foodborne, i.e. actually due to the consumption of contaminated food, and not due to other sources such as for instance water, the environment, contact with animals or person to person transmission [17].

- Campylobacteriosis

-Salmonellosis

- Other bacterial toxin outbreaks

- Yersiniosis

- Norovirus \& other caliciviruses

$\because$ STEC

n Listeriosis

Echinococcosis

- Hepatitis A

- Brucellosis

- Trichinellosis

- Congenital toxoplasmosis

- Botulism outbreaks
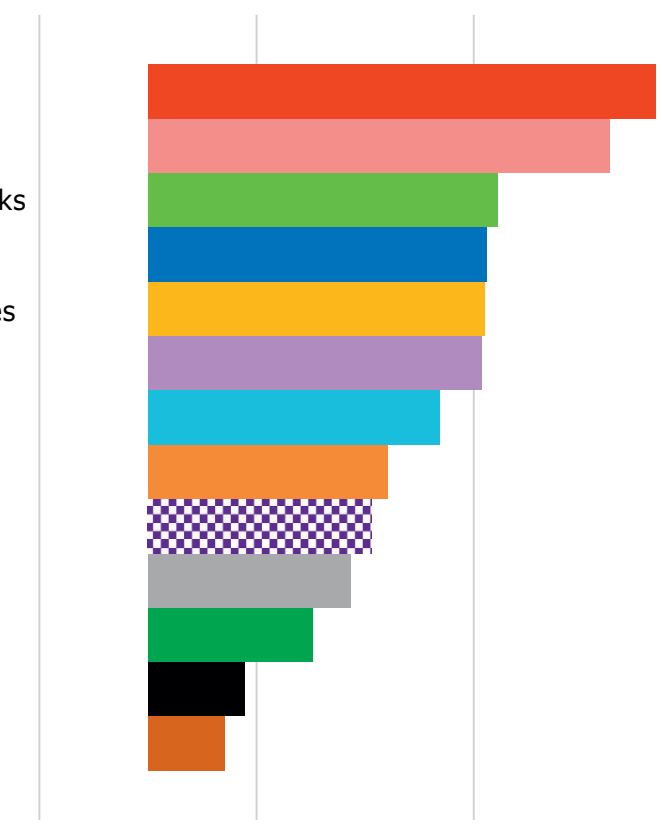

0.001

0.1

10

1000

\section{Cases per million inhabitants}

Figure 1. Reported cases of food related illnesses in the European Union in 2017. Values on the $\mathrm{x}$-axis are presented on a logarithmic scale. Cases due to outbreaks are presented for both strong and weak links with food vehicles. Bacterial toxin outbreaks refer to outbreaks caused by the toxins of bacteria other than C. botulinum. Data are based on the annual EFSA/ECDC report on trends of zoonoses and outbreaks [8] and are expressed as total confirmed cases per million inhabitants in the EU-28 using Eurostat demographic data [18]. 


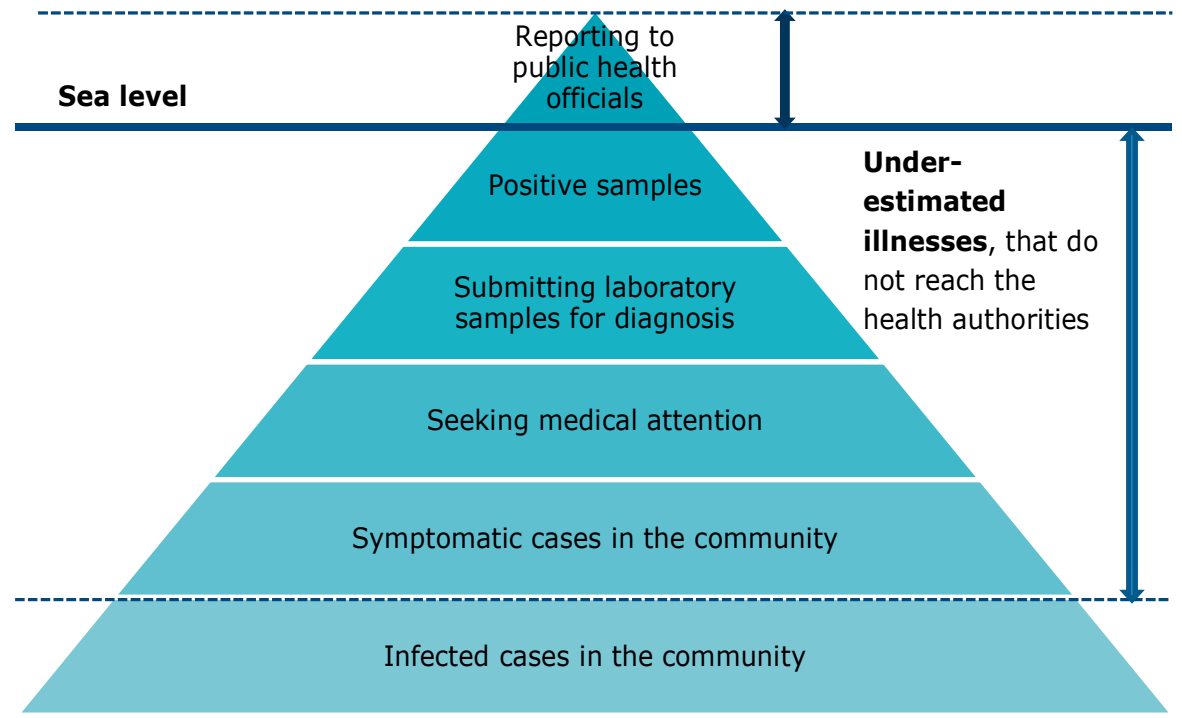

Figure 2. The surveillance pyramid of foodborne illness (adapted from Clark et al., Vijgen et al., Mead et al. and van Lier et al.) $[12,13,15,19]$. Since most illnesses are hidden from the health authorities by not resulting in physician consultations, correct diagnosis and reporting, their incidence can be compared to an "iceberg", only the tip of which is exposed above the "sea level", that is the actual horizon of the surveillance system.

Although it is not possible to provide exact numbers of the incidence of foodborne illnesses in a community, mainly because of uncertainties associated with food attribution and under-estimation, different national studies [14, 20-22] have determined that a considerable percentage of the population is affected every year and that most of the illnesses are caused by hazards that remain unknown/unidentified. As an example, in a recent study in the US, it was found that for every estimated case of illness due to a known agent in food there are approximately four cases due to unknown/unspecified agents [14, 20]. All these illnesses are associated with significant morbidity and mortality and have thus an important impact on public health and peoples' lives, but also on the economy due to medical costs, loss of productivity, recall expenses, cost of legal actions and investigations [23]. In addition, foodborne illnesses can have a great political and social impact, looking for instance at the repercussions of well-known multi-country food crises (e.g. dioxins, bovine spongiform encephalopathy (BSE), melamine), which all attracted considerable media attention, resulted in several ministers resigning and seriously undermined consumer trust in food safety [24-27]. In terms of the societal impact of illnesses associated with the consumption of unsafe food, foodborne risks are often much less acceptable than for instance risks associated to driving or flying, as they tend to be characterized by several elements that render them more fearful in the eyes of the general 
public. Such elements have been referred to as "fright factors" [28] or "outrage factors" [29]. Table 1 lists several fright factors and the foodborne hazard(s) that they may apply to. Notably, most of these fright factors apply to the global outbreak of variant CreutzfeldtJakob disease ( $\mathrm{VCJD}$ ) as a result of exposure of consumers to BSE prions which may explain why the risk of contracting mad cow disease created such mass panic in the 1990s. Responding to this major food scare and earlier events, and in an effort to rebuild consumer trust, the European Union radically revised its Food Law and created the European Food Safety Authority (EFSA) [24, 25, 30]. Considering the significant political and social sensitivity around foodborne illnesses, over the years many learnings and technical advances have allowed governments to establish more effective food safety controls, although at times controls might be implemented that are ineffective or overcautious.

Table 1. Fright factors with examples of foodborne hazards for which they may apply selected for the purpose of this study

\begin{tabular}{ll}
\hline $\begin{array}{l}\text { Fright factor build on Bennett (1999) } \\
\text { [28] }\end{array}$ & $\begin{array}{l}\text { Example of foodborne hazard } \\
\text { incorporating the fright element (this } \\
\text { study) }\end{array}$ \\
\hline Involuntary nature & $\begin{array}{l}\text { waterborne hazards, e.g. Cryptosporidium } \\
\text { cysts in drinking water [31] } \\
\text { food adulterants, e.g. melamine in milk, } \\
\text { Sudan red dyes in spices [32] }\end{array}$ \\
\hline Unfairly distributed in society & $\begin{array}{l}\text { Listeria monocytogenes in its severe form } \\
\text { affecting mainly the susceptible population } \\
\text { (young, old, pregnant and immune- }\end{array}$ \\
\hline compromised) [33] \\
\hline precautions & $\begin{array}{l}\text { toxic chemical contaminants } \\
\text { microbiological hazards when eating outdoors }\end{array}$ \\
\hline Uncommon or new & prions, acrylamide, dioxins at the time they \\
& first appeared in the news \\
\hline Created by man and not nature & certain toxic chemical contaminants, e.g. \\
& chemical pesticides \\
\hline Causing secret and irreversible damage & carcinogenic contaminants \\
which may result in disease many years & prions [34], stomach cancer as a result of \\
later & Helicobacter pylori infection [35] \\
\hline Being a threat for future generations, & $\begin{array}{l}\text { Toxoplasma gondii (pregnant women)[36], } \\
\text { Cronobacter spp. (neonates and infants) [37] }\end{array}$ \\
\hline
\end{tabular}




\begin{tabular}{ll}
\hline & $\begin{array}{l}\text { Haemolytic Uraemic Syndrome (HUS) in } \\
\text { children as a result of enterohaemorrhagic } \\
\text { Escherichia coli infection (EHEC)[38] }\end{array}$ \\
\hline Causing a terrible and/or fatal illness & Echinococcus multilocularis [39], prions [34] \\
\hline Insufficiently understood by science & prions [40], Brainerd diarrhea [41] \\
\hline $\begin{array}{l}\text { Related with contradictory statements from } \\
\text { the authorities }\end{array}$ & dioxins, prions [42] \\
\hline
\end{tabular}

\section{History of managing food safety}

Considering the impact of food safety on public health, the economy, politics and society, it is no wonder that it has been one of the first concerns of mankind, whose understanding and approaches of managing the issue grew over several millennia and most rapidly progressed since the industrialization of societies (Figure 3).

In forager societies the selection of plant and animal species suitable for consumption was based on trial and error as well as experience gained over the years [43]. Gradual changes in the way hunting and gathering took place in those days led to men being more clearly involved and aware of plant and animal life cycles, which led to their domestication [44]. This allowed the formation of agricultural societies and the start of organized food production $[43,44]$.

In agricultural societies, the first observations were made regarding spoilage and food safety, in relation to the way food items were stored. The most obvious ones were that contact with water and air may spoil goods and that sometimes products that were accidentally allowed to stand for some days went into some kind of change that made them last longer (e.g. grape juice turning into wine, milk turning into yoghurt). This led to the first preservation methods (drying, salting, smoking, fermentation, immersion in oil) [43]. Archaeological evidence of this period, suggests that fermentation was already in use in the seventh millennium BC in China and Anatolia [45, 46], while salting, smoking and the use of spices were commonly applied to prevent spoilage by 1000 BC [47]. In those times, although most epidemics would be attributed to the wrath of gods or saints for the misdeeds of men (Figures 4 and 5), some observations related to food safety were made and passed into religious taboos as a means of preventing foodborne illnesses [48], e.g. hygiene laws in India, prohibition of pork in the Jewish and Muslim religions [43]. It was also in the first civilizations of this period that the role of food in human health was clearly recognised, for instance by Hippocrates ( 460 BC) [49]. His perhaps most famous phrase "let thy food be thy medicine and thy medicine be thy food" pointed out the importance of diet in avoiding illness. Eventually, observations related with the role of food in health 


\begin{tabular}{|c|c|}
\hline $\begin{array}{l}\text { Prehistoric } \\
\text { times }\end{array}$ & $\begin{array}{l}\text { Forager societies: } \\
\text { - Trial and error approach for selecting edible plant and animal } \\
\text { species } \\
\text { - Off-flavor and taste leading to rejection of food items }\end{array}$ \\
\hline 9000 B.C. & $\begin{array}{l}\text { Agricultural societies: } \\
\text { - Obvious observations and religious taboos in relation to food } \\
\text { safety } \\
\text { - First recordings of preservation methods (drying, salting, } \\
\text { smoking, fermentation, oil) } \\
\text { - First laws regarding hygiene and adulteration }\end{array}$ \\
\hline $\begin{array}{l}\text { N1760 A.D. } \\
\text { until present }\end{array}$ & $\begin{array}{l}\text { Industrial societies: } \\
\text { - Production of food on a mass scale } \\
\text { - New preservation methods } \\
\text { - Identification of causes of foodborne illness } \\
\text { - Foundation of international organizations dealing with food safety } \\
\text { - Development of risk-based approaches to control hazards in food }\end{array}$ \\
\hline 1809,1810 & $\begin{array}{l}\text { Invention of appertization (Nicolas Appert, France) and first } \\
\text { canning patent (Peter Durand, England) }\end{array}$ \\
\hline 1834 & First mechanical refrigeration patent (Jacob Perkins, USA) \\
\hline 1842 & Freezing begins to be used commercially \\
\hline 1867 & $\begin{array}{l}\text { First commercial use of pasteurization for wine (Louis Pasteur, } \\
\text { France) }\end{array}$ \\
\hline 1890 & $\begin{array}{l}\text { Commercial pasteurization of milk is introduced for the first time } \\
\text { (Denmark) }\end{array}$ \\
\hline 1900 & Start of microbiological examination of food \\
\hline 1905 & Chlorination of drinking water \\
\hline 1922 & Botulinum cook (Esty and Meyer, USA) \\
\hline $1930-1960$ & Performance criteria for the pasteurization of milk \\
\hline 1963 & Founding of the Codex Alimentarius Commission \\
\hline $\begin{array}{l}1959-1969, \\
1971\end{array}$ & $\begin{array}{l}\text { Development of the Hazard Analysis and Critical Control Point } \\
\text { (HACCP) system for the American space program (NASA, United } \\
\text { States Army Laboratories, Pillsbury, US); first HACCP system public } \\
\text { presentation at the US National Conference of Food Protection }\end{array}$ \\
\hline 1995 & $\begin{array}{l}\text { Agreement on sanitary and phytosanitary measures (WTO) } \\
\text { Application of risk analysis to food standards issues (FAO/WHO) }\end{array}$ \\
\hline 1996 & Mandatory use of $\mathrm{HACC}$ principles in the European Union \\
\hline 2002 & Foundation of the European Food Safety Authority \\
\hline 2006 & $\begin{array}{l}\text { The implementation of HACCP as a food safety system becomes } \\
\text { obligatory in the European Union }\end{array}$ \\
\hline
\end{tabular}

Figure 3. Timeline of major changes in the understanding and approaches of ensuring the production of safe food [43, 50-59]. 


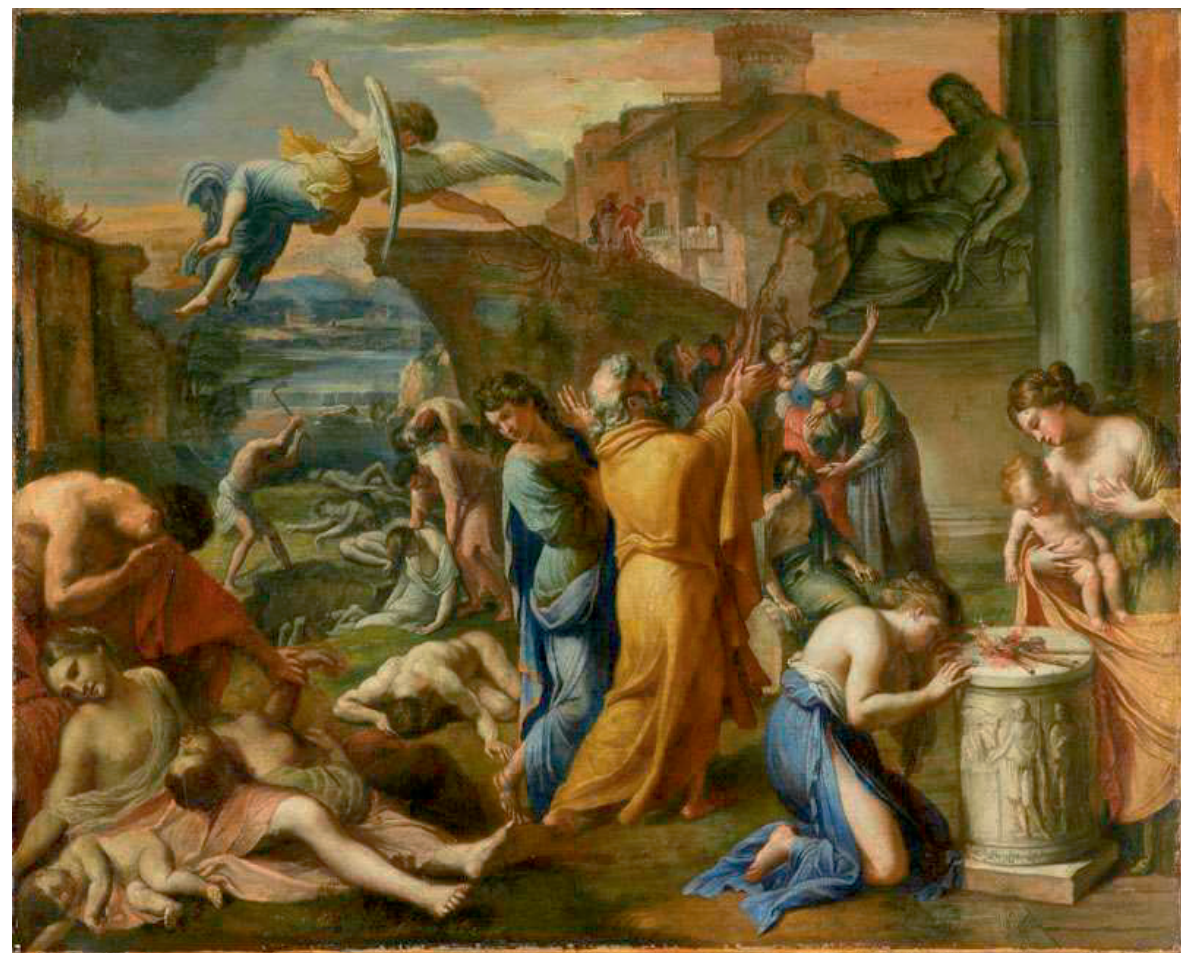

Figure 4. "La peste d' Athènes" (The plague of Athens), oil painting on canvas by François Perrier, @Dijon museum of fine arts, France. Plague in Greek may refer to any kind of illness, traditionally perceived as divine punishment [60]; this particular epidemic at 430 $B C$ was favoured by over-crowded, wartime conditions and resulted in the demise of over one quarter of the inhabitants of Athens including its leader Pericles. DNA from the dental pulp of victims from a mass burial site points today to typhoid fever as a likely cause of the epidemic [61].

(C)Musée des Beaux-Arts de Dijon/François Jay (reproduced with permission).

resulted in laws and even in the appointment of officers responsible for the control of goods in food markets. For instance, in ancient Greece, "ayopavónoı" or market commissioners were responsible for checking that all articles were pure and unadulterated [62]. Similarly, in ancient Rome, the "aediles" or churchwardens were responsible for control and inspection of markets as well as for confiscating spoiled goods [43]. Some examples of laws enforced to protect public health from unsafe food are:

- Mosaic and Egyptian decrees from around $2500 \mathrm{BC}$ targeting the contamination of meat

- The prohibition of the adulteration of grains and edible fats in India about 2000 years ago [63] 
- The ban on blood sausages by Emperor Leo VI (886-911 AD) in Byzantium (because of their association with botulism) and

- The prohibition of sale of fish that is older than one day in Switzerland (1319 AD) [43].

In industrialized societies, production of food on a mass scale began and unlike before, the vast majority of people started relying on food produced by others. As a result, and despite several new preservation methods becoming available (see Figure 3 ), the first outbreaks were recorded and investigations allowed to link diseases to specific product groups and microorganisms. In other words, in contrast with forager and agricultural societies, a scientific cause and effect relationship was established between the hazard and the disease. As an example, in 1854 the first waterborne cholera outbreak was successfully investigated by John Snow, now considered to be the father of modern epidemiology [64, 65], and some years later Louis Pasteur and Robert Koch consolidated the "germ theory of disease" which postulated microorganisms as the cause of infectious diseases [64]. The setting of science based criteria for ensuring the safety of products followed these events, with the work of Bigelow in 1921 on the heat resistance of Clostridium botulinum spores and of Esty and Meyer in 1922 on the 12 log reduction of these spores (botulinum cook) being considered as the first big developments in the field of predictive microbiology [66].

Three waves of change are apparent in the way food safety was managed in industrialised societies and how it is managed to date: I) the microbiological sampling of end products alongside the use of Good Manufacturing Practices (GMP) and Good Hygienic Practices (GHP), II) the use of the Hazard Analysis and Critical Control Point (HACCP) system and III) the introduction of the risk analysis framework [67]. The last wave signified a fundamental transformation in the way food safety is managed, turning the focus from the hazard (presence in food or process environment) to the risk it pauses (significance of illness on public health) [68]. The trigger for this switch to risk-based approaches of managing food safety was the launching of the Agreement on Sanitary and Phytosanitary measures (SPS Agreement) in 1995 by the World Trade Organization (WTO) [52] suggesting that targets for food safety should be based on an assessment of the risk to the population. To help countries use this new framework of thought in food safety standards issues, the Food and Agricultural Organization of the United Nations (FAO) and the World Health Organization (WHO) launched the same year a consultation to agree on definitions for risk analysis, a general model for risk assessment and guidelines for its implementation [69]. The subsequent introduction of the "General Food Law" (Regulation 178/2002) in the European Union [70], constituted the use of this risk analysis framework, legally binding for the Member States, and may be viewed as the beginning of risk-based food safety management within the European continent. 


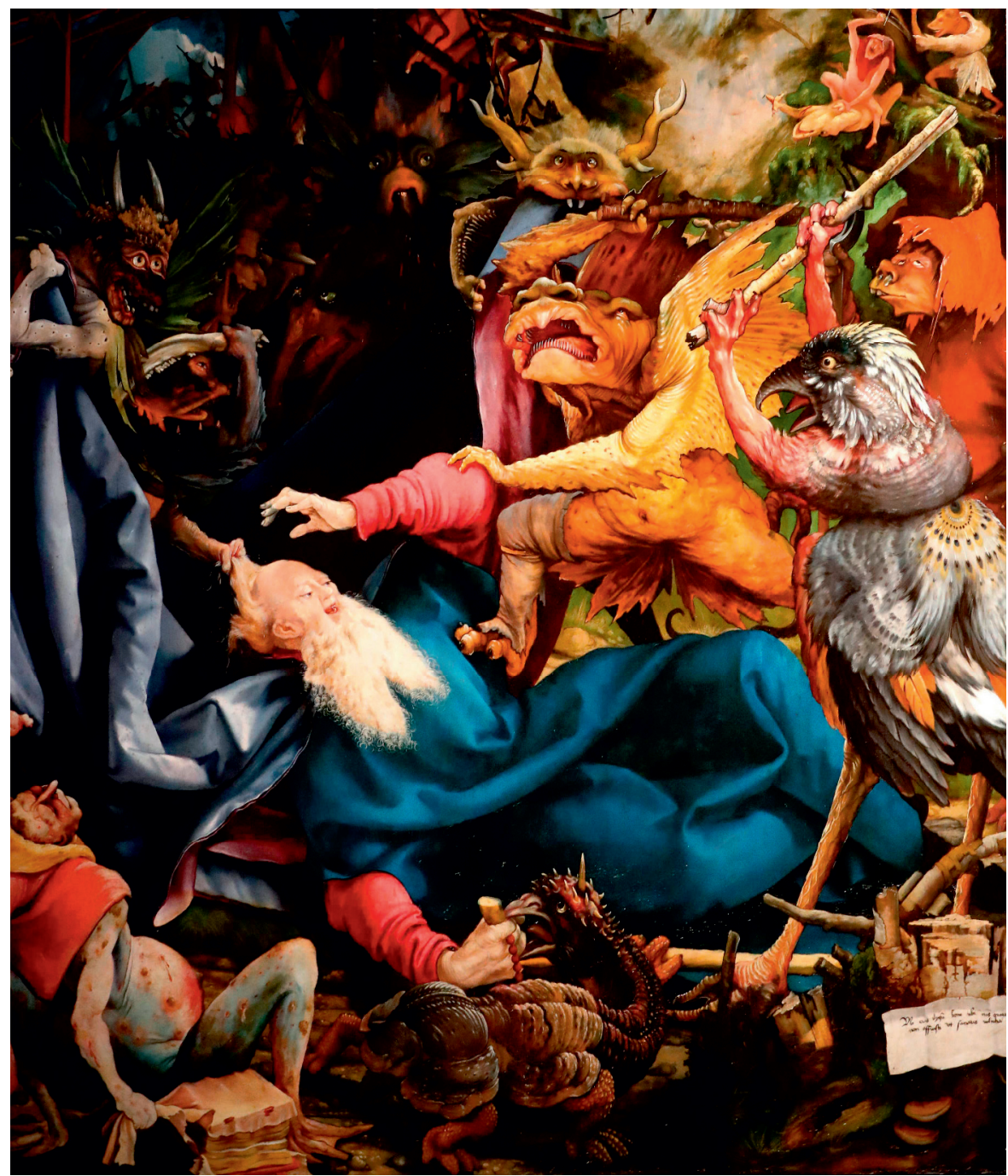

Figure 5. Detail from the "Temptations of Saint Antony panel" Isenheim altarpiece, oil on wood by Matthias Grünewald, Unterlinden Museum, Colmar, France. The saint is depicted here to fight daemonic figures next to a sufferer of ergotism, a disease also known as "Saint Antony's fire" because of the burning sensations it caused resulting in gangrene limbs. Epidemics of ergotism were frequent in the Middle Ages and are now known to have been caused by eating bread contaminated with the sclerotia of the fungi Claviceps purpurea [71].

(c) Godong / Alamy Stock Photo (reproduced with permission). 


\section{The risk analysis framework}

Risk analysis is a framework designed to elaborate, science-based decisions in the area of food safety by allowing to identify interventions that are most effective in the protection of public health considering available resources and attendant uncertainties. Risk analysis consists of three unified components (Figure 6) [69, 72, 73]:

i) Risk assessment: A systematic procedure of assessing, in a qualitative or quantitative way risk, the severity and probability of an adverse health effect resulting from the consumption of a hazard in food. Risk assessments consist of four separate steps: i) hazard identification, the recognition of which agents in food have the potential to cause an adverse effect, ii) exposure assessment, the qualitative or quantitative appraisal of hazard intake, iii) hazard characterization, the qualitative or quantitative evaluation of the probability and severity of health effect(s) as a function of the dose of the hazard and iv) risk characterization, the integration of the three previous steps that provides a qualitative or quantitative estimation of risk and includes associated uncertainties [69]. Within the European Union, risk assessment is primarily the responsibility of EFSA [74].

ii) Risk management: The process of selecting, implementing and monitoring suitable options to accept, minimize or reduce the assessed risk after carefully evaluating different policy alternatives [69]. Within the European Union this is to a large extent the responsibility of the European Commission and authorities in the Member States [74].

iii) Risk communication: The interaction between risk assessors, risk managers, consumers, food businesses, academics and other interested parties, who are likely to be affected by risk management decisions, throughout the risk analysis process, aiming at the exchange of information and opinions $[69,74,75]$.

Within the risk analysis framework, risk managers are responsible for identifying a potential food safety problem, establishing a profile of the situation and recognizing that it is a management priority by means of risk ranking, which may lead to the commissioning of a risk assessment [75]. After this step, the risk managers should ideally not interfere in the work of the risk assessors as a means of ensuring the scientific integrity of the process [75]. However, although a functional and organizational separation should take place, some interaction is unavoidable and even desired, for instance when clarifications of the questions raised to the risk assessors are needed or when the results of the assessment are to be communicated to the managers so that they can be properly understood and used efficiently [76], which is necessary for identifying and selecting suitable management options. Risk communication is essential throughout the risk analysis process framework and for it to be effective care should be taken that all interested parties are involved and risks are communicated by trained individuals, transparently and in a way that they are 
readily understood by the target audience [77]. Following the implementation of a management decision, it is necessary to monitor the measures taken as well as their effectiveness to mitigate an issue, whereas the assessment itself and management options need to be reviewed in a timely manner as necessary [75].

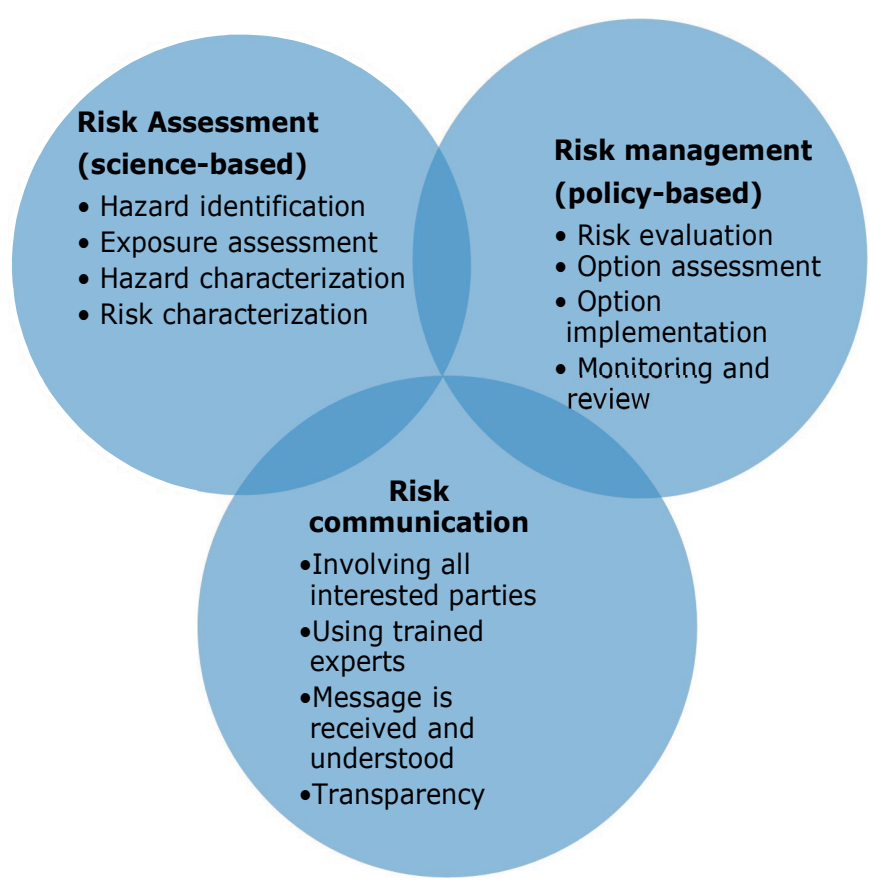

Figure 6. The process of risk analysis and key elements of its three interconnected components $[72,77]$.

\section{The ALOP/FSO concepts and their associated benchmarks}

For the risk analysis framework to become operational, the introduction of new food safety management benchmarks was required in order to translate governmental policy regarding the protection of public health from foodborne illnesses into meaningful targets for the control of hazards in the food chain [78] (Figure 7). For this reason, the concept of the Appropriate Level of Protection (ALOP), referred to by some countries as an "acceptable level of risk" [52], initially introduced for the purpose of solving trade disputes [52], was used as a reference point for the development of several risk-based food safety management targets (Table 2). The ALOP may be considered by some countries as the "status quo" in relation to the level of public health protection [79] when the current risk of illness is acceptable and by other countries as a future public health goal when the 
current risk of illness is unacceptable [80]. To translate the ALOP into manageable control targets in the food chain, a series of other benchmarks were proposed. First, a link was suggested between an ALOP and a Food Safety Objective (FSO), that is a target for the maximum level of the hazard in the product at the point of consumption [81, 82]. However, since an FSO is not a practical target to verify, two additional targets were suggested: the Performance Objective (PO), being the maximum level of the hazard in the product at a particular point before consumption and the Performance Criterion ( $P C$ ) referring to the change in the hazard level that is required to meet the PO or FSO that it relates to [81].

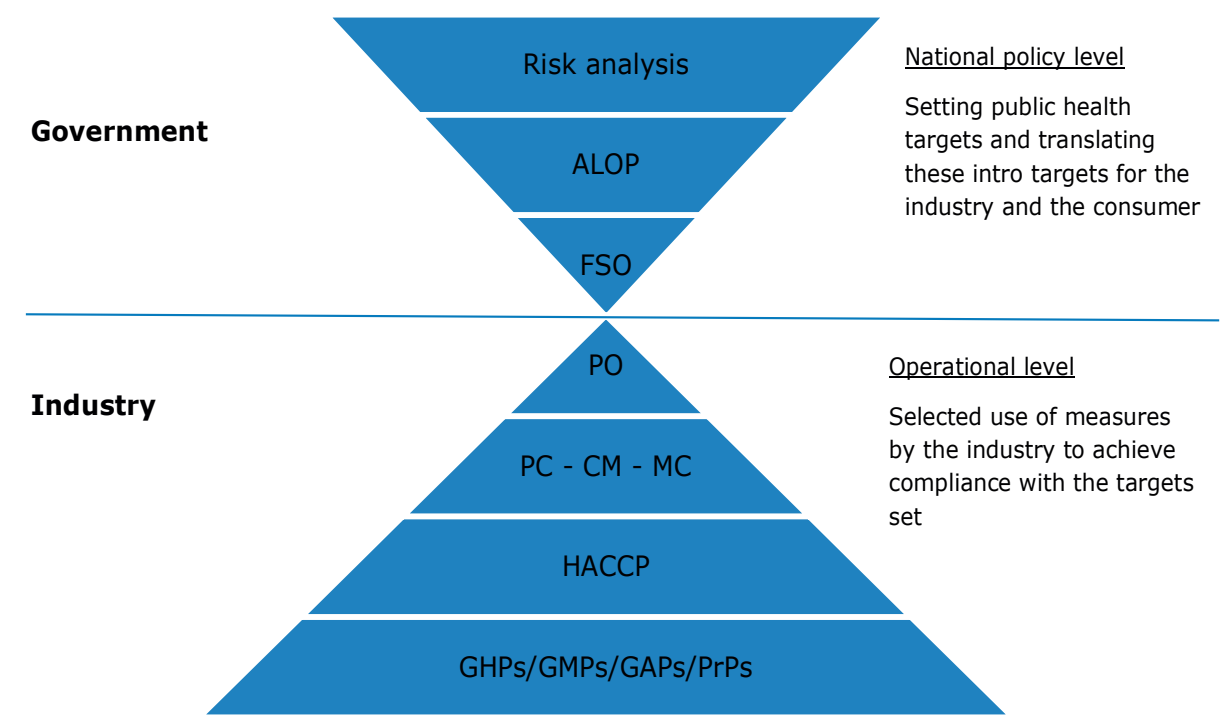

Figure 7. Illustration of how the Appropriate Level of Protection (ALOP), Food Safety Objective (FSO), Performance Objective (PO) and Performance Criterion (PC) serve as links between governmental risk analysis and operational food safety management in the food supply chain (adapted from Gorris, 1995). MC: Microbiological Criterion; CM: Control Measure, HACCP: Hazard Analysis and Critical Control Point; GHP: Good Hygienic Practices; GMP: Good Manufacturing Practices; GAP: Good Agricultural Practices; PrPs: Prerequisite Programs [78]. 
Table 2. Risk-based targets for the management of hazards in the food chain

\begin{tabular}{|c|c|c|}
\hline $\begin{array}{l}\text { Risk-based } \\
\text { target }\end{array}$ & Definition & Fictive example \\
\hline $\begin{array}{l}\text { Appropriate } \\
\text { Level of } \\
\text { Protection } \\
\text { (ALOP) }\end{array}$ & $\begin{array}{l}\text { "The level of protection deemed appropriate by } \\
\text { the Member (country) establishing a sanitary or } \\
\text { phytosanitary measure to protect human, } \\
\text { animal or plant life or health within its territory" } \\
\text { [52] }\end{array}$ & $\begin{array}{l}\text { No more than } 50 \text { cases } \\
\text { of salmonellosis per } \\
\text { million inhabitants per } \\
\text { year }\end{array}$ \\
\hline $\begin{array}{l}\text { Food Safety } \\
\text { Objective } \\
(\text { FSO) }\end{array}$ & $\begin{array}{l}\text { "The maximum frequency and/or concentration } \\
\text { of a hazard in food at the time of consumption } \\
\text { that provides or contributes to the appropriate } \\
\text { level of protection" [81] }\end{array}$ & $\begin{array}{l}\text { The concentration of } \\
\text { Listeria monocytogenes } \\
\text { in ready-to-eat deli } \\
\text { meats at the time of } \\
\text { consumption should not } \\
\text { exceed } 4 \text { log CFU per } \\
\text { gram }\end{array}$ \\
\hline $\begin{array}{l}\text { Performance } \\
\text { Objective } \\
\text { (PO) }\end{array}$ & $\begin{array}{l}\text { "The maximum frequency and/or concentration } \\
\text { of a hazard in food at a specified step in the } \\
\text { food chain before the time of consumption that } \\
\text { provides or contributes to an FSO or ALOP as } \\
\text { applicable" [81] }\end{array}$ & $\begin{array}{l}\text { The concentration of } L \text {. } \\
\text { monocytogenes in } \\
\text { ready-to-eat products } \\
\text { should not exceed } 100 \\
\text { CFU per gram when } \\
\text { placed on the market }\end{array}$ \\
\hline $\begin{array}{l}\text { Performance } \\
\text { Criterion (PC) }\end{array}$ & $\begin{array}{l}\text { "The effect in frequency and/or concentration of } \\
\text { a hazard in food that must be achieved by the } \\
\text { application of one or more control measures to } \\
\text { provide or contribute to a PO or FSO" [81] }\end{array}$ & $\begin{array}{l}12 \text { Log reduction of } \\
\text { Clostridium botulinum in } \\
\text { low acid canned foods } \\
\text { and avoidance of } \\
\text { recontamination }\end{array}$ \\
\hline
\end{tabular}

Codex has published guidelines for microbiological risk management [83] in which the various risk-based metrics are elaborated. To date, no countries have actually formally stipulated ALOPS, FSOs or other related metrics, although the language already has been partly introduced by some, such as by the European Union [70], and the concept of ALOP has been the subject of some debate $[79,84]$. Risk assessment (preferably quantitative for increased transparency when comparisons of protection levels are to be made) has been suggested to be the means of setting ALOPs and their associated targets [52, 85]. Since there are no specific guidelines for setting ALOPs, different risk assessment approaches can be followed: i) using epidemiological data as a starting point to first derive the current level of protection (LOP), decide on an ALOP and then an FSO, ii) using food 
chain contamination data to first derive the current level FSO and then the LOP, decide on an ALOP and then the future FSO, iii) other approaches or combination of the above [86].

The selection of one approach over the other would depend on available data, resources and the nature of the hazard/food commodity.

It is important to note that there is a separation of responsibilities when it comes to establishing the new risk-based targets. Thus, while ALOPs and FSOs can only be set by governments, POs and PCs may be set within a food supply chain by the industry as tools that helps to meet the end of chain FSO target. The industry has considerable flexibility in the way these POs or PCs are to be achieved [78]. The separation of responsibilities depicted in Figure 7 is not absolute as to some extent interaction between different key players can take place. For instance, considering that the setting of an ALOP and an FSO is fundamentally a risk management decision, besides science, other factors may also need to be taken into account such as for instance environmental, economical, societal, and ethical factors as well as traditions, feasibilities and practicalities related with controlling hazards [74]. So, although the risk-based targets themselves can originally be decided on by risk managers of competent authorities on the basis of risk assessment, consumers and the industry may influence the final decision through bringing up for instance specific societal factors or the practicalities of achieving these targets. Moreover, Regulation (EC) $178 / 2002$ that forms the basis of European food law legislation dictates that food law should be prepared, revised or evaluated in consultation with the public [70], which would provide the consumers and the industry with the opportunity to comment or voice their concerns. Similarly, although it is the industry that has the upper hand in producing food that complies with a set FSO/PO, the government and the consumer can influence compliance. For example, the government can impact by introducing a default PO or PC where it deems necessary, for instance when there is a concern that some industries may not have the ability to do so themselves. Consumers can impact meeting risk-based targets by changing their food handling practices e.g. ensuring that their fridge temperature is below $5^{\circ} \mathrm{C}$ or handling separately raw and cooked foods [87]. Generally, food safety needs multiple controls acting simultaneously and not one single measure can totally control risks.

\section{Aim of the thesis and outline of chapters}

From the above it should be clear that the use of the ALOP and FSO targets within the risk analysis framework is very much desired for making food safety management more transparent and quantifiable by clearly defining and separating responsibilities among all relevant stakeholders in the food chain [88]. Moreover, being based on an assessment of the impact of resulting risks on the health of the population, the targets have the potential 
to facilitate international trade by making the necessary measures for the control of foodborne hazards more defendable in case of disputes [52]. However, despite these obvious advantages, the ALOP and FSO are still evolving as concepts [89] and they are not explicitly used as such to inform national policy. A number of case studies dealing with their implementation are available, some as the result of an expert consultation coordinated by FAO/WHO [84, 90-92] and more as independent work from the academia, industry, national food safety agencies or combination of the above [89, 93-101]. However, very few of these studies are based on national data [99-101] discussing the actual bottlenecks and decision-making processes preceding the adoption of the targets in food safety management. Most importantly perhaps, only a small number of countries has attempted to estimate the public health impact of foodborne risks on a national level [14$16,20-22,102-106]$, a process that is essential before resolving whether these risks can be tolerated or need to be reduced and deciding on an ALOP [80]. It seems that despite the availability of some practical guidelines on this topic [107], lack of available data and harmonization in methodologies are among the major challenges for such studies on the burden of foodborne diseases [108].

To facilitate the use of the ALOP and FSO targets more studies are needed that address the challenges for competent authorities wishing to establish and implement these riskbased metrics in order: i) to test the feasibility of their use at national or international levels, ii) to evaluate the use of different risk assessment approaches available for this purpose, iii) to demonstrate ways of making the best use of currently available data and iv) to identify key areas where more research is needed. The aim of this dissertation was to work on all of these topics. To this end four different case studies were developed (Tables 3 and 4), dealing with different microbial hazards, food products and population groups as well as addressing a number of different "real life" settings faced by competent authorities in various countries. The general objective was to show that the risk-based targets can be applicable in different settings using publicly available data but that it does require dealing with bottlenecks and making decisions based on the available risk assessment estimates and potential risk management options. Overall, this thesis consists of 6 chapters:

The current chapter introduces the reader to the impact of food related illnesses on society, the changes in approaches available to manage food safety in the course of mankind's history leading to the risk analysis framework and its accompanying risk-based metrics (ALOP, FSO, PO, PC).

In chapter 2, the first case-study is presented, which uses a range of publicly available data to rank all foodborne risks in Greece, in order to set national priorities for food safety management. The use of the results of this study for setting ALOPs is part of the discussion (chapter 6). 
In chapter 3, the second case-study is presented, dealing with setting of ALOP and FSO targets for Listeria monocytogenes in deli meats in the Netherlands. Here the focus is on a severe, low incidence disease, usually associated with medium to high doses through contaminated products consumed on a regular basis by the vast majority of the Dutch population.

In chapter 4, the third case study is presented that concerns the implementation of riskbased targets for Salmonella in poultry meat in the Netherlands and in 22 other EU Member States. Here the focus is a mostly mild but, on occasion, severe disease, due to longer term sequellae, usually associated with ingestion of low doses of the pathogen through contaminated or undercooked products consumed frequently by the vast majority of the European population.

In chapter 5, the fourth case is presented, addressing the application of the targets for $C$. perfringens in Cornish pasties in the United Kingdom. Here the focus is on a mostly selflimiting, rarely fatal illness, usually associated with very high doses of the pathogen in a Protected Geographical Indication product [109], infrequently consumed by the British population.

Finally, in chapter 6, the lessons learned from the case-studies are discussed, with emphasis on common issues regarding the implementation of ALOP and FSO and their use in the context of continuously improving food safety management.

Table 3. Overview of different case-studies developed for the purpose of demonstrating the implementation of the ALOP and/or FSO targets

\begin{tabular}{lcccc}
\hline Case study & Country & Pathogens & Product & Population \\
\hline $\begin{array}{l}\text { Quantifying and ranking } \\
\text { risks on a country level }\end{array}$ & Greece & All known & All & All \\
\hline Listeria in deli meat & Netherlands & 1 & 1 product group & $\begin{array}{r}\text { Healthy } \\
\text { \& YOPI }\end{array}$ \\
\hline Salmonella in poultry & 23 EU countries & 1 & 1 product group & All \\
\hline $\begin{array}{l}\text { C. perfringens in Cornish } \\
\text { pasties }\end{array}$ & UK & 1 & 1 niche product & All \\
\hline
\end{tabular}

Table 4. Characteristics of diseases in case-studies dealing with specific pathogens

\begin{tabular}{lccc}
\hline Case study & Incidence & Severity & Typical infectivity \\
\hline Listeria in deli meat & Low & Medium to very high & Very low to medium \\
\hline Salmonella in poultry & High & Varies & High \\
\hline $\begin{array}{l}\text { C. perfringens in } \\
\text { Cornish pasties }\end{array}$ & Average/high & Self-limiting & Very low \\
\hline
\end{tabular}




\section{References}

1. Saunders, J., T. Smith, and M. Stroud. Malnutrition and undernutrition. Medicine. 2011; 39: p. 45-50.

2. WHO. (2012). Obesity and overweight. Fact sheet $N^{\circ} 311$. World Health Organization: Geneva. Available from: http://www.who.int/mediacentre/factsheets/fs311/en/\#

3. FAO/WHO. (2006). Food safety risk analysis. A guide for national food safety authorities. ISBN: 978-92-5-105604. Food and Agriculture Organization of the United Nations/World Health Organization: Rome/Geneva. Available from: http://www.who.int/foodsafety/publications/micro/riskanalysis06.pdf

4. Jung, A. Quo vadis risk communication? Journal of Risk Research. 2006; 9: p. 819821.

5. WHO Food Safety Programme. (2002). WHO global strategy for food safety: safer food for better health. World Health Organization: Geneva. Available from: https://apps.who.int/iris/handle/10665/42559

6. Murray, C.J.L., T. Vos, R. Lozano, M. Naghavi, A.D. Flaxman, C. Michaud, M. Ezzati, K. Shibuya, J.A. Salomon, S. Abdalla, V. Aboyans, J. Abraham, I. Ackerman, R. Aggarwal, S.Y. Ahn, M.K. Ali, M.A. AlMazroa, M. Alvarado, H.R. Anderson, L.M. Anderson, K.G. Andrews, C. Atkinson, L.M. Baddour, A.N. Bahalim, S. Barker-Collo, L.H. Barrero, D.H. Bartels, M.-G. Basáñez, A. Baxter, M.L. Bell, E.J. Benjamin, D. Bennett, E. Bernabé, K. Bhalla, B. Bhandari, B. Bikbov, A.B. Abdulhak, G. Birbeck, J.A. Black, H. Blencowe, J.D. Blore, F. Blyth, I. Bolliger, A. Bonaventure, S. Boufous, R. Bourne, M. Boussinesq, T. Braithwaite, C. Brayne, L. Bridgett, S. Brooker, P. Brooks, T.S. Brugha, C. Bryan-Hancock, C. Bucello, R. Buchbinder, G. Buckle, C.M. Budke, M. Burch, P. Burney, R. Burstein, B. Calabria, B. Campbell, C.E. Canter, H. Carabin, J. Carapetis, L. Carmona, C. Cella, F. Charlson, H. Chen, A.T.-A. Cheng, D. Chou, S.S. Chugh, L.E. Coffeng, S.D. Colan, S. Colquhoun, K.E. Colson, J. Condon, M.D. Connor, L.T. Cooper, M. Corriere, M. Cortinovis, K.C. de Vaccaro, W. Couser, B.C. Cowie, M.H. Criqui, M. Cross, K.C. Dabhadkar, M. Dahiya, N. Dahodwala, J. Damsere-Derry, G. Danaei, A. Davis, D.D. Leo, L. Degenhardt, R. Dellavalle, A. Delossantos, J. Denenberg, S. Derrett, D.C. Des Jarlais, S.D. Dharmaratne, M. Dherani, C. Diaz-Torne, H. Dolk, E.R. Dorsey, T. Driscoll, H. Duber, B. Ebel, K. Edmond, A. Elbaz, S.E. Ali, H. Erskine, P.J. Erwin, P. Espindola, S.E. Ewoigbokhan, F. Farzadfar, V. Feigin, D.T. Felson, A. Ferrari, C.P. Ferri, E.M. Fèvre, M.M. Finucane, S. Flaxman, L. Flood, K. Foreman, M.H. Forouzanfar, F.G.R. Fowkes, M. Fransen, M.K. Freeman, B.J. Gabbe, S.E. Gabriel, E. Gakidou, H.A. Ganatra, B. Garcia, F. Gaspari, R.F. Gillum, G. Gmel, D. Gonzalez-Medina, R. Gosselin, R. Grainger, B. Grant, J. Groeger, F. Guillemin, D. Gunnell, R. Gupta, J. Haagsma, H. Hagan, Y.A. Halasa, W. Hall, D. Haring, J.M. Haro, J.E. Harrison, R. Havmoeller, R.J. Hay, H. Higashi, C. Hill, 
B. Hoen, H. Hoffman, P.J. Hotez, D. Hoy, J.J. Huang, S.E. Ibeanusi, K.H. Jacobsen, S.L. James, D. Jarvis, R. Jasrasaria, S. Jayaraman, N. Johns, J.B. Jonas, G. Karthikeyan, N. Kassebaum, N. Kawakami, A. Keren, J.-P. Khoo, C.H. King, L.M. Knowlton, O. Kobusingye, A. Koranteng, R. Krishnamurthi, F. Laden, R. Lalloo, L.L. Laslett, T. Lathlean, J.L. Leasher, Y.Y. Lee, J. Leigh, D. Levinson, S.S. Lim, E. Limb, J.K. Lin, M. Lipnick, S.E. Lipshultz, W. Liu, M. Loane, S.L. Ohno, R. Lyons, J. Mabweijano, M.F. MacIntyre, R. Malekzadeh, L. Mallinger, S. Manivannan, W. Marcenes, L. March, D.J. Margolis, G.B. Marks, R. Marks, A. Matsumori, R. Matzopoulos, B.M. Mayosi, J.H. McAnulty, M.M. McDermott, N. McGill, J. McGrath, M.E. Medina-Mora, M. Meltzer, Z.A. Memish, G.A. Mensah, T.R. Merriman, A.-C. Meyer, V. Miglioli, M. Miller, T.R. Miller, P.B. Mitchell, C. Mock, A.O. Mocumbi, T.E. Moffitt, A.A. Mokdad, L. Monasta, M. Montico, M. Moradi-Lakeh, A. Moran, L. Morawska, R. Mori, M.E. Murdoch, M.K. Mwaniki, K. Naidoo, M.N. Nair, L. Naldi, K.M.V. Narayan, P.K. Nelson, R.G. Nelson, M.C. Nevitt, C.R. Newton, S. Nolte, P. Norman, R. Norman, M. O'Donnell, S. O'Hanlon, C. Olives, S.B. Omer, K. Ortblad, R. Osborne, D. Ozgediz, A. Page, B. Pahari, J.D. Pandian, A.P. Rivero, S.B. Patten, N. Pearce, R.P. Padilla, F. Perez-Ruiz, N. Perico, K. Pesudovs, D. Phillips, M.R. Phillips, K. Pierce, S. Pion, G.V. Polanczyk, S. Polinder, C.A. Pope, III, S. Popova, E. Porrini, F. Pourmalek, M. Prince, R.L. Pullan, K.D. Ramaiah, D. Ranganathan, H. Razavi, M. Regan, J.T. Rehm, D.B. Rein, G. Remuzzi, K. Richardson, F.P. Rivara, T. Roberts, C. Robinson, F.R. De Leòn, L. Ronfani, R. Room, L.C. Rosenfeld, L. Rushton, R.L. Sacco, S. Saha, U. Sampson, L. Sanchez-Riera, E. Sanman, D.C. Schwebel, J.G. Scott, M. Segui-Gomez, S. Shahraz, D.S. Shepard, H. Shin, R. Shivakoti, D. Silberberg, D. Singh, G.M. Singh, J.A. Singh, J. Singleton, D.A. Sleet, K. Sliwa, E. Smith, J.L. Smith, N.J.C. Stapelberg, A. Steer, T. Steiner, W.A. Stolk, L.J. Stovner, C. Sudfeld, S. Syed, G. Tamburlini, M. Tavakkoli, H.R. Taylor, J.A. Taylor, W.J. Taylor, B. Thomas, W.M. Thomson, G.D. Thurston, I.M. Tleyjeh, M. Tonelli, J.A. Towbin, T. Truelsen, M.K. Tsilimbaris, C. Ubeda, E.A. Undurraga, M.J. van der Werf, J. van Os, M.S. Vavilala, N. Venketasubramanian, M. Wang, W. Wang, K. Watt, D.J. Weatherall, M.A. Weinstock, R. Weintraub, M.G. Weisskopf, M.M. Weissman, R.A. White, H. Whiteford, N. Wiebe, S.T. Wiersma, J.D. Wilkinson, H.C. Williams, S.R.M. Williams, E. Witt, F. Wolfe, A.D. Woolf, S. Wulf, P.-H. Yeh, A.K.M. Zaidi, Z.-J. Zheng, D. Zonies and A.D. Lopez. Disability-adjusted life years (DALYs) for 291 diseases and injuries in 21 regions, 1990-2010: a systematic analysis for the Global Burden of Disease Study 2010. The Lancet. 380: p. 2197-2223.

7. UNICEF. Diarrhoea remains a leading killer of young children, despite the availability of a simple treatment solution [cited 2016 July 28]. Available from: http://data.unicef.org/child-health/diarrhoeal-disease.html 
8. EFSA/ECDC. The European Union summary report on trends and sources of zoonoses, zoonotic agents and food-borne outbreaks in 2017. EFSA Journal. 2018; 16: e05500

9. Fhogartaigh, N.C. and J.D. Edgeworth. Bacterial gastroenteritis. Medicine. 2009; 37: p. $586-593$.

10. Lindsay, J.A. Chronic sequelae of foodborne disease. Emerging Infectious Diseases. 1997; 3: p. 443-452.

11. Ford, L., M. Kirk, K. Glass, and G. Hall. Sequelae of foodborne illness caused by 5 pathogens, Australia, circa 2010. Emerging Infectious Diseases. 2014; 20: p. 1865.

12. Clark, J., M. Sharp, and W.B.J. Reilly. (2000). Surveillance of foodborne disease, in "The microbiological safety and quality of food". Aspen Publishers, Inc.: Gaithersburg, Maryland

13. van Lier, A., S.A. McDonald, M. Bouwknegt, E.P.I. group, M.E. Kretzschmar, A.H. Havelaar, M.-J.J. Mangen, J. Wallinga, and H.E. de Melker. Disease burden of 32 infectious diseases in the Netherlands, 2007-2011. PLoS ONE. 2016; 11: p. e0153106.

14. Scallan, E., R.M. Hoekstra, F.J. Angulo, R.V. Tauxe, M.A. Widdowson, S.L. Roy, J.L. Jones, and M.P. Griffin. Foodborne illness acquired in the United States - Major pathogens. Emerging Infectious Diseases. 2011; 17: p. 7-15.

15. Mead, P.S., L. Slutsker, V. Dietz, L.F. McCaig, J.S. Breese, C. Shapiro, P.M. Griffin, and R.V. Tauxe. Food-related illness and death in the United States. Emerging Infectious Diseases. 1999; 5: p. 607-625.

16. Havelaar, A.H., J.A. Haagsma, M.-J.J. Mangen, J.M. Kemmeren, L.P.B. Verhoef, S.M.C. Vijgen, M. Wilson, I.H.M. Friesema, L.M. Kortbeek, Y.T.H.P. van Duynhoven, and W. van Pelt. Disease burden of foodborne pathogens in the Netherlands, 2009 International Journal of Food Microbiology. 2012; 156: p. 231-238.

17. Havelaar, A.H., A.V. Galindo, D. Kurowicka, and R.M. Cooke. Attribution of foodborne pathogens using structured expert elicitation. Foodborne Pathogens and Disease. 2008; 5: p. 649-659.

18. Eurostat. EU28 population 507.4 million at 1 January 2014 [cited 2016 July 12]. Available from: http://ec.europa.eu/eurostat/en/web/products-press-releases/-/310072014-BP

19. Vijgen, S.M.C., M.J.J. Mangen, L.M. Kortbeek, Y.T.H.P. van Duijnhoven, and A.H. Havelaar. (2007). Disease burden and related costs of cryptosporidiosis and giardiasis in the Netherlands. National Institute for Public Health and the Environment: Bilthoven. Available from: http://www.rivm.nl/bibliotheek /rapporten/330081001.pdf 
20. Scallan, E., P.M. Griffin, F.J. Angulo, R.V. Tauxe, and R.M. Hoekstra. Foodborne illness acquired in the United States-Unspecified agents. Emerging Infectious Diseases. 2011; 17: p. 17-22.

21. Tam, C.C., L.C. Rodrigues, L. Viviani, J.P. Dodds, M.R. Evans, P.R. Hunter, J.J. Gray, L.H. Letley, G. Rait, D.S. Tompkins, and S.J. O'Brien. Longitudinal study of infectious intestinal disease in the UK (IID2 study): incidence in the community and presenting to general practice. Gut. 2012; 61: p. 69-77.

22. Hall, G., D.M. Kirk, N. Becker, E.J. Gregory, L. Unicomb, G. Millard, R. Stafford, K. Lalor, and O.W. Group. Estimating foodborne gastroenteritis, Australia. Emerging Infectious Diseases. 2005; 11: p. 1257-1264.

23. Todd, E.C.D. Costs of acute bacterial foodborne disease in Canada and the United States. International Journal of Food Microbiology. 1989; 9: p. 313-326.

24. Houghton, J.R., G. Rowe, L.J. Frewer, E. Van Kleef, G. Chryssochoidis, O. Kehagia, S. Korzen-Bohr, J. Lassen, U. Pfenning, and A. Strada. The quality of food risk management in Europe: perspectives and priorities. Food Policy. 2008; 33: p. 13-26.

25. Garcia, R. and D. Jukes. The Spanish system of food controls--its administration and enforcement. Food Control. 2004; 15: p. 51-59.

26. Anonymous. BBC News. World: Europe Belgian dioxin inquiry begins [cited 2012 September 10]. Available from: http://news.bbc.co.uk/2/hi/europe/448648.stm

27. Anonymous. BBC News. Europe's BSE crisis. [cited 2012 September 10]. Available from: http://news.bbc.co.uk/2/hi/europe/1142660.stm

28. Hunter, R.P. and L. Fewtrell. (2001). Acceptable risk, in "Water Quality. Guidelines, standards and health: assessment of risk and risk management for water-related infectious disease". IWA Publishing: London

29. Covello, V. and P.M. Sandman. (2001). Risk communication: evolution and revolution, in "Solutions to an environment in peril". John Hopkins University Press: Baltimore, Maryland

30. Knowles, T., Moody, R., McEachern, M.G. European food scares and their impact on EU food policy. British Food Journal. 2007; 109: p. 43-67.

31. Widerström, M., C. Schönning, M. Lilja, M. Lebbad, T. Ljung, G. Allestam, M. Ferm, B. Björkholm, A. Hansen, J. Hiltula, J. Långmark, M. Löfdahl, M. Omberg, C. Reuterwall, E. Samuelsson, K. Widgren, A. Wallensten, and J. Lindh. Large outbreak of Cryptosporidium hominis infection transmitted through the public water supply, Sweden. Emerging Infectious diseases. 2014; 20: p. 581-589.

32. Moore, J.C., J. Spink, and M. Lipp. Development and application of a database of food ingredient fraud and economically motivated adulteration from 1980 to 2010. Journal of Food Science. 2012; 77: p. R118-R126. 
33. Doorduyn, Y., C.M. de Jager, W.K. van der Zwaluw, W.J.B. Wannet, A. van der Ende, L. Spanjaard, and Y.T.P.H. van Duynhoven. Invasive Listeria monocytogenes infections in the Netherlands, 1995-2003. European Journal of Clinical Microbiology \& Infectious Diseases. 2006; 25: p. 433-442.

34. Kranitz, F.J. and D.M. Simpson. Using non-pharmacological approaches for CJD patient and family support as provided by the CJD foundation and CJD insight. CNS \& Neurological Disorders - Drug Targets. 2009; 8: p. 1-8.

35. Huang, J.Q., S. Sridhar, Y. Chen, and R.H. Hunt. Meta-analysis of the relationship between Helicobacter pylori seropositivity and gastric cancer. Gastroenterology. 1998; 114: p. 1169-1179.

36. Cook, A.J.C., R.E. Gilbert, W. Buffolano, J. Zufferey, E. Petersen, P.A. Jenum, W. Foulon, A.E. Semprini, and D.T. Dunn. Sources of toxoplasma infection in pregnant women: European multicentre case-control study. BMJ. 2000; 321: p. 142-147.

37. Kandhai, M.C., A.E. Heuvelink, M.W. Reij, R.R. Beumer, R. Dijk, J.J.H.C. van Tilburg, M. van Schothorst, and L.G.M. Gorris. A study into the occurrence of Cronobacter spp. in The Netherlands between 2001 and 2005. Food Control. 2010; 21: p. 11271136.

38. Ammon, A. Surveillance of enterohaemorrhagic E. coli (EHEC) infections and Haemolytic Uraemic Syndrome (HUS) in Europe. Eurosurveillance. 1997; 2: p.

39. Wilson, J.F., R.L. Rausch, and F.R. Wilson. Alveolar hydatid disease. Review of the surgical experience in 42 cases of active disease among Alaskan Eskimos. Annals of Surgery. 1995; 221: p. 315-323.

40. Khachatourians, G.G. (2002). How well understood is the "science" of food safety?, in "Governing food: science, safety and trade". Queen-McGill University Publishing: Montreal

41. Fredricks, D.N. Novel pathogens and chronic diseases. Clinical Microbiology Newsletter. 2002; 24: p. 41-44.

42. Verbeke, W. (2008). Consumer risk perception with regards to food products, in "Towards a safer food supply in Europe". Belgian Science Policy: Brussels

43. Notermans, S. and A.W. Barendsz. (2002). The evolution of microbiological risk assessment, in "Microbiological risk assessment in food processing". Woodhead Publishing Limited: Cambridge, England

44. Erdkamp, P. (2012). Introduction, in "A cultural history of food in antiquity". Berg: London

45. Legras, J.L., D. Merdinoglu, J.M. Cornuet, and F. Karst. Bread, beer and wine: Saccharomyces cerevisiae diversity reflects human history. Molecular Ecology. 2007; 16: p. 2091-2102. 
46. Evershed, R.P., S. Payne, A.G. Sherratt, M.S. Copley, J. Coolidge, D. Urem-Kotsu, K. Kotsakis, M. Ozdogan, A.E. Ozdogan, O. Nieuwenhuyse, P.M.M.G. Akkermans, D. Bailey, R.-R. Andeescu, S. Campbell, S. Farid, I. Hodder, N. Yalman, M. Ozbasaran, E. Bicakci, Y. Garfinkel, T. Levy, and M.M. Burton. Earliest date for milk use in the Near East and southeastern Europe linked to cattle herding. Nature. 2008; 455: p. 528-531.

47. Anonymous. American Chemical Society National Historic Chemical Landmarks. Frozen foods research: time-temperature tolerance [cited 2014 August 7]. Available from: https://www.acs.org/content/acs/en/education/whatischemistry/landmarks ffrozenfoods.html

48. Baird-Parker, A.C. Development of industrial procedures to ensure the microbiological safety of food. Food Control. 1995; 6: p. 29-36.

49. Hutt, P.B. Government regulation of the integrity of the food supply. Annual Review of Nutrition. 1984; 4: p. 1-20.

50. Adegoke, G.O. and A.A. Olapade. (2012). Preservation of plant and animal foods: An overview, in "Progress in food preservation". Wiley-Blackwell: Oxford, UK

51. Baird-Parker, T.C. The production of microbiologically safe and stable foods (1st edition). 2000. B.M. Lund, T.C. Baird-Parker, and G.W. Gould (eds). Aspen Publishers, Inc.: Gaithersburg, Maryland

52. WTO. (1995). World Trade Organization. Agreement on the application of sanitary and phytosanitary measures (SPS Agreement). Available from: http://www.wto.org/english/docs_e/legal_e/15-sps.pdf

53. Hulebak, K.L. and W. Schlosser. Hazard analysis and critical control point (HACCP) history and conceptual overview. Risk Analysis. 2002; 22: p. 547-552.

54. Anonymous. Codex Alimentarius. International Food Standards [cited 2013 January 26]. Available from: http://www.codexalimentarius.org/

55. Anonymous. European Food Safety Authority [cited 2013 January 26]. Available from: http://www.efsa.europa.eu/

56. Jarvis, N. Curing and canning of fishery products: a history. Marine Fisheries Review. 1988; 50: p. 180-185.

57. Sperber, W.H. and R.F. Stier. Happy 50th birthday to HACCP: Retrospective and prospective, in Food Safety Magazine, Issue: December 2009/January 2010. Available from: http://www.foodsafetymagazine.com/magazine-archive1/december2009january-2010/happy-50th-birthday-to-haccp-retrospective-and-prospective/

58. European Community. (2004). European Parliament and Council of the European Union. Regulation (EC) No 852/2004 of the European Parliament and of the Council of 29 April 2004 on the hygiene of foodstuffs. Available from: http://eurlex.europa.eu/LexUriServ/LexUriServ.do?uri=OJ:L:2004:139:0001:0054:en:PDF 
59. European Community. (1993). European Parliament and Council of the European Union. Council Directive 93/43/EEC on the hygiene of foodstuffs. Available from: https://eur-lex.europa.eu/legal-content/EN/ALL/?uri=CELEX:31993L0043

60. Smith, C.A. Plague in the Ancient World: A study from Thucydides to Justinian [cited 2016 August 1]. Available from: http://www.loyno.edu/ history/journal/19967/Smith.html\#1

61. Papagrigorakis, M.J., C. Yapijakis, P.N. Synodinos, and E. Baziotopoulou-Valavani. DNA examination of ancient dental pulp incriminates typhoid fever as a probable cause of the Plague of Athens. International Journal of Infectious Diseases. 2006; 10: p. 206-214.

62. Kenyon, F.G. The Athenian Constitution. Aristotle [cited 2013 February 3]. Available from: http://ebooks.adelaide.edu.au/a/aristotle/athenian/

63. Ihegwuagu, N.E. and M.O. Emeje. Food quality control: History, present and future, in Scientific, health and social aspects of the food industry, B. Valdez, Editor 2012, InTech: Croatia.

64. Lederberg, J. Infectious history. Science. 2000; 288: p. 287-293.

65. Fox, G.A. Practical causal inference for ecoepidemiologists. Journal of Toxicology and Environmental Health. 1991; 33: p. 359-373.

66. Augustin, J.C. Challenges in risk assessment and predictive microbiology of foodborne spore-forming bacteria. Food Microbiology. 2011; 28: p. 209-213.

67. Sutherland, P. and D. Miles. Food safety objectives in the post-production sector. Australian Journal of Dairy Technology. 2007; 62: p. 83-88.

68. Buchanan, R.L. Understanding and managing food safety risks, in Food Safety Magazine, Issue: December 2010/January 2011. Available from: http://www.foodsafetymagazine.com/magazine-archive1/december-2010january2011/understanding-and-managing-food-safety-risks/

69. FAO/WHO. (1995). Application of risk analysis to food standards issues. Report of the Joint FAO/WHO Expert Consultation. Food and Agriculture Organization/World Health Organization: Rome/Geneva. Available from: http://www.fao.org/3/ae922e Lae922e00.htm

70. European Community. (2002). European Parliament and Council of the European Union. Regulation (EC) No 178/2002 of the European Parliament and of the Council of 28 January 2002 laying down the general principles and requirements of food law, establishing the European Food Safety Authority and laying down procedures in matters of food safety. Available from: http://eur-lex.europa.eu/LexUriServ LLexUriServ.do?uri=OJ:L:2002:031:0001:0024:EN:PDF

71. Battin, J. Le feu Saint-Antoine ou ergotisme gangreneux et son iconographie médiévale. Histoire des Sciences Medicales. 2010; 44: p. 373. 
72. Food and Agriculture Organization of the United Nations. Risk communication in food safety decision making [cited 2009 September 15]. Available from: http://www.fao.org/docrep/005/y4267m/y4267m03.htm

73. Doyle, M.P. (2008). Preface, in "Microbial risk analysis of foods". ASM Press: Washington, D.C.

74. van der Meulen, B. and M. van der Velde. Food safety law in the European Union. An introduction (2nd edition). 2006. (eds). Wageningen Academic Publishers: Wageningen

75. FAO/WHO. (1997). Risk management and food safety. Report of a joint FAO/WHO consultation. Rome, Italy, 27 to 31 January 1997. Food and Agriculture Organization of the United Nations/ World Health Organization: Rome/Geneva. Available from: http://www.fao.org/docrep/w4982e/w4982e00.htm

76. FAO/WHO. (2000). The interaction between assessors and managers of microbiological hazards in food. Report of a FAO/WHO expert consultation, Kiel, Germany Food and Agricultural Organization of the United Nations/World Health Organization: Rome/Geneva. Available from: http://www.fao.org/tempref /docrep/nonfao/ae586e/ae586e00.pdf

77. FAO/WHO. (1998). The application of risk communication to food standards and safety matters. Food and Agriculture Organization of the United Nations/World Health Organization: Rome/Geneva. Available from: http://www.fao.org/3/x1271e X1271E00.htm

78. Gorris, L.G.M. Food safety objective: An integral part of food chain management. Food Control. 2005; 16: p. 801-809.

79. EFSA. Opinion of the Scientific Panel on Biological Hazards on microbiological criteria and targets based on risk analysis (Question No EFSA-Q-2005-296). EFSA Journal. 2007; 5: 462

80. ICMSF. (2006). A simplified guide to understanding and using Food Safety Objectives and Performance Objectives. International Commission on Microbiological Specifications for Foods: Available from: http://www.icmsf.org/publications/quide/

81. Joint FAO/WHO Food Standards Programme. (2015). Codex Alimentarius Commission. Procedural Manual. Twenty-fourth edition. Food and Agriculture Organization of the United Nations/World Health Organization: Rome/Geneva. Available from: http://www.fao.org/3/a-i5079e.pdf

82. ICMSF. International Commission on Microbiological Specifications for Foods. Book 7. Microbiological testing in food safety management (2nd edition). 2002. International Commission on Microbiological Specifications for Foods (eds). Springer International Publishing AG: Cham, Switzerland 
83. Codex Alimentarius. (2007). Principles and guidelines for the conduct of microbiological risk management (MRM), CAC/GL 63-2007. Available from: www.fao.org/input/download/standards/10741/CXG 063e.pdf

84. FAO/WHO. (2006). The use of microbiological risk assessment outputs to develop practical risk management strategies. Food and Agricultural Organization of the United Nations/World Health Organization: Rome/Geneva. Available from: https://www.who.int/foodsafety/publications/micro/MRA Outputs.pdf

85. WTO. (2000). World Trade Organization. Committee on Sanitary and Phytosanitary Measures. Guidelines to further the practical implementation of Article 5.5. Available from: http://www.wto.org/english/tratop e/sps e/decisions06 e.htm

86. Whiting, R.C. What risk assessments can tell us about setting criteria. Food Control. 2011; 22: p. 1525-1528.

87. WHO. Five keys to safer food [cited 2013 January 10]. Available from: http://www.who.int/foodsafety/publications/consumer/en/5keys_en.pdf

88. Zwietering, M. Practical considerations on food safety objectives. Food Control. 2005; 16: p. 817-823.

89. Stringer, M. Food safety objectives - role in microbiological food safety management. Food Control. 2005; 16: p. 775-794.

90. Buchanan, R., R. Whiting, and T. Ross. (2006). Background paper for the joint FAO/WHO expert consultation on development of practical risk management strategies based on microbiological risk assessment outputs. Kiel, Germany, 3-7 April 2006. Case study: Listeria monocytogenes in smoked fish. "Development of Risk Management Metrics for Food Safety". Food and Agriculture Organization of the United Nations/World Health Organization: Rome/Geneva. Available from: http://www.fao.org/3/a-au625e.pdf

91. DePaola, A., R. Lee, D. Mahoney, I. Rivera, and M. Tamplin. (2006). Background paper for the joint FAO/WHO expert consultation on the development of practical risk management strategies based on microbiological risk assessment outputs. Kiel, Germany, 3-7 April 2006. Case study: Vibrio vulnificus in oysters. Food and Agriculture Organization of the United Nations/World Health Organization: Rome/Geneva. Available from: http://www.fao.org/3/a-au626e.pdf

92. Butler, F., G. Duffy, D. Engeljohn, A.M. Lammerding, and R.B. Tompkin. (2006). Background paper for the joint FAO/WHO expert consultation on the development of practical risk management strategies based on microbiological risk assessment outputs. Kiel, Germany, 3-7 April 2006. Case study: Escherichia coli 0157:H7 in fresh ground beef. Food and Agriculture Organization of the United Nations/World Health Organization: Rome/Geneva. Available from: http://www.fao.org/3/a-au624e.pdf 
93. Anderson, N.M., J.W. Larkin, M.B. Cole, G.E. Skinner, R.C. Whiting, L.G.M. Gorris, A. Rodriquez, R. Buchanan, C.M. Stewart, J.H. Hanlin, L. Keener, and P.A. Hall. Food safety objective approach for controlling Clostridium botulinum growth and toxin production in commercially sterile foods. Journal of Food Protection. 2011; 74: p. 1956-1989.

94. Crouch, E.A., D. LaBarre, N.J. Golden, J.R. Kause, and K.L. Dearfield. Application of quantitative microbial risk assessments for estimation of risk management metrics: Clostridium perfringens in ready-to-eat and partially cooked meat and poultry products as an example. Journal of Food Protection. 2009; 72: p. 2151-2161.

95. Havelaar, A.H., M.J. Nauta, and J.T. Jansen. Fine-tuning food safety objectives and risk assessment. International Journal of Food Microbiology. 2004; 93: p. 11-29.

96. Membré, J.M., J. Bassett, and L.G.M. Gorris. Applying the food safety objective and related standards to thermal inactivation of Salmonella in poultry meat. Journal of Food Protection. 2007; 70: p. 2036-2044.

97. Perni, S., R.R. Beumer, and M.H. Zwietering. Multi-tools approach for food safety risk management of steam meals. Journal of Food Protection. 2009; 72: p. 2638-2645.

98. Rieu, E., K. Duhem, E. Vindel, and M. Sanaa. Food safety objectives should integrate the variability of the concentration of pathogen. Risk Analysis. 2007; 27: p. 373-386.

99. Tuominen, P., J. Ranta, and R. Maijala. Studying the effects of POs and MCs on the Salmonella ALOP with a quantitative risk assessment model for beef production. International Journal of Food Microbiology. 2007; 118: p. 35-51.

100. Pouillot, R., V. Goulet, M.L. Delignette-Muller, A. Mahé, and M. Cornu. Quantitative risk assessment of Listeria monocytogenes in French cold-smoked salmon: II. Risk characterization. Risk Analysis. 2009; 29: p. 806-819.

101. Tromp, S.O., E. Franz, H. Rijgersberg, E. Van Asselt, and I. Van Der Fels-Klerx. A model for setting performance objectives for Salmonella in the broiler supply chain. Risk Analysis. 2010; 30: p. 945-951.

102. Adak, G.K., S.M. Meakins, H. Yip, B.A. Lopman, and S.J. O'Brien. Disease risks from foods, England and Wales, 1996-2000. Emerging Infectious Diseases. 2005; 11: p. 365-372.

103. RIVM. (2006). Our food our health. Healthy diet and safe food in the Netherlands. RIVM report number 270555009. National Institute for Public Health and the Environment: Bilthoven. Available from: http://www.rivm.nl/bibliotheek /rapporten/270555009.pdf

104. Vaillant, V., H. De Valk, E. Baron, T. Ancelle, P. Colin, M.-C. Delmas, B. Dufour, R. Pouillot, Y. Le Strat, P. Weinbreck, E. Jougla, and J.C. Desenclos. Foodborne infections in France. Foodborne Pathogens and Disease. 2005; 2: p. 221-232. 
105. Lake, J.R., J.P. Cressey, M.D. Campbell, and E. Oakley. Risk ranking for foodborne microbial hazards in New Zealand: burden of disease estimates. Risk analysis. 2010; 30: p. 743-752.

106. Thomas, M.K., R. Murray, L. Flockhart, K. Pintar, F. Pollari, A. Fazil, A. Nesbitt, and B. Marshall. Estimates of the burden of foodborne illness in Canada for 30 specified pathogens and unspecified Agents, circa 2006. Foodborne Pathogens and Disease. 2013; 10: p. 639-648.

107. Mathers, C.D., T. Vos, A.D. Lopez, J. Salomon, and M. Ezzati. (2001). National burden of disease studies: A practical guide. Edition 2.0. Global Program on Evidence for Health Policy. World Health Organization: Geneva. Available from: http://www.who.int/healthinfo/nationalburdenofdiseasemanual.pdf

108. Haagsma, J.A., S. Polinder, C.E. Stein, and A.H. Havelaar. Systematic review of foodborne burden of disease studies: Quality assessment of data and methodology. International Journal of Food Microbiology. 2013; 166: p. 34-47.

109. EC. (2011). European Commission. Commission implementing regulation (EU) No $717 / 2011$ of 20 July 2011 entering a name in the register of protected designations of origin and protected geographical indications (Cornish Pasty (PGI)). Available from: http://eur-lex.europa.eu/LexUriServ/LexUriServ.do?uri=OJ:L:2011: 193:0013:0014:EN:PDF 


\section{Chapter 2}

Risk-based estimate of effect of foodborne diseases on public health, Greece

Elissavet Gkogka, Martine W. Reij, Arie H. Havelaar, Marcel H. Zwietering and Leon G.M. Gorris 


\begin{abstract}
The public health effects of illness caused by foodborne pathogens in Greece during 1996-2006 was quantified by using publicly available surveillance data, hospital statistics, and literature. Results were expressed as the incidence of different disease outcomes and as disability-adjusted life years (DALY), a health indicator combining illness and death estimates into a single metric. It has been estimated that each year $\approx 370,000$ illnesses/million inhabitants are likely caused because of eating contaminated food; 900 of these illnesses are severe and 3 fatal, corresponding to $896 \mathrm{DALY} /$ million inhabitants. Ill-defined intestinal infections accounted for the greatest part of reported cases and $27 \%$ of the DALY. Brucellosis, echinococcosis, salmonellosis, and toxoplasmosis were found to be the most common known causes of foodborne illnesses, being responsible for $70 \%$ of the DALY. Overall, the DALY metric provided a quantitative perspective on the impact of foodborne illness that may be useful for prioritizing food safety management targets.
\end{abstract}




\section{Introduction}

To initiate and sustain efforts for prevention and control of foodborne diseases, it is essential to determine the extent and dimensions of the problem [1]. Accurate knowledge of disease incidence and severity is invaluable to competent national authorities for use in selecting appropriate management actions to reduce the overall public health impact. However, much of the information collated regarding foodborne illnesses by different systems cannot be directly translated into policy [2] for three main reasons. First, not all cases are reported to health authorities, and estimates of under-reporting result in considerable uncertainty in burden of illness studies, which limits the interpretation and analysis of available information [3,4]. Second, often only a fraction of illnesses caused by foodrelated pathogens are actually foodborne because transmission can also be through the environment, direct contact with animals, or from person to person [5]. Third, foodborne illnesses may vary not only in their incidence but also in their severity, resulting in widely different clinical manifestations and potentially involving long-term sequelae, although for their accurate description and quantification a uniform health measure would be needed [6].

To circumvent the latter issue, the World Health Organization (WHO) recommends using Disability Adjusted Life Years (DALY) as a metric to express the public health effects of foodborne diseases [2], and DALY is increasingly used for a wide variety of illnesses [6-8]. The aim of this study was to test the feasibility of using publicly available relevant data sources combined with the DALY metric to quantify the annual impact of foodborne illnesses in a country in a format useful for policy decisions. The country selected was Greece. The study used available surveillance data, hospital statistics from 1996 through 2006, and literature. In an attempt to address the first two limitations of the types of study mentioned above, we account in our estimates for uncertainty caused by underreporting and food attribution by using probability distributions to describe a range of plausible values for these parameters. Results are also expressed as cases in the general population, reported or estimated severe cases, and deaths to enable comparisons with similar studies in other countries.

\section{Methods}

The various steps taken to estimate the incidence and impact of foodborne illness in Greece are shown in Figure 1. 


\section{Data collection}

Collecting data on 19 causes of illness that may be transmitted through food:

- National Statistical Service of Greece [9]

- Hellenic Center of Infectious Diseases Control [10]

- WHO reports and databases [11-13]

- Scientific literature

\section{Reported and estimated cases of illness}

Reported incidence of illness that may be transmitted through food Estimated incidence of illness that may be transmitted through food for cryptosporidiasis, giardiasis and toxoplasmosis<smiles>C1=CCCC1</smiles>

\section{Adjustment for food attribution}

Foodborne illness based on reported incidence

Foodborne illness based on estimated incidence of cryptosporidiasis, giardiasis and toxoplasmosis

\section{Adjustment for underreporting}

Reported or estimated cases caused by food

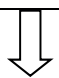

Under-reported or under-estimated cases caused by food

5. Estimating components of DALY formula

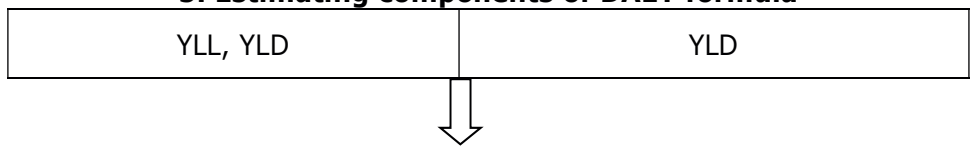

6. Combining YLL and YLD components into DALY

DALY

Figure 1. Working scheme for estimating the incidence and effects of foodborne illness in Greece. For cryptosporidiosis and giardiasis, because estimated cases are on the same level of the surveillance pyramid as reported cases, the cases occurring in the community (under-estimated cases) were based on underreported factors suitable for these pathogens. In the case of toxoplasmosis, disability-adjusted-life years (DALYs) are calculated only on the basis of estimated cases which cover already the entire population. WHO, World Health Organization; YLL, years of life lost caused by premature death in the population; YLD, years lived with disability for incident cases of the health condition. 
Reported cases of illnesses that may be transmitted through food were for the larger part collected from the Hellenic Statistical Authority (ELSTAT) [9] and the Hellenic Center for Infectious Diseases Control (HCIDC) [10]. A limited number of data were obtained from WHO disease surveillance reports where HCIDC was mentioned to be the source $[12,13]$ for better transparency and from other literature when no other information was available [14]. The study included the period 1996-2006 for which data were available from both national sources. ELSTAT collects information regarding hospitalizations for case-patients who have a duration of stay $\geq 1$ day based on the Basic Tabulation List (BTL) of the International Classification of Diseases, $9^{\text {th }}$ revision (ICD-9). ELSTAT data are based on sampling of hospitalized patients' bulletins.

This sampling includes bulletins of deceased patients, although these bulletins are not recorded separately. Hospitalizations recorded by the ELSTAT are likely to vary in their severity because the population in Greece had free access to hospital centers where it was possible to be treated even for minor health issues [15]. HCIDC collects information on notified cases from hospital microbiologic laboratories and district health authorities [12] and also performs active surveillance on the general incidence of gastroenteritis through physicians' reports [10]. HCIDC data can thus be representative of hospitalizations or visits to physicians and are a mixture of laboratory-confirmed and symptom-based notified cases. In the absence of a study validating these two systems of collecting information on disease incidence, we considered ELSTAT and HCIDC data to be representative of reported (severe) cases of illness. Corrections for under-notification or over-notification were not made because this would require a country-specific study that is not currently available. For the few illnesses for which data were available from both systems, ELSTAT data were preferred. For cryptosporidiosis, giardiasis and toxoplasmosis, cases were estimated indirectly taking into account studies on prevalence of these parasites in the general population $[16,17]$. The mean and standard deviation of reported and estimated cases for 1996-2006 were used to create normal distributions which were considered representative of the annual incidence of these illnesses [18].

Deciding on a precise estimate of the proportion of cases that can be attributed to food is complicated [5]. Because of differences in food production, consumption and the ecology of pathogens, the percentage of foodborne transmission is expected to vary among countries and constitutes a major area of uncertainty. To make an adjustment for food attribution, PERT distributions were used as multipliers [19] (Table 1). Minimum and maximum parameters of PERT 
distributions were based on a literature search covering the range of potential values. Most likely values were based on data most relevant to Greece and Europe because endemicity of illnesses is often related to specific regions [20, 21].

Table 1. Parameters of the PERT distributions used to describe foodborne transmission, underreporting and case fatality rate for foodborne illnesses, Greece, 1996-2006

\begin{tabular}{|c|c|c|c|}
\hline \multirow[b]{2}{*}{ Illnesses } & \multicolumn{3}{|c|}{ Minimum, most likely, maximum $\dagger$} \\
\hline & $\begin{array}{c}\text { Food attribution } \\
(\%)\end{array}$ & Under-reporting & $\begin{array}{c}\text { Case fatality } \\
(\%)\end{array}$ \\
\hline \multicolumn{4}{|l|}{ Bacterial } \\
\hline Botulism & $80,100,100$ & $1.625,1.8125,2$ & $3,10.15,17.3$ \\
\hline Brucellosis & $50,84,100$ & $2,10.85,19.7$ & $0.9,2,5$ \\
\hline Campylobacteriosis & $30,55,80$ & $7.6,274.8,542$ & $0.1,0.1265,0.153$ \\
\hline Enterohaemorrhagic Escherichia coli & $40,51,90$ & $2,14.05,26.1$ & $0.25,0.54,0.83$ \\
\hline Leptospirosis & $1,5,49$ & $10,15,20$ & $5,10,15$ \\
\hline Listeriosis & $69,99,100$ & $1.1,1.7,2.3$ & $10,30,44$ \\
\hline Salmonellosis & $55,95,95$ & $3.2,51.45,99.7$ & $0.5,0.701,0.902$ \\
\hline Shigellosis & $8.2,10,31$ & $3.4,18.35,33.3$ & $0.1,0.13,0.16$ \\
\hline Typhoid and paratyphoid fever & $55,80,95$ & $2,7.65,13.3$ & $0.4,0.95,1.5$ \\
\hline Food poisoning & $87,100,100$ & $29.3,185.65,342$ & $0,0.025,0.05$ \\
\hline \multicolumn{4}{|l|}{ Parasitic } \\
\hline Amoebiasis & $10,50,100$ & $9.2,9.6,10$ & $0.1,0.2,0.3$ \\
\hline Cryptosporidiosis & $5.6,5.6,8$ & $7.4,53,98.6$ & $0.07,0.335,0.6$ \\
\hline Echinococcosis & $30,30,100$ & $2,3,4$ & $1,2.24,3$ \\
\hline Giardiasis & $5,10,30$ & $4.6,25.45,46.3$ & $0,0.05,0.1$ \\
\hline Toxoplasmosis & $30,50,63$ & NA* & $3.3,3.75,4.8$ \\
\hline \multicolumn{4}{|l|}{ Viral } \\
\hline Acute hepatitis $A$ & $5,8,11$ & $2,5.55,9.1$ & $0.3,1.35,2.4$ \\
\hline \multicolumn{4}{|l|}{ Mixed/IIl-defined causes } \\
\hline Other helminthiases & $30,90,100$ & $4.6,51.6,98.6$ & $3.37 \neq$ \\
\hline $\begin{array}{l}\text { Intestinal infections due to other } \\
\text { specified microorganism }\end{array}$ & $1,36,70$ & $2,402,1562$ & $0.25 \ddagger$ \\
\hline Ill-defined intestinal infections & $1,36,50$ & $2,402,1562$ & $0.0045 \ddagger$ \\
\hline
\end{tabular}

*NA, Not applicable

†Minimum, most likely (mean), and maximum parameters of each PERT distribution. More information, including an expanded version of this table can be found in the online Technical Appendix: https://wwwnc.cdc.gov/eid/article/17/9/10-1766-techapp1.pdf fFor these illnesses, an average fixed value was used for the case fatality rates estimated by using data from the World Health Organization Mortality Database on the deaths and incidence data from the Hellenic Statistical Authority. 
Not all cases of foodborne illness are reported to health authorities [3] and the degree of under-reporting varies greatly among diseases between countries or within one country in different periods [22]. To make an adjustment for underreporting, PERT distributions were used as multipliers [19] and extremes were selected to cover the full range of values found in literature. Most likely values were set at the middle of this range to give equal weight to extremes of each distribution (Table 1). We assumed that under-reporting factors primarily represent under-reported cases for serious illnesses that result in physician visits, and under-reporting factors for gastrointestinal illnesses are primarily associated with cases not resulting in physician visits. Although in some studies an arbitrarily assigned factor is used to cover for misdiagnosed or undiagnosed hospitalizations and deaths $[3,19]$, it was omitted in the absence of specific data for Greece and under-reported cases caused by this phenomenon were considered to be included in the "ill-defined intestinal infections" BTL code as suggested by other authors [18]. We also assumed that all reported cases were diagnosed and coded correctly.

DALY values were calculated as $D A L Y=Y L L+Y L D$, where $Y L L$ are the Years of Life Lost because of premature death in the population and YLD are the Years Lived with Disability for incident cases of the health condition [23]. YLD was estimated for reported or estimated cases and under-reported cases, while YLL was estimated based only on reported or estimated cases. The rationale for this was that fatal cases contributing to YLL occur at the top of the surveillance pyramid and, if diagnosed, most likely are notified, particularly for obligatory notifiable diseases such as most of the ones examined here. Moreover, for illnesses contributing to $Y L D$ such as gastrointestinal illnesses, under-reported cases not resulting in hospitalization are not expected to have fatal outcomes. The sole exception was listeriosis, in DALY values mainly accounted for through YLL [24] because it has been under surveillance only since 2004. Thus, even serious cases of this infection were expected to be considerably under-notified in part of the period under study because physicians and laboratories might not immediately be aware of the new reporting requirements. Therefore, to avoid under-estimation of deaths, YLD for listeriosis was estimated on the basis of reported and under-reported cases.

The individual components of the DALY formula are estimated as follows:

- $Y L L=d \cdot e$, where $d$ is the number of deaths and $e$ is the expected individual life span at the age of death in years. 
- $\quad Y L D=n \cdot t \cdot w$, where $n$ is the number of cases of a specific illness, $t$ is its duration in years and $w$ is a weight factor (disability weight) that reflects its severity on a scale from 0 (perfect health) to 1 (death) [23, 25].

In calculating YLL:

- The number of deaths $(d)$ was estimated by multiplying reported or estimated cases caused by food for each illness with a PERT distribution describing a plausible range of pathogen specific case-fatality rates [19] on the basis of literature data from other industrialized countries (Table 1). Selected casefatality ratios were always from the same level of the surveillance pyramid as reported or estimated cases. For some generic BTL codes (e.g. "Other helminthiases", "Intestinal infections due to other specified microorganism" and "Ill-defined intestinal infections") the number of deaths was based on data from the WHO Mortality Database [11].

- Regarding the expected individual life span at the age of death in years $(e)$, the age of death was estimated on the basis of data collected by the HCIDC and ELSTAT on patients' age in reported cases. When no explicit information was available in these sources, which was the case for 5 illnesses, age at time of death was assumed to be 40 years. To check the impact of this assumption on the ranking of foodborne risks, we tested both extremes by assuming 0 years as the age of death and by assuming YLL to be 0 . For "Other helminthiases", data from the WHO Mortality Database were used. General life expectancy was based on the life table for Greece for 2000 [23]. For comparison, estimates were also made by using the WHO standard West Level 26 life table [23].

In calculating $Y L D$ :

- Duration of illness $(t)$ was based on data collected by ELSTAT and on literature regarding serious and mild forms of each cause of illness.

- Different disability weights $(w)$ were used for each disease based on the severity of its sequelae and whether estimated cases likely reach the health system or not (Table 2). All under-reported cases were assumed to be mild or self-limiting for gastroenteritis-related illnesses. For serious, non-self-limiting diseases such as brucellosis or echinococcosis that are not related to gastroenteritis, non-reported cases were considered to be as severe as reported or estimated cases.

All estimations were performed by using the @RISK 5.7 software (Palisade Corporation, Ithaca, NY, USA) as an add-in in Microsoft Excel 2010 (Microsoft, 
Redmond, WA, USA). Full details regarding estimations of DALY, selection of input distributions and simulation settings can be found in the online Technical Appendix (https://wwwnc.cdc.gov/eid/article/17/9/10-1766-techapp1.pdf).

Table 2. Disability weights related to the diseases included in study of the effects of foodborne infections, Greece, 1996-2006

\section{Disability weights*}

\begin{tabular}{lcc}
\hline Illnesses & $\begin{array}{c}\text { Reported or } \\
\text { estimated cases }\end{array}$ & Under-reported cases \\
\hline
\end{tabular}

\section{Bacterial}

Botulism

- moderate cases

0.600

0.600

- severe cases

0.906

0.906

Brucellosis

0.200

0.200

Campylobacteriosis

0.067

- gastroenteritis

0.393

- reactive arthritis

0.140

- Guillain-Barré Syndrome, $1^{\text {st }}$ year

0.250

- GBS long term sequelae

0.160

- Inflammatory Bowel Disease

0.260

- Irritable Bowel Syndrome

0.042

Enterohaemorrhagic Escherichia coli

- watery diarrhea and hemorrhagic

0.393

colitis

- Haemolytic-uraemic syndrome and

end-stage renal disease

Leptospirosis

0.920

0.096

Listeriosis

$\neq$

$\neq$

0.067

0.393

0.260

0.042

0.150

0.220

0.096

0.042

0.600

0.096

0.220

0.067 


\section{Parasitic}

Amoebiasis

0.400

0.067

Cryptosporidiosis

0.393

0.067

Echinococcosis

- cured

0.200

0.200

- post surgical conditions

0.239

0.239

- relapse

0.809

0.809

- undiagnosed

0.200

0.200

Giardiasis

0.393

0.067

Toxoplasmosis

- clinical symptoms in the $1^{\text {st }}$ year of

0.140

$-9$

life $\S$

- asymptomatic at birth,

0.080

$-9$

chorioretinitis later in life

\begin{tabular}{lll}
\hline Viral: Acute hepatitis A & 0.500 & 0.500
\end{tabular}

Mixed/IIl-defined causes

$\begin{array}{lll}\text { Other helminthiases } & 0.463 & 0.067 \\ \text { Intestinal infections due to other } & 0.400 & 0.067 \\ \begin{array}{l}\text { specified microorganism } \\ \text { Ill-defined intestinal infections }\end{array} & 0.400 & 0.067\end{array}$

*For an explanation of this selection, see the online Technical Appendix.

†For haemolytic-uraemic syndrome (including end-stage renal disease as a sequela) it is estimated that every case corresponds to 1.05 Years Lived with Disability [25].

¥Not applicable for listeriosis. Because of the high case fatality rate $>95 \%$ of the DALY estimates is composed of YLL [24] that mainly determine the burden of the disease. Therefore no YLD were estimated.

§Clinical symptoms in the first year of life include chorioretinitis, intracranial calcifications, hydrocephalus and central nervous system abnormalities that lead to neurological deficiencies such as mental retardation.

qToxoplasmosis cases are estimates for the entire population. Consequently, under-reporting does not apply. 


\section{Results}

Annual incidence of foodborne illnesses

For 1996-2006, we estimated 369,305 (95\% credible interval [CrI]: 68,283$910,608)$ illnesses per million inhabitants per year attributable to eating contaminated food, at least 905 of which (95\% CrI: 499-1,340) are reported or estimated to be severe and 3 fatal (95\% CrI: 2.0-4.8) (Table 3). Ill-defined intestinal infections accounted for most (94\%) cases (sum of reported/estimated and under-reported cases). Regarding reported/estimated cases, ill-defined intestinal infections were responsible again for the greatest part (72\%), followed by salmonellosis $(8.2 \%)$, brucellosis $(7.1 \%)$, food poisoning $(4.0 \%)$ and echinococcosis $(2.7 \%)$. Most deaths $(48 \%)$ were estimated to be due to brucellosis, although salmonellosis, echinococcosis, listeriosis and toxoplasmosis also contributed substantially to deaths.

Table 3. Mean estimated incidence of total foodborne illnesses, reported /estimated illnesses and deaths attributed to food in Greece per 1 million inhabitants, 1996-2006*

\begin{tabular}{|c|c|c|c|c|c|c|}
\hline \multirow{3}{*}{ Illnesses } & \multicolumn{6}{|c|}{ Incidence per million inhabitants } \\
\hline & \multicolumn{2}{|c|}{ Total illnesses } & \multicolumn{2}{|c|}{$\begin{array}{c}\text { Reported/estimated } \\
\text { illnesses }\end{array}$} & \multicolumn{2}{|r|}{ Deaths } \\
\hline & tmean & $\begin{array}{c}\neq 95 \% \\
\text { CrI }\end{array}$ & tmean & $\neq 95 \% \mathrm{CrI}$ & tmean & $\neq 95 \% \mathrm{CrI}$ \\
\hline \multicolumn{7}{|l|}{ Bacterial } \\
\hline Botulism & 0.13 & $\begin{array}{c}0.011- \\
0.28\end{array}$ & 0.066 & $0.056-0.15$ & 0.0067 & $0.00052-0.017$ \\
\hline Brucellosis & 699 & $\begin{array}{l}225- \\
1,378\end{array}$ & 64 & $30-102$ & 1.5 & $0.52-3.0$ \\
\hline Campylobacteriosis & 3,571 & $\begin{array}{l}851- \\
7,733\end{array}$ & 13 & $5.6-22$ & 0.016 & $0.0069-0.029$ \\
\hline EHEC & 1.0 & $\begin{array}{c}0.069- \\
2.8\end{array}$ & 0.072 & $0.0058-0.17$ & $\begin{array}{c}0.0003 \\
9\end{array}$ & $\begin{array}{c}0.000030- \\
0.00098\end{array}$ \\
\hline Leptospirosis & 4.0 & $0.34-13$ & 0.27 & $0.023-0.84$ & 0.027 & $0.0022-0.087$ \\
\hline Listeriosis & 0.89 & $0.11-1.9$ & 0.41 & $0.049-0.85$ & 0.19 & $0.021-0.45$ \\
\hline Salmonellosis & 3,793 & $\begin{array}{l}750- \\
8,350\end{array}$ & 74 & $22-128$ & 0.52 & $0.15-0.93$ \\
\hline Shigellosis & 25 & $1.1-77$ & 1.4 & $0.068-3.8$ & 0.0018 & $0.000088-0.0050$ \\
\hline $\begin{array}{l}\text { Typhoid and } \\
\text { paratyphoid fever }\end{array}$ & 37 & $3.3-92$ & 4.8 & $0.47-10$ & 0.046 & $0.0043-0.11$ \\
\hline Food poisoning & 6,636 & $\begin{array}{c}450- \\
17,569\end{array}$ & 36 & $2.8-80$ & 0.0089 & $0.00055-0.025$ \\
\hline
\end{tabular}


Parasitic

\begin{tabular}{lcccccc}
\hline Amoebiasis & 13 & $1.9-29$ & 1.3 & $0.19-3.0$ & 0.0026 & $0.00037-0.0064$ \\
Cryptosporidiosis & 197 & $71-360$ & 3.7 & $2.4-5.3$ & 0.013 & $0.0050-0.022$ \\
Echinococcosis & 72 & $29-140$ & $\mathbf{2 4}$ & $10-45$ & $\mathbf{0 . 5 2}$ & $0.19-1.0$ \\
Giardiasis & 159 & $47-358$ & 6.3 & $2.7-12$ & 0.0031 & $0.00069-0.0074$ \\
Toxoplasmosis & 3.4 & $2.5-4.1$ & 3.2 & $2.4-4.0$ & $\mathbf{0 . 1 2}$ & $0.090-0.16$ \\
Other helminthiases & 137 & $22-322$ & 2.7 & $0.56-5.1$ & 0.089 & $0.019-0.17$ \\
\hline
\end{tabular}

Viral

\begin{tabular}{|c|c|c|c|c|c|c|}
\hline Hepatitis A & 6.9 & $1.4-15$ & 1.2 & $0.27-2.4$ & 0.017 & $0.0031-0.038$ \\
\hline $\begin{array}{l}\text { Mixed/IIl-defined } \\
\text { causes }\end{array}$ & & & & & & \\
\hline $\begin{array}{l}\text { Intestinal infections } \\
\text { due to other } \\
\text { specified } \\
\text { microorganism }\end{array}$ & 7,394 & $\begin{array}{c}354- \\
25,558\end{array}$ & 14 & $1.2-36$ & 0.035 & $0.031-0.091$ \\
\hline $\begin{array}{l}\text { Ill-defined intestinal } \\
\text { infections }\end{array}$ & 346,558 & $\begin{array}{l}45,985- \\
886,276\end{array}$ & 655 & $256-1,082$ & 0.030 & $0.012-0.049$ \\
\hline $\begin{array}{l}\text { Total of } \\
\text { gastroenteritis }\end{array}$ & 368,520 & $\begin{array}{l}67,536- \\
909,457\end{array}$ & 812 & $408-1,245$ & 0.95 & $0.52-1.4$ \\
\hline TOTAL & 369,305 & $\begin{array}{l}68,283- \\
910,608\end{array}$ & 905 & $499-1,340$ & 3.1 & $2.0-4.8$ \\
\hline
\end{tabular}

*Values have been rounded to include significant digits and thus not all summations necessarily tally. Boldface indicates the top five contributors to the estimates. EHEC, enterohemorrhagic Escherichia coli; CrI, credible interval. †These estimates correspond to the mean of the output distributions. $\$ 95 \%$ credible interval representative of the 2.5 and 97.5 percentiles.

Public health impact of foodborne illnesses expressed in DALY

Foodborne illnesses accounted for approximately 896 DALY per one million inhabitants annually (95\% CrI: 470-1,461), of which $14 \%$ were attributable to YLL and $86 \%$ to YLD (Table 4). As much as $34 \%$ of the estimated effects of foodborne disease in Greece could be attributed to gastroenteritis-related illnesses, and the remaining $66 \%$ was unevenly split among six nongastroenteritis-related illnesses (brucellosis, echinococcosis, toxoplasmosis, leptospirosis, hepatitis $A$ and botulism). Notwithstanding attendant uncertainty (Figure 2), the most serious foodborne illness in Greece was brucellosis, 
representing $\approx 55 \%$ of the estimated DALY and contributing greatly due to illness $(>88 \%)$. Ill-defined intestinal infections were the second most serious contributor to disease burden $(\approx 27 \%$ of DALY), followed by echinococcosis $(7.8 \%)$ and salmonellosis $(4.6 \%)$ as known causes of illness.

Table 4. Estimates of YLL, YLD and DALY due to foodborne illnesses in an average year in Greece per one million inhabitants, including plausible range attributable to uncertainty*

\begin{tabular}{|c|c|c|c|}
\hline Illnesses & $\begin{array}{l}\text { estimated YLL } \\
(95 \% \mathrm{CrI}) \dagger\end{array}$ & $\begin{array}{l}\text { estimated YLD } \\
(95 \% \mathrm{CrI}) \dagger\end{array}$ & $\begin{array}{l}\text { estimated DALY } \\
(95 \% \mathrm{CrI})^{\dagger}\end{array}$ \\
\hline \multicolumn{4}{|l|}{ Bacterial } \\
\hline \multirow[t]{2}{*}{ Botulism } & 0.27 & 0.0066 & 0.28 \\
\hline & $(0.021-0.67)$ & $(0.00056-0.015)$ & $(0.021-0.69)$ \\
\hline \multirow[t]{2}{*}{ Brucellosis } & 59 & 434 & 493 \\
\hline & $(21-121)$ & $(140-856)$ & $(174-943)$ \\
\hline \multirow[t]{2}{*}{ Campylobacteriosis } & 1.2 & 3.9 & 5.14 \\
\hline & $(0.51-2.1)$ & $(1.5-7.5)$ & $(2.0-9.4)$ \\
\hline \multirow{2}{*}{$\begin{array}{l}\text { Enterohemorrhagic Escherichia } \\
\text { coli }\end{array}$} & 0.016 & 0.039 & 0.054 \\
\hline & $(0.0012-0.039)$ & $(0.0031-0.091)$ & $(0.0043-0.13)$ \\
\hline \multirow[t]{2}{*}{ Leptospirosis } & 0.81 & 0.015 & 0.83 \\
\hline & $(0.066-2.7)$ & $(0.0013-0.046)$ & $(0.067-2.7)$ \\
\hline \multirow[t]{2}{*}{ Listeriosis } & 4.1 & $t$ & 4.1 \\
\hline & $(0.45-9.7)$ & + & $(0.45-9.7)$ \\
\hline \multirow[t]{2}{*}{ Salmonellosis } & 31 & 10 & 41 \\
\hline & $(8.7-55)$ & $(2.9-19)$ & $(12-72)$ \\
\hline \multirow[t]{2}{*}{ Shigellosis } & 0.12 & $0.041^{1}$ & 0.16 \\
\hline & $(0.060-0.34)$ & $(0.0021-0.12)$ & $(0.0081-0.46)$ \\
\hline \multirow[t]{2}{*}{ Typhoid and paratyphoid fever } & 2.3 & 0.17 & 2.4 \\
\hline & $(0.21-5.4)$ & $(0.016-0.38)$ & $(0.23-5.7)$ \\
\hline \multirow[t]{2}{*}{ Food Poisoning } & 0.36 & 1.3 & 1.6 \\
\hline & $(0.022-0.98)$ & $(0.088-3.3)$ & $(0.12-4.1)$ \\
\hline \multicolumn{4}{|l|}{ Parasitic } \\
\hline \multirow[t]{2}{*}{ Amoebiasis } & 0.079 & 0.013 & 0.092 \\
\hline & $(0.011-0.20)$ & $(0.0019-0.030)$ & $(0.013-0.22)$ \\
\hline
\end{tabular}

\footnotetext{
${ }^{1}$ In the original publication of this article in Emerging Infectious Diseases a different mean YLD value was reported for shigellosis (4.1) due to a typographic error.
} 


\begin{tabular}{lccc} 
Cryptosporidiosis & 0.50 & 0.20 & 0.69 \\
Echinococcosis & $(0.20-0.88)$ & $(0.10-0.32)$ & $(0.35-1.2)$ \\
& $\mathbf{1 6}$ & $\mathbf{5 4}$ & $\mathbf{7 0}$ \\
Giardiasis & $\mathbf{( 5 . 9 - 3 1 )}$ & $\mathbf{( 2 2 - 1 0 6 )}$ & $\mathbf{( 2 8 - 1 3 5 )}$ \\
& 0.12 & 0.48 & 0.61 \\
Toxoplasmosis & $(0.028-0.29)$ & $(0.18-0.99)$ & $(0.24-1.2)$ \\
& $\mathbf{9 . 7}$ & $\mathbf{1 4}$ & $\mathbf{2 3}$ \\
Other helminthiases & $\mathbf{( 7 . 0 - 1 3 )}$ & $\mathbf{( 1 0 - 1 7 )}$ & $\mathbf{( 1 7 - 2 9 )}$ \\
& 0.92 & 0.17 & 1.1 \\
\hline Viral: Hepatitis A & $(0.19-1.8)$ & $(0.029-0.38)$ & $(0.23-2.1)$ \\
& & & $(0.22-2.6)$ \\
\hline
\end{tabular}

\section{Mixed/IIl-defined causes}

Intestinal infections due to

1.4

5.2

6.6

other specified microorganism

$(0.12-3.6)$

$(0.26-18)$

$(0.45-21)$

Ill-defined intestinal infections

1.2

243

245

$(0.5-2.0)$

(33-621)

(34-622)

Total of gastroenteritis $\S$

43

265

308

\begin{tabular}{lccc} 
& $(20-68)$ & $(55-643)$ & $(94-687)$ \\
\hline TOTAL & 130 & 767 & 896 \\
& $(81-196)$ & $(361-1,308)$ & $(470-1,461)$
\end{tabular}

*Values have been rounded to include significant digits and thus not all summations necessarily tally. Boldface indicates the top five contributors to each estimate category. YLL, Years of Life Lost; YLD, Years Lived with Disability; DALY, Disability Adjusted Life Years; CrI, credible interval.

$\S 95 \%$ credible interval representative of the 2.5 and 97.5 percentiles.

‡DALY due to listeriosis are mainly determined by the YLL [24]; therefore, no YLD were estimated.

§Gastroenteritis-related illnesses are considered to be all of the above except: botulism, brucellosis, leptospirosis, echinococcosis, hepatitis A and toxoplasmosis. 


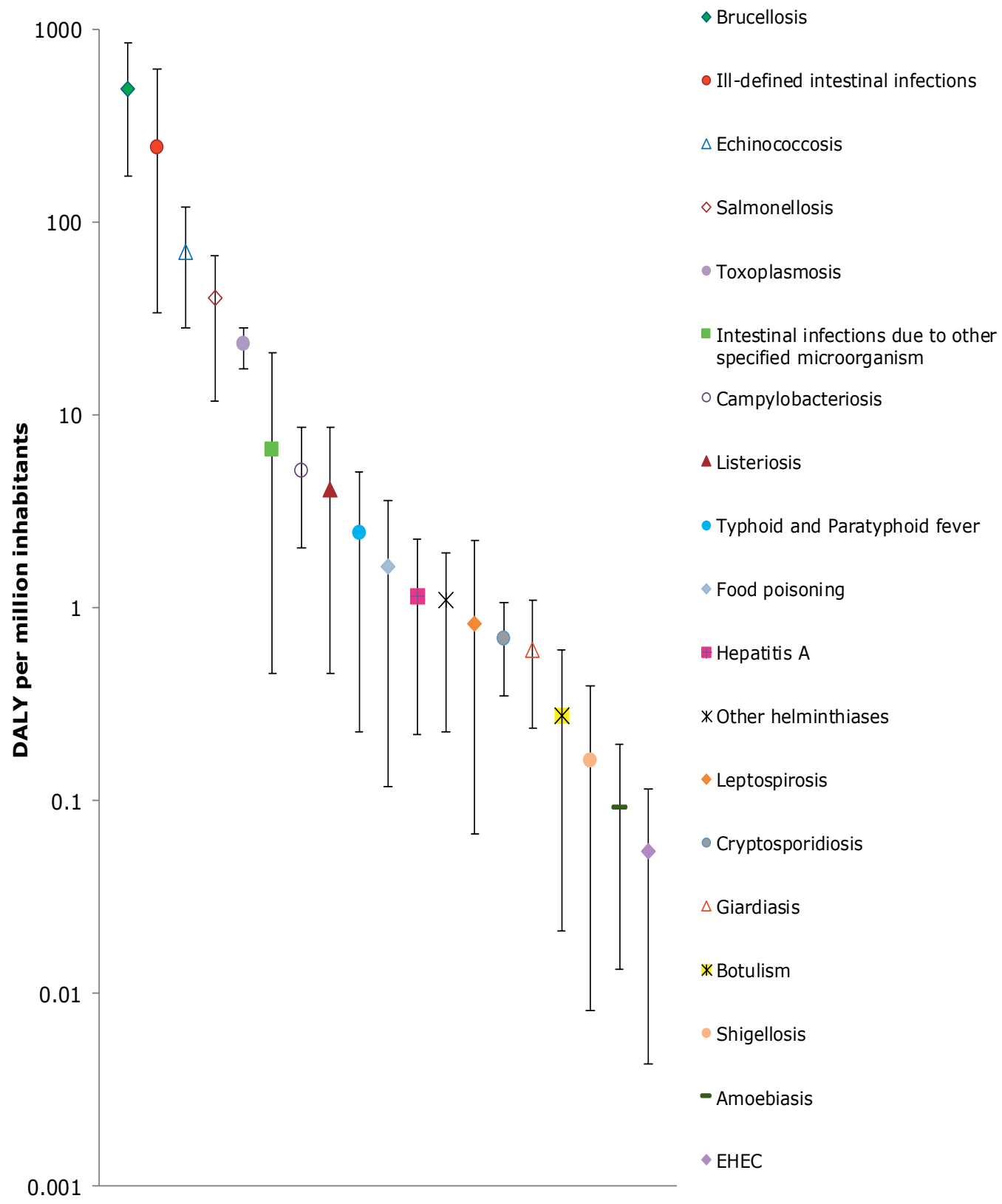

Figure 2. Disability-adjusted life years caused by different foodborne diseases per million inhabitants in the course of an average year in Greece, including uncertainty. Estimates are presented on a logarithmic scale on the $y$-axis. Whiskers represent 95\% credible intervals. EHEC, enterohemorrhagic Escherichia coli. 


\section{Discussion}

The DALY metric provided a different view on the burden of foodborne illnesses on public health in comparison to incidence estimates (Table 5). Although salmonellosis was captured as a major contributor by all four rankings, there was variation regarding other causes of illness. Interestingly, diseases that have the highest effect on public health either in terms of illness (ill-defined intestinal infections), death (toxoplasmosis) or both (brucellosis) are not identified in the ranking based on a single individual incidence parameter, but they are captured by DALY, which has the advantage of enabling comparisons between different disease endpoints. For instance, although toxoplasmosis is not among the five major contributors on the basis of the total incidence or on reported/estimated cases, it is given more prominence through using the DALY metric because this also accounts for severe outcomes and sequelae of this disease. Although selflimiting diseases may appear to be important in terms of incidence, on the basis of DALY they do not greatly contribute to either illness or death. Therefore, use of the DALY metric, gives a different and risk-based perspective of the influence of foodborne illnesses on the health of a country's population because it is estimated on the basis of the diseases' frequency (incidence) and severity (health impact).

Table 5. Ranking of the top 5 causes contributing to the effects of foodborne illness in Greece as estimated on the basis of individual incidence parameters and disability-adjusted life years, 1996-2006

\begin{tabular}{|c|c|c|c|c|}
\hline \multirow[b]{2}{*}{ Rank } & \multicolumn{3}{|c|}{ Incidence estimates } & \multirow[b]{2}{*}{$\begin{array}{l}\text { Disability- } \\
\text { adjusted life } \\
\text { years }\end{array}$} \\
\hline & All illnesses & $\begin{array}{l}\text { Reported/ } \\
\text { estimated } \\
\text { illnesses }\end{array}$ & Deaths & \\
\hline 1 & $\begin{array}{l}\text { Ill-defined } \\
\text { intestinal } \\
\text { infections }\end{array}$ & $\begin{array}{l}\text { Ill-defined } \\
\text { intestinal } \\
\text { infections }\end{array}$ & Brucellosis & Brucellosis \\
\hline 2 & $\begin{array}{l}\text { Intestinal infections } \\
\text { due to other } \\
\text { specified causes }\end{array}$ & Salmonellosis & Salmonellosis & $\begin{array}{l}\text { Ill-defined } \\
\text { intestinal } \\
\text { infections }\end{array}$ \\
\hline 3 & Food poisoning & Brucellosis & Echinococcosis & Echinococcosis \\
\hline 4 & Salmonellosis & Food poisoning & Listeriosis & Salmonellosis \\
\hline 5 & Campylobacteriosis & Echinococcosis & Toxoplasmosis & Toxoplasmosis \\
\hline
\end{tabular}


Most of the foodborne illness cases in Greece were caused by ill-defined intestinal infections (Table 3). This finding is consistent with results from similar studies in other countries $[3,18]$. Using the current Greek surveillance system, we cannot attribute this burden to known causes of gastroenteritis other than the ones included in this study. Noroviruses could be the etiological agents in a large proportion of these ill-defined intestinal infections because they have been considered the most likely agent of foodborne illness caused by unknown agents [26] and have been found in other studies to be a most common cause of foodborne illness due to known agents $[18,19]$. Outbreak data found for these pathogens were scarce [27] and therefore not included in this study. A considerable part of this category might also have been caused by other unknown agents of illness or known agents that have been misdiagnosed. For instance, campylobacteriosis, is expected to be undiagnosed to a great extent in Greece because few laboratories in the country have the ability to identify the pathogen [10]. This finding could partially explain the high under-reporting factor estimated for this illness for Greece, based on the approach of Ekdahl and Giesecke [28] compared with results for other Western countries [3, 29].

Brucellosis was found to be the leading cause of illness and death in Greece. Although its incidence showed a reasonably consistent decline during the period of this study, it still constitutes a serious public health problem (Figure 3). The disease is most common in rural areas of the country, and risk factors for its contraction are occupational contact with animals and the consumption of unpasteurized milk and milk products [30, 31].

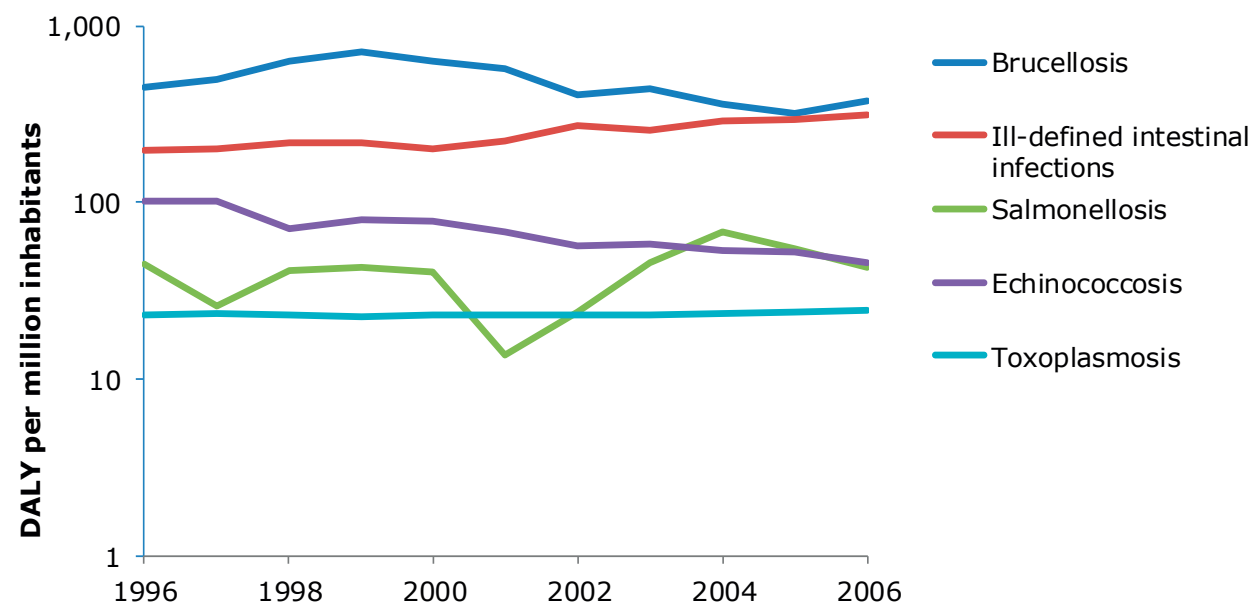

Figure 3. Trends for the top 5 contributors to the burden of foodborne diseases in Greece, 1996-2006. DALY, disability-adjusted life years. 
Echinococcosis was the second most notable foodborne illness. This disease has been recognized as a serious health problem in the country [32] and linked with contaminated food [10, 33]. Echinococcosis due to Echinococcus granulosus (cystic echinococcosis) is its dominant form in Greece [32], where the infection is hyperendemic [20]. Although its incidence has gradually reduced since 1984 as a result of a long anti-echinococcosis campaign and general improvements in living and hygiene standards [32], it still is a serious health risk for the population (Figure 3).

Salmonellosis was the third most serious foodborne illness of known etiology in terms of public health impact, and it also was the most prominent gastroenteritisrelated illness of identified cause (Table 3 ). This finding is consistent with it being a noteworthy zoonosis, which contributes to a high prevalence of gastrointestinal illness in the European Union [34] and the most often reported causative agent of outbreaks of an identified etiological agent worldwide [35].

After salmonellosis, congenital toxoplasmosis was also a major contributor to the disease burden, although in terms of incidence it is an uncommon illness with $<4$ cases per million inhabitants. The disease has not been recognized as a major foodborne illness in the country, although its serious health consequences have been well documented [36].

There are four major factors that add to the uncertainty in our estimates that are not independent: 1) under-reporting, 2) food attribution, 3) the quality of incidence data and 4) value choices in the DALY formula. Given the limited data available for Greece, data from other countries have been used to create multipliers for under-reporting and foodborne transmission (Technical Appendix), these data were of variable quality and representativeness. For instance, in the case of campylobacteriosis and salmonellosis, under-reporting factors based on tourist studies $[28,37]$ have been included in the multipliers which were higher than under-reporting factors from other western countries for the same pathogens [4, 19]. Such underreporting factors might not be completely representative of the difference between reported cases resulting in physician visits and cases in the general population because these studies can be subject to several biases (e.g. tourists differ from natives in exposure) [28] although at the same time they cover for phenomena such as under-notification and misdiagnosis of illnesses which were beyond our intention. As a consequence of including data derived by using different method approaches, the plausible range of these multipliers was wide, which resulted in DALY estimates with similarly wide 
credible intervals (Figure 2). However, despite this limitation, our estimates can still be used for risk ranking purposes.

Uncertainty is also an inherent property of incidence data. Specifically, data for reported cases in Greece (and elsewhere) rely on insufficiently detailed codes, there is incomplete or lacking separate surveillance for many foodborne pathogens, and a specific diagnosis is not given for most episodes of enteric illness requiring hospitalization. These factors result in the greater part of reported cases of gastroenteritis being attributed to ill-defined causes. As with other studies of this kind, assumptions had to be made, notably considering the age of death. Although this assumption did not change the five major foodborne risks, it had considerable impact on the individual estimates. We also had to assume that serious cases of illness that have been reported because of a specific agent have been diagnosed and coded correctly or notified to the appropriate authorities. This assumption might not always be the case because at least some of these illnesses are expected to be part of the ill-defined illnesses. A correction for misdiagnosis and under-notification cannot be included for the reported illnesses until country specific data are available. Assigning an arbitrary factor as in other studies [3] introduces new uncertainties and, unlike incidence data in the case of DALY, can affect the ranking of foodborne risks. Thus, our estimates are based only on the illnesses that the surveillance system in Greece currently exposes, and the estimates' robustness can only be further improved through improved surveillance.

As for uncertainty resulting from value choices in the DALY formula itself, in the present study no age-weighting or discounting were used because their combined use has been criticized as attributing considerably fewer disease impacts and effects to younger age groups [38], and disability weights were carefully selected. For policy-making purposes, ideally, disability weights should be based on the opinion of the general public because they should reflect preferences of the society being studied [22]. Conceivably, use of the DALY metric could help reduce a considerable part of overall uncertainty by accounting for sequelae, which are not normally taken into consideration in studies focusing solely on incidence of foodborne illness yet do constitute a substantial part of the overall effects on a population. In our study, all well-defined sequelae for which information existed in literature were used for DALY calculations, but our findings could be subject to change when new insights become publicly available. For instance, rates of post hospitalization morbidity related to gastrointestinal illnesses have not been taken 
into account in the absence of a specific study, although the duration of illness can be longer than the actual hospital stay.

Finally, selection of life tables is another factor that can influence the DALY estimates. When our estimates could be based on West Level 26 life tables, total burden of illness expressed as DALY increased by only $0.0042 \%$, although individual estimates for illnesses could differ by up to $5.0 \%$ (results not shown).

Regarding the total incidence of foodborne illnesses, our estimates were in the same range as the estimates for Australia (Table 6), although somewhat higher because the study by Hall et al. was restricted to gastroenteritis-related foodborne illnesses [18]. Our estimates of severe reported or estimated cases are between the range of hospitalization rates mentioned for different countries and the same is the case for our case-fatality rates. Our DALY estimates were higher than estimates for the Netherlands [7] or New Zealand [39], although our estimated overall impact for gastrointestinal illnesses is still comparable to the one from the Netherlands where brucellosis is not a major foodborne risk.

Our finding that brucellosis, salmonellosis, echinococcosis and toxoplasmosis together accounted for about $70 \%$ of annual DALY means that these diseases might be major targets for policy making regarding appropriate food safety management actions, especially because their causative agents and likely transmission routes are generally known. Overall, the approach may be of interest to competent authorities in other countries requiring risk-based estimates ranking the impact of foodborne pathogens on public health to prioritize risk management actions.

\section{Acknowledgments}

We thank UNILEVER for sponsoring this research and the Hellenic Statistical Authority and the Hellenic Center of Infectious Diseases Control for providing us with data necessary for the completion of this study. 


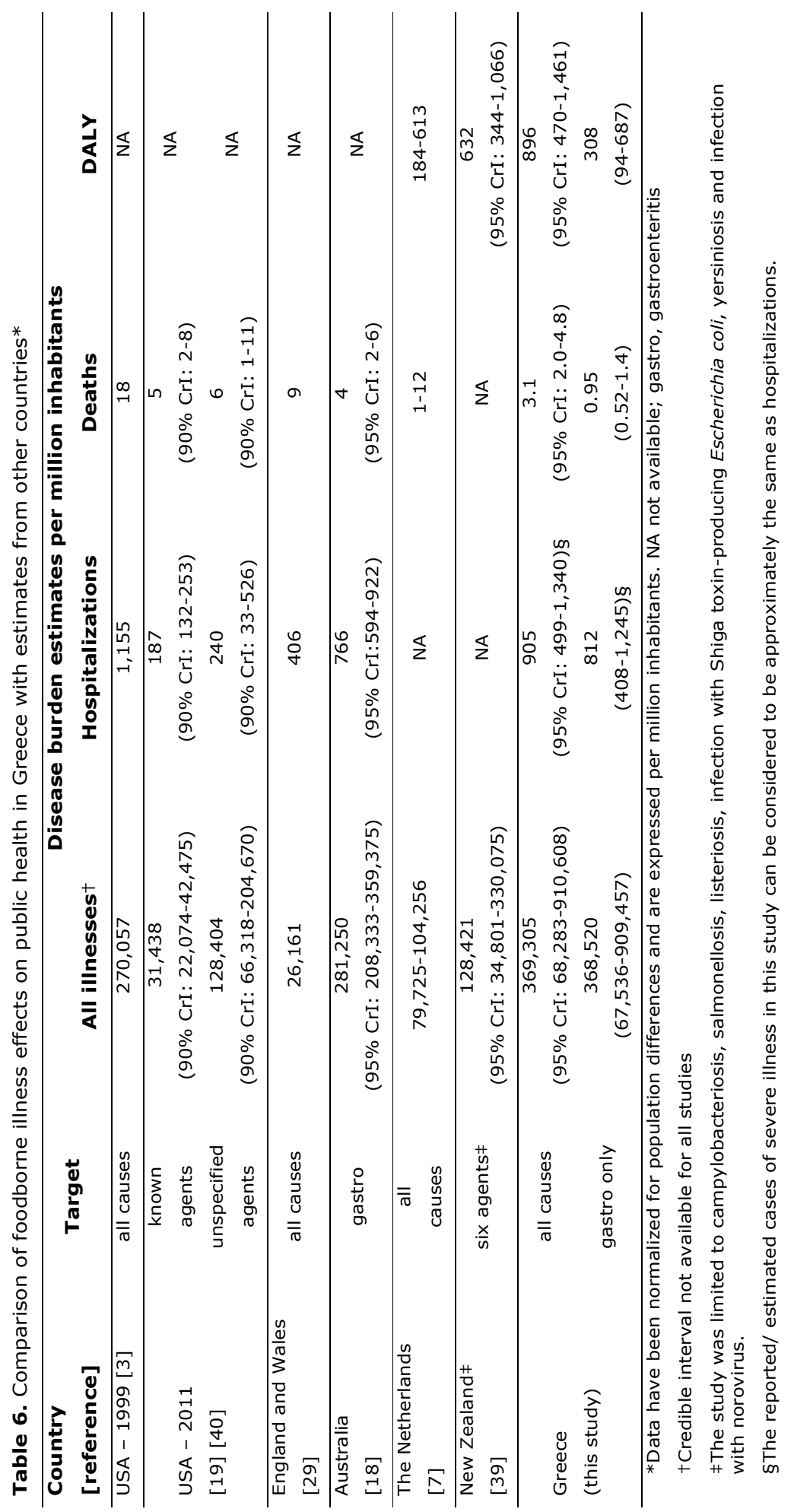




\section{Technical Appendix}

\section{Selection of input distributions and other parameters for the DALY estimates}

Reported cases: Reported cases of illnesses that may be transmitted through food were for the larger part collected from the National Statistical Service of Greece (NSSG) [9] and the Hellenic Center for Infectious Diseases Control (HCIDC) [10]. A limited number of data were obtained from WHO disease surveillance reports where HCIDC was mentioned to be the source $[12,13]$ and from other literature when no other information was available [14]. The study included the period 1996 through 2006 for which data were available from both national sources (Table 1A). NSSG collects information regarding hospitalizations for cases that have a duration of stay of at least one day based on the Basic Tabulation List (BTL) of the International Classification of Diseases, $9^{\text {th }}$ revision (ICD-9). NSSG data are based on sampling of hospitalized patients' bulletins. This sampling includes bulletins of deceased patients though the latter are not recorded separately. Recorded hospitalizations by the NSSG are likely to differ in their severity as Greece's population had free access to hospital centers during the period of the study where it was possible to be treated even for minor health complaints [15]. HCIDC collects information on notified cases from hospital microbiological laboratories and district health authorities [12] while it also performs active surveillance on the general incidence of gastroenteritis in the country through physicians [10]. HCIDC data can thus be representative of hospitalizations or visits to physicians and they are a mixture of laboratory confirmed and symptom based notified cases. For the few gastrointestinal illnesses (shigellosis, typhoid and paratyphoid fever) for which data were available from both sources, cases were usually more for hospitalizations (NSSG data) than for notified cases (HCIDC data). Amongst the non-gastrointestinal illnesses (echinococcosis and brucellosis) this was always the case. This could be due to the fact that either there is serious under-notification (both by hospitals and physicians) to the HCIDC or extended repetition of tests and prescriptions in hospitals as suggested by Mossialos et al. [15] that could result in more than one bulletin for the same person. For the purpose of our estimates we considered both NSSG and HCIDC data to be representative of reported (severe) cases of illness and we decided not to include under-notification (or possible overnotification) since a correction for these phenomena would require a country specific study on the validation of the two systems which is not at the moment 
available. For the four illnesses for which data were available from both systems, NSSG data were often considered preferable.

Percentage foodborne: To cover for the uncertainty associated with food attribution, Pert distributions were used as multipliers [19]. The minimum and maximum parameters of the Pert distributions were based on a literature search covering the range of potential values for this factor for every illness, while the most likely values were based on data most relevant to Greece/Europe as the endemicity of illnesses is often related to a specific region $[20,21,41]$. When no European data could be found, data from other developed countries $[3,19]$ and in the absence of the latter expert elicitation data [5] were used. When no other information was available to construct an upper limit for foodborne transmission a value of $100 \%$ was assumed as in the case of brucellosis, echinococciasis, amoebiasis and other helminthiases. A synopsis of the selected parameters accompanied by the country of origin of the data is provided in Table 2A. More detailed information about the range of values found for every illness during the literature search is provided below.

Under-reporting: To cover for the uncertainty associated with under-reporting, Pert distributions were used as multipliers [19]. The minimum and maximum parameters of these distributions were selected so as to cover the full range of values found in literature for this factor and the most likely values were set at the middle of this range for every illness since unlike food attribution there is no particular reason to consider European data more representative than data from other developed countries for this phenomenon. A synopsis of the selected parameters accompanied by the country of origin of the data is provided in Table $2 \mathrm{~A}$. More detailed information about the range of values found for every illness during the literature search is provided below.

Case fatality ratio: To cover for the uncertainty associated with the case-fatality ratio, Pert distributions were also used as multipliers. The minimum and maximum parameters of these distributions were selected so as to cover the range of values found in literature for this factor and the most likely values were set at the middle of this range for every illness. The literature search was focused on reviews for specific pathogens, outbreak studies and national burden of disease studies. The selected case fatality ratios from these studies were always based on reported cases of serious illness resulting in physician visits so that they are on the same level of the surveillance pyramid as the cases reported in 
Greece's surveillance system. In some instances few national data were available to estimate case fatality rates for generic codes ("Ill-defined intestinal infections", "Other helminthiases" and "Intestinal infections due to other specified microorganism") found in the WHO Mortality Database [11]. A synopsis of the selected parameters accompanied by the country of origin of the data is provided in Table 2A. More detailed information about the range of values found for every illness during the literature search is provided below.

Disability weights: To select the disability weights, studies were collected from literature in which the burden of every illness was quantified using DALY. Selected studies involved review studies on the global burden of specific illnesses (e.g. echinococcosis [42], brucellosis [43]) or on the burden of foodborne pathogens in the EU or in the Netherlands and other countries where the same indicator was used $[22,25,36,44]$. For generic codes involving gastrointestinal illness due to various causes (e.g. "Other helminthiases") or unknown causes (e.g. "Ill-defined intestinal infections") disability weights were selected conservatively using the classification system by Murray [45] in such a way that they would coincide with the upper range of every disability weight class. For example in the case of the illdefined illness a disability weight of 0.4 was selected which corresponds to the upper range of class 3 disability weights (ranging from 0.220-0.4) used to describe severe gastrointestinal illness in other studies (e.g. 0.393 for severe gastroenteritis due to EHEC and Giardiasis [22, 25]). For underreported mild cases of gastrointestinal illness when no data on disability weights could be found in literature (e.g. "Ill-defined intestinal infections" or "Amoebiasis") given the similarity of mild diarrheal symptoms of infectious origin [46] a disability weight of 0.067 was chosen as in other studies where weights are assigned to mild diarrheal symptoms $[22,24]$. A synopsis of all the selected disability weights is provided in Table 3A.

\section{BACTERIAL DISEASES}

\section{Botulism}

Reported cases: Based on HCIDC data (Table 1A).

Percentage foodborne: According to Abgueguen $80-100 \%$ of cases of botulism in the EU are foodborne [47] and $100 \%$ of the cases in France have been attributed to food [48]. Given the fact that wound botulism, which is the only form of the disease not related with food, occurs very rarely in Europe [49] the estimate of $100 \%$ was chosen for Greece. 
Case fatality: The most likely case fatality rate was considered to be $10.15 \%$, the average of the range suggested by US data $(3-17.3 \%)[19,50]$.

Disability weight: It is estimated that approximately $25 \%$ of the patients have to be intubated (severe cases) [50] and the remaining 75\% are considered to be moderate cases. Disability weights of 0.906 were assigned to the severe cases and 0.6 to the moderate cases based on the description of the symptoms of the latter by Mann et al. [51] and the definitions of disability weights by Murray [45]. Duration of illness: The duration of illness was estimated to be 60 days for the patients ending up in need of mechanical help for respiration according to EU studies $[47,52]$ while for the moderate cases the reported hospitalization time is 1 [51] to 2 weeks [53]. The latter value was considered to be more reliable since it is based on estimates from a much larger outbreak of botulism that did not involve any pending legal actions unlike the former value.

Under-reporting: A factor of 1.8125 was considered which is in the middle of the range $1.625-2[3,49]$.

Note: The reported cases for Greece between 1998 and 2007 do not involve any incidents of infant botulism [10]. Reported and underreported cases were considered to be equally severe. Though mild cases of botulism can also occur and they have often been reported during outbreaks they were not considered here because affected persons seldom seek medical care and are not normally captured by surveillance unless they are part of an outbreak [19]. Annually reported cases in Greece are $\leq 1$ and they do not fit the outbreak definition ( $\geq 2$ cases) [54].

\section{Brucellosis}

Reported cases: Based on NSSG data (ICD-9 code 023; BTL code 031) (Table 1A).

Percentage foodborne: In a Greek study foodborne transmission was mentioned to be $84 \%[55]$ and in USA studies $50 \%[3,19]$. Given the fact that brucellosis is a disease that is considered to have a high transmission rate via food [7] the value from the Greek study was selected to represent the mean of the Pert distribution. The minimum value of the distribution was based on the USA studies and the maximum value on an arbitrarily assigned conservative value of $100 \%$ since no other upper limit has been found in literature.

Case fatality: The case fatality of brucellosis is $5 \%$ based on Mead et al. [3] but on the HCIDC website it is stated that the mortality rate for the disease is less than $2 \%$ [10] and Roth et al. mention that mortality is negligible although the disease itself can last for several years [43]. A case-fatality rate of $2 \%$ was finally 
selected since it was considered to be closer to the situation in Greece [30]. We considered $0.9 \%$ as a lower limit for the case-fatality rate based on recent US data [19].

Disability weight: A disability weight of 0.2 was assigned as in another study by Roth et al. based on the fact that the disease is perceived as very painful and affecting occupational ability even during periods of remission [43].

Duration of illness: The median duration of the disease (clinical manifestation) is 3.11 years based on Roth et al. [43].

Under-reporting: Given the seriousness of the disease whose clinical manifestations can last for years the under-reporting factor would in theory be expected to be low e.g 2 as suggested for serious illnesses [3]. Nonetheless, it can be as high as 19.7 based on estimates for the annual incidence of the disease in certain regions in Greece [56] and the average annual incidence of hospitalizations due to brucellosis in the period 1996-2005 [9]. The average of these extremes was selected (10.85).

Note: Reported and under-reported cases were considered to be equally severe.

\section{Campylobacteriosis}

Reported cases: Based on HCIDC data (Table 1A).

Percentage foodborne: The percentage of cases of campylobacteriosis that can be attributed to food ranges from 30 to $80 \%$ based on various European studies summarized by Havelaar et al. [5]. Although some of these studies mention $80 \%$ of the cases to be foodborne $[3,29]$ data from a recent publication of the European Food Safety Authority on campylobacteriosis in the EU point out towards lower food attribution values, since only $35 \%$ of outbreaks and less than $50 \%$ of outbreak cases based on this study are due to food and drinking water [57] and the same is the case for another recent expert elicitation study according to which only $42 \%$ of the cases are due to food [5]. Therefore, given this large variation among studies the average of the reported range of food attribution values in the European studies was selected as the most likely value for the Pert distribution (55\%).

Case fatality: A case fatality ratio of $0.1265 \%$ was selected which is in the middle of the observed range 0.1-0.153 for reported cases [3, 19, 29].

Disability weight: Different disability weights were assigned to each of the potential outcomes for reported cases of campylobacteriosis based on van Lier and Havelaar [25] and Haagsma et al. [58] as can be seen in Table 4A of the Annex. All under-reported cases were assumed to be cases of self-limiting gastroenteritis and were thus assigned a disability weight of 0.067 [59]. 
Duration of illness: The estimated duration of each outcome for the reported cases can be seen in Table 4A of the Annex. The under-reported cases were assumed to have a duration of 3.48 days which corresponds to gastroenteritis due to Campylobacter that does not result in a visit to GP [24].

Under-reporting: Mead et al. mention that the disease is under-reported by a factor of 38 [3]. According to European studies under-reporting of campylobacteriosis is estimated to be much lower; 7.6 based on Wheeler et al. [60] and 10.3 based on Adak et al. [29]. However, taking into account that in Greece very few laboratories have the ability to identify the pathogen [10] the underreporting is expected to be higher than in other European countries and this was indeed found to be the case in a study by Ekdahl and Giesecke [28]. However, in the latter study the incidence data for campylobacteriosis in Greece used to derive the underreporting factor where much lower than what is known for the year 2000 based on WHO. Therefore by repeating the calculations for the correct national data the under-reporting factor was estimated as:

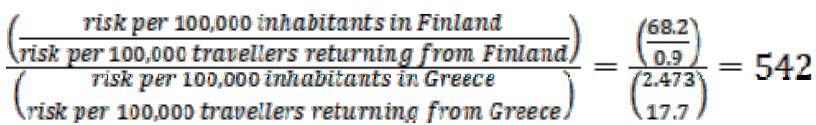

To cover for uncertainty due to this parameter the whole range of under-reporting factors was considered (7.6-542) and the most likely value (274.8) was considered to be at the middle of this range.

\section{EHEC}

Reported cases: Based on HCIDC data (Table 1A).

Percentage foodborne: Approximately $51 \%$ of the sources of EHEC outbreaks are foodborne or waterborne in Europe according to a study by Ammon for the period 1992-1996 [61]. The range of values for this percentage could be larger (4090\%) [5].

Case fatality: The case fatality rate for $E$. coli 0157 has been estimated to be in the middle of the range suggested for EHEC $0157(0.25-0.83 \%)[3,62]$.

Disability weight: There are four important conditions related with EHEC infection that determine the burden of the disease, watery diarrhea, haemorrhagic colitis, haemolytic-ureamic syndrome [63] and end-stage renal disease (ESRD). For watery diarrhea and haemorrhagic colitis a disability weight of 0.393 was assigned based on van Lier and Havelaar [25]. It was also considered that for every reported case of EHEC, 0.5 cases of HUS occur, and that every case of HUS (including ESRD as a sequella) corresponds to 1.05 YLD [25]. All under-reported 
cases were considered to be cases of mild gastroenteritis for which a disability weight of 0.067 was selected [59].

Duration of illness: The duration of EHEC related gastroenteritis varies between 2-9 days [64]. Here, an average duration of 5.6 days was selected for watery diarrhea and hemorrhagic colitis due to EHEC infection according to van Lier and Havelaar [25]. For the under-reported cases a duration of 3 days was assumed based on the median duration of non-bloody STEC 0157 gastroenteritis [24].

Under-reporting: Can range between 2 a has been mentioned for VTEC in England and Whales [29] and 26.1 as mentioned for the US [19]. The most likely value (14.05) was considered to be in the middle of this range. Given the fact that cases of EHEC have only recently started to be under surveillance in Greece [10] under-notification of EHEC is also possible.

\section{Leptospirosis}

Reported cases: Based on HCIDC data (Table 1A).

Percentage foodborne: Leptospirosis is contracted by direct or indirect contact with the urine of an infected animal [65] and thus common vehicles of the infection are contaminated food, water and soil [66]. Though leptospirosis is considered to be a foodborne disease $[66,67]$ estimating an actual percentage of cases that can be attributed to food is complicated since this disease has various ways of transmission [66]. In a recent review of leptospirosis in the north of Greece, the source of the infection had been identified in only $51 \%$ of the cases studied where it was found to be non-food related [68]. This means that the percentage of cases that can be attributed to food is anywhere between 1 and $49 \%$. Taking into account another review of the disease in Germany where different types of exposure are mentioned [69] it can be concluded that food is not a common vehicle of the disease but keeping in mind that the only outbreak of leptospirosis in Greece reported in literature was foodborne (involved drinking water at a café) [65] we assumed a very low food attribution of $5 \%$ which is in the same range as the one of hepatitis A or Rotavirus infections [5].

Case fatality: The severity of the disease caused by leptospirosis can vary a lot ranging from a subclinical infection to a severe syndrome of multi-organ infection with high mortality [65]. Among those that become ill, leptospirosis has two clinically recognizable syndromes, the anicteric form ( $90 \%$ of patients) and the icteric form or Weil's Syndrome [70]. Mortality from the anicteric form of the disease has been reported as rare [70] or almost nil [65] while in the approximately $10 \%$ of the patients that have the icteric form there is an associated $10 \%$ mortality (ranging from $5 \%$ to $10 \%$ ) [65, 70]. In our study we 
assumed all reported cases to be representative of the icteric form of the disease and thus the latter case fatality rate was considered.

Disability weight: The anicteric form includes the great majority of infections which are either subclinical or of very mild severity for which we assumed a class 1 disability weight of 0.096 [45]. The icteric form of the disease is very severe and is characterized by impaired renal and hepatic function, hemorrhage, vascular collapse, and mental status changes [70] and can have severe sequelae like acute renal failure (ARF) which occurs in 16 to $40 \%$ of the cases [65]. Thus, for icteric leptospirosis a class 6 disability weight of 0.920 was assumed [45].

Duration of illness: Leptospirosis is listed in the ICD 10 coding system under code A27. Based on the average of countries that have submitted information in the EHMD for this disease in the years 2004-2006 we have considered the average duration of hospitalization to be approximately 12 days [71]. The under-reported cases are assumed to belong to people that present the anicteric form of the disease which is not likely to result in medical consultation and lasts for about a week [65].

Under-reporting: We assumed that all reported cases belong to the icteric form of the disease which is very serious and that all under-reported cases can be attributed to the anicteric form of the disease. Thus an under-reporting factor of 15 was applied since the ratio of icteric/anicteric leptospirosis has a possible range between $1 / 20$ and $1 / 10$ [65].

\section{Listeriosis}

Reported cases: Based on HCIDC data. For 2001 and 2002 data from a European report on listeriosis in EU countries [14] were used since no data were available from the HCIDC for these years (Table $1 \mathrm{~A}$ ).

Percentage foodborne: $99 \%$ of the cases were considered to be foodborne [29]. Other authors, however, mention this percentage being in the range of $69-99 \%$ [5] or $100 \%$ [19].

Case fatality: The case fatality rate can range between $10 \%$ and $44 \%$ based on outbreak data covering both perinatal and other outbreak cases of severe listeriosis tabulated by Schlech [72]. The average of these extreme values was considered (27\%)

Disability weight: No disability weight was assigned to this disease since the burden of illness is determined mainly by the fatal cases [24]. Moreover given the variety of symptoms related with either postnatal or adult acquired listeriosis (meningitis, sepsis, septicemia, pneumonia, abortion to mention but a few) assigning a uniform disability weight is extremely complex. 
Duration of illness: For the same reason, as mentioned for disability weight, no assumptions were made regarding the duration of illness.

Under-reporting: An under-reporting factor of 1.7 was selected which is in the midlle of the range found in literature for this pathogen 1.1-2.3 $[4,19]$ Underreported cases were assumed to have the same severity as reported cases. Listeriosis is also the only disease in our study for which under-reported cases were also used in estimating the total number of deaths. The reason for this is that the disease has only recently started to be under surveillance in Greece by the HCIDC and it is thus expected to be under-notified. Given again the fact that the DALY due to listeriosis are defined by the fatal cases any under-notification of the disease is likely to lead to a considerable underestimation of its true impact on the health of a population. Thus deaths are also estimated based on the expected number of under-reported cases.

Note: mild cases of listeriosis resulting in diarrhea are not considered in this study.

\section{Salmonellosis}

Reported cases: Based on HCIDC data (Table $1 \mathrm{~A}$ ).

Percentage foodborne: $95 \%$ of the cases are considered to be foodborne $[3,48]$. However, this value may also be considered to be in the range of $55-95 \%$ [5].

Case fatality: The case fatality rate is considered to be $0.701 \%$ which is in the middle of the range $0.5-0.902 \%$ suggested for laboratory confirmed cases [19, 29].

Disability weight: According to other studies on the burden of illness [25, 58] salmonellosis has 4 potential outcomes: gastroenteritis, inflammatory bowel disease, irritable bowel syndrome and reactive arthritis for which the incidence and disability weights are presented in Table 5A. For the under-reported cases, which we assumed that they did not result in a visit to a physician, a disability weight of 0.067 was selected [24].

Duration of illness: The duration of illness for reported cases of illness is shown in Table 5A. For the under-reported cases a duration of 5.58 days was assumed based on the median duration of gastroenteritis in salmonellosis patients that do not visit a GP [24].

Under-reporting: Mead et al. mention that the disease is under-reported by a factor of 38 [3] and in European studies under-reporting factors of 3.2 [60] or 3.9 [29] are mentioned though in a recent study by de Jong and Ekdahl the underreporting factor for several other European countries was mentioned to be much higher and in particular for Greece 99.7 [37]. Thus the whole range was 
considered (3.2-99.7) with a most likely value set at the middle of the extreme values (51.45).

\section{Shigellosis}

Reported cases: Based on HCIDC and NSSG data (ICD-9 code 004; BTL code 012) (Table 1A). HCIDC data were not available for 1996-2003 and then NSSG data were used. For the remainder years (2004-2006) data from the HCIDC were used.

Percentage foodborne: $10 \%$ of the cases were considered as foodborne [48]. This value may nonetheless range between 8.2 based on data from England [29] and $31 \%$ based on recent US data [19].

Case fatality: The case fatality rate was considered to be in the range of 0.1 $0.16 \%[3,19]$ with the average $(0.13 \%)$ as the most likely value.

Disability weight: A disability weight of 0.22 was selected based on Wijewardene and Spohr [44]. For the under-reported cases a disability weight of 0.067 was selected [24]. To describe sequelae related with irritable bowel syndrome the same disability weight as for campylobacteriosis and salmonellosis derived IBS was used [58].

Duration of illness: The duration of hospitalizations (4.6 days) is based on data from the NSSG. For the under-reported cases the duration of illness was assumed to be the same as for E. coli 0157 i.e. 3 days [24]. For irritable bowel syndrome the same duration as for campylobacteriosis and salmonellosis derived IBS was used [58].

Under-reporting: Scallan et al. mention an under-reporting factor of 33.3 [19] while Adak et al. report a factor of 3.4 [29]. The whole range was considered (3.4-33.3) with a most likely value set at the middle of the extreme values (18.35).

\section{Typhoid and paratyphoid fever}

The clinical manifestation of paratyphoid fever is very similar to the one of typhoid fever though usually milder [73]. Nonetheless, given the fact that these infections are discussed together we also decided to treat them as one when estimating their health burden.

Reported cases: Based on HCIDC and NSSG data (ICD-9 code 002; BTL code 011) (Table 1A).

Percentage foodborne: $80 \%$ of the total cases are estimated to be foodborne based on data from England and Whales [29]. Nonetheless, variation could be 
much greater if we accept the range of what is considered foodborne for Salmonella spp. (55-95\%) [5].

Case fatality: Is in the range of $0.4-1.5 \%$. The average of these extremes $(0.95 \%)$ was considered to be the most likely value $[3,48]$.

Disability weight: A disability weight of 0.096 has been selected by Wijewardene et al. [44]. However, considering that the disability weight for non typhoidal gastroenteritis due to salmonellosis is 0.393 only for hospitalized cases according to van Lier and Havelaar [25] a disability weight of 0.096 does not reflect the severity of the disease. Therefore it was decided to arbitrarily assign a class 4 disability weight of 0.6 to severe cases of typhoid fever (hospitalizations) and a class 1 disability weight of 0.096 to uncomplicated cases that can be treated at home since no other studies regarding the severity weight of this disease have been found in literature [45].

Duration of illness: Acute cases were assumed to last approximately 2 weeks and uncomplicated cases usually 1 week $[73,74]$.

Under-reporting: An under-reporting factor of 2 has been used for typhoid fever $[3,29]$ but a factor of 13.3 has also been suggested [19]. The most likely value was set at the middle of this range (7.65).

\section{Food poisoning}

Reported cases: Based on NSSG data (ICD-9 codes 003, 005; BTL code 013) (Table 1A).

The BTL code under this item includes the following two ICD-9 codes [75]:

Other salmonella infections (003) and

Other food poisoning (bacterial) (005). The latter category includes:

- Staphylococcal food poisoning

- Botulism

- $\mathrm{Cl}$. perfringens food poisoning

- Food poisoning due to other Clostridium species

- Food poisoning due to Vibrio parahaemolyticus

- Other microbial food poisoning (B. cereus food poisoning)

- Other unspecified food poisoning

Since we have separate data for the category "other salmonella infections" and "botulism" though the HCIDC, these have been used separately to estimate disease burden due to salmonellosis and botulism. Given the fact that fish and shellfish are always consumed cooked in Greece V. parahaemolyticus is not expected to be a pathogen of concern to the public health although it has been isolated from fresh fish in the country [76] and is currently not included in the 
microorganisms that are notified to the HCIDC. B. cereus, St. aureus and $\mathrm{Cl}$. perfringens are mentioned as the most frequent causes of food poisoning in different countries [77-81] and thus it was assumed that the DALY due to food poisoning are defined by these three microorganisms. The short duration of hospitalization in Greece for food poisoning (weighted average of 4 days based on data from 1998-2005 that include cases of salmonellosis and botulism that are known to last longer) supports this assumption.

Percentage foodborne: By definition $100 \%$ is foodborne. Nonetheless, in some studies the percentage foodborne of the diseases caused by St. aureus, B. cereus and $\mathrm{Cl}$. perfringens is somewhat lower ranging from $87-91 \%$ [5].

Case fatality: Food poisoning due to the above microorganisms is generally selflimiting with an extremely low case fatality ratio, that ranges from 0 to $0.05 \%$ for these 3 pathogens $[3,82]$. The average of this range $(0.025 \%)$ was considered as the most likely value.

Disability weight: B. cereus, St. aureus and $\mathrm{Cl}$. perfringens cause mild, selflimiting illnesses [83] so a class 1 disability weight of 0.067 was assigned to under-reported cases to match the disability weights of other underreported gastrointestinal illnesses included in this study and a class 2 disability weight of 0.220 to reported cases based on Murray, 1994 [45].

Duration of illness: Recovery from this kind of food poisoning is rapid and ranges usually from 1 to 3 days $[64,84]$. The highest observed duration of illness ( 3 days) was selected for hospitalized cases and the lowest 1 day for under-reported cases.

Under-reporting: An under-reporting factor was difficult to establish since we do not know the relative incidence of $B$. cereus, St. aureus and $C l$. perfringens food poisoning cases in this item. Nonetheless, since St. aureus has been mentioned to be responsible for more than half of documented food poisoning cases [77] an under-reporting factor of 185.65 was selected which is in the middle of the range found for this pathogen 29.3-342 [4, 19].

\section{PARASITIC DISEASES}

\section{Amoebiasis}

Reported cases: Based on NSSG data (ICD-9 code 006; BTL code 014) (Table 1A).

Percentage foodborne: Infection is initiated by ingestion of faecally contaminated food or water [63] and water, food and food-handlers have been reported to be the sources of infections [85] so in theory $100 \%$ of cases can be foodborne. However, the cysts of Entamoeba histolytica can survive in water [86] meaning 
that swimming in pools and beaches can also result in infections [87] and venereal transmission has also been observed [88]. Moreover, the role of insects in the transmission of the disease has not been properly investigated [89]. Given these uncertainties we assumed that $50 \%$ of the cases are due to food. In theory this percentage could be as low as $10 \%$ which was the case for foodborne transmission of Giardia lamblia which like E. histolytica is also transmitted by water, food and food handlers [85] but has been reported to be more often transmitted by faecally contaminated water than food [90].

Case fatality: The case fatality rate was considered to be approximately $0.2 \%$ based on tabulated data by Walsh [46] regarding the global prevalence and incidence of amoebiasis (range: $0.1-0.3 \%$ ).

Disability weight: A value of 0.4 was selected based on Wijewardene et al. [44]. For the cases that go under-reported a disability weight of 0.067 was selected [24] based on similarity of the mild diarrheal syndrome of amoebiasis with salmonellosis, giardiasis, toxigenic E. coli diarrhea, many other diarrheas of infectious origin, or the irritable bowel syndrome [46].

Duration of illness: Based on NSSG data the average duration of the illness was assumed to be 4.74 days based on the average duration of hospitalization according to the NSSG [9]. For the under-reported cases the duration of diarrhea was assumed to be 3 days based on the same rationale of the disability weight selection and the fact that non-bloody diarrhea by STEC 0157 lasts for 3 days [24].

Under-reporting: An under-reporting factor of 10 is plausible as suggested for protozoan infections by Casemore [91]. According to Evangelopoulos et al. (2001) [92] the prevalence of E. histolytica in Greece is 1 in every 38 immigrants. So considering that the total population of immigrants (people of foreign nationality) in Greece in 2001 was 796713 based on the NSSG [9], infected individuals were 20966. About $10 \%$ of infected individuals have symptoms, and out of these people $2-20 \%$ (average $=11 \%$ ) have symptoms related with the invasion of $E$. histolytica beyond the intestinal mucosa [86] which are presumed to require hospitalization. Therefore about 230 people with amoebiasis in 2001 are presumed to have required hospitalization. Nevertheless in 2001 only 25 people sought medical care [9] which means that the under-reporting factor is at least 9.2. However, this is a very conservative estimate based on the prevalence of the pathogen in only one (although the largest) of the high risk groups in developed countries (immigrants, travellers, migrant workers, immunocompromised individuals, institutionalized individuals and sexually active homosexuals) [86]. Here a factor of 9.6 was selected which is in the middle of the range (9.2-10). 


\section{Cryptosporidiosis}

Estimated cases: No data are available for cryptosporidiosis so the number of cases is estimated indirectly as follows. The prevalence of Cryptosporidium parvum infection in the Greek population is $2.7 \%$ based on data collected from Papazahariadou et al. [17] which is in line with the available information on the incidence of this parasitic infection in Europe [86]. We assumed that this rate of infection applies to all patients getting hospitalized for gastroenteritis where a protozoan infection could be the cause (BTL Code 015, "intestinal infections due to other specified microorganism" and BTL code 016, "Ill-defined intestinal infections).

Percentage foodborne: Based on the study for the USA [3] 10\% of the cases are foodborne while based on a study for England and Wales [29] 5.6\% of the cases are attributed to food. The data resulting from the European study were considered to be more relevant for Greece.

Case fatality: A range of $0.07-0.6 \%$ has been mentioned $[22,29]$ and the average has been considered to be the most likely value.

Disability weight: A disability weight of 0.393 was selected since in our scenario we estimated the cases of the disease as a proportion of the cases that result in visits to a physician for gastroenteritis or hospitalization. A disability weight of 0.067 was selected for the under-reported cases [22].

Duration of illness: The average duration of illness was considered to be 18.4 days for cases resulting in hospitalization and 3.5 days for cases not resulting in a visit to a physician [22].

Under-reporting: The under-reporting factors for Cryptosporidium parvum infections range from 7.4 [29] to 98.6 [19]. We set the most likely value for under-reporting at the middle of this range.

\section{Echinococcosis}

It is assumed that all cases in Greece are due to Echinococcus granulosus which causes cystic echinococcosis that is easier to treat and has a lower case fatality than alveolar echinococcosis caused by E. multilocularis [93]. This assumption is based on the fact that alveolar echinococcosis is a rare form of echinococcosis in Greece since this country is not among the endemic regions of $E$. multilocularis [94] and only one case has been reported between 1981 and 2000 [95]. Moreover, according to a recent review on echinococcosis in Greece [32] it is rather certain that the majority if not all of the cases of the disease in humans in the country are due to E. granulosus. Additionally it is assumed that all cases of 
cystic echinococcosis are treated with surgery which still remains the only potentially curative treatment for cystic echinococcosis [96].

Reported cases: Based on NSSG data (ICD-9 code 122; BTL code 073) (Table 1A). Though HCIDC data were also available for the same period, NSSG data were used instead as they were considered of better quality. This was because the officially reported cases (through the HCIDC) have been found to be few in comparison to the actual number of diagnosed cases in hospitals in the country as mentioned by Sotiraki et al. [32].

Percentage foodborne: Cystic echinococcosis requires ingestion of the eggs [93] which can be the result of handling hosts of the parasite or ingesting food contaminated with eggs [20]. The exact percentage of cases that can be attributed to food is not known [7]. According to WHO [2], as much as $30 \%$ of cystic echinococcosis is transmitted through food by contamination with parasite eggs. Given the fact that the disease is hyperendemic in Greece [20] contamination of food from the environment can be high, so in our study $30 \%$ of the cases were considered to be foodborne. In theory though since $E$. granulosus is a helminth, foodborne transmission could be as high as 100\% (see disease category "other helminthiases").

Case fatality: A case fatality rate of $2.24 \%$ was selected that corresponds to all cases receiving surgery in Greece [42]. A wider range of $1-3 \%$ is also possible $[93,97]$.

Disability weight: Several disability weights were selected depending on the outcome of surgery for cystic echinococcosis according to Budke et al. [42] and are presented in Table 6A.

Duration of illness: The selected values are based on the recovery time reported for each possible outcome of surgery for cystic echinococcosis [42] and are shown in Table 6A.

Under-reporting: Budke et al. [42] suggest an under-reporting factor of 4 on a global level, this was not found to be very realistic for a western developed country given the seriousness of the disease. Moreover, echinococcosis is considered to be a serious health problem in Greece and the notification of the disease is obligatory in both humans and animals. An under-reporting factor of 2 based on the rationale of Mead et al. [3] for serious diseases is also possible. Given the fact that the reliability of official data was questioned in a recent review of the disease in the country [32] it was finally decided to select a factor of 3 which is in the middle of the above range. It was also assumed that $10 \%$ of the total cases are undiagnosed and thus do not receive medical treatment. These 
cases were assigned a disability weight of 0.2 for 10 years [42]. Lastly, reported and under-reported cases were assumed to have the same severity.

\section{Giardiasis}

Estimated cases: No data are available for giardiasis so the number of cases is estimated indirectly as follows. The prevalence of the parasite in the Greek population according to a recent study is $2.3 \%$ [17] which is in line with what has been mentioned about the rates of detection of this parasite in industrialized countries [86]. We assumed that this rate of infection applies to all patients getting hospitalized for gastroenteritis where a protozoan infection could be the cause (BTL Code 015, "intestinal infections due to other specified microorganism" and BTL code 016, "IIl-defined intestinal infections").

Percentage foodborne: Mentioned anywhere between 5 and 30\% [5]. Here a value of $10 \%$ was assumed as in [29].

Case fatality: The case fatality rate is very low according to Mead et al. [3] or zero according to Vijgen et al. [22] and this seems also to be the case in a more recent study by Adak et al. [29]. However based on more recent US data it can be $0.1 \%$ for laboratory confirmed cases [19]. Thus a most likely value of $0.05 \%$ was considered which is in the middle of this range (0-0.1\%).

Disability weight: A disability weight of 0.393 was selected for hospitalized cases and 0.067 for under-reported cases [22].

Duration of illness: It was considered to be 10 days for people not visiting a physician and 30 days for hospitalized individuals [22].

Under-reporting: This factor is in the range of $4.6-46.3[19,29]$ and the average has been considered to be the most likely value.

\section{Toxoplasmosis}

Estimated cases: The disease has only recently started to be reported to the HCIDC (since 2004) and almost no cases were notified in the period 2004-2008 for which information is available [10]. At the same time there are hospital studies on congenital toxoplasmosis that point out towards a much higher incidence of the disease in the country $[98,99]$. Given this situation, it was considered more logical to estimate the total number of cases by multiplying the number of pregnancies for each year of the study with the percentage of seronegative women of reproductive age $(\sim 70 \%)$, the incidence of primary infection among pregnant women $(0.51 \%)$ and the maternofetal transmission rate $(19.4 \%)[16,98,100]$ (see Table 7A of the Annex). The number of cases found in this way is in agreement with what is known so far regarding the 
incidence of the disease in developed countries which ranges between 1 and 10 cases per 10,000 births [36].

Percentage foodborne: In a European study by Cook et al. foodborne transmission for toxoplasmosis has been mentioned to be in the range of 30 to $63 \%$ [101]. Here $50 \%$ of the cases were assumed to be foodborne since this value is approximately in the middle of the above range and has been used in other national studies as well $[3,19,48]$.

Case fatality: The case-fatality rate is $2.3 \%$ according to Gibbs based on the percentage of stillbirths or neonatal deaths observed when toxoplasmosis occurs during pregnancy [102] while according to Havelaar et al. [36] the incidence of fetal loss or neonatal death is $3.75 \%(3.3-4.8 \%)$ among cases of congenital toxoplasmosis in the Netherlands. The data by Havelaar et al. selected for this study because it is more recent and derived through traceable and better quality data.

Disability weight: Toxoplasmosis can have various outcomes (fetal loss, neonatal death, chorioretinitis, abnormalities of the central nervous system that lead to neurological deficiencies such as psychomotor, convulsions and mental retardation, hydrocephalus and intracranial calcifications) which differ in their severity and incidence. These data are presented in Table 8A of the Annex.

Duration of illness: All outcomes of toxoplasmosis are considered to be life-long sequelae of the disease. Their duration is summarized in Table 8A of the Annex.

Under-reporting: Not applicable.

Note: The study of Diza et al. [16] dealt with the seroprevalence of Toxoplasma gondii on the North of Greece and it was assumed that the seroprevalence of the parasite is the same for the whole of Greece. However, this is not the case since in rural areas and in the island of Crete the percentage of sero-positive individuals appears to be higher [103].

\section{Other Helminthiases}

Reported cases: Based on NSSG data (ICD-9 codes 121, 123, 124, 127-129; BTL code 076) (Table 1A).

Percentage foodborne: All of the helminthic parasites included in this category of diseases [75] have been reported to be transmitted through food [64, 85, 89, 104-109]. However, it is not possible to make a precise estimate of the actual percentage of cases that are transmitted through food since this information is not available for many of the sub-categories of diseases included under this classification while the relative importance of each in this BTL code is not very clear. For some of these diseases (trichinellosis, taeniasis, anisakiasis) the 
percentage foodborne is mentioned to be $100 \%[3,48]$ and thus all the cases under this general category of diseases can be considered to be $100 \%$ foodborne. On the other hand certain species of helminthes included in this category have also been reported to have different modes of transmission i.e. Strongyloides stercoralis can enter the body through the skin [110] and since many of them can be found in contaminated water in pools [111] they can be transmitted by swimming in such waters. Finally, helminthic infections are also known to have a venereal mode of transmission [112]. Nonetheless, the above modes of transmission are not expected to be the case for most of the species in this category and thus $90 \%$ of the cases was assumed to be foodborne. In a very conservative scenario, only $30 \%$ of the cases were assumed to be foodborne as in the case of the tapeworm Echinococcus granulosus.

Case fatality: A case fatality of approximately $3.4 \%$ has been estimated for this group of illnesses based on the number of deaths among hospitalized cases [11] and the total number of hospitalizations for the period 1996-2006 [9].

Disability weight: Most of the helminthic intestinal infections in the Greek native population are caused by the species Enterobius vermicularis, Ascaris lumbricoides, Strongyloides stercoralis and Taenia sp. [17, 113]. However autochthonous cases of helminthic infections have been mentioned to be extremely rare in Greece and most of the reported cases of helminthiases are imported following the influx of immigrants in the country [113]. The helminthic infection most commonly identified in the foreign population (emigrants and refugees) is ancylostomiasis (caused by Ancylostoma sp.) $[17,113]$ while other species found in foreigners are Trichuris trichiura, Ascaris lumbricoides, Strongyloides stercoralis, Taenia sp., Enterobius vermicularis and Schistostoma mansonii [17]. Helminthic infections due to Ancylostoma sp. and Schistostoma sp. are part of other BTL codes (075 and 072) [75] while Strongyloides stercoralis is not transmitted through food but cutaneously [110] so only the rest of the species mentioned above are of relevance for this item. Though all of the remaining helminthic species are primarily associated with gastrointestinal symptoms [114-117] they can also be associated with sequellae such as nutrient deficiencies and anaemia or even epilepsia $[114,118]$. The disability weights for these illnesses and their sequellae according to Lopez et al. [119] range from 00.463 . Here the upper value of this range was considered to be of relevance for the reported cases and for the underreported cases which we assumed to be related with gastrointestinal symptoms a disability weight of 0.067 was selected [24]. 
Duration of illness: The duration of the disease was assumed to be 5.67 days based on NSSG data [9]. For the under-reported cases the median duration of diarrhea before visiting a GP in the Netherlands (6 days) was selected [120].

Under reporting: This factor could also be in the range of 4.6-98.6 based on what is known for the under-reporting of protozoan parasites $[4,19]$. We set the most likely value for under-reporting at the middle of this range.

\section{VIRAL DISEASES}

\section{Acute hepatitis A}

Reported cases: Based on HCIDC data (Table 1A).

Percentage foodborne: $8 \%$ of the total cases were considered to be food-borne which is the average of the range suggested by a recent expert study (5\%-11\%) [5].

Case fatality: A case fatality rate of $0.4 \%$ was estimated by taking into account the age of acute hepatitis A patients in Greece and the case fatality rates for different age groups as presented in the HCIDC website [10].

Disability weight: A disability weight of 0.5 was selected for cases of acute hepatitis A [121]. Reported an underreported cases where assumed to have the same severity.

Duration of illness: The duration of acute cases of hepatitis A is considered to be 9.5 days for both reported and underreported cases according to the average duration of hospitalizations in EU countries for which information could be found in the European Health For All Database (HFA-DB) (Table 9A).

Under-reporting: An under-reporting factor of 2 is possible based on the seriousness of the disease [3] though it can be as high as 9.1 [19]. We set the most likely value for under-reporting at the middle of this range.

\section{DISEASES DUE TO MIXED ILL-DEFINED CAUSES}

\section{Intestinal infections due to other specified microorganism}

Reported cases: Based on NSSG data (ICD-9 codes 007, 008; BTL code 015) (Table 1A).

Percentage foodborne: $36 \%$ based on the relative frequency of foodborne transmission for known pathogens [3]. In theory looking at the microorganisms included in this category (Table 10A) and at the percentages foodborne mentioned for some of these in literature this figure may vary between 1 and $70 \%$.

Case fatality: To estimate mortality due to this category of diseases data for Greece from the WHO Mortality Database were used [11]. According to this 
database mortality is very low for this particular ICD code ranging between 0 and 1 cases per year for the whole country population. The upper limit was considered more realistic although it is still likely to result in under-estimating of the real situation since the quality of data in this particular source has been mentioned to be low [122]. Given the very generic nature of this category assuming a casefatality rate is not possible.

Disability weight: Since the reported cases correspond to patients that were hospitalized, a class 3 disability weight of 0.4 was assigned [45]. For the underreported cases a class 1 disability weight of 0.067 was assigned [24].

Duration of illness: The average hospitalization time for these diseases in Greece (3.84 days) was considered [9]. For the under-reported cases the duration of illness before visiting a GP for Norovirus was considered (3.8 days) [24].

Under-reporting: It was estimated by multiplying two separate under-reporting factors: the first underreporting factor covers the underreporting of gastroenteritis related illnesses between hospitalizations (NSSG data [9]) and visits to physicians (HCIDC data (S. Bonovas, T. Panagiotopoulos, E. Triantafillou, pers. comm.) and the second one is used to cover the underreporting between visits to physicians for gastroenteritis and cases in the community [29]. In this way four different underreporting factors were estimated for the period 20062003. For the rest of the years for which no information was available to estimate the first underreporting factor, the average of the estimated underreporting factors for the period 2005-2003 was used. In theory these under-reporting factors could be anywhere between 2 and 1562 based on what is mentioned about the underreporting of some of the pathogens included in this category (Table 10A).

\section{Ill-defined intestinal infections}

Reported cases: Based on NSSG data (ICD-9 code 009; BTL code 016) (Table 1A).

Percentage foodborne: A value of $36 \%$ was selected for foodborne transmission as in cases of acute gastroenteritis due to unknown etiology [3]. Given the fact that the nature of microorganisms in this category is not known this percentage could range between 1 and $100 \%$.

Case fatality: The mortality rate was considered to be 1 case per year for the whole country population based again on the WHO Mortality Database [11] as in the previous item. 
Disability weight: Since the reported cases correspond to patients that were hospitalized a class 3 disability weight of 0.4 was assigned [45]. For the underreported cases a class 1 disability weight of 0.067 was assigned [24].

Duration of illness: The average hospitalization time for these diseases in Greece (3 days) was considered [9]. For the under-reported cases the duration of illness before visiting a GP for Norovirus was considered (3.8 days) [24].

Under-reporting: The same under-reporting rate as for the previous category was assumed. Nonetheless, the range of underreporting can vary a lot in theory given what we have so far observed regarding the range of under-reporting factors for foodborne pathogens (2-1562). 


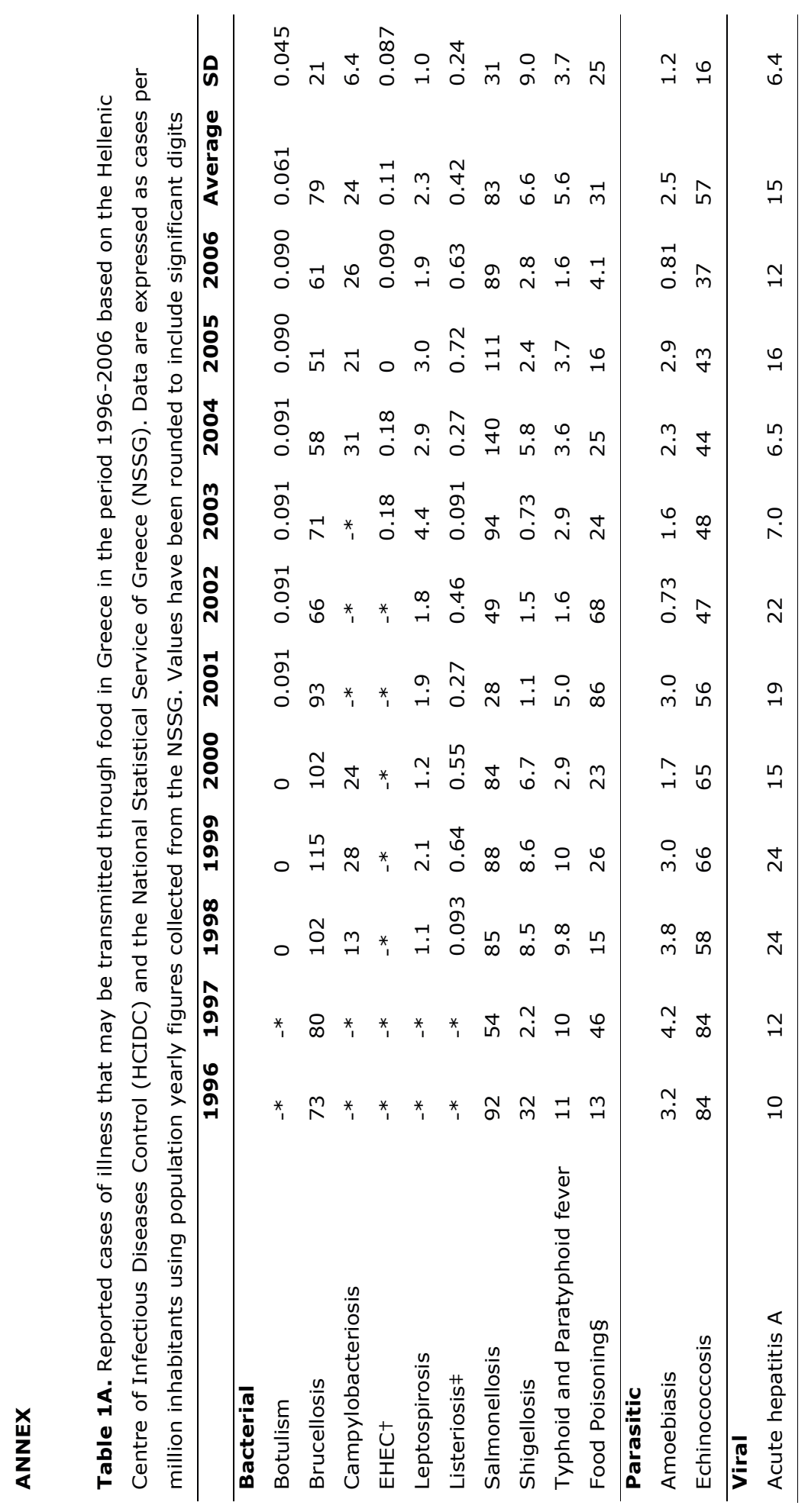




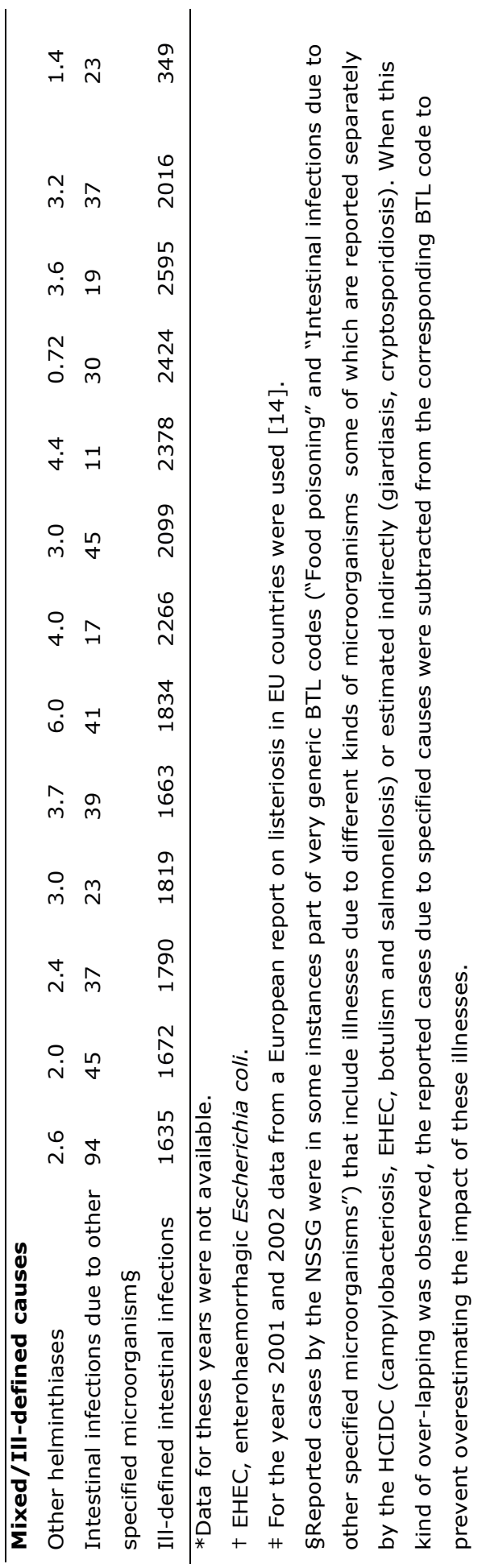




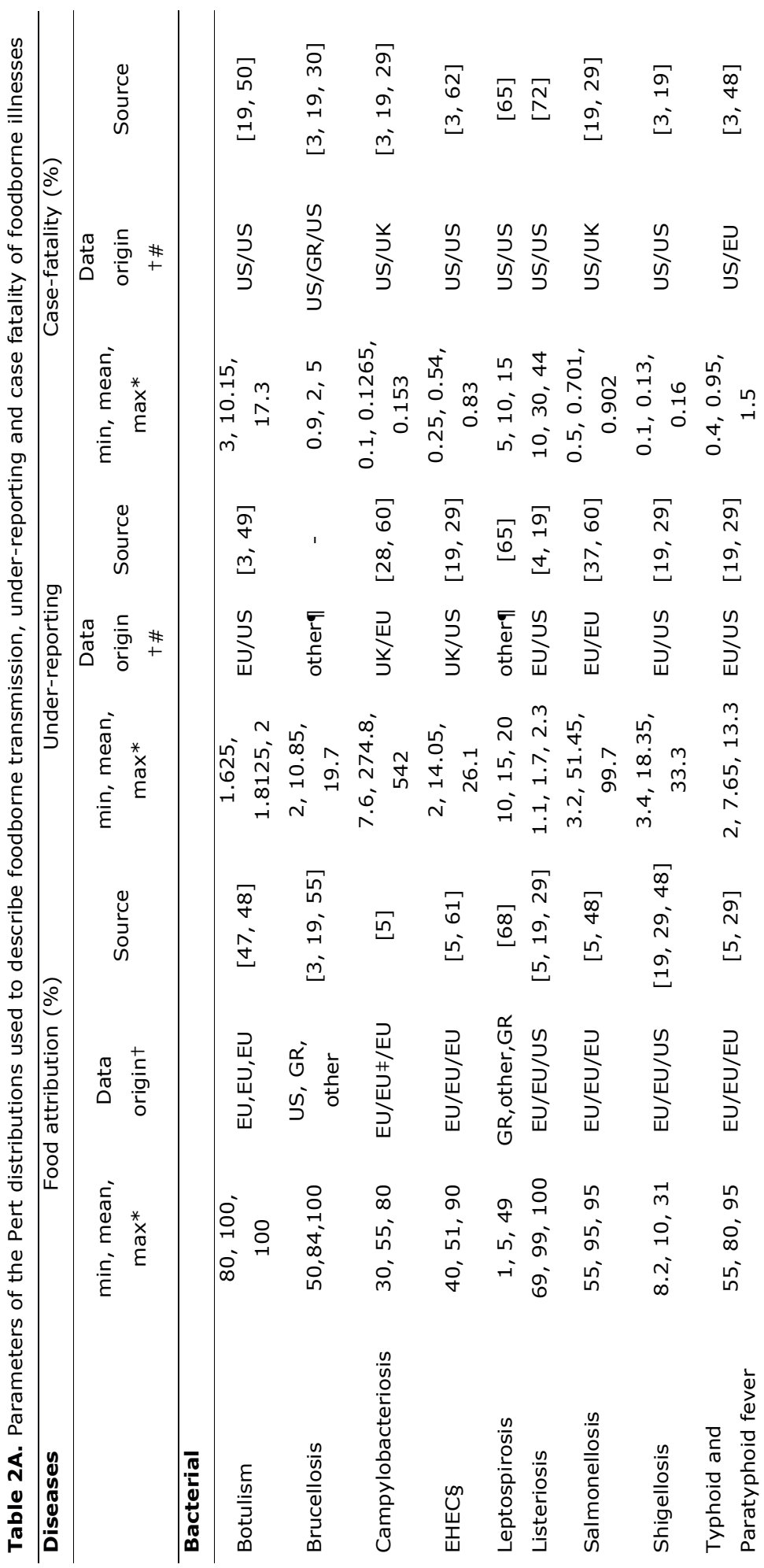




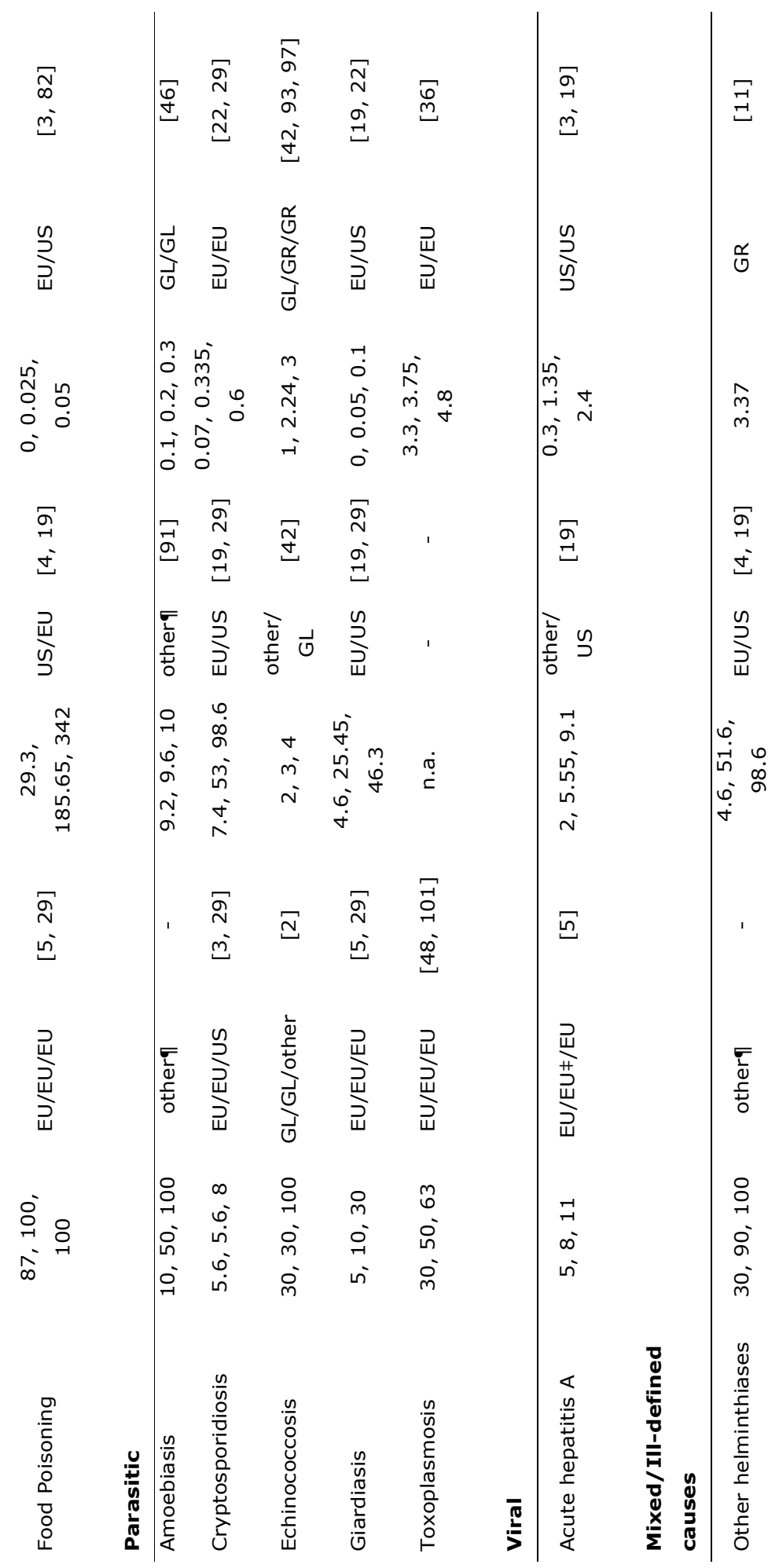




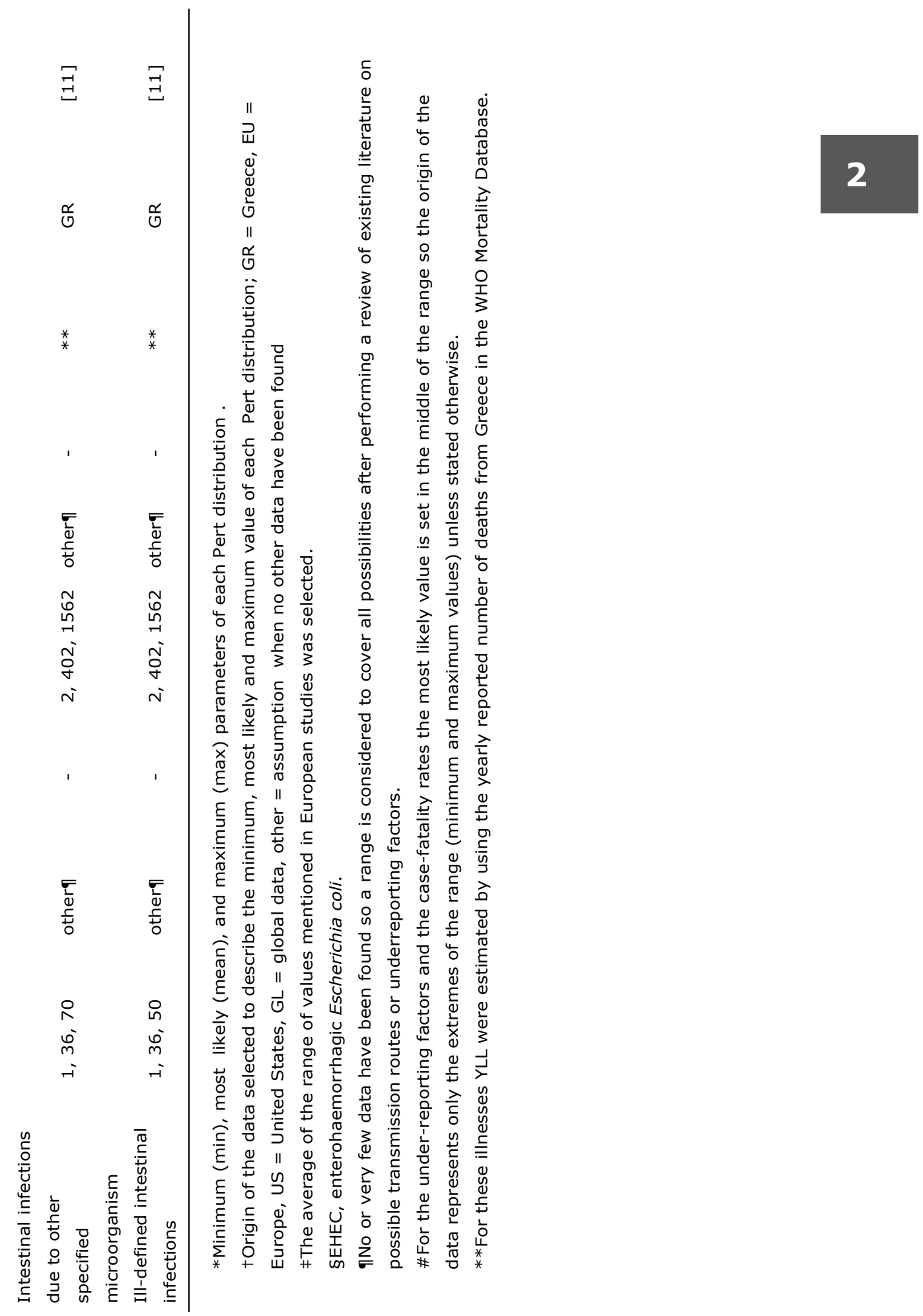




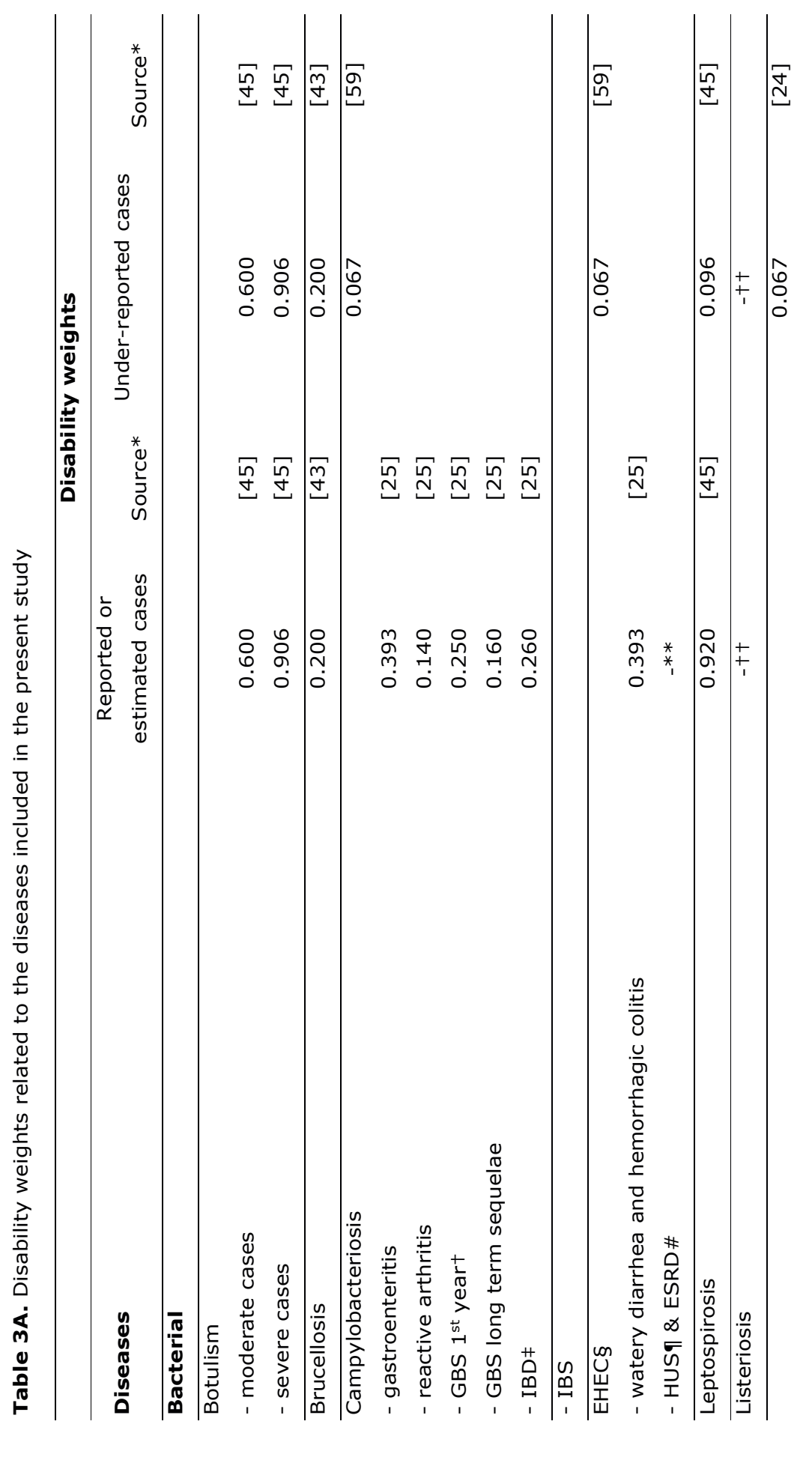




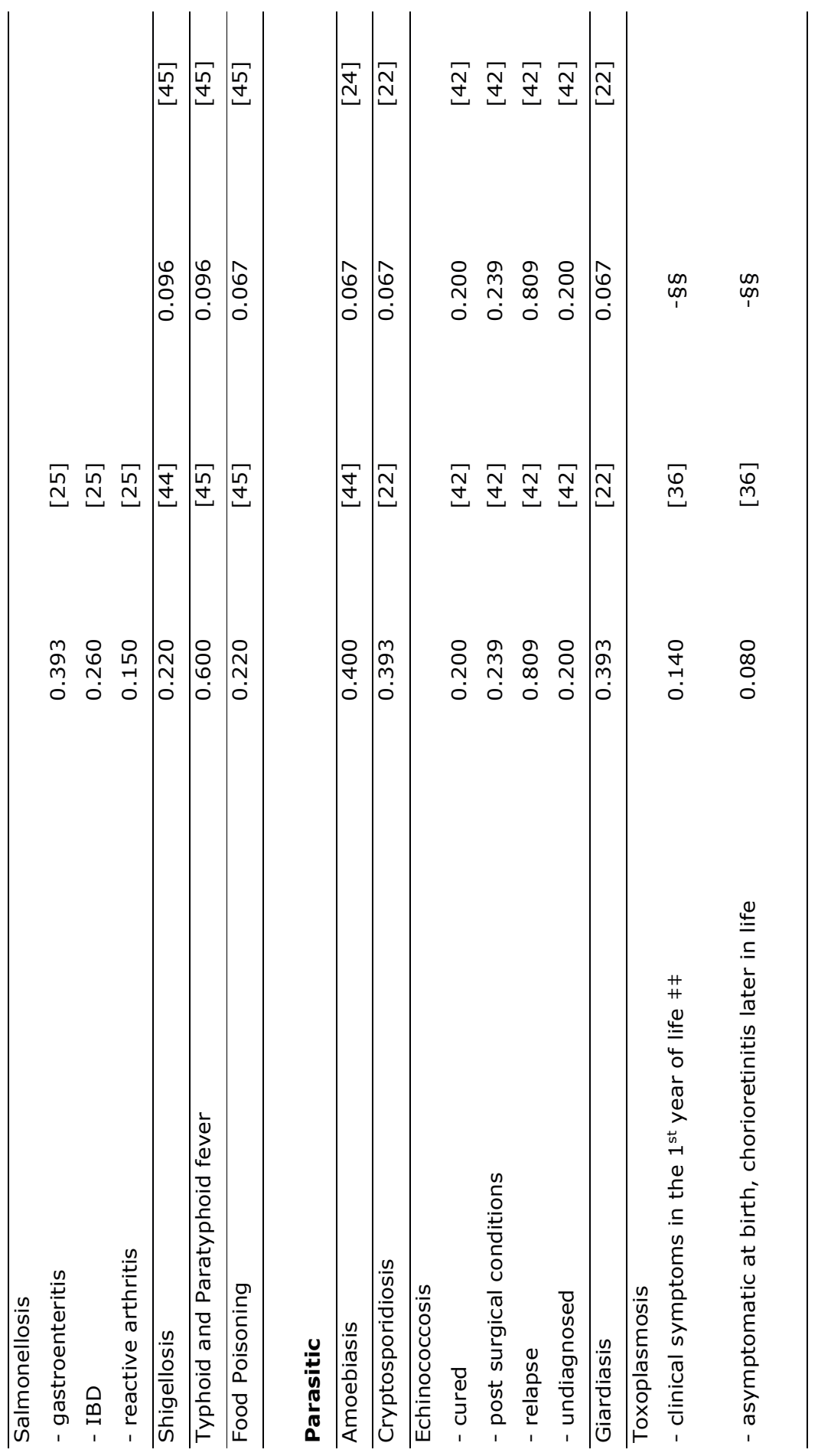




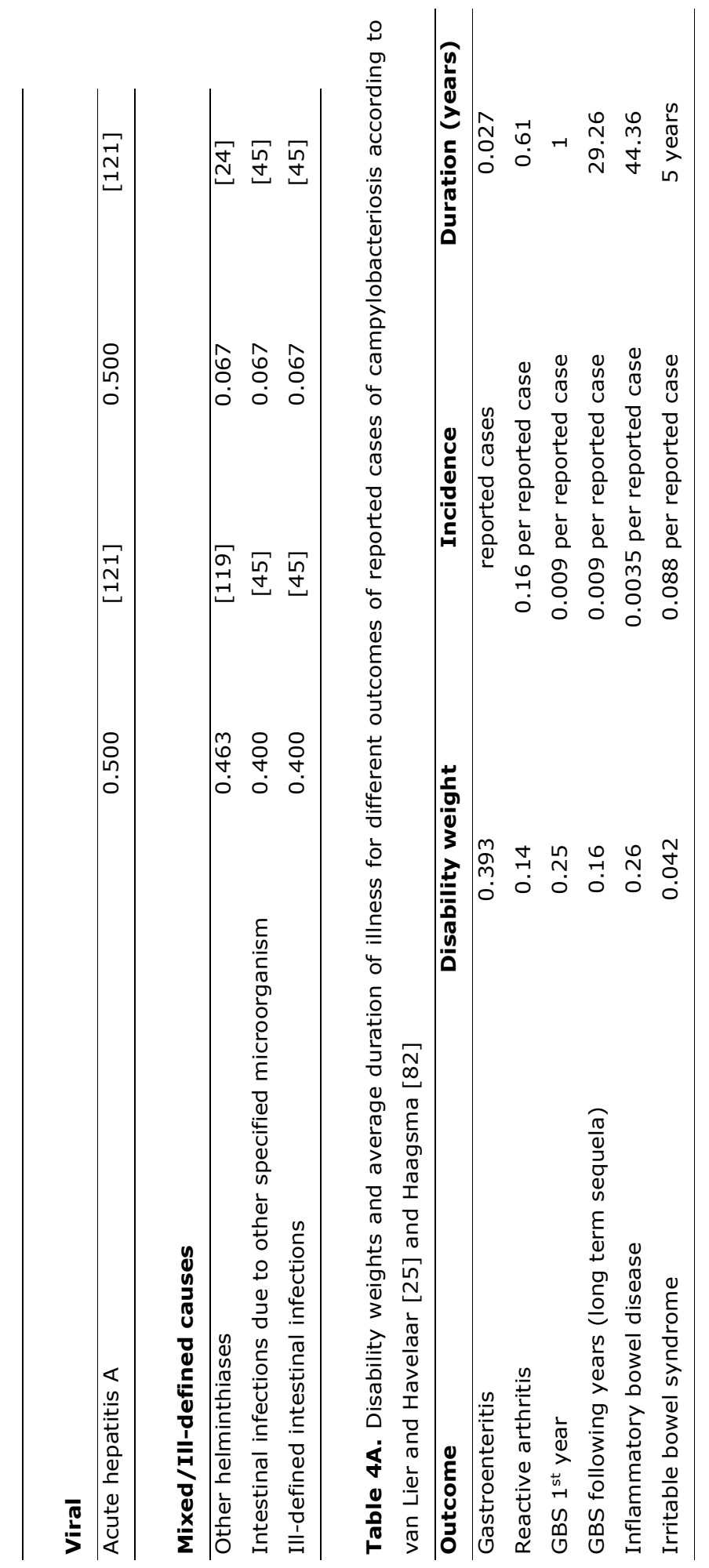



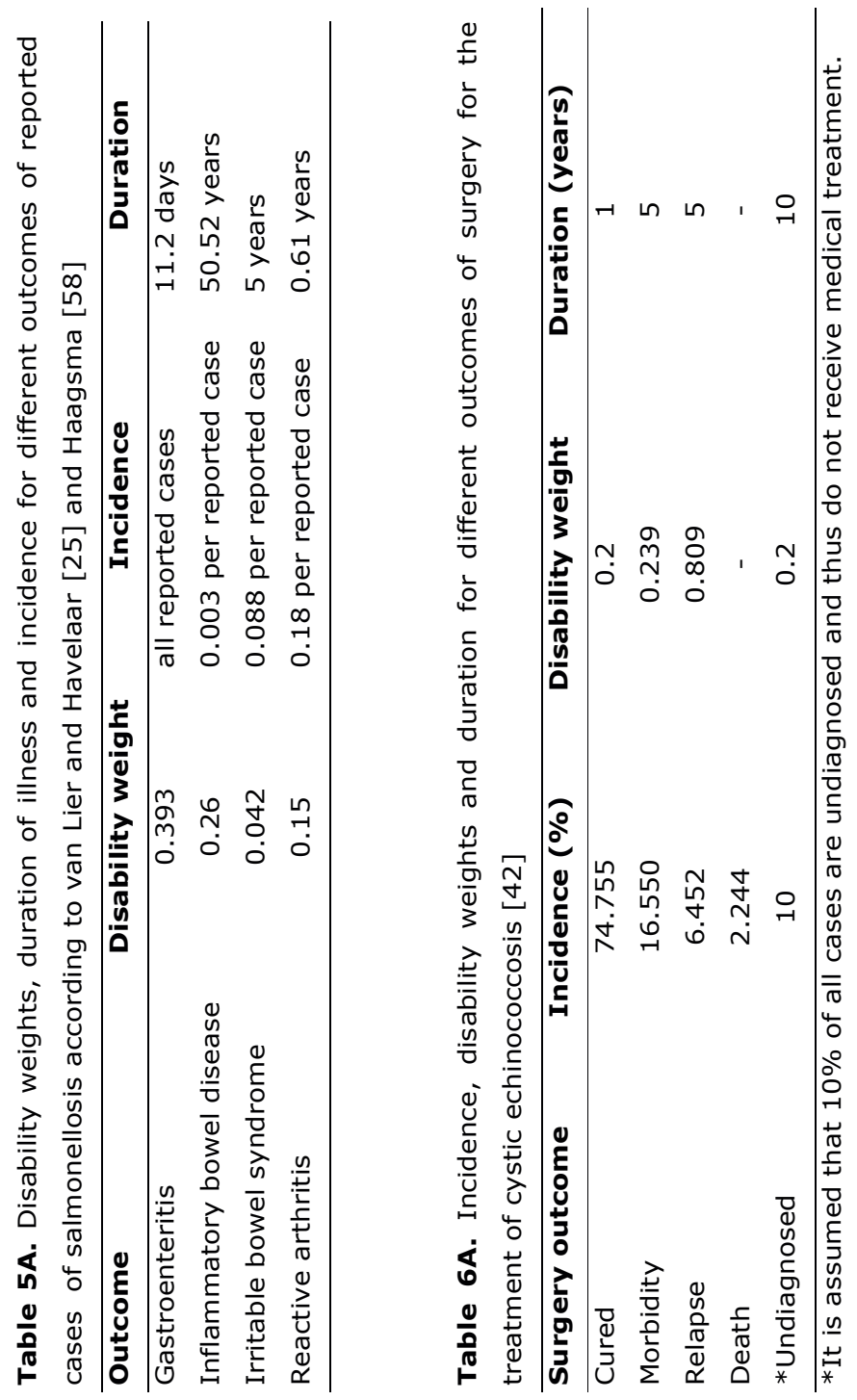
Table 7A. Number of births during the period 1996-2006 and cases of toxoplasmosis based on the percentage of seronegative women of reproductive age $(\sim 70 \%)$, the incidence of primary infection among pregnant women $(0.51 \%)$ and the maternofetal transmission rate $(19.4 \%)[16,98,100]$

\begin{tabular}{lcc}
\hline Year & Pregnancies/year & Cases of toxoplasmosis \\
\hline 1996 & 100718 & 70 \\
1997 & 102038 & 71 \\
1998 & 100894 & 70 \\
1999 & 100643 & 70 \\
2000 & 103274 & 72 \\
2001 & 102282 & 71 \\
2002 & 103569 & 72 \\
2003 & 104420 & 72 \\
2004 & 105655 & 73 \\
2005 & 107545 & 75 \\
2006 & 112042 & 78 \\
\hline
\end{tabular}

Table 8A. Possible outcomes of congenital toxoplasmosis, incidence among patients, duration of illness and disability weights. The duration of illness has been adjusted based on the life expectancy of the Greek population. Source: Havelaar et al. [36]

\begin{tabular}{lccc}
\hline & $\begin{array}{c}\text { Incidence } \\
(\%)\end{array}$ & $\begin{array}{c}\text { Disability } \\
\text { weights }\end{array}$ & $\begin{array}{c}\text { Duration } \\
\text { (years) }\end{array}$ \\
\hline Fetal loss & 3 & 1 & 78.2 \\
\hline Clinical symptoms in the first year & & & \\
of life & 14 & 0.17 & 78.2 \\
\hline Chorioretinitis & 11.4 & 0.01 & 78.2 \\
$\begin{array}{l}\text { Intracranial calcification } \\
\text { Hydrocephalus }\end{array}$ & 1.9 & 0.36 & 78.2 \\
CNS abnormalities* & 2.7 & 0.36 & 78.2 \\
Neonatal death & 0.75 & 1 & 78.2 \\
$\begin{array}{l}\text { Asymptomatic at birth, } \\
\text { chorioretinitis later in life }\end{array}$ & 16.9 & 0.08 & 68.2 \\
*Includes abnormalities of the CNS that lead to neurological deficiencies, that is \\
$\begin{array}{l}\text { psychomotor or other neurological } \\
\text { retardation. }\end{array}$
\end{tabular}


Table 9A. Average duration of acute hepatitis $A$ based on data regarding the average length of stay in hospitals for $8 \mathrm{EU}$ countries in 2006 according to the HFA-DB [123]

\begin{tabular}{lc}
\hline Country & Duration of illness \\
\hline Czech Republic & 16.1 \\
Austria & 6.9 \\
Slovenia & 6.1 \\
Cyprus & 7.0 \\
Croatia & 12.7 \\
Denmark & 5.5 \\
Finland & 6.6 \\
Slovakia & 15.2 \\
\hline Average & $\mathbf{9 . 5}$ \\
\hline
\end{tabular}

Table 10A. Microorganisms included in BTL code "015 - Intestinal infections due to other specified microorganism accompanied by the percentage foodborne and under-reported rates found for each species in literature

\begin{tabular}{|c|c|c|}
\hline Disease (microorganism) & $\begin{array}{l}\text { Percentage } \\
\text { foodborne }\end{array}$ & $\begin{array}{c}\text { Under-reporting } \\
\text { factor }\end{array}$ \\
\hline \multicolumn{3}{|l|}{ Protozoal infections } \\
\hline Balantidium coli & - & $\geq 10[91]$ \\
\hline Giardia lamblia & $5-30 \%[5]$ & $\geq 10[91]$ \\
\hline $\begin{array}{l}\text { Coccidiosis (Isospora belli, } \\
\text { Isospora hominis) }\end{array}$ & - & $\geq 10[91]$ \\
\hline Trichomoniasis & 0 (not foodborne) & - \\
\hline $\begin{array}{l}\text { Other intestinal diseases due to } \\
\text { protozoa }\end{array}$ & - & $\geq 10[91]$ \\
\hline $\begin{array}{l}\text { Undefined protozoal } \\
\text { diarrhea/dysentery }\end{array}$ & - & $\geq 10[91]$ \\
\hline \multicolumn{3}{|l|}{$\underline{\text { Intestinal infections }}$} \\
\hline E. coli & $30-70[3]$ & $38[3]$ \\
\hline Arizona group of paracolon bacilli & - & - \\
\hline Aerobacter aerogenes & - & - \\
\hline Proteus mirabilis, P. morganii & - & - \\
\hline
\end{tabular}




\begin{tabular}{lll}
\hline $\begin{array}{l}\text { Other defined microorganisms } \\
\text { (staphylococcal enterocolitis) }\end{array}$ & \multicolumn{1}{c}{-} \\
\hline Microbial enteritis (undefined) & - & - \\
\hline $\begin{array}{l}\text { Enteritis due to specified virus } \\
\text { (adenovirus, enterovirus) }\end{array}$ & $\begin{array}{l}6 \%-10 \% \text { based on } \\
\text { what is known for } \\
\text { Enterovirus [5] and }\end{array}$ & $\begin{array}{l}721.3 \text { (for } \\
\text { astrovirus) [29] }\end{array}$ \\
& $\begin{array}{l}\text { Astrovirus/Adenovirus } \\
\text { [18] }\end{array}$ & \\
\hline Other microorganisms that & $1-40 \%$ [5] (based on & $21.5-1562$ (based \\
cannot be classified elsewhere & what is known for & on data for \\
(viral gastroenteritis and & Norovirus and & Norovirus and \\
enteritis) & Rotavirus) & Rotavirus) [29, 60]
\end{tabular}




\section{References}

1. Flint, A.J., Y.T. van Duynhoven, J.F. Angulo, M.S. de Long, P. Braun, M. Kirk, E. Scallan, M. Fitzgerald, K.G. Adak, P. Sockett, A. Ellis, G. Hall, N. Gargouri, H. Walke, and P. Braam. Estimating the burden of acute gastroenteritis, foodborne disease, and pathogens commonly transmitted by food: An international review. Clinical Infectious Diseases. 2005; 41: p. 698-704

2. World Health Organization. (2007). The global burden of foodborne disease: taking stock and charting the way forward: WHO consultation to develop a strategy to estimate the global burden of foodborne diseases, Geneva, 2527 September 2006. The Organization: Geneva. Available from: http://www.who.int/foodsafety/publications/foodborne disease/fbd 2006.p df

3. Mead, P.S., L. Slutsker, V. Dietz, L.F. McCaig, J.S. Breese, C. Shapiro, P.M. Griffin, and R.V. Tauxe. Food-related illness and death in the United States. Emerging Infectious Diseases. 1999; 5: p. 607-625.

4. Rocourt, J., G. Moy, K. Vierk, and J. Schlundt. (2003). The present state of foodborne disease in OECD countries. World Heath Organization: Geneva. Available from: http://www.adiveter.com/ftp_public/articulo702.pdf

5. Havelaar, A.H., A.V. Galindo, D. Kurowicka, and R.M. Cooke. Attribution of foodborne pathogens using structured expert elicitation. Foodborne Pathogens and Disease. 2008; 5: p. 649-659.

6. Havelaar, A.H., Y.T.H.P. van Duynhoven, M.J. Nauta, M. Bouwknegt, A.E. Heuvelink, G.A. De Wit, M.G.M. Nieuwenhuizen, and N.C.A.J. Van de Kar. Disease burden in The Netherlands due to infections with Shiga toxinproducing Escherichia coli 0157. Epidemiology and Infection. 2004; 132: p. 467-484.

7. RIVM. (2006). Our food our health. Healthy diet and safe food in the Netherlands. RIVM report number 270555009. National Institute for Public Health and the Environment: Bilthoven. Available from: http://www.rivm.nl /bibliotheek/rapporten/270555009.pdf

8. Melse, J.M., M.L. Essink-Bot, P.G.N. Kramers, and N. Hoeymans. A national burden of disease calculation: Dutch Disability-Adjusted Life Years. American Journal of Public Health. 2000; 90: p. 1241-1247.

9. General Secretariat of the National Statistical Service of Greece. Hellenic Statistical Authority [cited 2010 March 25]. Available from: www.statistics.gr 
10. Ministry of Health and Welfare: Hellenic Center for Infectious Diseases Control (HCIDC). Center for Infectious Diseases Control [cited 2010 March 25]. Available from: http://www.keelpno.gr/

11. World Health Organization. WHO Mortality Database The Organization: Geneva.

12. World Health Organization. (1999-2000). WHO Surveillance Programme for Control of Foodborne Infections and Intoxications in Europe. 8th Report 1999-2000. Country Reports: Greece. The Organization: Geneva. Available from: http://www.bfr.bund.de/internet/8threport/CRs/gre.pdf

13. World Health Organization. (2003). WHO Surveillance Programme for Control of Foodborne Infections and Intoxications in Europe. 7th Report. Country Reports: Greece 1993-1998. The Organization: Geneva. Available from: http://www.bfr.bund.de/internet/7threport/CRs/GRE.pdf

14. Denny, J. and J. McLaughlin. Human Listeria monocytogenes infections in Europe - An opportunity for improved European Surveillance. Eurosurveillance. 2008; 13: p. 8082.

15. Mossialos, E., S. Allin, and K. Davaki. Analysing the Greek health system: A tale of fragmentation and inertia. Health Economics. 2005; 14: p. S151S168.

16. Diza, E., F. Frantzidou, E. Souliou, M. Arvanitidou, G. Gioula, and A. Antoniadis. Seroprevalence of Toxoplasma gondii in northern Greece during the last 20 years. Clinical Microbiology \& Infection. 2005; 11: p. 719-723.

17. Papazahariadou, M.G., E.G. Papadopoulos, S.E. Frydas, C. Mavrovouniotis, T.C. Constantinidis, K. Antoniadou-Sotiriadou, and A.E. Siochu. Prevalence of gastrointestinal parasites in the Greek population: local people and refugees. Annals of Gastroenterology. 2004; 17: p. 194-198.

18. Hall, G., D.M. Kirk, N. Becker, E.J. Gregory, L. Unicomb, G. Millard, R. Stafford, K. Lalor, and O.W. Group. Estimating foodborne gastroenteritis, Australia. Emerging Infectious Diseases. 2005; 11: p. 1257-1264.

19. Scallan, E., R.M. Hoekstra, F.J. Angulo, R.V. Tauxe, M.A. Widdowson, S.L. Roy, J.L. Jones, and M.P. Griffin. Foodborne illness acquired in the United States - Major pathogens. Emerging Infectious Diseases. 2011; 17: p. 7-15.

20. McManus, D.P., W. Zhang, J. Li, and P.B. Bartley. Echinococcosis. The Lancet. 2003; 362: p. 1295-1304.

21. Pappas, G., P. Papadimitriou, N. Akritidis, L. Christou, and E.V. Tsianos. The new global map of human brucellosis. The Lancet infectious diseases. 2006; 6: p. 91-99. 
22. Vijgen, S.M.C., M.J.J. Mangen, L.M. Kortbeek, Y.T.H.P. van Duijnhoven, and A.H. Havelaar. (2007). Disease burden and related costs of cryptosporidiosis and giardiasis in the Netherlands. National Institute for Public Health and the Environment: Bilthoven. Available from: http://www.rivm.nl/bibliotheek Lrapporten/330081001.pdf

23. The Organization. World Health Organization [cited 2009 December 12]. Available from: www.who.int

24. Kemmeren, J.M., M.J.J. Mangen, Y.T.H.P. van Duynhoven, and A.H. Havelaar. (2006). Priority setting of foodborne pathogens: disease burden and costs of selected enteric pathogens. National Institute for Public Health and the Environment: Bilthoven. Available from: http://www.rivm.nl Lbibliotheek/rapporten/330080001.pdf

25. Van Lier, E.A. and A.H. Havelaar. (2007). Disease burden of infectious diseases in Europe: a pilot study. National Institute for Public Health and the Environment: Bilthoven. Available from: http://www.rivm.nl/bibliotheek /rapporten/215011001.pdf

26. McCabe-Sellers, B.J. and S.E. Beattie. Food safety: emerging trends in foodborne illness surveillance and prevention. Journal of the American Dietetic Association. 2004; 104: p. 1708-1717.

27. Vorou, R., G. Dougas, K. Gkolfinopoulou, and K. Mellou. Gastroenteritis outbreaks in Greece. The Open Infectious Diseases Journal. 2009; 3: p. 99105.

28. Ekdahl, K. and J. Giesecke. Travellers returning to Sweden as sentinels for comparative disease incidence in other European countries, Campylobacter and Giardia infection as examples. Eurosurveillance. 2004; 9: p. 6-9.

29. Adak, G.K., S.M. Long, and S.J. O'Brien. Trends in indigenous foodborne disease and deaths, England and Wales: 1992 to 2000. Gut. 2002; 51: p. 832-841.

30. Vorou, R., K. Gkolfinapoulou, G. Dougas, K. Mellou, I.N. Pierroutsakos, and T. Papadimitriou. Rapid communications. Local brucellosis outbreak on Thassos, Greece: a preliminary report. Eurosurveillance. 2008; 13: p. 1-2.

31. Minas, M., A. Minas, K. Gourgulianis, and A. Stournara. Epidemiological and clinical aspects of human brucellosis in Central Greece. Japanese Journal of Infectious Diseases. 2007; 60: p. 362-366.

32. Sotiraki, S., C. Himonas, and P. Korkoliakou. Hydatidosis-echinococcosis in Greece. Acta Tropica. 2003; 85: p. 197-201.

33. Kardaras, F., D. Kardara, D. Tselikos, A. Tsoukas, N. Exadactylos, M. Anagnostopoulou, C. Lolas, and L. Anthopoulos. Fifteen year surveillance of 
echinococcal heart disease from a referral hospital in Greece. European Heart Journal. 1996; 17: p. 1265-1270.

34. ECDC. (2007). The first European communicable disease epidemiological report. European Centre for Disease prevention and Control: Stockholm. Available from: http://www.ecdc.europa.eu/en/publications/Publications $\angle 0706$ SUR First \%20Annual Epidemiological Report 2007.pdf

35. World Health Organization/ Food and Agriculture Organization of the United Nations. (2002). Risk assessments of Salmonella in eggs and broiler chickens. The Organizations: Geneva/Rome. Available from: http://www.who.int/foodsafety/publications/micro/en/salmonella.pdf

36. Havelaar, A.H., J.M. Kemmeren, and L.M. Kortbeek. Disease burden of congenital toxoplasmosis. Clinical Infectious Diseases. 2007; 44: p. 14671474.

37. de Jong, B. and K. Ekdahl. The comparative burden of salmonellosis in the European Union member states, associated and candidate countries. BCM Public Health. 2006; 6

38. Arnesen, T. and L. Kapiriri. Can the value choices in DALYs influence global priority-setting? Health Policy. 2004; 70: p. 137-149.

39. Lake, J.R., J.P. Cressey, M.D. Campbell, and E. Oakley. Risk ranking for foodborne microbial hazards in New Zealand: burden of disease estimates. Risk analysis. 2010; 30: p. 743-752.

40. Scallan, E., P.M. Griffin, F.J. Angulo, R.V. Tauxe, and R.M. Hoekstra. Foodborne illness acquired in the United States-Unspecified agents. Emerging Infectious Diseases. 2011; 17: p. 17-22.

41. EFSA/ECDC. The Community summary report on trends and sources of zoonoses, zoonotic agents, antimicrobial resistance and foodborne outbreaks in the European Union in 2006. EFSA Journal. 2007; 5: 130r

42. Budke, M.C., P. Deplazes, and R.P. Torgerson. Global socioeconomic impact of cystic echinococcosis. Emerging Infectious Diseases. 2006; 12: p. 296303.

43. Roth, F., J. Zinsstag, D. Orkhon, G. Chimed-Ochir, G. Hutton, O. Cosivi, G. Carrin, and J. Otte. Human health benefits from livestock vaccination for brucellosis: case study. Bulletin of the World Health Organization. 2003; 81: p. 867-876.

44. Wijewardene, K. and M. Spohr. An attempt to measure burden of disease using disability adjusted life years for Sri Lanka. Ceylon Medical Journal. 2000; 45: p. 110-115. 
45. Murray, C.J.L. Quantifying the burden of disease: the technical basis for disability-adjusted life years. Bulletin of the World Health Organization. 1994; 72: p. 429-445.

46. Walsh, J.A. Problems in recognition and diagnosis of amebiasis: estimation of the global magnitude of morbidity and mortality. Reviews of Infectious Diseases. 1986; 8: p. 228-238.

47. Abgueguen, P., V. Delbos, J.M. Chennebault, S. Fanello, O. Brenet, P. Alquier, J.C. Granry, and E. Pichard. Nine cases of foodborne botulism type $B$ in France and literature review. European Journal of Clinical Microbiology \& Infectious Diseases. 2003; 22: p. 749-752.

48. Vaillant, V., H. De Valk, E. Baron, T. Ancelle, P. Colin, M.-C. Delmas, B. Dufour, R. Pouillot, Y. Le Strat, P. Weinbreck, E. Jougla, and J.C. Desenclos. Foodborne infections in France. Foodborne Pathogens and Disease. 2005; 2: p. 221-232.

49. Therre, H. Botulism in the European Union. Eurosurveillance. 1999; 4: p.

50. Sobel, J., N. Tucker, A. Sulka, J. McLaughlin, and S. Maslanka. Foodborne botulism in the United States, 1990-2000. Emerging Infectious Diseases. 2004; 10: p. 1606-1611.

51. Mann, J.M., S. Martin, R. Hoffman, and S. Marrazzo. Patient recovery from type A botulism: morbidity assessment following a large outbreak. Am J Public Health. 1981; 71: p. 266-269.

52. Aureli, P., M. Di Cunto, A. Maffei, G. De Chiara, G. Franciosa, L. Accorinti, A.M. Gambardella, and D. Greco. An outbreak in Italy of botulism associated with a dessert made with mascarpone cream cheese. European Journal of Epidemiology. 2000; 16: p. 913-918.

53. Kongsaengdao, S. An outbreak of botulism in Thailand: clinical manifestations and management of severe respiratory failure. Clinical infectious diseases. 2006; 43: p. 1247-1256.

54. World Health Organization. (2008). Foodborne disease outbreaks: Guidelines for investigation and control. World Health Organization: Geneva. Available from: https://apps.who.int/iris/bitstream/handle/10665/43771 $\angle 9789241547222$ eng.pdf;jsessionid $=43038$ F7861362D3E79DD6EC22C002 6 A6? sequence $=1$

55. Andriopoulos, P., M. Tsironi, S. Deftereos, A. Aessopos, and G. Assimakopoulos. Acute brucellosis: presentation, diagnosis and treatment of 144 cases. International Journal of Infectious Diseases. 2007; 11: p. 52-57. 
56. Bikas, C., Jelastopulu, M. Leotsinidis, and X. Kondakis. Epidemiology of human brucellosis in a rural area of north-western Peloponnese in Greece. European Journal of Epidemiology. 2003; 18: p. 267-274.

57. Andreoletti, O., H. Budka, S. Buncic, J.D. Collins, J. Griffin, T. Hald, A.H. Havelaar, J. Hope, G. Klein, J. McLauchlin, W. Messens, C. Muller-Graf, C. Nguyen-The, B. Noerrung, L. Peixe, M.P. Maradona, A. Ricci, J. Sofos, J. Threlfall, I. Vagsholm, and E. Vanopdenbosch. (2010). EFSA Panel on Biological Hazards (BIOHAZ); Scientific opinion on quantification of the risk posed by broiler meat to human campylobacteriosis in the EU. EFSA Journal, 8: 1437

58. Haagsma, J.A., P.D. Siersema, N.J. de Wit, and A.H. Havelaar. Disease burden of post-infectious irritable bowel syndrome in the Netherlands. Epidemiology and Infection. 2010; 138: p. 1650-1656.

59. Havelaar, A.H., M.A.S. de Wit, R. van Koningsveld, and E. van Kempen. Health burden in the Netherlands due to infection with thermophilic Campylobacter spp. Epidemiology and infection. 2000; 125: p. 505-522.

60. Wheeler, G.J., D. Sethi, M.J. Cowden, G.P. Wall, C.L. Rodrigues, S.D. Tompkins, J.M. Hudson, and J.P. Roderick. Study of infectious intestinal disease in England: rates in the community, presenting to general practice, and reported to national surveillance. BMJ. 1999; 318: p. 1046-1050.

61. Ammon, A. Surveillance of enterohaemorrhagic E. coli (EHEC) infections and Haemolytic Uraemic Syndrome (HUS) in Europe. Eurosurveillance. 1997; 2: p. 91-96.

62. Rangel, M.J., H.P. Sparling, C. Crowe, M.P. Griffin, and L.D. Swerdlow. Epidemiology of Escherichia coli O157-H7 outbreaks, United States, 19822002. Emerging Infectious Diseases. 2005; 11: p. 603-609.

63. Haque, R., C.D. Huston, M. Hughes, E. Houpt, and W.A. Petri. Amebiasis. The New England Journal of Medicine. 2003; 348: p. 1565-1573.

64. International Commisssion on Microbiological Specifications for Foods. Microorganisms in Foods 5. Characteristics of microbial pathogens (1st edition). 1996. T.A. Roberts, A.C. Baird-Parker, and R.B. Tompkin (eds). Blackie Academic and Professional: London

65. Levett, P.N. Leptospirosis. Clinical Microbiology Reviews. 2001; 14: p. 296326.

66. Unz, R.F. (2009). Disease transmission by contaminated water, in "Environmental engineering: volume 2. Prevention and response to water-, food-, soil-, and air-borne disease and illness". Wiley: New York 
67. Czachor, S.J. A brief overview of food-borne illness. Antimicrobials and Infectious Diseases Newsletter. 1998; 17: p. 73-75.

68. Theocharidou, D., K. Loga, and A. Papa-Konidari. Pulmonary involvement in leptospirosis, Northern Greece, in 18th European Congress of Clinical Microbiology and Infectious Diseases, Barcelona, Spain 19-22 April 2008

69. Jansen, A., I. Schoneberg, C. Frank, K. Alpers, T. Schneider, and K. Stark. Leptospirosis in Germany, 1962-2003. Emerging Infectious Diseases. 2005; 11: p. 1048-1054.

70. Binder, W.D. and L.A. Mermel. Leptospirosis in an urban setting: case report and review of an emerging infectious disease. Journal of Emergency Medicine. 1998; 16: p. 851-856.

71. World Health Organization Regional Office for Europe. European Hospital Morbidity Database (EHMD): Geneva.

72. Schlech III, W.F. Foodborne listeriosis. Clinical Infectious Diseases. 2000; 31: p. 770-775.

73. Bhan, M.K., R. Bahl, and S. Bhatnagar. Typhoid and paratyphoid fever. Lancet. 2005; 336: p. 749-762.

74. Kadhiravan, T., N. Wig, A. Kapil, S.K. Kabra, K. Renuka, and A. Misra. Clinical outcomes in typhoid fever: adverse impact of infection with nalidixic acid-resistant Salmonella typhi. BMC Infectious Diseases. 2005; 5

75. World Health Organization. (1980). Manual of the international statistical classification of diseases, injuries and causes of death [in Greek]. National Statistical Service of Greece: Athens. Available from: http://dlib.statistics.gr BBook/GRESYE $02 \quad 2006$ 00001.pdf

76. Davies, A.R., C. Capell, D. Jehanno, G.J.E. Nychas, and R.M. Kirby. Incidence of foodborne pathogens on European fish. Food Control. 2001; 12: p. 67-71.

77. Johnson, D. Food-borne poisoning. Australian Emergency Nursing Journal. 1999; 2: p. 19-20.

78. Le Loir, Y., F. Baron, and M. Gautier. Staphylococcus aureus and food poisoning. Genetics and Molecular Research. 2003; 2: p. 63-76.

79. Granum, P.E. and T. Lund. Bacillus cereus and its food poisoning toxins. FEMS Microbiology Letters. 2006; 157: p. 223-228.

80. Shandera, W.X., O.C. Tacket, and P.A. Blake. Food poisoning due to Clostridium perfringens in the United States The Journal of Infectious Diseases 1983; 147: p. 167-170.

81. de Jong, A.E.I. (2003). Clostridium perfringens: spores \& cells, media \& modelling. PhD thesis. Wageningen University 
82. Haagsma, J.A., B.P. van der Zanden, L. Tariq, W. Van Pelt, Y.T.P.H. Van Duynhoven, and A.H. Havelaar. (2009). Disease burden and costs of selected foodborne pathogens in the Netherlands, 2006. National Institute for Public Health and the Environment: Bilthoven. Available from: http://www.rivm.nl/bibliotheek/rapporten/330331001.pdf

83. Adams, M.R. and M.O. Moss. Food Microbiology (2nd edition). 2006. The Royal Society of Chemistry: Cambridge

84. Pinto, B., E. Chenoll, and R. Aznar. Identification and typing of food-borne Staphylococcus aureus by PCR-based techniques. Systematic and Applied Microbiology. 2005; 28: p. 340-352.

85. Orlandi, A.P., T.D.M. Chu, W.J. Bier, and J.G. Jackson. Parasites and the food supply. Scientific Status Summary. IFT. Food Technology. 2002; 56: p. 72-81.

86. Marshall, M.M., D. Naumovitz, Y. Ortega, and C.R. Sterling. Waterborne protozoan pathogens. Clin. Microbiol. Rev. 1997; 10: p. 67-85.

87. Fodor, T. Unanswered questions about the transmission of amebiasis. Bulletin of the New York Academy of Medicine. 1981; 57: p. 224-226.

88. Hurwitz, L.A. and L.R. Owen. Venereal transmission of intestinal parasites. Medical Information. 1978; 128: p. 89-91.

89. Antwerp Institute of Tropical Medicine. Illustrated lecture notes on Tropical Medicine: Antwerp.

90. Porter, D.J., P.H. Ragazzoni, D.J. Buchanon, A.H. Waskin, D.D. Juranek, and E.W. Parkin. Giardia transmission in a swimming pool. American Journal of Public Health. 1988; 78: p. 659-662.

91. Casemore, D.P. Foodborne protozoal infection. The Lancet 1990; 336: p. 1427-1432.

92. Evangelopoulos, A., N. Legakis, and N. Vakalis. Microscopy, PCR and ELISA applied to the epidemiology of amoebiasis in Greece. Parasitology International. 2001; 50: p. 185-189.

93. Carabin, H., M.C. Budke, D.L. Cowan, L.A. Willingham III, and R.P. Torgeson. Methods for asessing the burden of parasitic zoonoses: echinococcosis and cysticercosis. Trends in Parasitology. 2005; 21: p. 327333.

94. Sreter, T., Z. Szell, Z. Egyed, and I. Varga. Echinococcus multilocularis: An emerging pathogen in Hungary and Central Eastern Europe? Emerging Infectious Diseases. 2003; 9: p. 384-386.

95. Kern, P., K. Bardonnet, E. Renner, H. Auer, Z. Pawloski, W.R. Ammann, D.A. Vuitton, and P. Kern. European echinococcosis registry: human alveolar 
echinococcosis, Europe, 1982-2000. Emerging Infectious Diseases. 2003; 9: p. 343-349.

96. Koulas, S.G., A. Sakellariou, J. Betzios, K. Nikas, N. Zikos, G. PappasGogos, and E.C. Tsimoyiannis. A 15-year experience (1988-2003) in the management of liver hydatidosis in Northwestern Greece. International Surgery. 2006; 91: p. 112-116.

97. Avgerinos, E.D., E. Pavlakis, A. Stathoulopoulos, E. Manoukas, G. Skarpas, and P. Tsatsoulis. Clinical presentations and surgical management of liver hydatidosis: our 20 year experience. HPB (Oxford). 2006; 8: p. 189-193.

98. Antsaklis, A., G. Daskalakis, N. Papantoniou, A. Mentis, and S. Michalas. Prenatal diagnosis of congenital toxoplasmosis. Prenatal Diagnosis. 2002; 22: p. 1107-1111.

99. Galanakis, E., A. Manoura, M. Antoniou, S. Sifakis, E. Korakaki, E. Hatzidaki, D. Lambraki, Y. Tselentis, and C. Giannakopoulou. Outcome of toxoplasmosis acquired during pregnancy following treatment in both pregnancy and early infancy. Fetal Diagnosis and Therapy. 2007; 22: p. 444-448.

100. Pappas, G., N. Roussos, and M.E. Falagas. Toxoplasmosis snapshots: Global status of Toxoplasma gondii seroprevalence and implications for pregnancy and congenital toxoplasmosis. International Journal for Parasitology. 2009; 39: p. 1385-1394.

101. Cook, A.J.C., R.E. Gilbert, W. Buffolano, J. Zufferey, E. Petersen, P.A. Jenum, W. Foulon, A.E. Semprini, and D.T. Dunn. Sources of toxoplasma infection in pregnant women: European multicentre case-control study. BMJ. 2000; 321: p. 142-147.

102. Gibbs, R.S. The origins of stillbirth: infectious diseases. Seminars in Perinatology. 2002; 26: p. 75-78.

103. Antoniou, M., H. Tzouvali, S. Sifakis, E. Galanakis, E. Georgopoulou, V. Liakou, C. Giannakopoulou, E. Koumantakis, and Y. Tselentis. Incidence of toxoplasmosis in 5532 pregnant women in Crete, Greece: management of 185 cases at risk. European Journal of Obstetrics \& Gynecology and Reproductive Biology. 2004; 117: p. 138-143.

104. Cho, S.Y., J. Bae, B.S. Seo, and S.H. Lee. Some aspects of human sparganosis in Korea. The Korean Journal of Parasitology. 1975; 13: p. 6077.

105. Fried, B., K.T. Graczyk, and L. Tamang. Food-borne intestinal trematodiases in humans. Parasitology research. 2004; 93: p. 159-170. 
106. Hemsrichart, V. Ternidens deminitus infection: first pathological report of a human case in Asia. Journal of the Medical Association of Thailand. 2005; 88: p. $1140-1143$.

107. Pelloux, H. and O. Faure. Toxocarose de l'adulte. La Revue de Médecine Interne. 2004; 25: p. 201-206.

108. Rusnak, M.J. and R.D. Lucey. Clinical gnathostomiasis: Case report and review of the english language literature. Clinical Infectious Diseases. 1993; 16: p. 33-50.

109. Smith, H.V. Detection of parasites in the environment. Parasitology 1998; 117: p. S113-S141.

110. Schad, G.A. and L.E. Rozeboom. Integrated control of helminths in human populations. Annual Review of Ecology and Systematics. 1976; 7: p. 393420.

111. Totkova, A., M. Klobusicky, M. Valent, and E. Tirjakova. [Helminth and protozoan findings in the water of school swimming pools]. Epidemiologie, mikrobiologie, imunologie 1994; 43: p. 130-136.

112. Phillips, S.C., D. Mildvan, and D.C. William. Sexual transmission of enteric protozoa and helminths in a venereal-disease-clinic population. New England Journal of Medicine. 1981; 305: p. 603-606.

113. Tzanetou, K. Diagnostic approach of helminthic parasitic infections with interest for clinical microbiologist. Acta Microbiologica Hellenica. 2008; 53: p. 16-31.

114. Bethony, J., S. Brooker, M. Albonico, S. Geiger, .M., A. Loukas, D. Diemert, and P.J. Hotez. Soil-transmitted helminth infections: ascariasis, trichuriasis and hookworm. The Lancet. 2006; 367: p. 1521-1532.

115. Song, E.K., I.H. Kim, and S.O. Lee. Unusual manifestations of Taenia solium infestation. Journal of Gastroenterology. 2004; 39: p. 288-291.

116. Ok, K.S., Y.S. Kim, J.H. Song, J.H. Lee, S.H. Ryu, J.H. Lee, J.S. Moon, D.H. Whang, and H.K. Lee. Trichuris trichiura infection diagnosed by colonoscopy: case reports and review of literature. Korean Journal of Parasitology. 2009; 47: p. 275-280.

117. Jardine, M., G. Kokai, and A.M. Dalzell. Enterobius vermicularis and colitis in children. Journal of Paediatric Gastroenterology and Nutrition. 2006; 43: p. 610-612.

118. Praet, N., N. Speybroeck, R. Manzanedo, D. Berkvens, D.N. Nforninwe, A. Zoli, F. Quet, P.M. Preux, H. Carabin, and S. Geerts. The disease burden of Taenia solium cysticercosis in Cameroon. PLoS Neglected Tropical Diseases. 2009; 3: p. e406. 
119. Lopez, D.A., D.C. Mathers, M. Ezzati, T.D. Jamison, and C.J.L. Murray. Global burden of disease and risk factors, 2006, Oxford University Press and The World Bank: New York.

120. de Wit, A.S.M., P.G.M. Koopmans, M.L. Kortbeek, N.J. van Leeuwen, A.I.M. Bartelds, and T.H.P.Y. van Duynhoven. Gastroenteritis in sentinel general practices, the Netherlands. Emerging Infectious Diseases. 2001; 7: p. 8291.

121. Shuval, H. Estimating the global burden of thalassogenic diseases: human infectious diseases caused by wastewater pollution of the marine environment. Journal of Water and Health. 2003; 1: p. 53-64.

122. Mathers, D.C., D. Ma Fat, M. Inoue, C. Rao, and D.L. Lopez. Counting the dead and what they died from: an assessment of the global status of cause of death data. Bulletin of the World Health Organization. 2005; 83: p. 171177.

123. World Health Organization Regional Office for Europe. European Health for All Database (HFA-DB) [cited 2009 June 30]. Available from: http://www.euro.who.int/hfadb 
Chapter 2 


\section{Chapter 3}

The Application of the Appropriate Level of Protection (ALOP) and Food Safety Objective (FSO) concepts in food safety management, using Listeria monocytogenes in deli meats as a case study

Elissavet Gkogka, Martine W. Reij, Leon G.M. Gorris, Marcel H.

Zwietering

Published in Food Control, 2013, 29(2):382-393 


\section{Abstract}

To establish a link between governmental food safety control and operational food safety management, the concepts of the Appropriate Level of Protection (ALOP) and the Food Safety Objective (FSO) have been suggested by international governmental bodies as a means for competent authorities to make food safety control transparent and quantifiable. The purpose of this study was to investigate how the concepts of ALOP and FSO could be practically linked using currently available data. As a case study, the risk of severe listeriosis due to consumption of deli meat products in the Netherlands was taken. The link between the concepts was explored following a "top-down" approach, using epidemiological country data as the starting point, and following a "bottom-up" approach, using data on the prevalence and concentration of the pathogen at retail as the starting point. For the top-down approach, the mean estimated value derived for ALOP was 3.2 cases per million inhabitants per year due to deli meats (95\% CrI: 1.1-6.6). For the bottom-up approach, mean ALOP values ranged considerably, 12-44 cases per million inhabitants per year due to deli meats (with $95 \%$ CrI ranging from 5.2 to 122), depending on the combination of input parameters used in the risk assessment model. The level of detail considered in the stochastic models applied considerably influenced the ALOP and FSO estimates. Models based on both approaches however were able to describe the link between ALOP and FSO and our results showed that meaningful estimations are feasible, although interpretations need to be made with care. 


\section{Introduction}

Foodborne diseases are recognized as a cause of morbidity and mortality worldwide. For developed countries it has been stated that up to one fourth $[1,2]$ or even one third [3] of the population is affected by foodborne illness each year. Thus managing food safety is an issue of fundamental public health concern. The globalization of the food market has made this problem even more intricate and achieving a safe food supply poses major challenges for national food safety authorities [4] whose key responsibility is to articulate the level of control that they expect the food industry to achieve. To this end, competent authorities commonly use food safety metrics in the form of limits or criteria for microbiological contaminations in food [5]. Until recently, these metrics have often been based on experience of food production and processing, research and expert opinions of what was considered achievable in relation to the systems/practices operationally available to ensure food safety (GHP, GMP, HACCP) [6]. However, such metrics based on the capabilities of the food production system have been very difficult to directly link to the level of public health protection achieved by their implementation [7]. In the past two decades the risk analysis framework as laid down by the Codex Alimentarius [8] and recent advances in this area have made this link increasingly possible [5] and legally required [9]. While a clear connection between government policy and a reduction in foodborne illness would be required [10], to date this still is difficult to achieve in practice.

To establish a link between public health outcomes and metrics in the food chain, the concepts of the Appropriate Level of Protection (ALOP) and the Food Safety Objective (FSO) have been proposed [11, 12]. The ALOP, introduced in the Agreement on Sanitary and Phytosanitary Measures (SPS Agreement) of the World Trade Organization (WTO), represents a country's currently achieved public health status in relation to food safety [6] and is defined as: "the level of protection deemed appropriate by the Member establishing a sanitary or phytosanitary measure to protect human, animal and plant life or health within its territory" [13]. The FSO, introduced at a later stage [12] to translate the ALOP into a benchmark in the food chain that could be communicated and managed by the food industry, is currently defined as: "the maximum frequency and/or concentration of a hazard in food at the time of consumption that provides or contributes to the appropriate level of protection $(A L O P)^{\prime \prime}[6,14,15]$. Given the fact that the FSO is not always verifiable as a regulatory standard, as it applies at the moment of consumption, the concepts of the Performance Objective (PO) and Performance criterion (PC) were created to complement the ALOP and FSO, providing targets for operational food safety management earlier in the food chain [16]. By their very definition all these concepts provide a linkage between government policy and benchmarks in the food chain and thus are very much desirable for making food safety management transparent and quantifiable [17]. The establishment 
of both ALOP and FSO values is a societal decision and the prerogative of competent authorities. Yet, to date, there is no country that deploys ALOPs and FSOs to inform operational food safety management. An important reason for this may be the difficulty for governments to set clear public health targets in the form of ALOPs and link them to FSOs. It seems that, despite their many strengths, there is still no uniform agreement with regards to their implementation [18].

From a legal point of view, a consistent approach should be in place for setting these kinds of metrics [19]. While such an approach is not yet available, a few documents have been developed for this purpose through a joint expert consultation of the World Health Organization (WHO) and the Food and Agricultural Organization (FAO) [20-23]. Several case-studies already exist in literature considering different aspects of working with ALOP and FSO [7, 24-28]. However, the practical interpretation of the definitions of the concepts and the selection of units to express them are issues that are not always clear [17]. Clearly, practical examples of real case-studies are needed in these areas to facilitate the use of the concepts.

The purpose of this study was to investigate how the utilization of the ALOP/FSO concepts could be approached by competent authorities and to develop a practical example for this, i.e. the risk of severe listeriosis due to the consumption of deli meat products (cooked ready to eat meat products) in the Netherlands. In this example, presented for the first time in the $7^{\text {th }}$ International Conference on Predictive Modeling in Foods [29] the two main approaches suggested for establishing this link between the concepts have been followed [5]. One approach was based on analysis of public health data and epidemiological surveys (from now on referred to as the top-down approach). The second approach was based on data related to the level and/or frequency of Listeria monocytogenes in deli meat which through a dose-response model are turned into disease incidence estimates (from now on referred to as the bottom-up approach). Our aims in this practical case study were 1) to test the feasibility of both approaches when using currently available and well documented work on this topic, 2) to compare their outcomes, 3) to discuss the advantages and disadvantages of each approach and 4) to pinpoint gaps in existing data that are needed to provide these estimates for deli meat products in the international food chain. Considering that the setting of the ALOP/FSO concepts is the responsibility of governments [12], we would like to emphasize that this is an exploratory study on the operationalization of the concepts from a risk assessor's/ risk manager's perspective, specific to the Dutch situation and that the final interpretation and setting of the benchmarks would still fall upon the shoulders of national policy makers. 


\section{Materials and methods}

\subsection{Top-down approach}

\subsubsection{Model description}

The status quo of public health protection in relation to severe listeriosis in the Netherlands was the starting point of this approach as the ALOP has been suggested to be representative of "the current public health status in relation to food safety" [6]. A stochastic model was built to convert epidemiological data into an ALOP, from which the FSO was derived through a series of estimation steps depicted in Figure 1. Given that dose-response models available for Listeria are based on a separate estimation of cases for the healthy and the susceptible population or YOPI (Young, Old, Pregnant, Immunocompromised), it was necessary to introduce two intermediate steps in the estimation of the link: the Level of Protection or $L O P_{1}$, that is the number of cases of listeriosis occurring in each risk group and Safety Objective or $\mathrm{SO}_{\mathrm{i}}$, that is the concentration of microorganisms responsible for the cases within each risk group. A detailed account of the parameters of the model is provided in Table 1 and a description of each estimation step is given below.

Step 1 - Reported cases. Annually reported cases of severe listeriosis (hospitalizations) in the Netherlands were collected from the national statistical service (Centraal Bureau voor de Statistiek, CBS) for the period 1998-2006 [30] and from Prismant for the period 20072009 [31]. The reported cases were expressed per million inhabitants based on population statistics for the Netherlands [30]. The mean and standard deviation of these data were 1.59 and 0.40 reported cases per million inhabitants per year, respectively, and these were used to construct a normal distribution that was considered representative of the variability associated with the annual reported incidence of the disease [32].

Step 2 - Total cases per million inhabitants (ALOP). The total number of cases in the population was derived from the reported number of cases after correcting for undernotification, under-reporting and misdiagnosis. Comparison of the data from CBS (2009) and Prismant (2009) with data on active surveillance of infections due to Listeria monocytogenes obtained from the National Institute for Public Health and the Environment (Rijksinstituut voor Volksgezondheid en Milieu, RIVM) [33] provided a range of undernotification factors for the period 2005-2009. The mean (2.5) and standard deviation (0.63) of these factors were used to build a normal distribution to cover for undernotification [32]. Uncertainty due to under-reporting of the illness was assumed to be represented by a beta Pert distribution with minimum and maximum values being based on literature $[2,34]$. 


\section{Step 1}

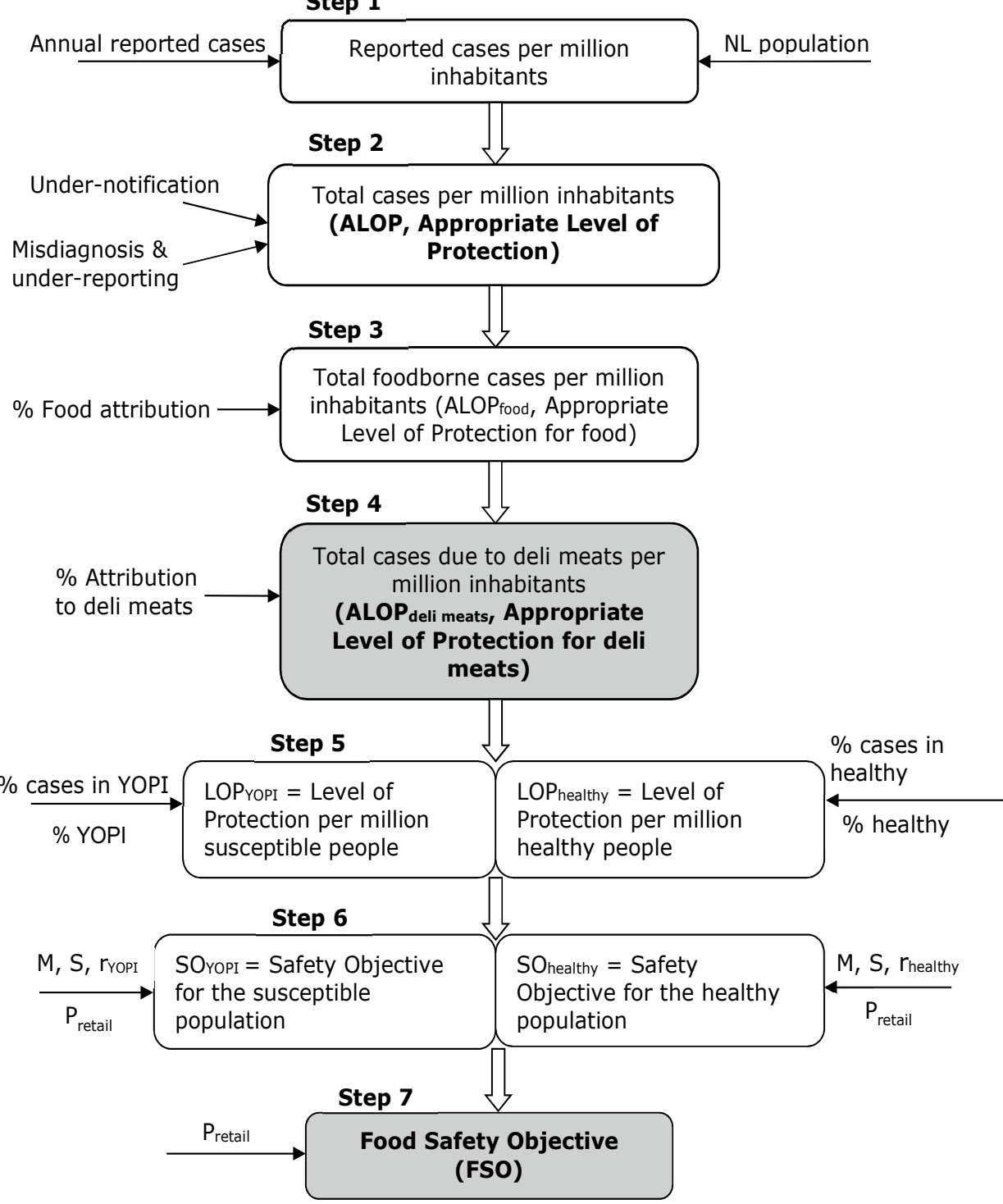

Figure 1. Outline of the estimation steps in the top - down approach model. Epidemiological data in the form of reported cases of severe listeriosis are the starting point for the estimation of the ALOP and the FSO. 


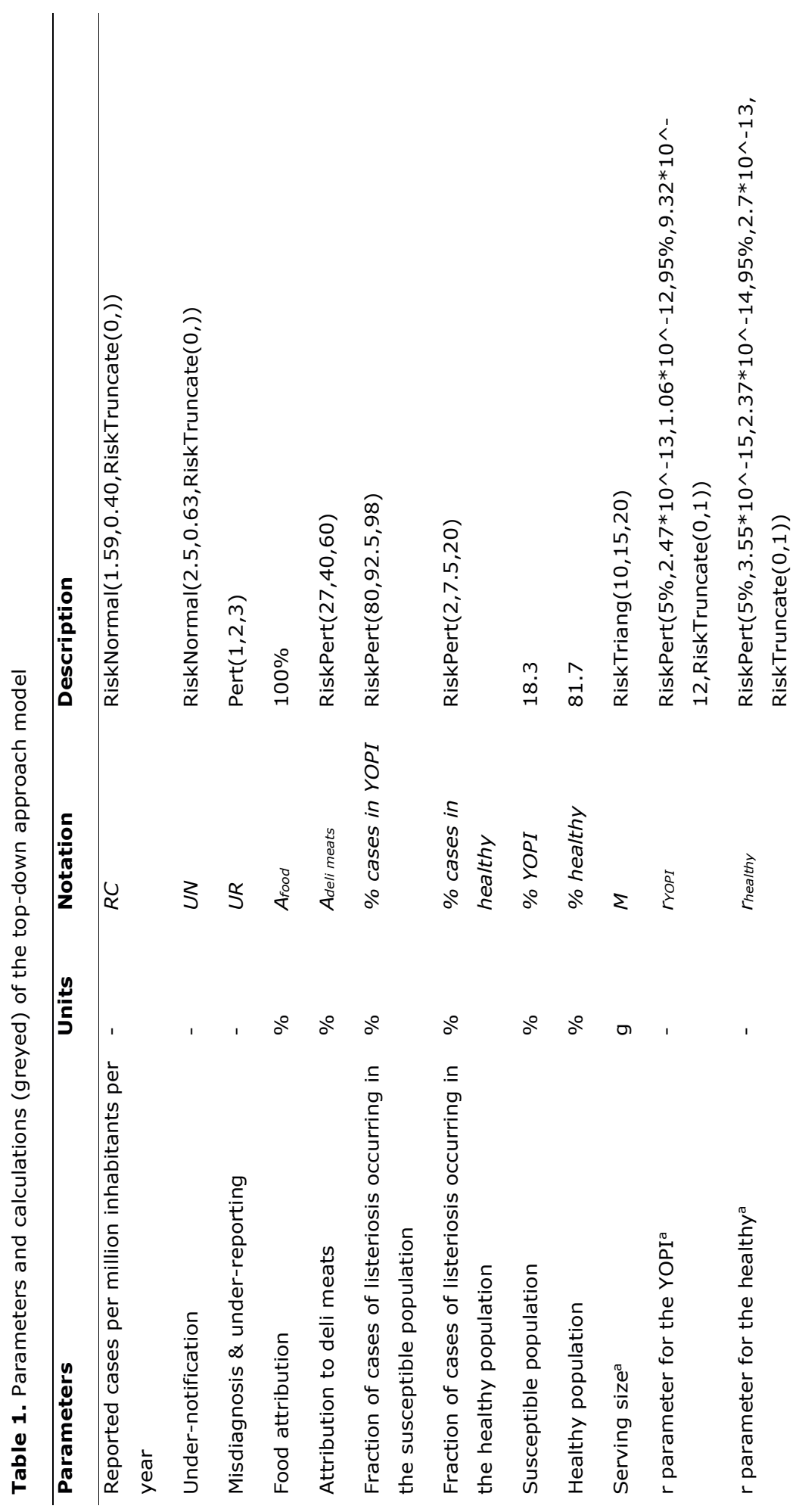




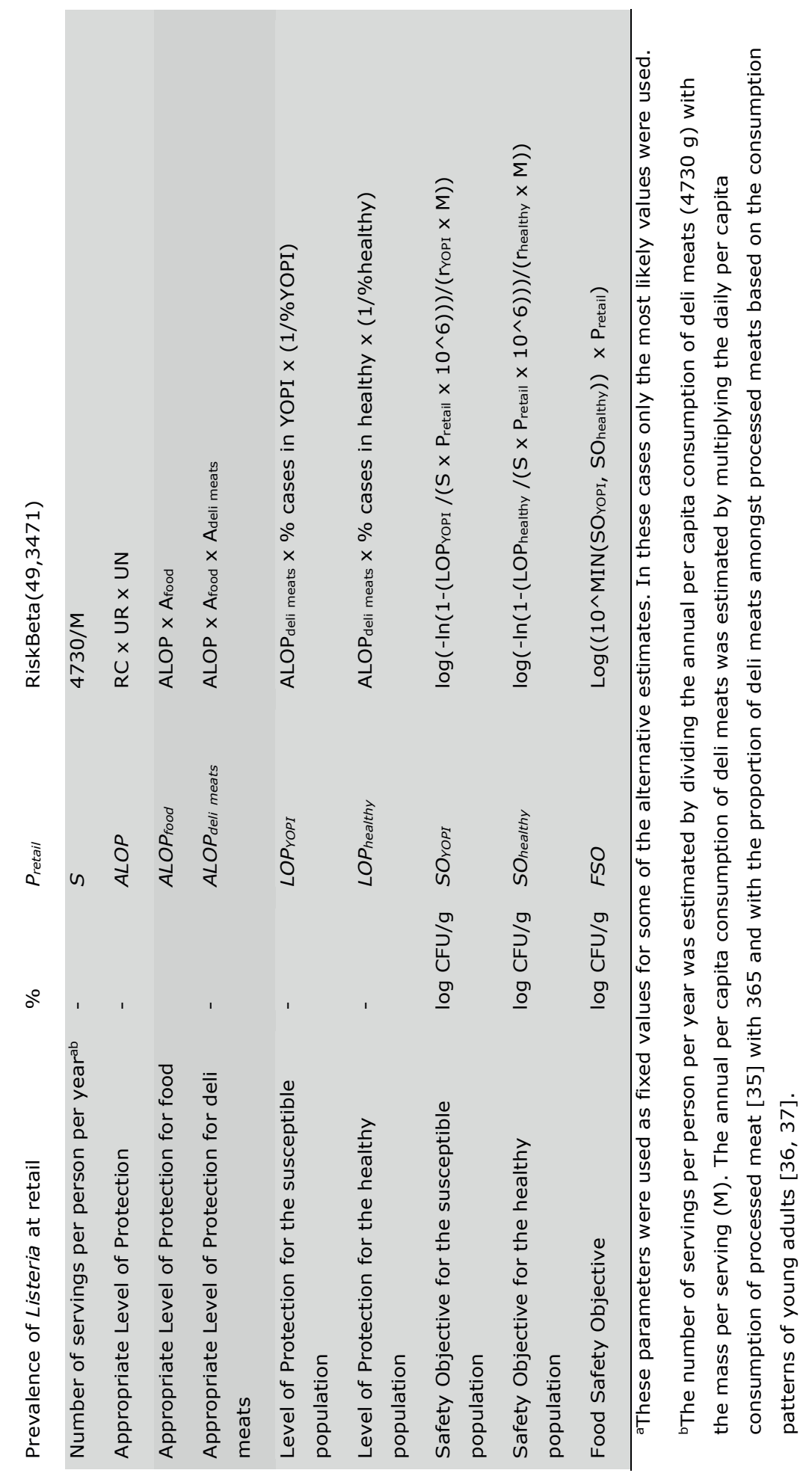


Step 3 - Total foodborne cases per million inhabitants (ALOPfood). The ALOP estimated through the previous step was then attributed to food [17]. All of the cases were considered to be due to food since in a recent Dutch nationwide study, listeriosis was presented as an exclusively foodborne disease [38].

Step 4 - Total cases due to deli meats per million inhabitants (ALOPdeli meats). Only a part of the total number of foodborne cases of listeriosis is due to the consumption of deli meats. To estimate the size of the relevant part, a food attribution fraction for this particular product group needs to be established, which is subsequently multiplied with the ALOPfood [17]. For the purpose of our estimates we considered that the fraction of foodborne cases of listeriosis due to the consumption of deli meats can be described by a Pert distribution with a most likely value of 0.40 [39]. The minimum $(0.27)$ and maximum $(0.60)$ values of the Pert distribution were based on lowest and highest possible estimates for this factor based on several food product attribution studies [39-42].

Step 5 - Level of Protection for the susceptible and healthy group. The estimated $A L O P_{\text {deli }}$ meats was subsequently allocated over the susceptible and healthy population to estimate a so-called Level of Protection ( $L O P$ ) for the healthy population (LOPhealthy) and for the susceptible population ( $L O P_{Y O P I}$ ). The $L O P$ signifies the number of cases per million people belonging to each specific risk group. To describe the uncertainty of the cases occurring in the each group, Pert distributions were used as multipliers (\% cases in YOPI, \% cases in healthy). The minimum and maximum values of these distributions were based on the FAO/WHO risk assessment of Listeria monocytogenes [43] which considers that only 2$20 \%$ of the cases occurs in the healthy population and $80-98 \%$ of the cases affects the susceptible population. Based on the observations of Doorduyn et al. that only $5-10 \%$ of the total cases of listeriosis in the Netherlands occur in individuals healthy prior to infection [44], 7.5\% was selected as the most likely value for the size of this fraction for the healthy group and $92.5 \%$ for the susceptible group. The proportion of people in the Dutch population belonging in the susceptible group or the so called "YOPI" group was considered to be the average of CBS data for the period 1998-2007 regarding the number of pregnancies, people older than 65 years of age and immunocompromised younger than 65 years in the Netherlands [30]. The number of immunocompromised people has been calculated based on CBS hospitalization data due to conditions that have been reported to predispose to listeriosis $[39,45]$. This is expected to be a rather conservative estimate of the proportion of YOPI in the Dutch population, since among patients of listeriosis more than one predisposing condition is possible [45]. 
Step 6 - Safety Objectives for the susceptible and the healthy group. The LOPs for the healthy and the susceptible population were used to estimate a so-called Safety Objective (SO) for each risk group. An SO was defined here as the concentration of microorganisms at the time of consumption that provides for or contributes to the $L O P$ for a particular population group. To estimate $S O$ values, the exponential dose - response model of FAO/WHO risk assessment was used [43] taking into account the number of contaminated servings consumed as follows:

$L O P_{i}=S \cdot 10^{6} \cdot P_{\text {retail }} \cdot\left(1-\exp \left(-r_{i} \cdot D\right)\right)$

where:

$L O P_{i}=$ the number of cases of severe listeriosis per million people in each risk group $\mathrm{i}$

$i=$ the risk group, i.e. the healthy or the susceptible part of the total population

$S=$ the number of servings per person per year

$P_{\text {retail }}=$ the prevalence of Listeria in deli meats at the point of retail

$r_{i}=$ the probability of a single microorganism causing listeriosis for each risk group i

$D=$ the dose consumed (number of cells per serving)

Given that $D=M \cdot 10^{S O_{i}}$, where $M$ is the mass per serving and $\mathrm{SO}_{i}$ is the logarithmic concentration of microorganisms at consumption, Eq. 1 becomes:

$$
L O P_{i}=S \cdot 10^{6} \cdot P_{\text {retail }} \cdot\left(1-\exp \left(-r_{i} \cdot M \cdot 10^{S O_{i}}\right)\right)
$$

Step 7 - Food Safety Objective. As defined by Codex Alimentarius, the FSO may express a concentration, a prevalence, or a combination of both (Codex, 2007). The FSO was estimated here by selecting the strictest of the two $S O$ values derived from the estimations of step 6 for the healthy and the susceptible population group and multiplying it with the prevalence at retail. The decision to estimate the FSO as a product of the prevalence and the concentration at consumption concurs with a previous study where this approach was suggested for pathogens with a prevalence lower than $100 \%$ [17] and recommendations of other authors to explicitly include prevalence when expressing an FSO $[25,46]$. 


\subsection{Bottom-up approach}

\subsubsection{Model description}

The bottom-up approach started with the occurrence of Listeria monocytogenes in the food chain prior to consumption to derive the population-level impact on public health. A stochastic risk assessment model was built to convert the available data on prevalence and concentration of the pathogen in deli meats at retail into an ALOP value through a series of estimation steps that are depicted in Figure 2. A detailed account of the parameters of the model is provided in Table 2. A description of each estimation step is given below.

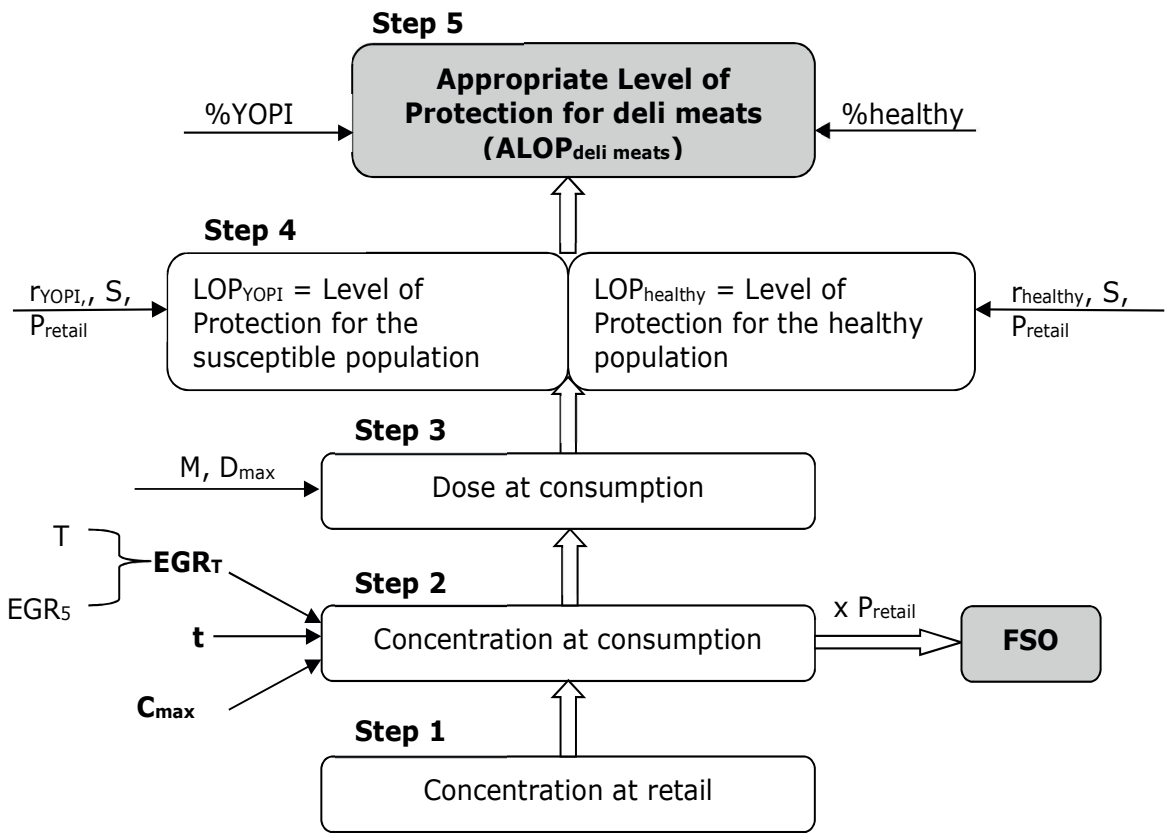

Figure 2. Outline of the estimation steps in the bottom-up approach model. The concentration of Listeria at the retail level is the starting point for the estimation of the FSO and the ALOP.

Step 1 - Prevalence and concentration at retail. Data on the prevalence of Listeria monocytogenes in cooked ready-to-eat meat products on the Dutch retail market were available for the period 2005-2009 [47-51]. These data refer to 3520 cooked ready-to-eat meat products (deli meat) which were tested for the presence/absence of the pathogen in samples of $25 \mathrm{~g}$ each. Out of this total number of products, 49 were found positive for the pathogen and samples were enumerated to assess whether the concentration exceeded the prevailing legal requirements of $<100 \mathrm{cfu} / \mathrm{g}$ [52]. Unfortunately, the enumeration 


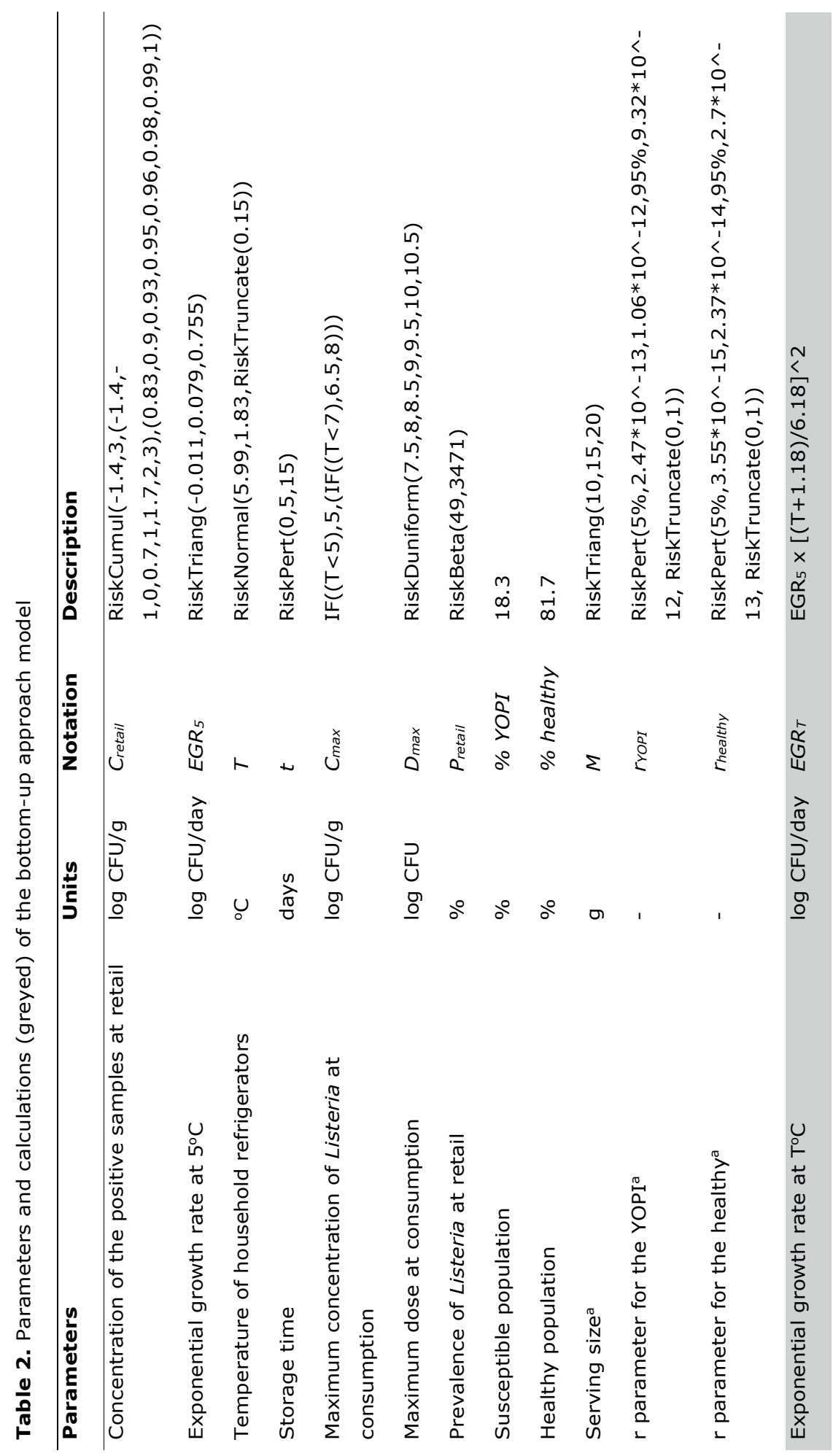




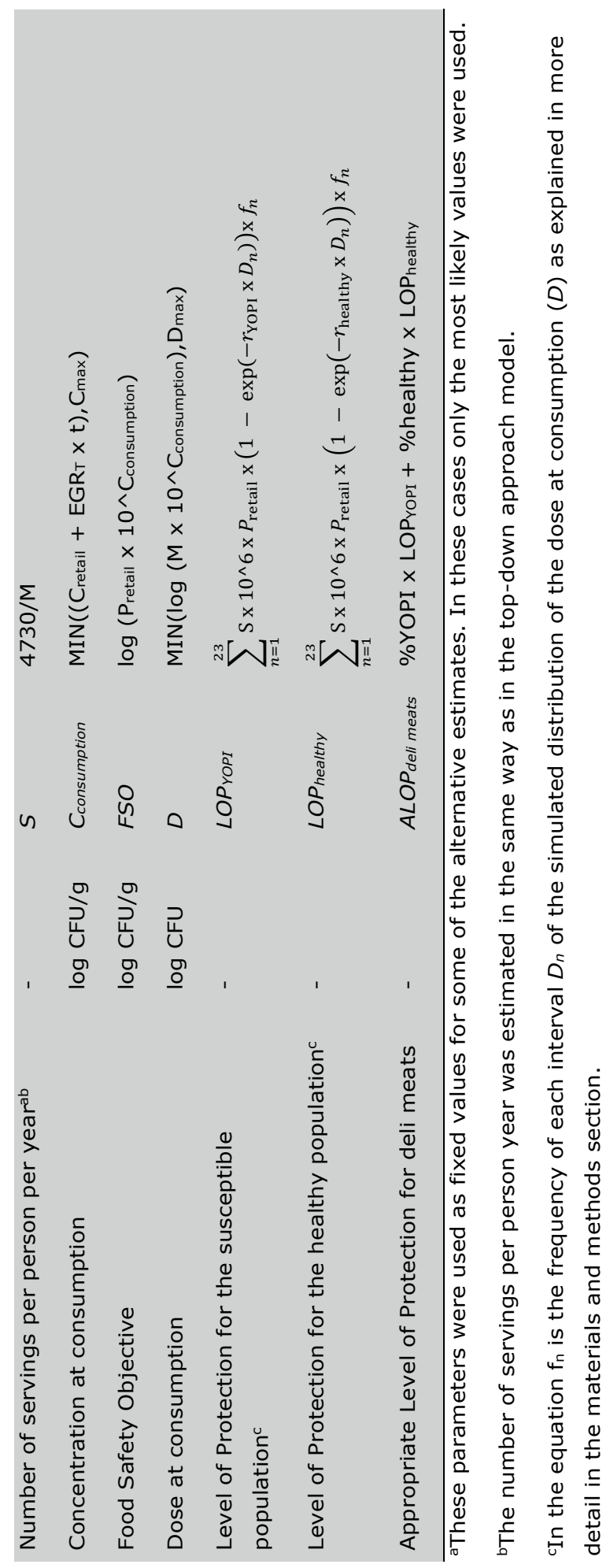


values are not available from public sources. Since the specific enumeration data for products found positive on the Dutch retail market were not available, data reported for the concentration of positive samples in the FDA/FSIS risk assessment that had been carried out at retail [53] as cited by others [54] were used.

Step 2 - Concentration at consumption. From the retail concentration data, the concentration at consumption was estimated by using the FDA/FSIS (2003) approach: the refrigeration time at the consumer household was multiplied with the exponential growth rate value to estimate growth during storage and this was added to the concentration of the positive samples at retail. Regarding the storage time of deli meats in the Netherlands, we assumed that this parameter is described by a Pert distribution with a most likely value of 5 , a minimum value of 0 and a maximum value of 15 days, as was done in a recent similar study in Australia [39]. The value for the exponential growth rate at any given temperature $\mathrm{T}\left(E G R_{T}\right)$ was estimated using a baseline EGR at $5^{\circ} \mathrm{C}\left(E G R_{5}\right)$ through the formula [53]:

$E G R_{T}=[(T+1.18) / 6.18]^{2} \cdot E G R_{5}$.

A normal distribution was used to describe the variation in refrigeration temperatures [55] which was truncated at 0 and $15^{\circ} \mathrm{C}$, to cover a wide range of temperatures that was considered plausible for household refrigerators. We also assumed that cells of the pathogen would not show any lag phase but were already adjusted to the relevant food environment given their psychrotrophic nature and the storage of deli meats before they reach retail at temperatures relevant for growth [56]. This assumption is realistic for a retail-to-table risk assessment model like ours since the incorporation of a lag phase has been shown not to have a significant effect on the risk after the retail phase [57]. To be consistent with the model of FDA/FSIS (2003), the same temperature dependant restrictions for the maximum concentration $\left(C_{\max }\right)$ of the pathogen were applied here, i.e. $10^{5}, 10^{6.5}$ and $10^{8} \mathrm{cfu} / \mathrm{g}$ for $<5,5-7$ and $>7^{\circ} \mathrm{C}$, respectively [53]. However, unlike the FDA/FSIS risk assessment we did not assume a correlation between the refrigeration time and the refrigeration temperature, because such a correlation is not well supported on the basis of a more recent study [58]. The FSO was estimated by multiplying the concentration at consumption with the prevalence at retail [17].

Step 3 - Dose at consumption. The dose at consumption was estimated by multiplying the concentration at consumption with the mass per serving. The mass per serving was considered to have a most likely value of $15 \mathrm{~g}$ based on different Dutch studies that suggested that this amount is a typical portion for processed meat [59-61]. Based on data 
regarding the variation in serving size for different ready-to-eat meat products in the Netherlands this parameter was also found to range between 10 and $20 \mathrm{~g}$ [62]. Besides the range and the most likely value no other information could be found regarding the mass per serving and thus a non-parametric distribution (triangular) was selected to describe it [63] although for the same purpose a Pert would have been an equally suitable choice. To be consistent with the FAO/WHO dose response model we assumed that the maximum dose of Listeria monocytogenes consumed ( $D_{\max }$ in log $\mathrm{cfu}$ ) is represented by a discrete uniform distribution with seven possible outcomes $(7.5 ; 8.0 ; 8.5 ; 9.0 ; 9.5 ; 10.0$; 10.5) [43] although a continuous uniform would at first glance seem a more logical choice to describe the same uncertainty range.

Step 4 - Level of Protection for the susceptible and the healthy group. To estimate the current levels of protection achieved for each population group, the simulated distribution of the dose at consumption was divided into 23 half log intervals $\left(D_{n}\right)$ ranging from -1 to $10.5 \log$ CFU, following approaches used in other risk assessments [53, 64]. Each half log interval of the dose was used to estimate 23 intervals of LOP $n$ through equation 1 . Every LOP $_{n}$ interval was then multiplied by $f_{n}$, being the frequency of each $D_{n}$ interval. These calculations result in values for the number of cases of listeriosis per half log interval of the dose. These 23 intervals were algebraically added to estimate the LOP for each risk group within the population:

$L O P_{i}=\sum_{n=1}^{23} P_{\text {retail }} \cdot S \cdot 10^{6} \cdot\left(1-\exp \left(-r_{i} \cdot D_{n}\right)\right) \cdot f_{n}$

The number of servings per person per year $(S)$ was estimated by dividing the annual per capita consumption of deli meats with the mass per serving $(M)$. In the absence of a more specific dataset, the annual per capita consumption of deli meats was estimated by multiplying the average daily per capita consumption of processed meat [35] with 365 and with the proportion of deli meats amongst processed meats based on the consumption patterns of young adults in the Netherlands $[36,37]$.

Step 5 - Appropriate Level of Protection. To estimate the ALOP from the two LOPs, the fraction of each risk group within the population (\%YOPI and \%healthy) was taken into account as follows:

$A L O P=\% Y O P I \times L O P Y O P I+\%$ healthy $\times L O P_{\text {healthy }}$

2.3 Baseline models and models with alternative combinations of input parameters

Considering that including all the different input parameters in a stochastic form would make the models complex and not necessarily more correct [65], models were built in 
their baseline version as simple as possible and alternative, more complex versions were then constructed that included the same parameters in a stochastic form (Table 3). For instance, while in the baseline versions the $r$ values used for the healthy and the susceptible group were the median values of these parameters in the FAO/WHO doseresponse model for Listeria [43], all other possibilities for these parameters ( $5^{\text {th }}$ and $95^{\text {th }}$ percentile values) were considered in the more complex models. Following the same rationale, the parameters $\mathrm{M}, \mathrm{S}$ were given fixed values in the baseline version and incorporated in a stochastic form in the alternative versions. To avoid errors in the calculations, all $r$-values were given 0 and 1 as a lower and upper truncation value, respectively. For the same reason 0 was applied as a lower truncation limit in the distributions describing the number of reported cases and the under-notification factors.

Table 3. Parameter combinations used in the top down and bottom up approach models

\begin{tabular}{|c|c|c|}
\hline $\begin{array}{l}\text { Parameter } \\
\text { combination }\end{array}$ & Description & Parameters \\
\hline Baseline & $r, M, S$ fixed & $\begin{array}{l}\text { rYOPI }=1.06 * 10^{\wedge}-12 \\
\text { rhealthy }=2.37 * 10^{\wedge}-14 \\
M=15 \mathrm{~g} \\
S=315\end{array}$ \\
\hline Alternative 1 & $\begin{array}{l}r \text { stochastic, } \\
M \& S \text { fixed }\end{array}$ & $\begin{array}{l}r_{\text {YOPI }}=\text { RiskPert }\left(5 \%, 2.47 * 10^{\wedge}-13,1.06 * 10^{\wedge}-\right. \\
\left.12,95 \%, 9.32 * 10^{\wedge}-12, \text { RiskTruncate }(0,1)\right) \\
r_{\text {healthy }}=\operatorname{RiskPert}\left(5 \%, 3.55 * 10^{\wedge}-15,2.37 * 10^{\wedge}-\right. \\
\left.14,95 \%, 2.7 * 10^{\wedge}-13, \text { RiskTruncate }(0,1)\right) \\
M=15 \mathrm{~g} \\
S=315\end{array}$ \\
\hline Alternative 2 & $\begin{array}{c}r \text { fixed, } \\
M, S \text { stochastic }\end{array}$ & $\begin{array}{l}r_{\text {YOPI }}=1.06 * 10^{\wedge}-12 \\
r_{\text {healthy }}=2.37 * 10^{\wedge}-14 \\
M=\text { RiskTriang }(10,15,20) \\
S=4730 / M\end{array}$ \\
\hline Alternative 3 & $\begin{array}{c}r, M, S \\
\text { stochastic }\end{array}$ & $\begin{array}{l}r_{\text {YOPI }}=\operatorname{RiskPert}\left(5 \%, 2.47 * 10^{\wedge}-13,1.06 * 10^{\wedge}-\right. \\
\left.12,95 \%, 9.32 * 10^{\wedge}-12, \text { RiskTruncate }(0,1)\right) \\
r_{\text {healthy }}=\operatorname{RiskPert}\left(5 \%, 3.55^{*} 10^{\wedge}-15,2.37 * 10^{\wedge}-\right. \\
\left.14,95 \%, 2.7 * 10^{\wedge}-13, \text { RiskTruncate }(0,1)\right) \\
M=\text { RiskTriang }(10,15,20) \\
S=4730 / M\end{array}$ \\
\hline
\end{tabular}




\subsection{Simulation settings}

All calculations were made in Microsoft Excel using the @RISK 5.7 software (Palisade Corporation). For every combination of input parameters one simulation of one million iterations was performed by applying the Latin Hypercube technique using a Mersenne Twister random number generator in combination with a fixed seed value of 1 to allow our results to be reproduced by others and to enable comparisons between the different stochastic outcomes. Before that, 10 simulations of 100,000 iterations each were performed using the same random number generator with different seed values, in order to assure the stability of the outcome distributions (results not shown).

\section{Results and Discussion}

\subsection{Appropriate Levels of Protection for deli meats}

The main results for the estimation of ALOPs related to deli meats by using the top-down or the bottom-up approach models and for the different combinations of input parameters considered in the two models can be seen in Figure 3. For the purpose of this study and given that the ALOP is an expression of public health related risk at population level that is to be established or communicated by governments, we have chosen to use "the number of cases per million people per year" as the unit of measure for the ALOP; this is in accord with earlier publications [64] and concurs with recommendations of ICMSF [15].

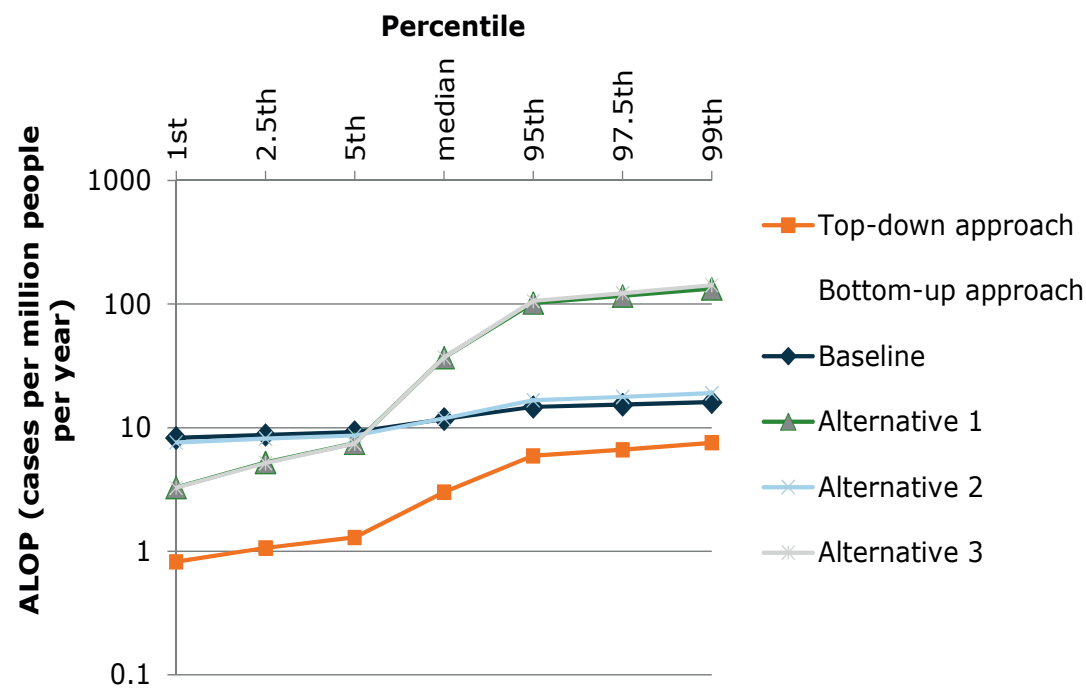

Figure 3. ALOPs derived with the top-down and the bottom-up approach. To facilitate comparisons estimates are presented on a logarithmic scale on the $y$-axis. 
Overall, mean estimates were different between the two approaches, though for some of the different input parameter combinations estimates were almost the same with the bottom-up approach. In particular, the baseline and alternative 2 yielded similar results (mean values of 11.8 and 12.2 cases per million inhabitants per year, respectively) as was the case for alternatives 1 and 3 (mean values of 43.4 and 44.2 cases per million inhabitants per year, respectively). The difference between the two sets of models related mainly to the use of the $r$ parameter. When the $r$ parameter of the exponential doseresponse model was incorporated in a stochastic form (alternatives 1 and 3), significantly higher values for ALOP were obtained but also the credibility intervals calculated were much wider. The mean estimate obtained with the top-down approach (3.2 cases per million people per year) was found to be significantly lower than all mean estimates obtained with the various input parameter combinations used in the bottom-up approach (ranging from 11.8 to 44.2 cases per million people per year). This difference, at least a factor of 4 between the estimates of the top-down and the bottom-up approach model was expected since risk estimates obtained through risk assessment are not always precisely in line with epidemiological estimates. For instance in a recently published risk assessment of Listeria in cold-smoked salmon in France the annual number of cases due to this food item was found to be 307 (95\% CrI: 10-12,453) [66] while the total annual number of cases of foodborne listeriosis in the country in another study based on epidemiological data was estimated to be 304 [67]. For Australia or the US though such risk assessment-based estimates for Listeria in ready to eat meats were found to be even better aligned with epidemiological estimates [39]. However, in the case of ALOPs it is not recommended to attempt comparisons using only the mean values of the output distributions but to also include the degree of confidence in the risk estimate [11]. The degree of confidence to be set in the ALOP estimate is left to the discretion of the risk manager with $95 \%$ often used [11] and given that the concept could be associated with the articulation of the acceptance of a maximum incidence of risk [46], it is likely that the upper percentiles such as the $95^{\text {th }}$, the $97.5^{\text {th }}$ or the $99^{\text {th }}$ percentile are most useful comparisons informing risk manager's decisions. For the several upper percentiles shown in Figure 3, the differences between outcomes are smaller between the top-down approach and the baseline and alternative 2 of the bottom-up approach than when comparing the mean values.

A sensitivity analysis of the ALOP output distributions obtained with both approaches using alternative input parameter combination 3 is provided in Figure 4 and ranks the impact of the variance in all possible stochastic input variables on ALOP estimates. Correlation coefficients between inputs and outputs showed that the under-notification factor (0.57), the reported cases per million inhabitants (0.56), the misdiagnosis and under-reporting factor $(0.42)$ and the attribution to the deli meats product group (0.33) 
a

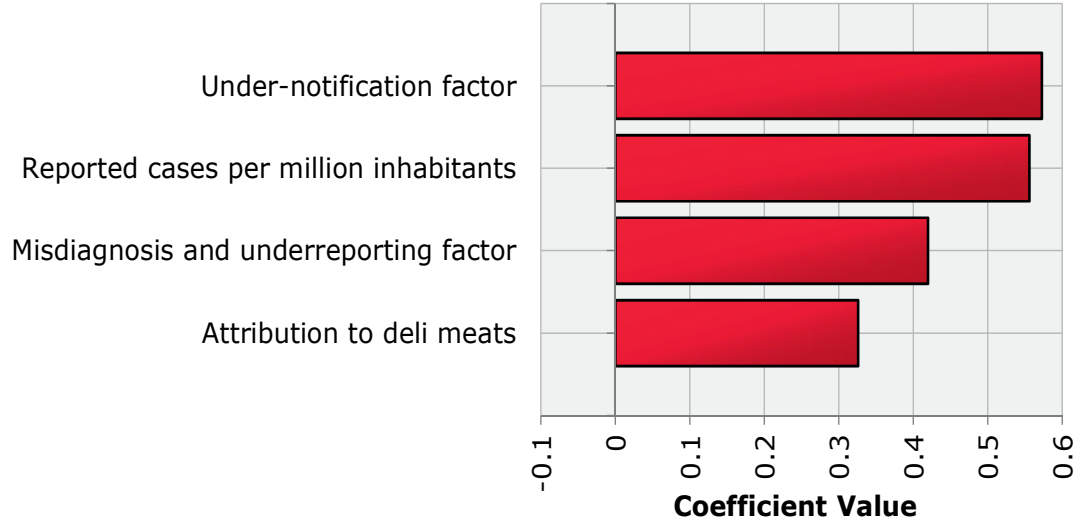

b

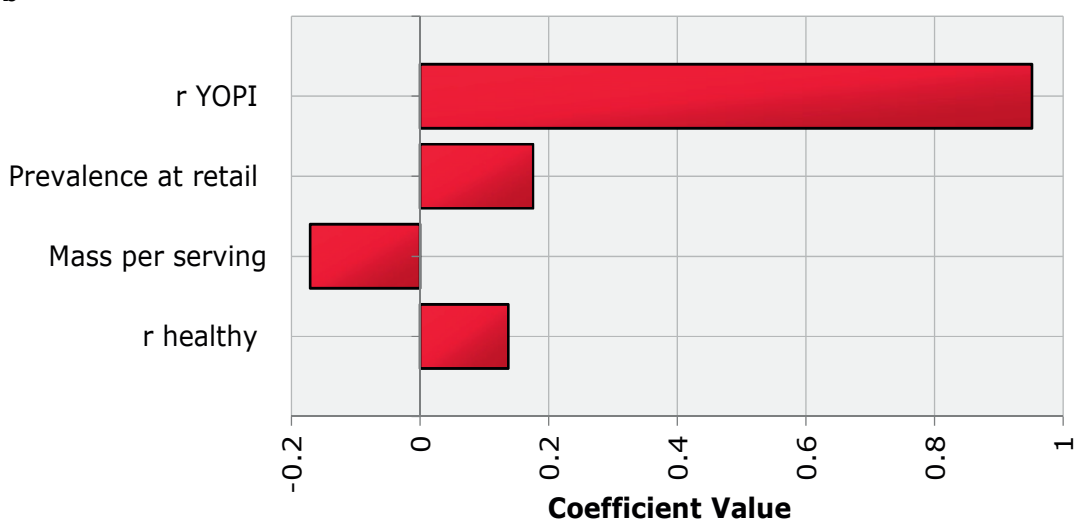

Figure 4. Ranking of the impact of the different stochastic input distributions using correlation coefficients (Spearman Rank) on the estimated ALOP using model 3 following the top-down approach (a) and the bottom-up approach (b).

all are variables whose variance affect the ALOP significantly when estimated using the top-down approach. When using the same input parameter combination following the bottom-up approach, the variable with the greatest influence on the estimated ALOP is the $r$ parameter of the dose response model for the YOPI (0.95) as compared to the impact of other variables such the prevalence at retail $(0.18)$, the mass per serving $(-0.17)$ and the $r$ parameter for the healthy population (0.14). The mass per serving was found to be negatively correlated because of its negative influence on the number of servings that has been estimated by dividing the per capita consumption with the mass per serving. Because of this, although the mass per serving is positively correlated for the dose during exposure assessment, in the risk characterization part its impact on the ALOP is negative. The fact that the $r$ parameter for the YOPI has a substantial impact on the ALOP does not come as 
a surprise, since considerable uncertainty is associated with this variable ( $90 \% \mathrm{CrI}$ : $\left.2.47 \cdot 10^{-13}-9.32 \cdot 10^{-12}\right)$.

\subsection{Food Safety Objectives}

The main results for the FSOs estimated with the top-down and the bottom-up approach models can be seen in Figure 5. The estimated FSOs were the same for all combinations of input parameters used in the bottom-up approach, with a mean value of -0.82 (95\% CrI: -3.2 to 5.6), since the inputs were the same for this model. In the top-down approach, the FSOs were the same for the baseline and alternative 2 , with a mean estimate of 3.4 log CFU per g (95\% CrI: 2.8-3.8 log CFU per g). For alternatives 1 and 3, the FSO estimates were also the same, with a mean of 2.7 log CFU per g (95\% CrI: 2.0-3.5 log CFU per $\mathrm{g}$ ). As in the case of the ALOPs, comparisons between different FSOs could also be made on the basis of upper percentiles [66]. Despite considerable differences when comparing the mean FSO values obtained with the two different approaches, in the case of the upper percentiles the differences observed were smaller with the FSO estimates coinciding at the $95^{\text {th }}$ percentile, being around 4 log CFU per g. Smaller differences at the higher percentiles were anticipated since in the case of the bottom-up FSO distribution only the high percentiles contribute to the ALOP, while in the case of the top-down FSO distribution the higher percentiles relate to the maximum concentration of Listeria that can be responsible for the ALOP. Thus, based on the very definition of the FSO, the benchmark is expected to be based in the higher percentiles of these output distributions.

\section{Percentile}

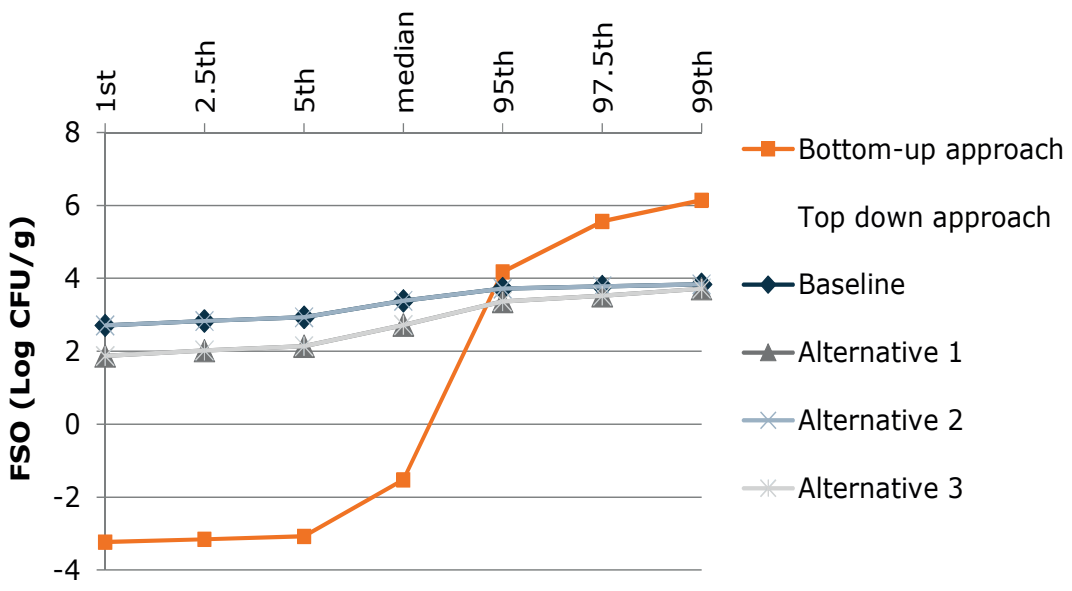

Figure 5. Comparison of the FSOs derived with the top-down and the bottom-up approach. 
It is worthwhile mentioning that although the estimated FSOs with this approach could vary for different input parameter combinations, the two estimated SO (step 6, Figure 1) were approximately the same for every combination of inputs used, with differences smaller than $<0.15 \log$ CFU. The reason for this was that the ratios $r_{\text {YopI }} / r_{\text {healthy }}$ and LOPYopI/LOPhealthy were in all cases such that they resulted in only small differences when estimating the SOyopi and SOhealthy through equation 2. In theory, the SOropI and SOhealthy should also be the same as there is no particular reason for the concentrations of the pathogen consumed by the elderly to be any different than those of the healthy population.

A sensitivity analysis of the FSO output distributions obtained with both approaches using alternative input parameter combination 3 is provided in Figure 6 to rank the impact of all possible stochastic inputs. The variables that influence the FSO estimated with the topdown approach are in declining order based on their correlation coefficients: the $r$ parameter for the healthy $(-0.57)$, the $r$ parameter for the YOPI $(-0.33)$, the undernotification factor (0.31), the reported cases per million inhabitants $(0.3)$, the percentage of cases amongst healthy (0.29), the misdiagnosis and under-reporting factor $(0.23)$, the attribution to the deli meats product group $(0.18)$ and the percentage of cases amongst YOPI (0.02). When using the same alternative input combination following the bottom-up approach, the variables found to be contributing to the variance of the FSO were in declining order: the exponential growth rate $(0.63)$, the storage time $(0.45)$, the temperature of household refrigerators $(0.44)$, the concentration at retail $(0.17)$ and the prevalence at retail $(0.04)$.

a

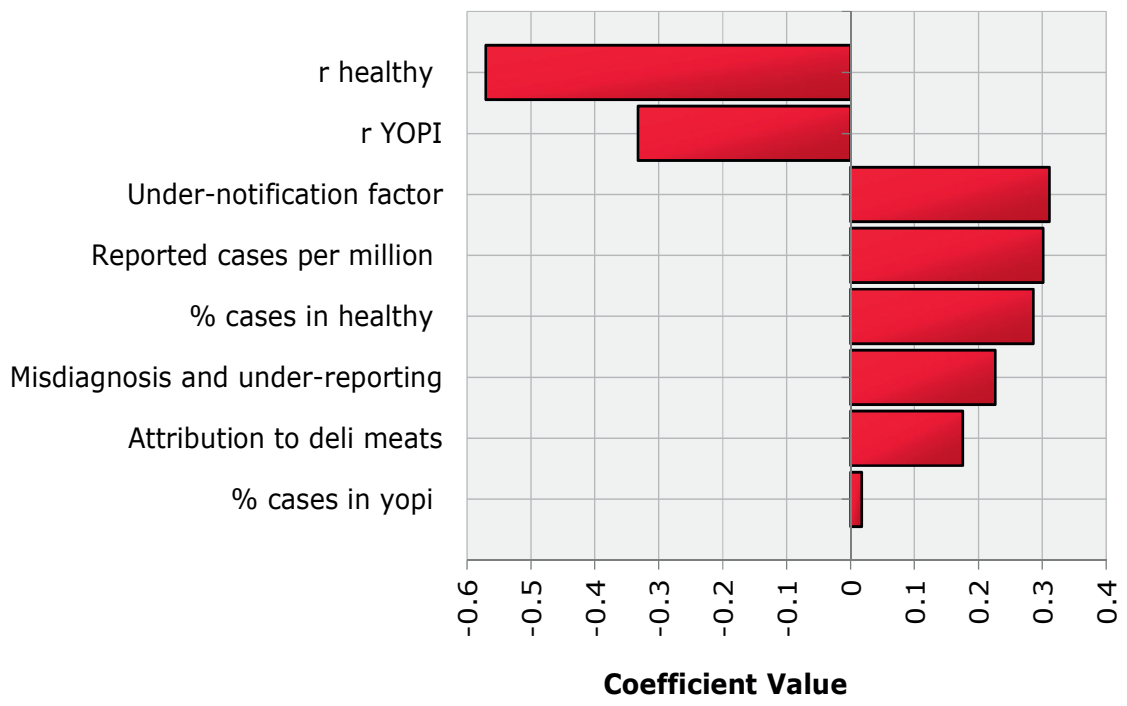


b

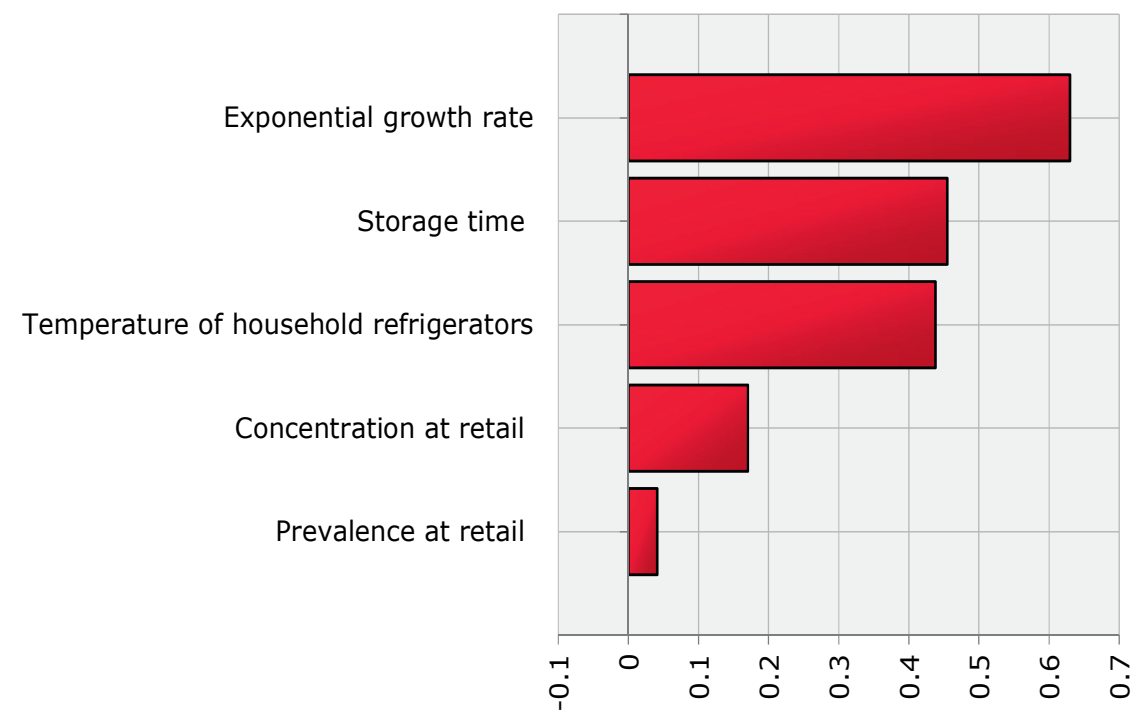

Coefficient Value

Figure 6. Ranking of the impact of the different stochastic input distributions in the estimated FSO with model 3 using correlation coefficients (Spearman Rank) following the top-down approach (a) and the bottom-up approach (b).

\subsection{Comparing the outcomes of the two approaches}

Overall, the bottom-up approach yielded ALOP values that were higher than the ones of the top-down approach (Figure 3, Table A of supplementary material) and an FSO with a credible interval several orders of magnitude wider than the ones obtained with the topdown approach (Figure 5, Table B of supplementary material). However results can still be comparable between the estimates for some of the input parameter combinations and also depending on the upper percentile that forms the basis for comparison. The introduction of more stochastic parameters in the place of point estimates was also found to lead to an increase in risk estimates (cases of listeriosis) using the bottom-up model, similar to the observations of other authors [68]. More specifically, by using a distribution instead of a point estimate for the $r$ parameter (alternative input combination 1 and 3 ) considerably more cases were estimated compared to the baseline input combination. This difference was even more evident when attempting the same comparison on the basis of the higher percentiles. Evidently, the level of detail that is incorporated in risk assessment based models used to estimate the ALOP and FSO benchmarks is a point that needs to be further agreed upon by all relevant stakeholders, especially in view of the fact that most 
of the factors that should be considered in the exposure assessment and risk characterization parts according to the guidelines of the Codex Alimentarius [8] can be characterized by considerable variability and uncertainty, which often dictates their incorporation in the form of stochastic inputs.

The top-down and the bottom-up approach should ideally yield comparable results [69] but in practice this will not always be feasible, as comparability will depend on the level of detail included in the models and on the assumptions made. Moreover although we recommend the combined use of the two approaches to allow for the validation of the risk estimates in reality only one of the two should be used since "common approaches or consistent procedures" should be established and used by competent authorities when assessing risks and evaluating measures to achieve the ALOP [19]. Most importantly however to be able to compare ALOPs in different situations on an international or national level "sufficient common elements" should be in place to allow for such comparisons [19]. Considering that the bottom-up and top-down approach are based on different data sets, in practice only one of the two is likely to be selected for building in the ALOP/FSO benchmarks.

\subsection{Advantages and disadvantages of each approach for use in benchmarking}

Each of the two approaches developed in the current case study has its advantages and disadvantages and the selection of one over the other depends on the application context and the data available. Looking at our results, setting the benchmarks top-down in this particular case provides for an estimated ALOP that is as close to the real situation as possible (total number of cases of listeriosis in the country based on epidemiological data) and results in FSO values that are quite well aligned (Fig. 5). The credible intervals obtained with the top down approach were also narrower than the ones obtained with the bottom-up approach, given that there was less uncertainty and variability in the input data. Conversely, with the bottom-up approach there was considerable variation between ALOP estimates and significant uncertainty in the estimated FSOs, reflecting the variability and uncertainty of input data such as growth rate, storage time and temperature. In addition to the above, existing case law suggests that the ALOP should be the starting point of setting sanitary and phytosanitary (SPS) measures such as FSO since by using an SPS measure as a starting point, the ALOP would always be achieved which is clearly not the case [70]. Thus, considering all of the above, the top-down approach could be more a promising practice for setting ALOP and FSO benchmarks at a national level. 
However, the top-down approach may be more difficult to implement as a way to compare ALOPs between different countries on an international level, since it requires good quality epidemiological data (active surveillance data) and attribution values to specific foods or food product groups that are currently not likely to be available for most countries. Conceivably, the surveillance systems that provide the epidemiological data should remain more or less the same over time so that fluctuations in the number of reported cases of a specific illness can be linked to the level of protection achieved in the food chain and not influenced by changes in the monitoring of foodborne diseases [6]. Taking this into account, the bottom-up approach might be more feasible to implement for international comparisons for instance in Europe, where the prevalence and concentration data for particular pathogens (such as Listeria) are generally available for most EU countries from the European Food Safety Authority (EFSA) [47-51] and are based on the same isolation protocol due to legal requirements [52]. Although the quality of these data is not yet optimal and deriving ALOP/FSO benchmarks bottom-up is technically more difficult and resource intensive, it is still possible to give useful results even with a relatively straightforward risk assessment model like the one used in the current study. A risk assessment based FSO furthermore allows the systematic and quantitative evaluation of the efficiency of different management options when aiming for a future level of protection (specified as an ALOP or as a public health goal) that is to be more strict; this is not possible when estimating the ALOP/FSO with the top-down approach.

\subsection{Further refinements in the estimates}

While working in this case study we identified several gaps in the data currently available for estimating ALOP/FSO benchmarks. We would like to point out the most important ones as areas where more information should become available to further refine such estimates and facilitate the use of these benchmarks in food safety management.

\subsubsection{Concentration of Listeria in deli meats}

At mentioned above, presently there is a considerable amount of information regarding the sampling of cooked ready-to-eat meat products for Listeria in the EU through the European Food Safety Authority (EFSA) [47-51]. However the level of detail in the data only allows for estimations of the prevalence and not the concentration of the pathogen for this product group. Enumeration takes place to identify samples exceeding the current legal limit of $100 \mathrm{CFU} / \mathrm{g}$ [52] but it is currently not obligatory by law to disclose the actual concentrations [71]. For such enumeration data to be more useful for in depth comparisons 
between different EU countries, it would be beneficial in the future to publicize also the precise concentrations in the positive samples.

\subsubsection{Additional information on the type of deli meat}

Additional information would be useful with regards to the type of deli meat sampled and in particular whether it was pre-packaged or retail sliced. In a recent study, retail sliced deli meat was associated with an about 4 times increased risk of listeriosis on a per serving basis in comparison to pre-packaged deli meat [72]. This means that over-representation of samples from either kind of deli meat in the EFSA data [47-50] in comparison to the actual situation in the market could lead to an over- or underestimation of the actual number of cases. More detailed information may also allow for grouping of deli meats into different categories for which then growth could be modelled using more specific models than currently possible. Finally, the country of origin of the deli meats tested would be another important piece of information that, when collected, could provide information on how representative the sampling results are with respect to the situation for products in different national/international markets. The latter would improve the utility of the ALOP concept, which was originally designed to aid in addressing international trade issues.

\subsubsection{Dose-response model}

A simple to use dose response model should ideally be in place for estimating the ALOP/FSO benchmarks. We selected the FAO/WHO dose-response model for Listeria [43] as one of the most recent ones and because of its international character. This considers several $r$ values to be plausible on the basis of different underlying assumptions about the $D_{\max }$. Variability in virulence between different strains is considered in this model given that the data used for the estimation of the $r$ values reflect the characteristics of many strains of $L$. monocytogenes including frequency of occurrence and virulence. For the purpose of risk estimates for products that can support the growth of Listeria (like deli meats), it is recommended to use the $r$ values that we have chosen for our baseline model assuming that the $D_{\max }$ varies uniformly from 7.5 to $10.5 \mathrm{log}$ CFU. It is not evident whether $r$ parameters should be used in a stochastic form or not and which distribution would be more representative when a stochastic form is used. Since $D_{\max }$ was also found to be the most influential factor on the estimated risk of listeriosis [68], the appropriate choice of $r$ parameters and the form of input are aspects of the modelling that need further work. It is also worthwhile to note that the FAO/WHO model is based on the assumption that the YOPI population varies between 15 and $20 \%$, which may not be the case for some developed countries with an ageing population. In the Netherlands, this value was $18.3 \%$ 
when considering elderly to be over the age of 65 years (as was done in the current study) and it was as high as $22.7 \%$ when they are considered to be older than 60 years. Had we used the latter value, our ALOP estimates with the top-down approach would remain almost the same (less than 2\% difference) but our ALOP estimates with the bottom-up approach would be considerably increased ( $\sim 21 \%$ difference). Given that the dose response model is a key element influencing estimates of the ALOP/FSO benchmarks, as can also be seen in our crude sensitivity analysis results (Figures 4b and 6a), adjusting the model so that it can account for an increase in the percentage of the susceptible population is an important point for future improvements.

\subsubsection{Storage time}

Data regarding the storage time of deli meats are scarce for the Netherlands as well as other EU countries. We choose to use expert elicitation data from Australia for deli meats [39] of which the range was in line with Swedish data for sliced cooked ham [73]. Considering that storage time was the second most influencing parameter in the FSO estimate (Figure 6b), more studies on consumer storage practices would be vital for providing more refined estimates.

\subsubsection{Exponential growth rate}

The exponential growth rate was estimated using a baseline exponential growth rate at $5^{\circ} \mathrm{C}\left(\mathrm{EGR}_{5}\right)$ as was also done in the FDA/FSIS risk assessment [53]. This EGR5 was based on a meta-analysis of international literature data for different categories of deli meats. Though the range of values provided with this method may be accurate enough for prediction purposes and has been used in other risk assessments as well [56], a considerable amount of new data has been published since the FDA/FSIS risk assessment was published and also new approaches on how to make best use of it in risk assessments have been proposed [74]. Taking into account that also the EGR ${ }_{5}$ influences estimates greatly (Figure 6b), updating the dataset on which it is based would be helpful for future reference.

\subsubsection{International food consumption database}

If ALOPs are to be used more widely for the purpose of international comparisons, it would be of particular benefit when an international food consumption database would be in place that would allow for consistent compilation and retrieval of information on food consumption patterns from different countries. Such a database has recently been 
launched in the EU, but because the consumption data collected so far have been generated using different methodologies their use for direct country to country comparisons is not recommended [75].

\section{Conclusions}

Based on this case-study, obtaining meaningful estimations of ALOP/FSO is feasible with both the top-down and the bottom-up approach deployed using readily available data sources for the Netherlands. However, choices need to be made regarding the level of detail that will be incorporated in stochastic models and what upper percentile of the output distribution would be best to base the benchmark on. Additional studies on the storage time of deli meats and improvements in the way information regarding the sampling of Listeria in deli meats is currently gathered and reported in the EU could help in further refining the estimates. Developments since the time of FAO/WHO and FDA/FSIS risk assessments might allow for a more optimal estimation of the dose-response model and the growth rate for Listeria but this was outside the scope of our paper. The top-down approach yielded the best results for the data available for the Netherlands and it may be the preferred approach at the national level when good quality epidemiological data are available, although the bottom-up approach may be more promising for the purpose of international comparisons of ALOP values in different countries. As a best practice, we recommend that both approaches should be used so that risk estimates may be validated to an extent. Depending on the application context, ultimately, one approach may appear to be more appropriate than the other.

\section{Acknowledgements}

The authors gratefully acknowledge Unilever for financially sponsoring this research. 


\section{Technical Appendix A}

ALOP values (cases of severe listeriosis due to the consumption of deli meat per million people per year) estimated with the top-down and the bottom up approach models for different combinations of input parameters. All values have been rounded to include three significant digits

\begin{tabular}{lccccccccc}
\hline & \multicolumn{7}{c}{ Level of certainty (percentile) } \\
\cline { 2 - 9 } & mean & SD & $1^{\text {st }}$ & $2.5^{\text {th }}$ & $5^{\text {th }}$ & $95^{\text {th }}$ & median & $97.5^{\text {th }}$ & $99^{\text {th }}$ \\
\hline $\begin{array}{l}\text { Bottom-up } \\
\text { approach }\end{array}$ & & & & & & & & & \\
\hline Baseline & 11.8 & 1.68 & 8.27 & 8.77 & 9.21 & 14.7 & 11.8 & 15.3 & 16.1 \\
Alternative 1 & 43.4 & 29.8 & 3.28 & 5.22 & 7.49 & 102 & 36.9 & 116 & 133 \\
Alternative 2 & 12.2 & 2.46 & 7.60 & 8.14 & 8.64 & 16.6 & 11.9 & 17.7 & 19.0 \\
Alternative 3 & 44.2 & 31.4 & 3.27 & 5.17 & 7.44 & 106 & 37.0 & 122 & 142 \\
\hline & & & & & & & & & \\
\hline Top-down & 3.23 & 1.44 & 0.824 & 1.07 & 1.30 & 5.91 & 3.01 & 6.63 & 7.55 \\
approach & & & & & & & & & \\
\hline
\end{tabular}

\section{Technical Appendix B}

FSOs (log CFU per gram) estimated with the top-down and the bottom up approach models for different combinations of input parameters. All values have been rounded to include two significant digits

\begin{tabular}{lccccccccc}
\hline & \multicolumn{10}{c}{ Level of certainty (percentile) } \\
\cline { 2 - 10 } & mean & SD & $1^{\text {st }}$ & $2.5^{\text {th }}$ & $5^{\text {th }}$ & median & $95^{\text {th }}$ & $97.5^{\text {th }}$ & $99^{\text {th }}$ \\
\hline $\begin{array}{l}\text { Top-down } \\
\text { approach }\end{array}$ & & & & & & & & & \\
\hline Baseline & 3.4 & 0.24 & 2.7 & 2.8 & 2.9 & 3.4 & 3.7 & 3.8 & 3.8 \\
Alternative 1 & 2.7 & 0.38 & 1.9 & 2.0 & 2.1 & 2.7 & 3.4 & 3.5 & 3.7 \\
Alternative 2 & 3.4 & 0.24 & 2.7 & 2.8 & 2.9 & 3.4 & 3.7 & 3.8 & 3.8 \\
Alternative 3 & 2.7 & 0.38 & 1.9 & 2.0 & 2.1 & 2.7 & 3.4 & 3.5 & 3.7 \\
\hline & & & & & & & & & \\
\hline Bottom-up & -0.82 & 2.2 & -3.2 & -3.2 & -3.1 & -1.5 & 4.2 & 5.6 & 6.1 \\
approach & & & & & & & & & \\
\hline
\end{tabular}




\section{References}

1. Scallan, E., P.M. Griffin, F.J. Angulo, R.V. Tauxe, and R.M. Hoekstra. Foodborne illness acquired in the United States-Unspecified agents. Emerging Infectious Diseases. 2011; 17: p. 17-22.

2. Scallan, E., R.M. Hoekstra, F.J. Angulo, R.V. Tauxe, M.A. Widdowson, S.L. Roy, J.L. Jones, and M.P. Griffin. Foodborne illness acquired in the United States - Major pathogens. Emerging Infectious Diseases. 2011; 17: p. 7-15.

3. Gkogka, E., M.W. Reij, A.H. Havelaar, M.H. Zwietering, and L.G.M. Gorris. Risk-based estimate of effect of foodborne diseases on public health, Greece. Emerging Infectious Diseases. 2011; 17: p. 1581-1590.

4. FAO/WHO. (2006). Food safety risk analysis. A guide for national food safety authorities. ISBN: 978-92-5-105604. Food and Agriculture Organization of the United Nations/World Health Organization: Rome/Geneva. Available from: http://www.who.int/foodsafety/publications/micro/riskanalysis06.pdf

5. Codex Alimentarius. (2007). Principles and guidelines for the conduct of microbiological risk management (MRM), CAC/GL 63-2007. Available from: www.fao.org/input/download/standards/10741/CXG 063e.pdf

6. EFSA. Opinion of the Scientific Panel on Biological Hazards on microbiological criteria and targets based on risk analysis (Question No EFSA-Q-2005-296). EFSA Journal, 2007; 5: 462

7. Crouch, E.A., D. LaBarre, N.J. Golden, J.R. Kause, and K.L. Dearfield. Application of quantitative microbial risk assessments for estimation of risk management metrics: Clostridium perfringens in ready-to-eat and partially cooked meat and poultry products as an example. Journal of Food Protection. 2009; 72: p. 2151-2161.

8. Codex Alimentarius. (1999). Principles and guidelines for the conduct of microbiological risk assessment. CAC/GL-30 Available from: http://www.fao.org /3/y1579e/y1579e05.htm

9. European Community. (2002). European Parliament and Council of the European Union. Regulation (EC) No 178/2002 of the European Parliament and of the Council of 28 January 2002 laying down the general principles and requirements of food law, establishing the European Food Safety Authority and laying down procedures in matters of food safety. Available from: http://eur-lex.europa.eu/LexUriServ LLexUriServ.do?uri=0]:L:2002:031:0001:0024:EN:PDF

10. Todd, C.D.E. Microbiological safety standards and public health goals to reduce foodborne disease. Meat Science. 2003; 66: p. 33-43.

11. FAO/WHO. (2002). Principles and guidelines for incorporating microbiological risk assessment in the development of food safety standards, guidelines and related texts. Report of a Joint FAO/WHO Consultation, Kiel, Germany, 18-22 March 2002. 
ISBN: 92-5-104845-2. Food and Agriculture Organization of the United Nations/World Health Organization: Rome/Geneva. Available from: http://www.fao.org/3/a-y4302e.pdf

12. ICMSF. International Commission on Microbiological Specifications for Foods. Book 7. Microbiological testing in food safety management (2nd edition). 2002. International Commission on Microbiological Specifications for Foods (eds). Springer International Publishing AG: Cham, Switzerland

13. WTO. (1995). Agreement on the application of sanitary and phytosanitary measures (SPS Agreement). World Trade Organization: Geneva. Available from: http://www.wto.org/english/docs e/legal e/15-sps.pdf

14. Codex Alimentarius. (2004). C. Alimentarius. Codex Alimentarius Commission. Procedural Manual. Fourteenth Edition. Available from: http://www.codexalimentarius.net/web/procedural manual.jsp

15. ICMSF. (2006). A simplified guide to understanding and using Food Safety Objectives and Performance Objectives. International Commission on Microbiological Specifications for Foods: Available from: http://www.icmsf.org/publications/quide/

16. Gorris, L.G.M. Food safety objective: An integral part of food chain management. Food Control. 2005; 16: p. 801-809.

17. Zwietering, M. Practical considerations on food safety objectives. Food Control. 2005; 16: p. 817-823.

18. Stringer, M. Food safety objectives - role in microbiological food safety management. Food Control. 2005; 16: p. 775-794.

19. WTO. (2000). World Trade Organization. Committee on Sanitary and Phytosanitary Measures. Guidelines to further the practical implementation of Article 5.5. Available from: http://www.wto.org/english/tratop e/sps e/decisions06 e.htm

20. Buchanan, R., R. Whiting, and T. Ross. (2006). Background paper for the joint FAO/WHO expert consultation on development of practical risk management strategies based on microbiological risk assessment outputs. Kiel, Germany, 3-7 April 2006. Case study: Listeria monocytogenes in smoked fish. "Development of Risk Management Metrics for Food Safety". Food and Agriculture Organization of the United Nations/World Health Organization: Rome/Geneva. Available from: http://www.fao.org/3/a-au625e.pdf

21. Butler, F., G. Duffy, D. Engeljohn, A.M. Lammerding, and R.B. Tompkin. (2006). Background paper for the joint FAO/WHO expert consultation on the development of practical risk management strategies based on microbiological risk assessment outputs. Kiel, Germany, 3-7 April 2006. Case study: Escherichia coli 0157:H7 in fresh ground beef. Food and Agriculture Organization of the United Nations/World 
Health Organization: Rome/Geneva. Available from: http://www.fao.org/3/aau624e.pdf

22. DePaola, A., R. Lee, D. Mahoney, I. Rivera, and M. Tamplin. (2006). Background paper for the joint FAO/WHO expert consultation on the development of practical risk management strategies based on microbiological risk assessment outputs. Kiel, Germany, 3-7 April 2006. Case study: Vibrio vulnificus in oysters. Food and Agriculture Organization of the United Nations/World Health Organization: Rome/Geneva. Available from: http://www.fao.org/3/a-au626e.pdf

23. FAO/WHO. (2006). The use of microbiological risk assessment outputs to develop practical risk management strategies. Food and Agricultural Organization of the United Nations/World Health Organization: Rome/Geneva. Available from: https://www.who.int/foodsafety/publications/micro/MRA Outputs.pdf

24. Membré, J.M., J. Bassett, and L.G.M. Gorris. Applying the food safety objective and related standards to thermal inactivation of Salmonella in poultry meat. Journal of Food Protection. 2007; 70: p. 2036-2044.

25. Rieu, E., K. Duhem, E. Vindel, and M. Sanaa. Food safety objectives should integrate the variability of the concentration of pathogen. Risk Analysis. 2007; 27: p. 373386.

26. Tuominen, P., J. Ranta, and R. Maijala. Studying the effects of POs and MCs on the Salmonella ALOP with a quantitative risk assessment model for beef production. International Journal of Food Microbiology. 2007; 118: p. 35-51.

27. Perni, S., R.R. Beumer, and M.H. Zwietering. Multi-tools approach for food safety risk management of steam meals. Journal of Food Protection. 2009; 72: p. 26382645.

28. Anderson, N.M., J.W. Larkin, M.B. Cole, G.E. Skinner, R.C. Whiting, L.G.M. Gorris, A. Rodriquez, R. Buchanan, C.M. Stewart, J.H. Hanlin, L. Keener, and P.A. Hall. Food safety objective approach for controlling Clostridium botulinum growth and toxin production in commercially sterile foods. Journal of Food Protection. 2011; 74: p. 1956-1989.

29. Gkogka, E., M.W. Reij, L.G.M. Gorris, and M.H. Zwietering. The application of the Appropriate Level of Protection (ALOP) and Food Safety Objective (FSO) concepts in food safety management, using Listeria monocytogenes in deli meats as a case study. in Seventh International Conference on Predictive Modelling of Food Quality and Safety. 2011. Dublin, Ireland (UCD, DIT, Teagasc).

30. CBS. Statistics Netherlands [cited 2009 September 30]. Available from: http://www.cbs.nl/en-GB/menu/home/default.htm

31. Prismant. Hospital Discharge Register - Diagnoses (in Dutch) [cited 2009 September 30]. Available from: http://cognosserver.prismant.nl/cognos7/cgi-bin 
$\angle p p d s c g i . c g i ? D C=Q \& E=/$ Prisma-Landelijke-LMR/Landelijke+LMR-informatie++Diagnosen

32. Hall, G., D.M. Kirk, N. Becker, E.J. Gregory, L. Unicomb, G. Millard, R. Stafford, K. Lalor, and O.W. Group. Estimating foodborne gastroenteritis, Australia. Emerging Infectious Diseases. 2005; 11: p. 1257-1264.

33. RIVM. National Institute for Public Health and the Environment. Ministry of Public Health Welfare and Sports [internet] [cited 2010 January 2010]. Available from: www.rivm.nl

34. Rocourt, J., G. Moy, K. Vierk, and J. Schlundt. (2003). The present state of foodborne disease in OECD countries. World Heath Organization: Geneva. Available from: http://www.adiveter.com/ftp public/articul0702.pdf

35. Health Council of the Netherlands. (2002). Health Council of the Netherlands. Committee on Trends in food consumption. Significant trends in food consumption in the Netherlands [in dutch]. Gezondheidsraad: The Hague. Available from: http://www.gezondheidsraad.nl/nl/adviezen/enkele-belangrijke-ontwikkelingen-devoedselconsumptie

36. RIVM. Dutch National Food Consumption Survey (DNFCS) - Young adults, 2011, National Institute for Public Health and the Environment: Bilthoven.

37. RIVM. Dutch National Food Consumption Surveys (DNFCS) [cited 2010 May 27]. Available from: http://www.rivm.nl/vcp en/overview/

38. RIVM. (2006). Our food our health. Healthy diet and safe food in the Netherlands. RIVM report number 270555009. National Institute for Public Health and the Environment: Bilthoven. Available from: http://www.rivm.nl/bibliotheek/rapporten 2270555009.pdf

39. Ross, T., S. Rasmussen, A. Fazil, G. Paoli, and J. Summer. Quantitative risk assessment of Listeria monocytogenes in ready-to-eat meats in Australia. International Journal of Food Microbiology. 2009; 131: p. 128-137.

40. Greig, J.D. and A. Ravel. Analysis of foodborne outbreak data reported internationally for source attribution. International Journal of Food Microbiology. 2009; 130: p. 7787.

41. Havelaar, A.H., A.V. Galindo, D. Kurowicka, and R.M. Cooke. Attribution of foodborne pathogens using structured expert elicitation. Foodborne Pathogens and Disease. 2008; 5: p. 649-659.

42. Batz, M.B., S.A. Hoffmanm, A.J. Krupnick, J.G. Morris, D.M. Sherman, M.R. Taylor, and J.S. Tick. (2004). Identifying the most significant microbiological foodborne hazards to public health: A new risk ranking model. Food Safety Research Consortium: Washington, DC. Available from: http://www.rff.org/RFF/Documents /FRSC-DP-01.pdf 
43. WHO/FAO. (2004). Risk assessment of Listeria monocytogenes in ready-to-eat foods: technical report. ISBN: 92-4-156262-5. World Health Organization/Food and Agriculture Organization of the United Nations: Geneva/Rome. Available from: http://www.who.int/foodsafety/publications/micro/mra listeria/en/

44. Doorduyn, Y., C.M. de Jager, W.K. van der Zwaluw, W.J.B. Wannet, A. van der Ende, L. Spanjaard, and Y.T.P.H. van Duynhoven. First results of the active surveillance of Listeria monocytogenes in the Netherlands reveal higher than expected incidence. Eurosurveillance. 2006; 11: p. 2945

45. Doorduyn, Y., C.M. de Jager, W.K. van der Zwaluw, W.J.B. Wannet, A. van der Ende, L. Spanjaard, and Y.T.P.H. van Duynhoven. Invasive Listeria monocytogenes infections in the Netherlands, 1995-2003. European Journal of Clinical Microbiology \& Infectious Diseases. 2006; 25: p. 433-442.

46. Havelaar, A.H., M.J. Nauta, and J.T. Jansen. Fine-tuning food safety objectives and risk assessment. International Journal of Food Microbiology. 2004; 93: p. 11-29.

47. EFSA/ECDC. The Community summary report on trends and sources of zoonoses, zoonotic agents, antimicrobial resistance and foodborne outbreaks in the European Union in 2005. EFSA Journal. 2006; 4: 94r

48. EFSA/ECDC. The Community summary report on trends and sources of zoonoses, zoonotic agents, antimicrobial resistance and foodborne outbreaks in the European Union in 2006. EFSA Journal. 2007; 5: 130r

49. EFSA/ECDC. The Community summary report on trends and sources of zoonoses and zoonotic agents in the European Union in 2007. EFSA Journal. 2009; 7: 223r

50. EFSA/ECDC. The Community summary report on trends and sources of zoonoses, zoonotic agents and food-borne outbreaks in the European Union in 2008. EFSA Journal. 2010; 8: 1496

51. EFSA/ECDC. The European Union summary report on trends and sources of zoonoses, zoonotic agents and food-borne outbreaks in 2009. EFSA Journal. 2011; 9: 2090

52. European Community. (2005). European Parliament and Council of the European Union. Commission Regulation (EC) No 2073/2005 of November 2005 on microbiological criteria for foodstuffs. Available from: http://eur-lex.europa.eu LLexUriServ/LexUriServ.do?uri=0J:L:2005:338:0001:0026:EN:PDF

53. FDA/FSIS. (2003). Quantitative assessment of relative risk to public health from foodborne Listeria monocytogenes among selected categories of ready-to-eat foods. U.S. Department of Health and Human Services Food and Drug Administration/U.S. Department of Agriculture Food Safety Inspection service: Washington DC. Available from: https://www.fda.gov/downloads/food/foodscienceresearch/ucm197330.pdf 
54. Mataragas, M., M.H. Zwietering, P.N. Skandamis, and E.H. Drosinos. Quantitative microbiological risk assessment as a tool to obtain useful information for risk managers - Specific application to Listeria monocytogenes and ready-to-eat meat products International Journal of Food Microbiology. 2010; 141: p. S170-S179.

55. Nauta, M.J., S. Litman, G.C. Barker, and F. Carlin. A retail and consumer phase model for exposure assessment of Bacillus cereus. International Journal of Food Microbiology. 2003; 83: p. 205-218.

56. Yang, H., A. Mokhtari, L.-A. Jaykus, R.A. Morales, S.C. Cates, and P. Cowen. Consumer phase risk assessment for Listeria monocytogenes in deli meats. Risk Analysis. 2006; 26: p. 89-103.

57. Pradhan, A.K., R. Ivanek, Y.T. Gröhn, R. Bukowski, I. Geornaras, J.N. Sofos, and M. Wiedmann. Qualitative risk assessment of listeriosis-associated deaths due to Listeria monocytogenes contamination of deli meats originating from manufacture and retail. Journal of Food Protection. 2010; 73: p. 620-630.

58. Pouillot, R., M.B. Lubran, S.C. Cates, and S. Dennis. Estimating parametric distributions of storage time and temperature of ready-to-eat foods for U.S. households. Journal of Food Protection. 2010; 73: p. 312-321.

59. Goldbohm, R.A., P.A. Van den Bradt, P. van't Veer, H.A.M. Brants, E. Dorant, F. Sturmans, and R.J.J. Hermus. A prospective cohort study on the relation between meat consumption and the risk of colon cancer. Cancer Research. 1994; 54: p. 718723.

60. Heinen, M.M., B.A.J. Verhage, R.A. Goldbohm, and P.A. van den Bradt. Meat and fat intake and pancreatic cancer risk in the Netherlands cohort study. International Journal of Cancer. 2009; 125: p. 1118-1126.

61. Luchtenborg, M., M.P. Weijenberg, A.F.P.M. de Goeij, P.A. Wark, M. Brink, G.M.J.M. Roemen, M.H.F.M. Lentjes, A.P.G. de Bruine, R.A., P. van't Veer, and P.A. van den Brandt. Meat and fish consumption, APC gene mutations and hMLH1 expression in colon and rectal cancer: a prospective cohort study (the Netherlands). Cancer Causes and Control. 2005; 16: p. 1041-1054.

62. Donders-Engelen, M., L. Van der Heijden, and K. Hulshof. Weights, measures and code numbers 2003 (in Dutch), 2003, Division of human nutrition, Wageningen University and Netherlands Organization for Applied Scientific Research (TNO): Wageningen/Zeist.

63. Vose, D. Risk analysis: a quantitative guide (3rd edition). 2008. John Wiley and Sons, Ltd: Chichester, West Sussex

64. Pérez-Rodríquez, F., E.D. van Asselt, R.M. García-Gimeno, G. Zurera, and M.H. Zwietering. Extracting additional risk managers information from a risk assessment 
of Listeria monocytogenes in deli meats. Journal of Food Protection. 2007; 70: p. 1137-1152.

65. Zwietering, M.H. Quantitative risk assessment: Is more complex always better? Simple is not stupid and complex is not always more correct. International Journal of Food Microbiology. 2009; 134: p. 57-62.

66. Pouillot, R., V. Goulet, M.L. Delignette-Muller, A. Mahé, and M. Cornu. Quantitative risk assessment of Listeria monocytogenes in French cold-smoked salmon: II. Risk characterization. Risk Analysis. 2009; 29: p. 806-819.

67. Vaillant, V., H. De Valk, E. Baron, T. Ancelle, P. Colin, M.-C. Delmas, B. Dufour, R. Pouillot, Y. Le Strat, P. Weinbreck, E. Jougla, and J.C. Desenclos. Foodborne infections in France. Foodborne Pathogens and Disease. 2005; 2: p. 221-232.

68. Pouillot, R. and M.B. Lubran. Predictive microbiology models vs. modeling microbial growth within Listeria monocytogenes risk assessment: What parameters matter and why. Food Microbiology. 2011; 28: p. 720-726.

69. Whiting, R.C. What risk assessments can tell us about setting criteria. Food Control. 2010; 22: p. 1525-1528.

70. Ming Du, M. Autonomy in setting appropriate level of protection under the WTO law: rhetoric or reality? Journal of International Economic Law. 2010; 13: p. 1077-1102.

71. EFSA. (2011). Manual for reporting on zoonoses, zoonotic agents and antimicrobial resistance in the framework of Directive 2003/99/EC and of some other pathogenic microbiological agents for information derived from the year 2010. Supporting publication 2011:135 [119 pp.]. European Food Safety Authority: Parma. Available from: http://www.efsa.europa.eu/en/supporting/doc/135e.pdf

72. Endrikat, S., D. Gallagher, R. Pouillot, H.H. Quesenberry, D. LaBarre, C.M. Schroeder, and K. Janell. A comparative risk assessment for Listeria monocytogenes in prepackaged versus retail-sliced deli meat. Journal of Food Protection. 2010; 73: p. 612-619.

73. Marklinder, I.M., M. Lindblad, L.M. Eriksson, A.M. Finnson, and R. Lindqvist. Home storage temperatures and consumer handling of refrigerated foods in Sweden. Journal of Food Protection. 2004; 67: p. 2570-2577.

74. den Besten, H.M.W. and M.H. Zwietering. Meta-analysis for quantitative microbial risk assessments and benchmarking data. Trends in Food Science and Technology. 2012; 25: p. 34-39.

75. EFSA. Guidance of EFSA: Use of the EFSA European Food Consumption Database in exposure assessment. EFSA Journal, 2011; 9: 2097. 
Chapter 3 


\section{Chapter 4}

Risk assessment strategies as a tool in the application of the Appropriate Level of Protection (ALOP) and Food Safety Objective (FSO) by risk managers

Elissavet Gkogka, Martine W. Reij, Leon G.M. Gorris and Marcel H. Zwietering 


\section{Abstract}

In the course of the last decade, the Appropriate Level of Protection (ALOP), the Food Safety Objective (FSO) and their associated metrics have been proposed by the World Trade Organization and Codex Alimentarius as a means for competent authorities to ultimately translate governmental public health policy regarding food safety into risk-based targets for the food industry. The industry needs to meet these targets through the effective choice of control measures that are part of its operational food safety management system. The aim of this study was to put the practical application of ALOP and FSO to the test in the case of Salmonella in chicken meat in the Netherlands. Two different risk assessment approaches were applied to derive potential ALOP and FSO values, a 'top-down' approach based on epidemiological data and a 'bottom-up' approach based on food supply chain data. To this end, two stochastic models specific to the Dutch situation were built. Comparisons between 23 countries in Europe were also made using the top-down model. The mean estimated current Level Of Protection values were similar for the two approaches applied, with the bottom-up model yielding 87 cases per 100,000 inhabitants per year (95\% CI: 0.03, 904) and the top-down model 71 (95\% CI: 9.9, 155). The estimated FSO values on the other hand were considerably different with the mean 'top down' FSO being $-4.6 \log$ CFU/g (95\% CI: $-5.4,-4.1)$ and the mean 'bottom-up' FSO $-6.0 \log$ CFU/g $(95 \%$ CI: $-8.1,-2.9)$ reflecting major differences in the output distributions of this parameter obtained with the two approaches. Significant differences were observed between current LOP values for different EU countries, although it was not clear whether this was due to actual differences in the factors influencing the risk of salmonellosis or due to the quality of the available data. 


\section{Introduction}

Food safety is an issue of ongoing public health concern. Recent mean estimates from developed economies show that known hazards in the food supply chain can account for approximately three to four thousand cases of foodborne illness per 100,000 inhabitants in the general community, while the total number of foodborne illness is much higher as in most cases the aetiological agent is not identified due to limitations of existing surveillance systems $[1,2]$. These foodborne illnesses can have big economic and societal impacts associated with medical costs, loss of productivity, recall expenses and cost of legal actions but also with personal suffering, pain and death [3]. Managing food safety therefore is of the outmost importance for all stakeholders involved in the food supply chain (i.e. primary production, processing, distribution and sale), but especially for governments whose role is to develop and enforce policy and for food business operators who have the ultimate responsibility of producing safe products $[4,5]$.

Food safety assurance is based on the establishment of appropriate control measures and operational food safety management systems throughout the food supply chain, which traditionally have been hazard-based. However, in the course of the last decades there has been a shift towards more risk-based approaches of managing food safety on an international level [6]. This shift began in the early 1970's with the introduction of the HACCP system into food operations as a means of identifying potential hazards and determining those that are essential to control on the basis of a more quantitative appreciation of risks associated with individual hazards. However, it was not until the mid1990 's that risk-based approaches became the international standard with the introduction of an agreement regarding the application of sanitary and phytosanitary measures (SPS Agreement) by the World Trade Organization (WTO). In this agreement, it was suggested for the first time that targets related to food safety should be based on science and in particular on an assessment of the risk to the population [7], and that this risk assessment should be quantitative where feasible [8]. Immediately after the launch of the SPS Agreement, the Codex Alimentarius Commission was called on to provide a framework with which adherence to these guidelines could be achieved. This led to the first report regarding the application of the risk analysis framework to food standards issues [9]. Many more documents have followed since, providing elaborate guidelines for the application of risk management and risk assessment by governments [10-13]. Also, the European Community made the setting of risk-based benchmarks legally binding by dictating in Regulation (EC) 178/2002 that legislation forced to ensure food safety should generally be founded on science using the risk analysis framework [4].

To make a risk-based approach of managing food safety operational, two new benchmarks can be set by governments on the basis of a quantitative risk assessment: the Appropriate 
Level of Protection (ALOP) and the Food Safety Objective (FSO) [7, 14]. The ALOP has been defined in the SPS agreement as "the level of protection deemed appropriate by the Member establishing a sanitary or phytosanitary measure to protect human, animal or plant life or health within its territory" [7]. In relation to food safety, this may be interpreted as the level of risk that is accepted by a country for a specific hazard in food. The FSO has been defined as "the maximum frequency and/or concentration of a hazard in food at the time of consumption that provides or contributes to the appropriate level of protection" [15] and is in essence the level of the hazard in food at consumption that is attuned to a given ALOP. Next to the FSO, Codex also defined two associated risk-based metrics, namely the Performance Objective (PO) and the Performance Criterion (PC) [15]. The PO is defined as "the maximum frequency and/or concentration of a hazard in food at a specified step in the food chain before the time of consumption that provides or contributes to an FSO or ALOP, as applicable. Unlike the ALOP and FSO that can only be set by governments, POs can also be set by the industry to achieve the established FSO and they can be viewed as targets for food safety managers controlling food supply chain operations [16]. Both the FSO and PO allow for considerable flexibility in the selection of appropriate control measures for individual steps in the food supply chain. The overall level of control that these control measures achieve is what Codex has termed the PC, which expresses the change in the hazard level that needs to be obtained to achieve a certain FSO or PO [15]. As understood from the above, the ALOP, FSO and their associated metrics are closely interconnected and provide a link between governmental public health policy and targets for industry managing hazards in the food chain with the potential to render food safety management transparent and quantifiable [17].

Although the advantages of the use of ALOP and FSO in managing food safety are clear, to this day no country applies the targets as such to inform national policy although some countries have established other specific targets in the food chain aiming at the reduction of their current disease burden. For instance, in Denmark several of these targets were established as part of a programme for the control of Salmonella in poultry and table eggs, initiated in 1996 [18]. Possible reasons for the ALOP and FSO targets on not being used as such could be that there is little guidance on how to establish them [19] and how to implement them in practice linked to each other $[20,21]$. Several documents have been drafted as the result of a joint expert consultation to provide guidance on the use of the metrics for specific pathogen/food combinations [22-25]. There is growing number of peerreviewed studies available discussing the practical implementation of the metrics using national data [26-29] or data for actual products in the market [20,30-34]. Most of these studies however deal with products that are ready-to-eat or partially cooked, involving little or no handling on the part of the consumer and only a few deal with raw products like meat $[28,29]$. The latter studies focus on POs, set either at the end of a processing 
operation [28] or at retail [29]. They do not consider the way the product is handled by consumers although this has been shown to substantially influence the risk of acquiring a foodborne disease [35]. Finally, despite the fact that the ALOP has originally been introduced as a means of solving trade disputes by comparing the level of risk that is accepted by different countries for the same type of product [7], the feasibility of international comparisons of ALOPs for pathogens between countries has not yet been investigated although it would be of considerable interest [21].

The goal of this study was to put the selection of the ALOP and FSO to the test for a specific country by investigating how values for these metrics can be derived from publicly available data, choosing the case of Salmonella in raw chicken meat in the Netherlands. Two different risk assessment strategies were followed to this end: an epidemiological approach having the current level of risk (current LOP) of the disease salmonellosis at country level as the starting point and a supply chain approach starting from data on the presence of the hazard (Salmonella) in the food product [36]. From this point onwards, the epidemiological approach will be referred to as the "top-down" approach, while the supply chain approach will be referred to as the "bottom-up" approach [26]. Also for the purpose of this study by "raw chicken meat" any type of raw chicken meat available at retail will be meant i.e. poultry carcasses, cuts (with or without skin), chicken fillets and uncooked preparations. Our specific objectives were to 1 ) investigate the selection of potential ALOP/FSO values regarding Salmonella in raw chicken meat on the basis of readily available national data following the two different approaches, 2) compare results obtained between the two approaches, 3) analyse the advantages and disadvantages of each approach, 4) examine the feasibility of comparing current LOP and FSO values for 23 member states of the European Union for the top-down approach and 5) identify important data gaps and provide recommendations to consider in future efforts to implement the metrics.

\section{Materials and methods}

\subsection{Bottom-up approach}

\subsubsection{Model description}

A "retail-to-table" stochastic risk assessment model [37] was built, starting with publicly available data on the concentration of Salmonella in raw chicken at the retail level in the Netherlands. This starting point was selected because data at retail level have been proposed to be more suitable for risk assessment purposes since they are more pertinent to the exposure of consumers to the pathogen via raw meat [38]. Furthermore, data from earlier points of the meat processing chain post-slaughter have been suggested not to be 
directly linked to the situation at retail due to cross-contamination and growth of Salmonella as a result of inadequate hygiene levels [39]. Events leading to the risk of consumers being exposed to the pathogen were considered to be: purchase and transport of a meat product home, storage at home, and preparation and consumption [37, 40-42]. A schematic representation of the different steps in the model is shown in Figure 1. A comprehensive overview of the inputs and outputs of the model is provided in Table 1 . The calculations underlying each individual step are discussed in the paragraphs below.

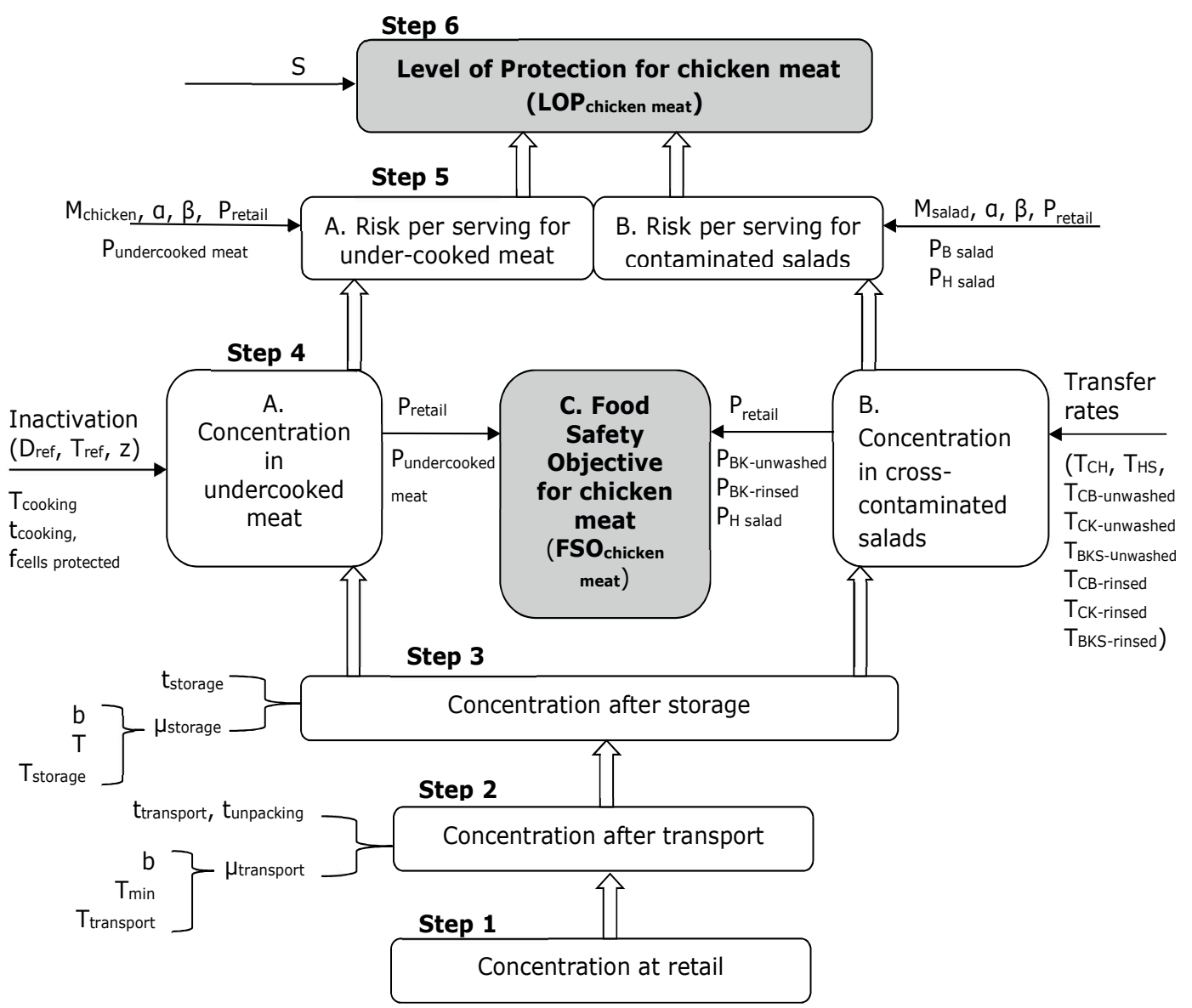

Figure 1. Outline of the estimation steps in the bottom-up approach model. The concentration of Salmonella at the retail level was the starting point for the estimation of the FSO and the current LOP. 


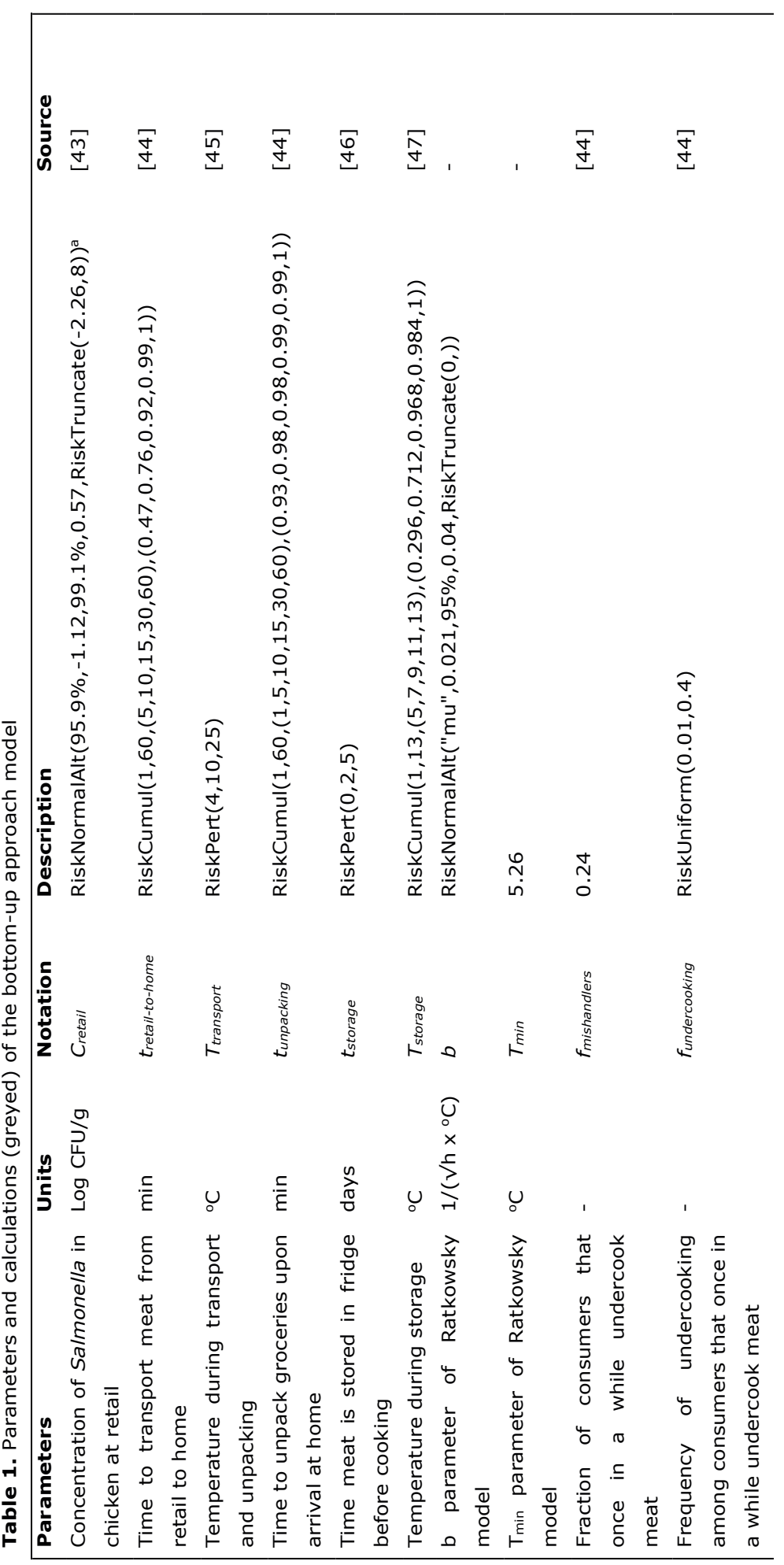




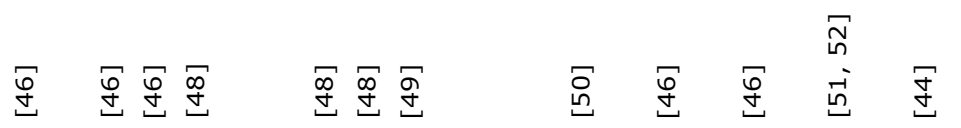
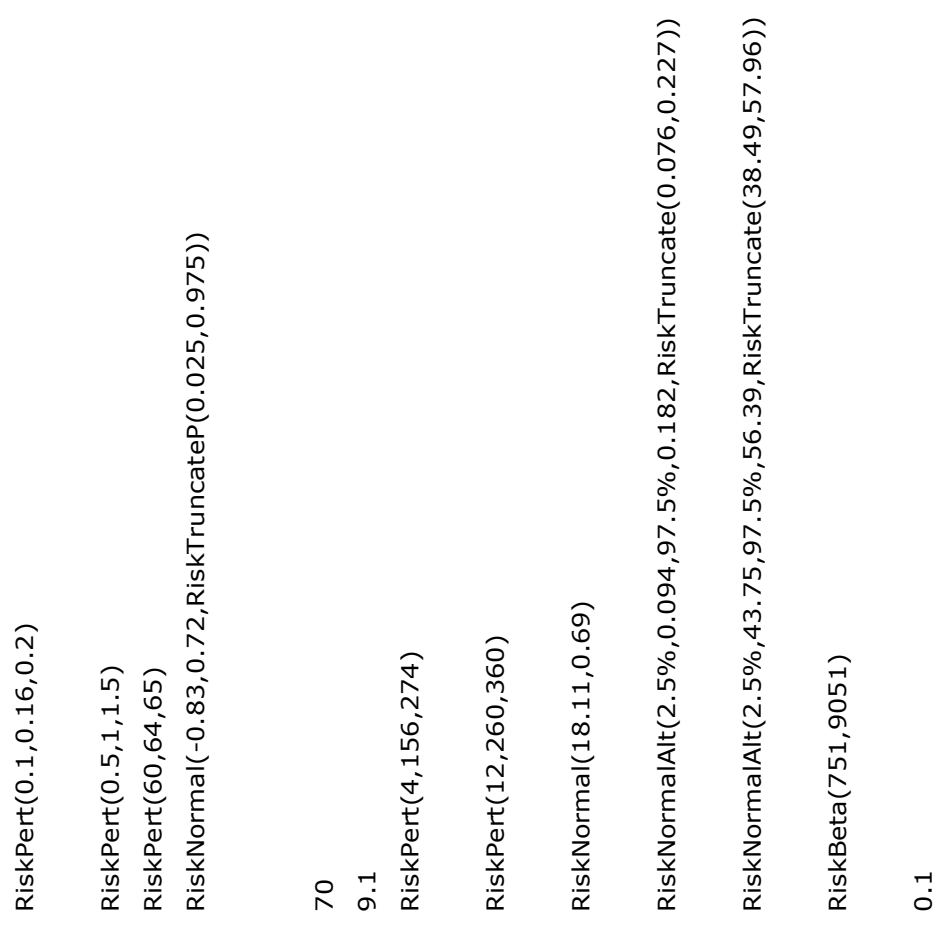

|

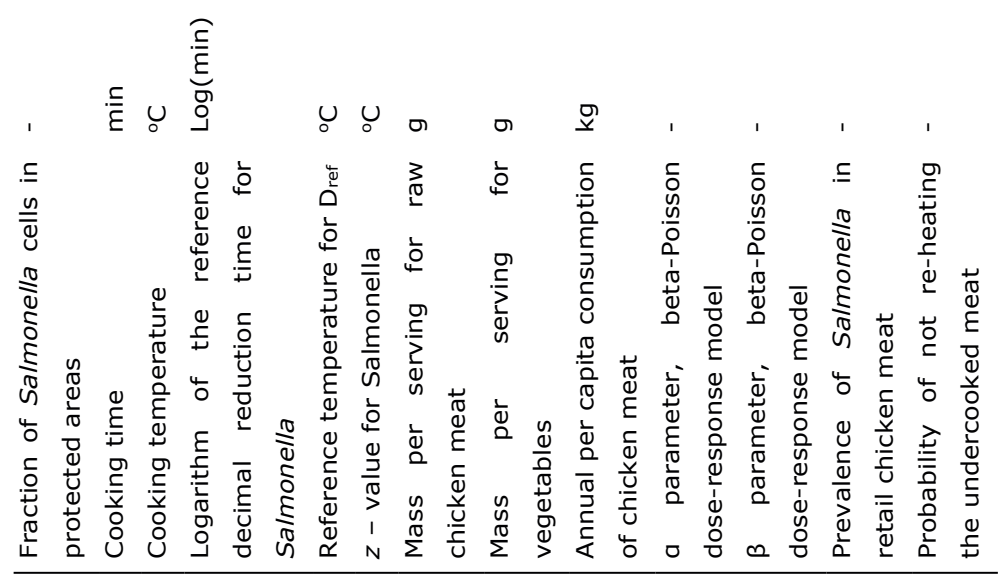




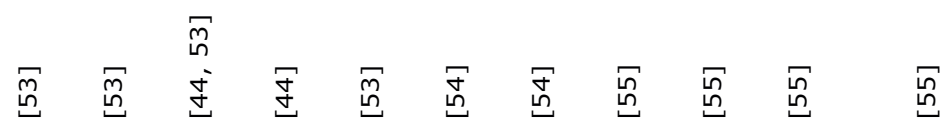
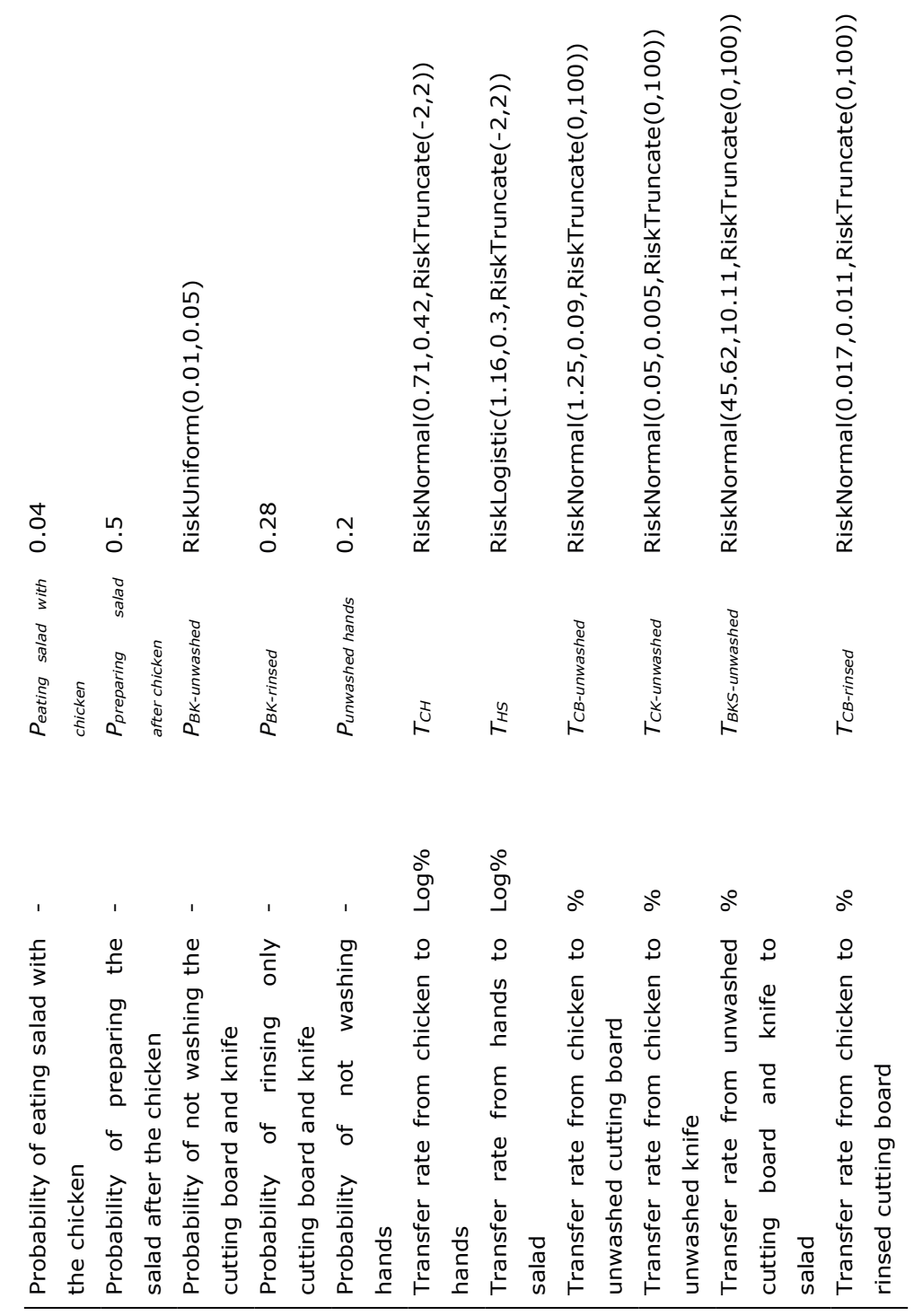


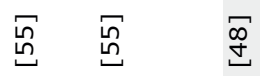

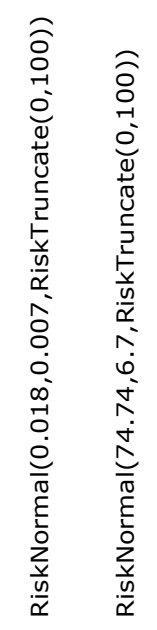

$$
\text { , }
$$

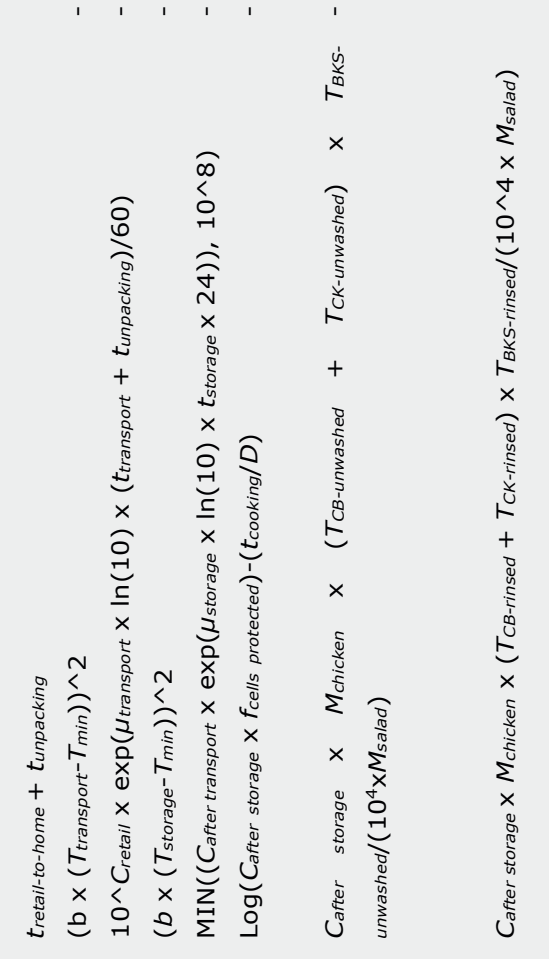

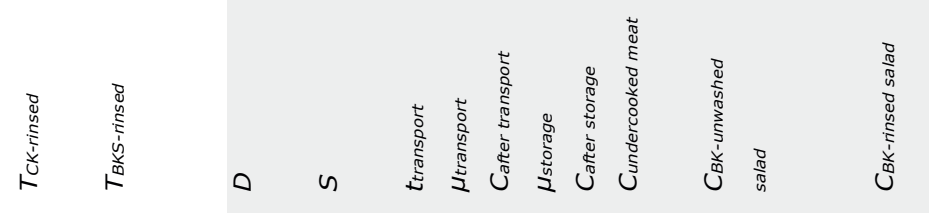

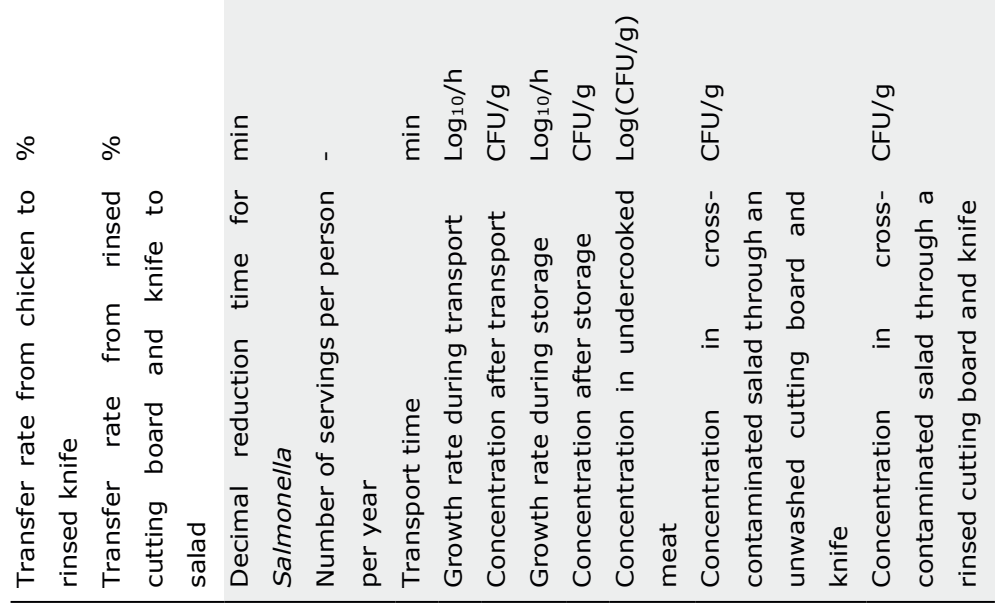




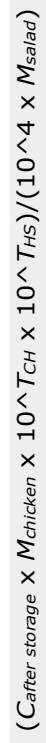
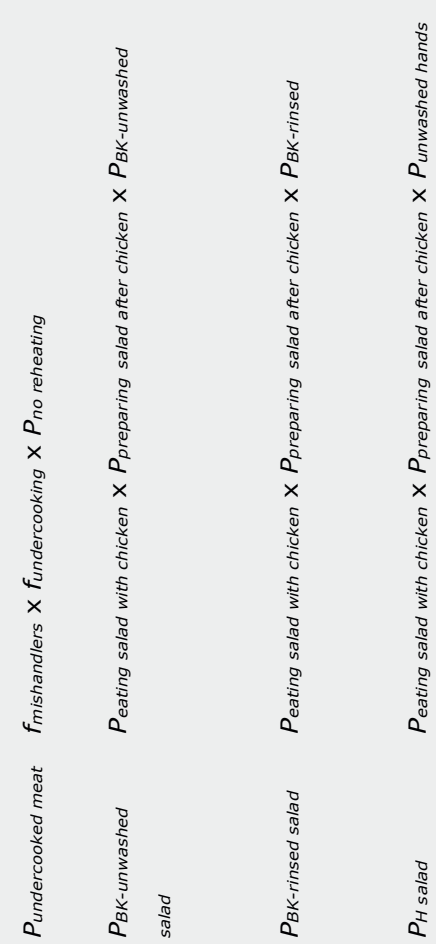

$\times$

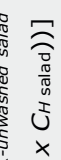

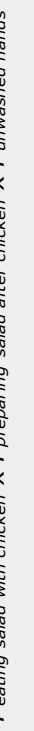

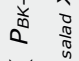

$+\frac{8}{2}$

है

离部

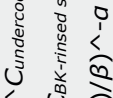

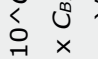

$\times$

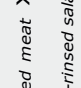

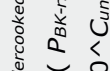

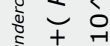

㲅

$\times$

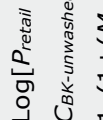

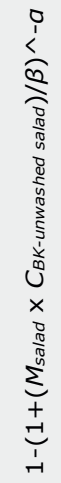

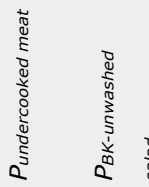

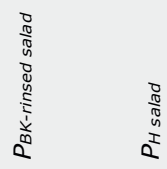

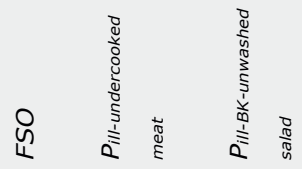

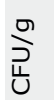

$\sum_{\text {Uे }}^{0}$

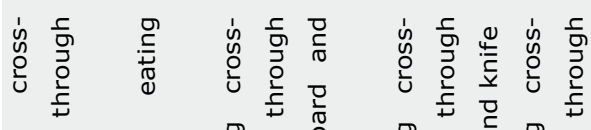

ㅇ.

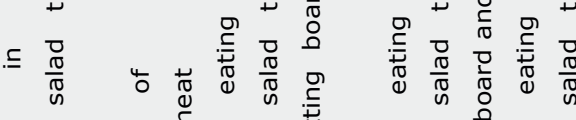

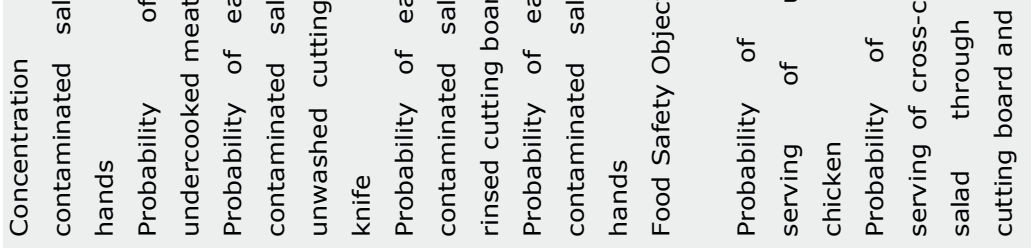




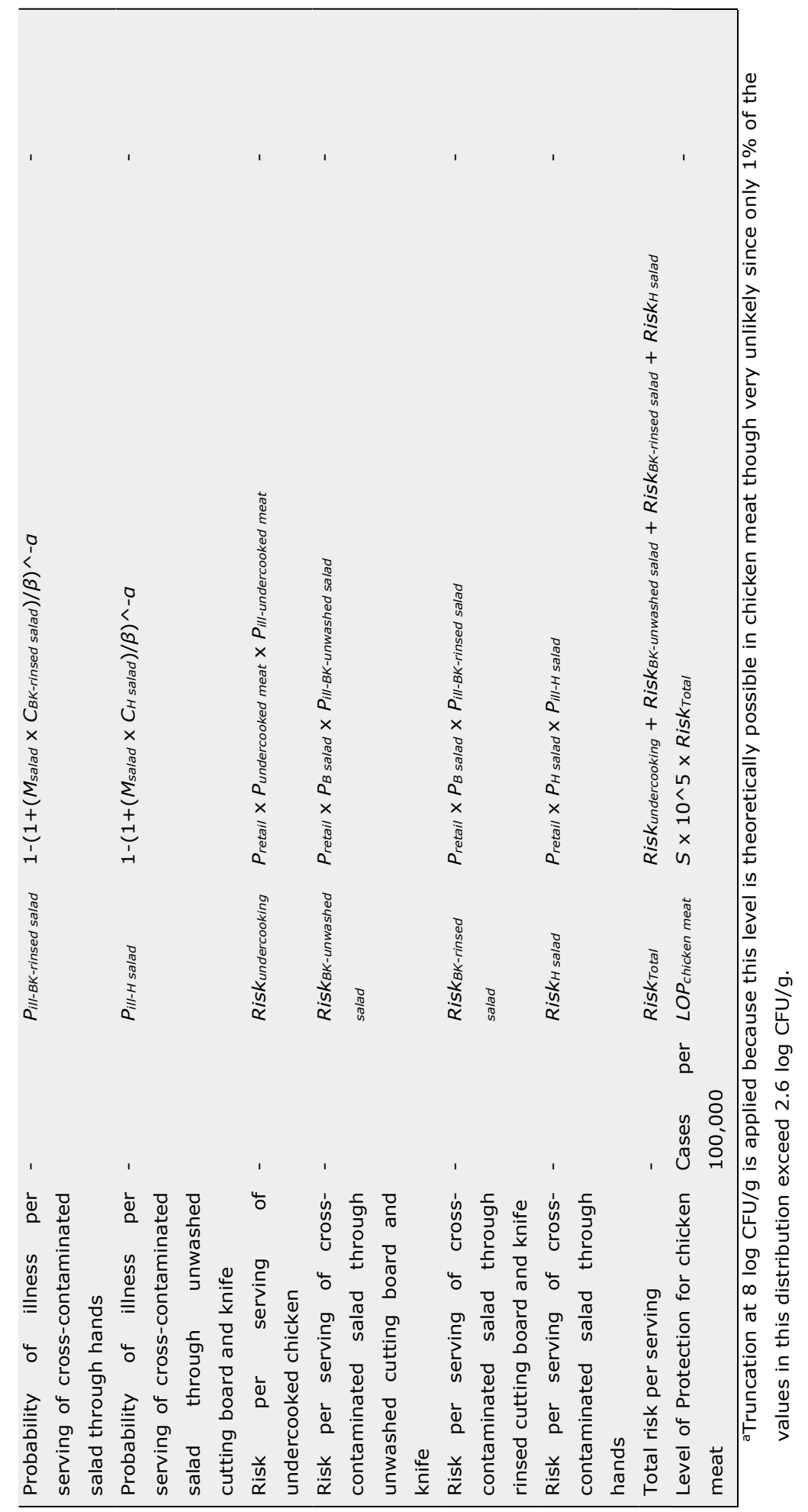


Step 1 - Concentration at retail ( $C_{\text {retail }}$ ). Risk was estimated on the basis of the concentration of Salmonella in contaminated portions of chicken meat at retail. Two relevant studies in the Netherlands could be retrieved with data on concentrations in positive samples: one involving chicken carcasses [56] and another involving chicken breast fillets [43]. Given the fact that contamination levels of Salmonella in chicken in the Netherlands have been declining since the first study was conducted as a result of the adaptation of control measures by the poultry industry $[43,57]$ only the data in Straver et al. (2007) were taken into consideration. Moreover, chicken carcasses represent a minor fraction of total household consumption (4.5\%) within the country in comparison with chicken breasts fillets that represent approximately $48 \%$ followed by various chicken parts ( $28.5 \%$ ) and chicken legs ( 19\%) (Richard Hol, personal communication). In the study by Straver et al. (2007) 220 chicken fillets were sampled at the Dutch retail market (representative share of supermarkets and butchers) in the period from October to December 2005 and tested as a whole for the prevalence and concentration of Salmonella. Levels of the pathogen in positive samples ranged between 1 and $3.81 \log$ MPN/fillet and were converted into log CFU/g on the basis of the average weight of fillets for use in this risk assessment and were assumed to be representative of all types of raw chicken meat. These concentration data for positive samples were used as part of a normal distribution to describe contaminated servings using the function RiskNormalAlt, which allows a normal distribution to be built based on percentile values. To avoid illogical values, the distribution was truncated at the physically possible minimum $(-2.26 \log \mathrm{CFU} / \mathrm{g})$ and maximum concentration (8 log $\mathrm{CFU} / \mathrm{g}$ ) in positive fillets.

Step 2 - Concentration after transport ( $C_{\text {after transport }}$ ). The concentration of the previous step was considered to be representative of samples stored already at retail temperatures. To estimate the concentration of Salmonella after transport, i.e. at the moment the meat product enters the refrigerator of the consumer, a simple exponential growth model without lag was used [58]. The time of transport ( $t_{\text {transport }}$ ) was considered to be the sum

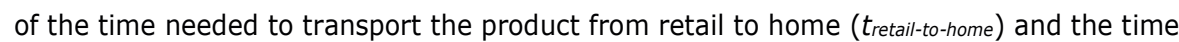
needed to unpack groceries (tunpacking) expressed as distributions on the basis of variation in consumer behaviour presented in a study regarding hygiene in households in the Netherlands [44]. Because this study is not available in English, a translation of the most important data used in this risk assessment is presented in Technical Appendix A. No pertinent Dutch data regarding transport temperature could be found and British data were used assuming that they were representative for the situation in the Netherlands as in other risk assessments for this country [45] while the meat was assumed to reach immediately environmental temperature. The growth rate $(\mu)$ for Salmonella was estimated by performing a meta-analysis of peer-reviewed publications as described by 
den Besten and Zwietering [59]. ComBase [60] was used as the source of publications regarding the growth rate of Salmonella spp. in raw poultry (meat and/or skin), assuming that this source captured the available literature well, by applying the following filtering criteria: $2-46^{\circ} \mathrm{C}$ for the temperature range that allows growth $[61,62], 5.0-8.0$ for the $\mathrm{pH}$ (rounding the range 5.7-7.2 published for poultry [63]) and 0.9-1.0 for the water activity. Studies involving antimicrobial compounds and studies involving irradiated, dried or smoked chicken $m$ were excluded since our study dealt with unprocessed raw chicken meat only. Products with added fat or salt were taken into consideration since these might be relevant. These filtering criteria resulted in a total of eight traceable publications [64-71]. Where possible, $\mu$ values were collected directly from the retrieved publications, otherwise datasets from ComBase in which total growth greater than 0.5 log CFU was observed were used to estimate growth rates using DMFit on the basis of the lowest SE of fit [60]. Overall, 61 maximum growth rate records $\left(\log _{10} / \mathrm{h}\right)$ for various temperatures were obtained. To this dataset, the simple square root model of Ratkowsky [72] was fitted [59], using the solver add-in of Microsoft $\circledast$ Excel 2010 after a $\log _{10}$-transformation of the data to improve the stabilization of the variance over the entire temperature range [59]. The estimated $b$ and $T_{\min }$ parameters of the model describing the mean growth rate of all data as a function of temperature were 0.021 and $5.26^{\circ} \mathrm{C}$ respectively (Table 1 ). In order to express strain variability, $\mathrm{b}$ was considered to be represented by a normal distribution whose confidence interval is estimated on the basis of the $95 \%$ confidence interval surrounding the mean growth rate. The predicted $T_{\min }$ was in line with the minimum temperature for growth mentioned by ICMSF for Salmonella $\left(5.2^{\circ} \mathrm{C}\right)$ [62] however in none of studies we used was growth observed at temperatures lower than $9^{\circ} \mathrm{C}$ for raw chicken meat (Technical Appendix B). Although these values then show potential growth at $7^{\circ} \mathrm{C}$, it should be realised that these parameters would result in a generation time of 22 days at $7^{\circ} \mathrm{C}$, meaning that practically no growth would be observed.

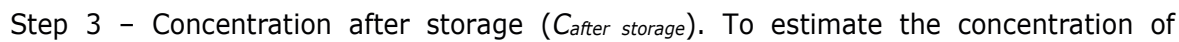
Salmonella after storage of the product by the consumer the same growth model as in the previous step was used. No quantitative data could be found for the storage time of different chicken meat products in the Netherlands, but it was assumed that this parameter can be described by a Pert distribution with a most likely value of 2 , a minimum value of 0 and a maximum value of 5 days as used in the FAO/WHO risk assessment on Salmonella in broiler chickens [46]. The range from this distribution is in agreement with qualitative results of a Dutch study in which it is mentioned that the majority of consumers store meat for a few days at most [73] and in the absence of other data regarding this parameter has been used in another risk assessment for chicken fillets in the Netherlands [43]. Realistic storage temperatures were based on data for the Netherlands [47] $(n=125)$ regarding the 
frequency of different temperature ranges in household refrigerators and used in the form of a cumulative distribution truncated at 1 and $13^{\circ} \mathrm{C}$ (maximum temperature found).

Step 4 - Preparation and consumption of chicken meat. During the preparation of chicken meat by the consumer, exposure to Salmonella is possible through either undercooking or cross-contamination to another food that is to be consumed raw (typically a salad). Both of these pathways have been taken into consideration and modelled separately as discussed below (step 4A and B) (Technical Appendix C). Since this step is the final stage prior to consumption, the FSO is derived at this point as discussed in step $4 \mathrm{C}$.

$4 \mathrm{~A}$ - Concentration in undercooked meat ( $\left.C_{\text {undercooked meat }}\right)$. The incomplete inactivation of Salmonella as the consequence of undercooking was modelled using a linear primary model without lag [74], $\log C=\log C_{0}-t / D$, where $C$ is the concentration (in CFU/g) after a cooking time $t$ (in $\mathrm{min}$ ), $C_{0}$ is the concentration (CFU/g) at time $t=0$ (start of cooking) and $D$ is the decimal reduction time (in $\mathrm{min}$ ). As in other risk assessments, it was assumed that a fraction of Salmonella in meat has the potential to survive the cooking process [37, 41, 46]. Thus, the concentration of Salmonella at the start of cooking was considered to be equal to the concentration after storage multiplied with the percentage of cells in protected areas that have the potential to survive the cooking process estimated elsewhere [46]. To cover for the variability in heat resistance between different Salmonella strains as well as the impact of different cooking temperatures and times, a distribution was assigned to the cooking temperature and time [46]. The $D$-value was modelled as a function of temperature on the basis of the logarithm of a reference $D$-value at $70^{\circ} \mathrm{C}\left(D_{\text {ref }}\right)$ (mean $-0.83, \mathrm{SD} 0.72)$ and a $z$-value $\left(9.1^{\circ} \mathrm{C}\right)$ obtained through meta-analysis of existing thermal inactivation data $(n=1141)$ for this pathogen in different products and at different temperatures [48].

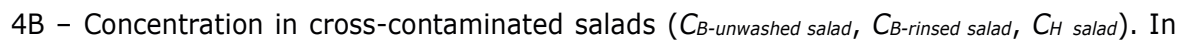
our study, we considered cross-contamination from chicken meat to raw salad being consumed in the same meal. Unwashed hands of persons handling raw meat and improper cleaning of cutting boards/utensils have been suggested to be the most important crosscontamination routes for chicken fillets [75] and these two contamination routes were assumed here to be the only events leading to Salmonella being present in the raw salad. The events were considered to be independent and thus modelled separately, taking into account the transfer rates of bacteria from one surface to the other and the frequencies of different kinds of unhygienic behaviour during food preparation [44, 76]. The concentrations of Salmonella in cross-contaminated salads through a cutting board and knife that were not washed after cutting meat ( $C_{B K}$-unwashed salad in $\mathrm{CFU} / \mathrm{g}$ ) or through a cutting board and knife only rinsed with water after cutting meat ( $C_{B K \text {-rinsed salad in }} \mathrm{CFU} / \mathrm{g}$ ), were estimated as: 
$C_{B K \text {-unwashed salad }}=C_{\text {after storage }} \times M_{\text {chicken }} \times\left(T_{C B \text {-unwashed }}+T_{C K \text {-unwashed }}\right) \times T_{B K S \text {-unwashed }} /\left(10^{4} \times M_{\text {salad }}\right)$

$C_{B K-\text { rinsed salad }}=C_{\text {after storage }} \times M_{\text {chicken }} \times\left(T_{C B \text {-rinsed }}+T_{C K \text {-rinsed }}\right) \times T_{B K S-\text {-rinsed }} /\left(10^{4} \times M_{\text {salad }}\right)$

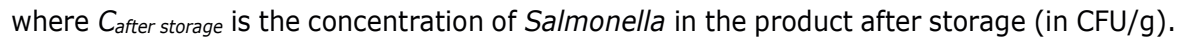
$M_{\text {chicken }}$ and $M_{\text {salad }}$ are the mass (in grams) of raw chicken and salad, respectively, based on ranges of the amount of these specific food items estimated to be consumed in a day in the Netherlands [77]. The following transfer rates of bacteria (\%) were obtained from Ravishankar et al. (2010): TCB-unwashed being the transfer rate from chicken to a cutting board when it is unwashed after its use, $T_{C K \text {-unwashed }}$ being the transfer rate from chicken to

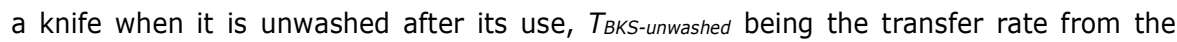
unwashed cutting board and knife to the salad, $T_{C B-\text { rinsed }}$ being the transfer rate from the chicken to a cutting board when it is only rinsed with water, $T_{C K \text {-rinsed }}$ being the transfer rate from the chicken to a knife when it is only rinsed with water, $T_{B K S \text {-rinsed }}$ being the transfer rate from the rinsed cutting board and knife to the salad.

Similarly, the concentration of Salmonella in cross-contaminated salad through the hands of the food handler ( $C_{H}$ salad in $\mathrm{CFU} / \mathrm{g}$ ) was estimated as:

$C_{H \text { salad }}=\left(C_{\text {after storage }} \times M_{\text {chicken }} \times 10^{\wedge} T_{C H} \times 10^{\wedge} T_{H S}\right) /\left(10^{4} \times M_{\text {salad }}\right)$

where $T_{C H}$ is the log transfer rate of bacteria from the chicken to the hands ( $\left.\log \%\right)$ and $T_{C H}$ is the log transfer rate of bacteria from the hands to the salad (Log\%) according to Montville et al. (2001).

$4 C$ - Food Safety Objective for chicken meat (FSO chicken meat). Based on its definition, an FSO may incorporate both the concentration and the frequency of the hazard at the point of consumption [15]. For the case at hand, four different concentrations of Salmonella at the point of consumption would contribute to the FSO (undercooked chicken, crosscontaminated salads by unwashed hands, unwashed cutting board or rinsed cutting board) $(4 A, B)$, each having a different frequency of occurrence. These frequencies would in turn be characterized by the prevalence of Salmonella in raw chicken meat at retail $\left(P_{\text {retail }}\right)$ and with the probability of each distinct concentration level occurring. Thus to include both concentration and frequency in the FSO as its definition suggests, it was here estimated in log CFU per $g$ as the summation of the product of the two across the four different types of contaminated servings:

\footnotetext{
$F S O_{\text {chicken meat }}=\log \left[P_{\text {retail }} \times\left(\left(P_{\text {undercooked meat }} \times 10^{\wedge} C_{\text {undercooked meat }}\right)+\left(P_{B K-\text { unwashed }} \times C_{B K \text {-unwashed }}\right.\right.\right.$

salad $)+\left(P_{B K-\text { rinsed }} \times C_{B K-\text {-rinsed salad }}\right)+\left(P_{H \text { salad }} \times C_{H}\right.$ salad $\left.)\right]$ 


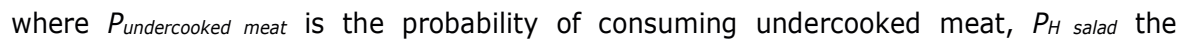
probability of consuming salad cross-contaminated through handling, $P_{B K \text {-unwashed salad }}$ the probability of consuming a salad cross-contaminated through an unwashed cutting board

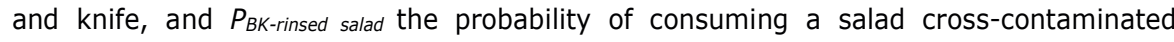
through a board and knife that were only rinsed with water. Regarding Pretail, because the prevalence found in the study by Straver et al. (2007) was characterised by considerable variability (mean $8.6 \%, 90 \% \mathrm{CI}: 5.7-12 \%$ ) as a result of the relatively small number of samples tested (despite the greater level of detail for concentration data that the larger sample size allowed) prevalence data from RIVM on the basis of presence absence tests in $25 \mathrm{~g}$ of retail chicken meat samples for the period 2004-2010 were used instead (mean: $7.7 \%, 90 \% \mathrm{CI}: 7.2-8.1 \%$ ) $[51,52]$.

The probability of consuming undercooked meat was estimated by taking into account data on the behaviour of Dutch consumers [44] as follows:

Pundercooked meat $=f_{\text {mishandlers }} \times f_{\text {undercooking }} \times P_{\text {no reheating }}$

where $f_{\text {mishandlers }}$ is the fraction of consumers that acknowledges that their meat can be undercooked once in a while, $f_{\text {undercooking }}$ is the estimated frequency of undercooking among these consumers and $P_{\text {no reheating }}$ is the percentage of consumers that decide to eat the undercooked meat without a reheating step. Notably, the frequency of undercooking, depends on the interpretation of the Dutch frequency adverb "wel eens" that expresses a frequency lower than the English adverb sometimes [78] and may range between 1-40\% [79]

The probabilities of consuming salads cross-contaminated via different routes $\left(P_{H}\right.$ salad, $P_{B K}$ -

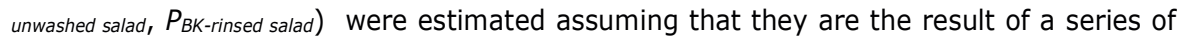
independent events:

$P_{H \text { salad }}=P_{\text {eating salad with chicken }} \times P_{\text {preparing salad after chicken }} \times P_{\text {unwashed hands }}$

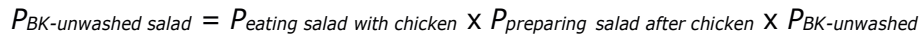

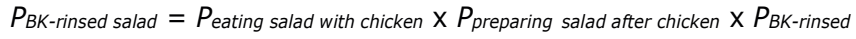

where:

Peating salad with chicken is the probability of consuming salad and chicken in the same meal, estimated by dividing the total number of servings of chicken fillet with salad reported for 2000 [53] with the total number of chicken meat servings in the Netherlands for the same year, estimated in turn by multiplying the per capita consumption of chicken meat [80] with the population for this year [81] and dividing the resulting quotient with the mean 
mass per serving of chicken meat [53]. The resulting estimate was similar to estimates regarding the mean probability of eating a raw item with a chicken meal in Belgium [40].

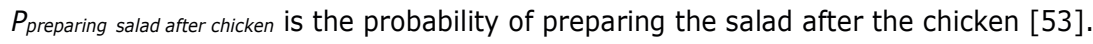

$P_{B K \text {-unwashed }}$ is the probability of using the same cutting board and knife with which meat was handled to cut vegetables. This was assumed to be the same probability as that of using an unwashed cutting board, which is in the range of 0.01-0.05 based on Dutch studies $[44,53]$ and which was represented in the model by a Uniform distribution.

$\mathrm{P}_{\mathrm{BK} \text {-rinsed }}$ is the probability of using the same cutting board and knife with which meat was handled after rinsing only with water to cut vegetables for a salad. This was represented here by the probability of using a cutting board that has only been rinsed with water, which is 0.28 [44].

Punwashed hands is the frequency of not washing hands after handling meat [53].

Step 5 - Risk per serving of undercooked meat and cross-contaminated salad. The risk of salmonellosis per serving was estimated with the beta-Poisson model used in the FAO/WHO risk assessment of Salmonella in chicken products [46]. In this model, based on outbreak data, the probability of illness $\left(P_{\text {ill }}\right)$ is estimated using the equation:

$P_{i l l}=1-\left[1+\frac{D}{\beta}\right]^{-a}$

where $D$ is the dose of Salmonella consumed (in CFU), calculated by multiplying the mass per serving of food product ( $M$, in g) [49] with the concentration of Salmonella at the point of consumption ( $C$ consumption, in CFU per $\mathrm{g}$ ), and $a, \beta$ are parameters of the model. The output of the model is defined as "acute gastroenteritis", meaning a self-limiting gastrointestinal illness lasting 2-7 days that is characterized by diarrhoea, fever, abdominal cramps, and dehydration. The risk per serving of undercooked meat or cross-contaminated salad was assessed separately (5A and $5 B$ ).

$5 \mathrm{~A}$ - Risk per serving of undercooked meat (Riskundercooking). The risk of salmonellosis per serving of undercooked chicken was estimated as follows:

Riskundercooking $=P_{\text {retail }} \times P_{\text {undercooked meat }} \times P_{\text {ill-undercooked meat }}$

where $P_{\text {retail }}$ is the prevalence of Salmonella in raw chicken meat at retail, $P_{\text {undercooked meat }}$ the possibility of eating undercooked meat (Eq. 5) and $P_{\text {ill-undercooked meat }}$ the probability of illness 
estimated through equation 9 based on the concentration of Salmonella in undercooked meat.

5B - Risk per serving of cross-contaminated salad (RiskH salad, RiskBK-unwashed salad, Risk $k_{B K \text {-rinsed }}$ salad). The risk of salmonellosis per serving of cross-contaminated salad through the hands (Risk $\left.\mathrm{H}_{\mathrm{salad}}\right)$ or via the cutting board and knife (Risk salad) was separately estimated using the following equations:

Risk $_{H \text { salad }}=P_{\text {retail }} \times P_{H \text { salad }} \times P_{\text {ill-H salad }}$

Risk $B K$-unwashed salad $=P_{\text {retail }} \times P_{B K}$-unwashed salad $\times P_{\text {ill-BK-unwashed salad }}$

Risk $_{B K-\text {-rinsed salad }}=P_{\text {retail }} \times P_{B K-\text {-rinsed salad }} \times P_{\text {ill-BK-rinsed salad }}$

where $P_{B K \text {-unwashed salad, }} P_{B K \text {-rinsed salad }}$ and $P_{H}$ salad are estimated as described in equations 6 to

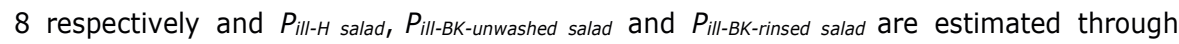
equation 9 based on the concentration of Salmonella in cross-contaminated salad by hands, unwashed board and knife, and rinsed board and knife, respectively.

Step 6 - Level of Protection for chicken meat ( $\left.L O P_{\text {chicken }}\right)$. The LOP for chicken meat was considered to be the product of the number of servings per 100,000 people with the total risk per serving (RiskTotal):

$L O P_{\text {chicken }}=\mathrm{S} \times 10^{5} \times$ Risk $\mathrm{Total}$

where RiskTotal is the sum of all risks per serving due to undercooking and crosscontamination and $S$ is the number of servings of chicken meat per person per year calculated by dividing the per capita consumption ( $\mathrm{kg}$ per person per year) after a correction of the data to include only the edible parts of the animals which is about $50 \%$ of the carcass (Richard Hol, personal communication) with the mass per serving [49].

\subsection{Top-down approach}

\subsubsection{Model description}

The starting point of this model was epidemiological data on the burden of salmonellosis in the Netherlands considering that the current level of public health protection (LOP) in a country has been suggested by some to be representative of an ALOP [82] though some countries may find this level of protection to be unacceptable and may wish to reduce it 
[83]. A schematic representation of the different steps in the model established to derive the metrics specifically relating to Salmonella in raw chicken meat is shown in Figure 2, while a comprehensive overview of the inputs and outputs of the model is provided in Table 2. Detailed descriptions of each individual step follow below.

Step 1 - Reported cases 100,000 inhabitants $(R C)$. National data on the number of reported laboratory confirmed cases of salmonellosis for the period 2004-2010 [51, 52] were expressed per 100,000 inhabitants on the basis of official population statistics [81].

Step 2 - Total cases per 100,000 inhabitants (LOP). Reported cases of salmonellosis represent only part of the actual burden of the specific illness in the population since the majority of cases are self-limiting and do not result in a visit to a physician [84]. To estimate the total number of cases of salmonellosis within the population, a correction was performed for underreporting on the basis of a recent study for the period 2005-2009 [85] where the Netherlands was the reference country for estimating this parameter.

Step 3 - Total foodborne cases per 100,000 inhabitants ( $L O P_{\text {food }}$ ). Based on a recent study for the Netherlands, Salmonella is almost exclusively transmitted via food [86] and the majority of salmonellosis cases is regarded as foodborne [87]. The actual fraction of cases attributable to food was considered to have a most likely value of 0.95 that fits the description of the RIVM study similar to Mead et al. (1999) and a range of 0.87-1.0 based on what is known from international studies [88-91].

Step 4 - Total cases per 100,000 inhabitants due to chicken meat ( $\left.L O P_{\text {chicken }}\right)$. To estimate the fraction of the cases that can be attributed to chicken meat, country specific data regarding the attribution of cases to broilers were used covering the period 2005-2010 (van Pelt, personal communication related to published data [51]). The data were available in the form of mean annual estimates for this parameter accompanied by a $95 \% \mathrm{CI}$ (from the $2.5^{\text {th }}$ to the $97.5^{\text {th }}$ percentile). The mean and standard deviation expressing the variation of the percentiles were used to build normal distributions which in turn were used to define a normal distribution to describe source attribution to broilers. This distribution was simulated separately under the same @RISK settings as the bottom-up model (see section 2.4.). Results from these simulations were best fitted with a loglogistic distribution and this distribution was therefore used in our estimates. 


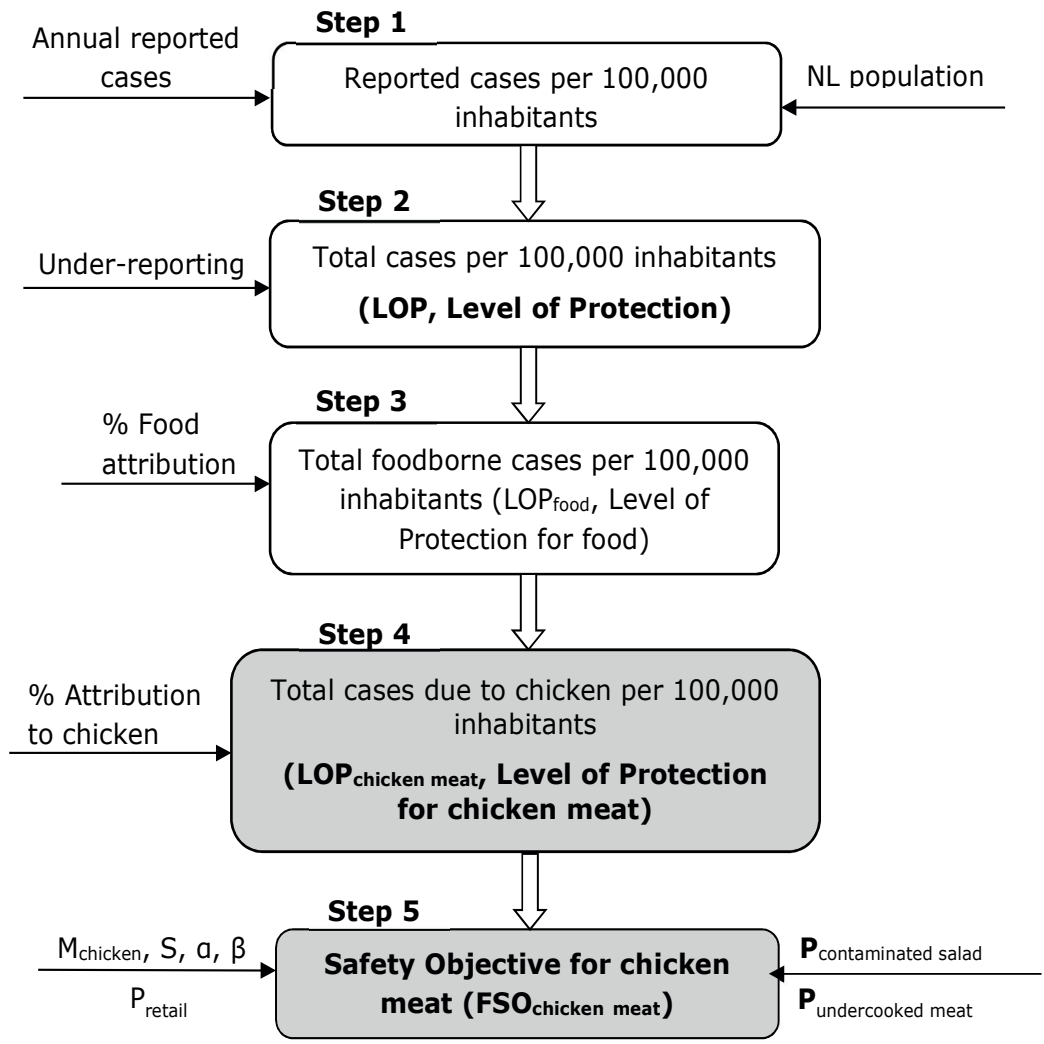

Figure 2. Outline of the estimation steps in the top-down approach model. Epidemiological data in the form of reported cases of salmonellosis in the Netherlands were the starting point for the estimation of the current LOP and the FSO.

Step 5 - Food Safety Objective for chicken meat ( $F S O_{\text {chicken meat }}$ ). Similarly to the bottomup approach, the beta-Poisson model of the FAO/WHO risk assessment [46] was used to connect the cases of salmonellosis due to chicken meat with the concentration of the pathogen at the point of consumption as follows:

$A L O P_{\text {chicken meat }}=S \times 10^{5} \times P_{\text {retail }} \times\left(P_{\text {undercooking }}+P_{\text {contaminated salad }}\right) \times P_{\text {ill }}$

where $P_{\text {contaminated salad }}=P_{B K \text {-unwashed }}+P_{B K \text {-rinsed }}+P_{H \text { salad }}$

Taking into account equation 9 and solving for the concentration at consumption, equation 15 becomes:

$C_{\text {consumption }}=\frac{\beta}{M} \cdot\left[10 \frac{\log \left[1-\left(\frac{L O P_{\text {chicken meat }}}{S \cdot 10^{5} \cdot P_{\text {retail }}\left(P_{\text {undercooking }}+P_{\text {contaminated salad }}\right)}\right)\right]}{-a}-1\right]$ 


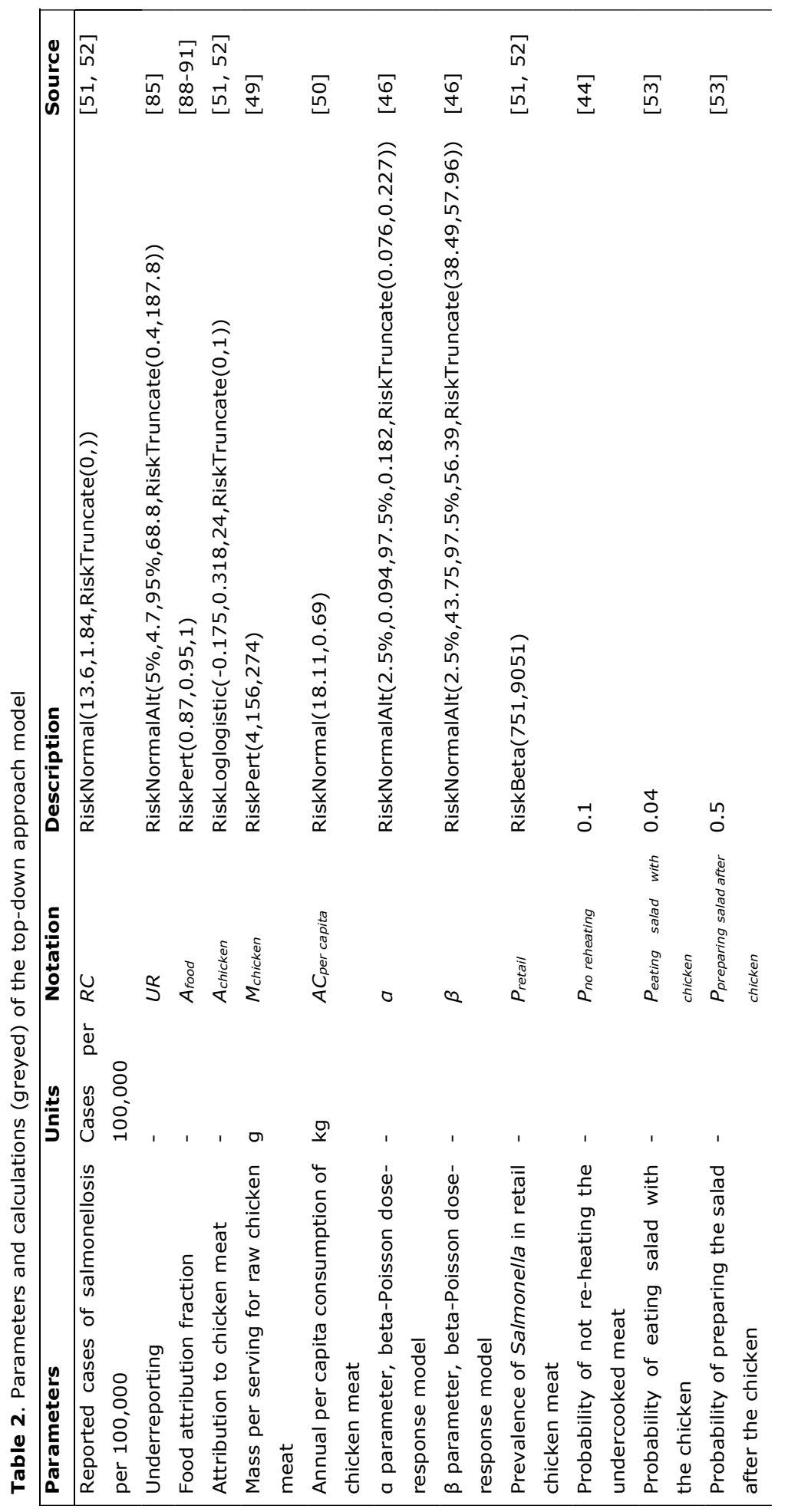



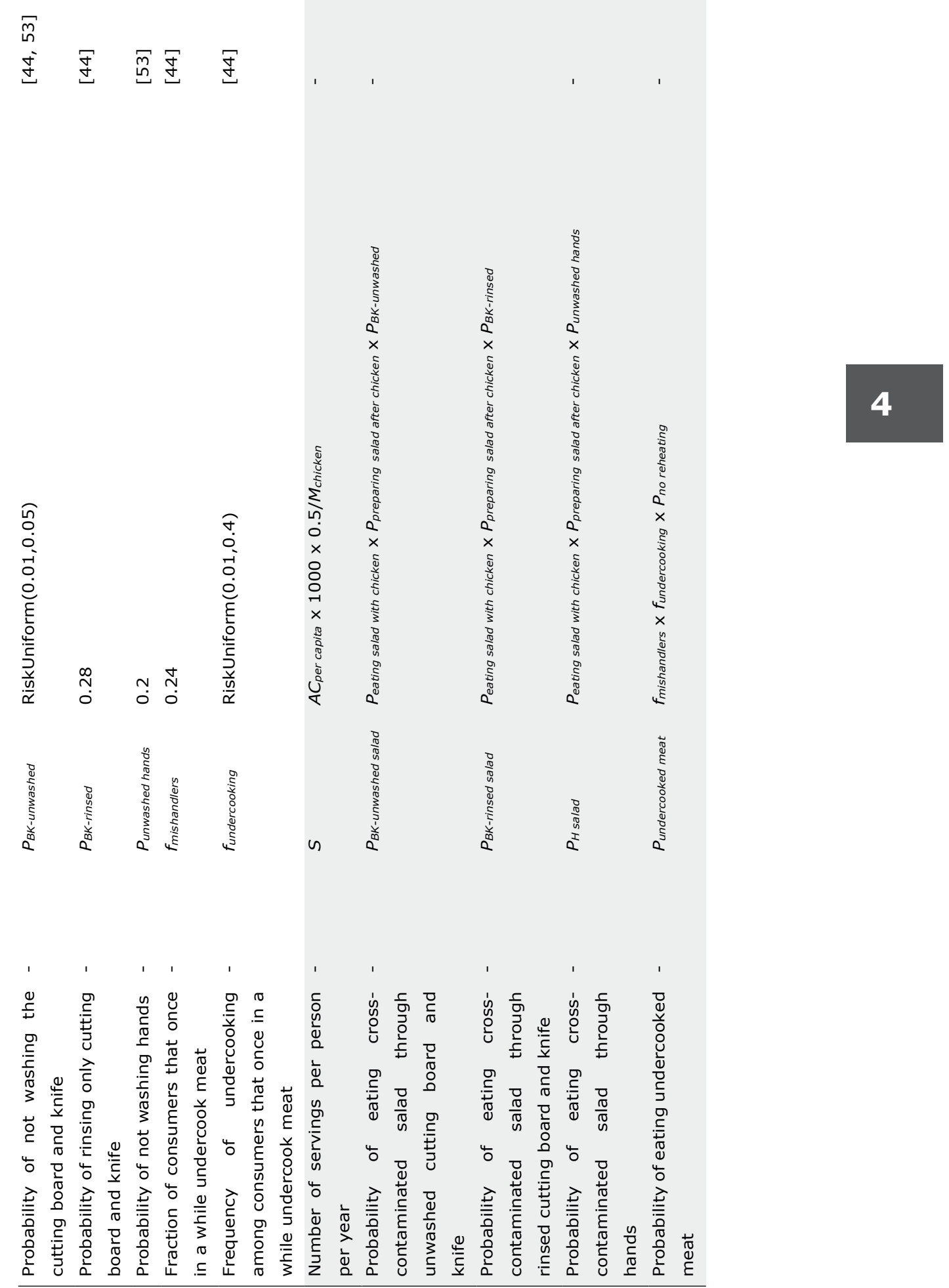


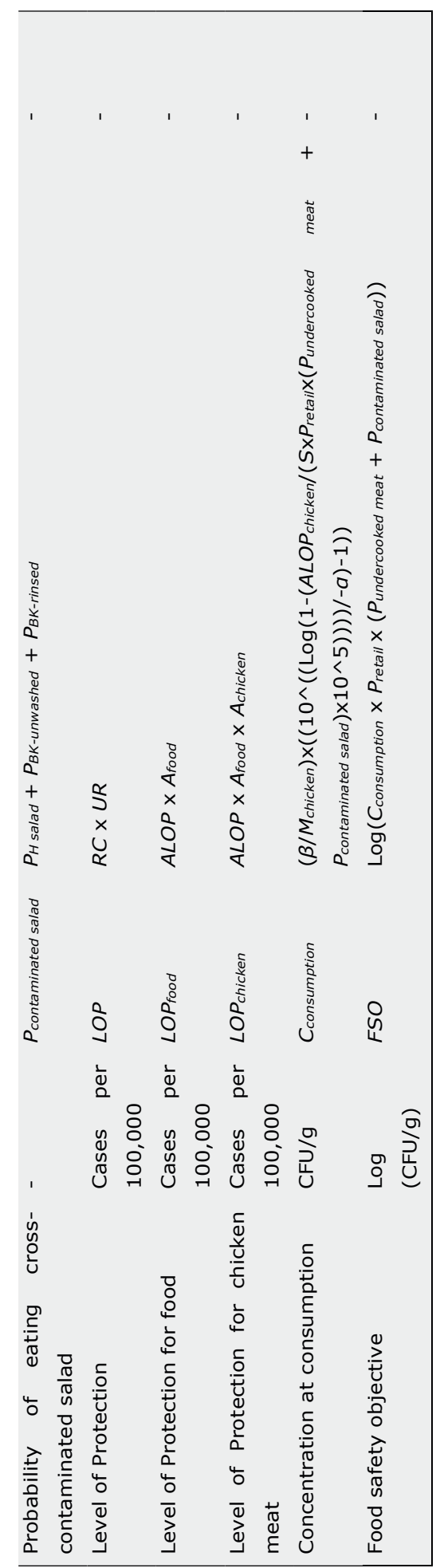


Similar to step 4C of the bottom-up approach where the FSO is set considering both the concentration of the hazard at consumption and its frequency, which, in turn is defined by the prevalence of Salmonella and probability of events leading to exposure (undercooking and cross-contamination of salads), the FSO is here estimated as:

FSO $O_{\text {chicken meat }}=\log \left[C_{\text {consumption }} \times P_{\text {retail }} \times\left(P_{\text {undercooked meat }}+P_{\text {contaminated salad }}\right)\right]$

2.3. International comparisons of LOPs using the top-down approach. The suitability of the top-down approach model for comparisons of LOPs for salmonellosis specifically attributed to chicken meat between 23 different EU countries was investigated using generic data. To this end, salmonellosis incidence data reported in the annual zoonoses reports of the EU were used [92-98] as well as European studies regarding underreporting [85] and source attribution factors based on microbial subtyping [99]. Considering that cases of salmonellosis are regarded to be mainly foodborne [88-91, 100, 101], in all estimations the input distribution for foodborne transmission used in step 3 of the Dutch top-down model was used for all 23 countries, assuming that this represents well the range for this parameter in these EU countries. An overview of the generic input data used for different European countries with the top-down approach can be found in Table 3. To evaluate the impact of using the country specific data for the Netherlands selected in our study rather than the generic data reported at the EU level for the Netherlands to estimate current LOP values, estimates produced with both types of datasets were compared.

2.4. Software and simulation settings. Models were built in Microsoft Excel 2010 (Microsoft, Redmond, WA, USA) using the add-in @RISK 5.7 (Palisade Corporation, Ithaca NY). For every model one simulation of 100,000 iterations was performed using Latin Hypercube sampling in combination with a Mersenne twister random number generator. A fixed seed value of 1 was selected so that the impact of alternative input parameters could be tested while avoiding changes in the outputs that are due to the effect of random sampling, but also to allow the exact reproduction of our results by others provided that the same spreadsheets are used [102]. Copies of the spreadsheets containing the models are available from the authors upon request.

\section{Results and Discussion}

3.1. Estimated LOP values for salmonellosis due to chicken meat in the Netherlands.

The mean estimated ALOP for salmonellosis due to chicken meat in the Netherlands was found to be 71 cases per 100,000 people per year (95\% CI: 9.9-155, SD 38) deploying the top-down approach model and 87 cases per 100,000 people per year (95\% CI: $0.03-$ 904, SD 412) with the bottom-up approach model. 


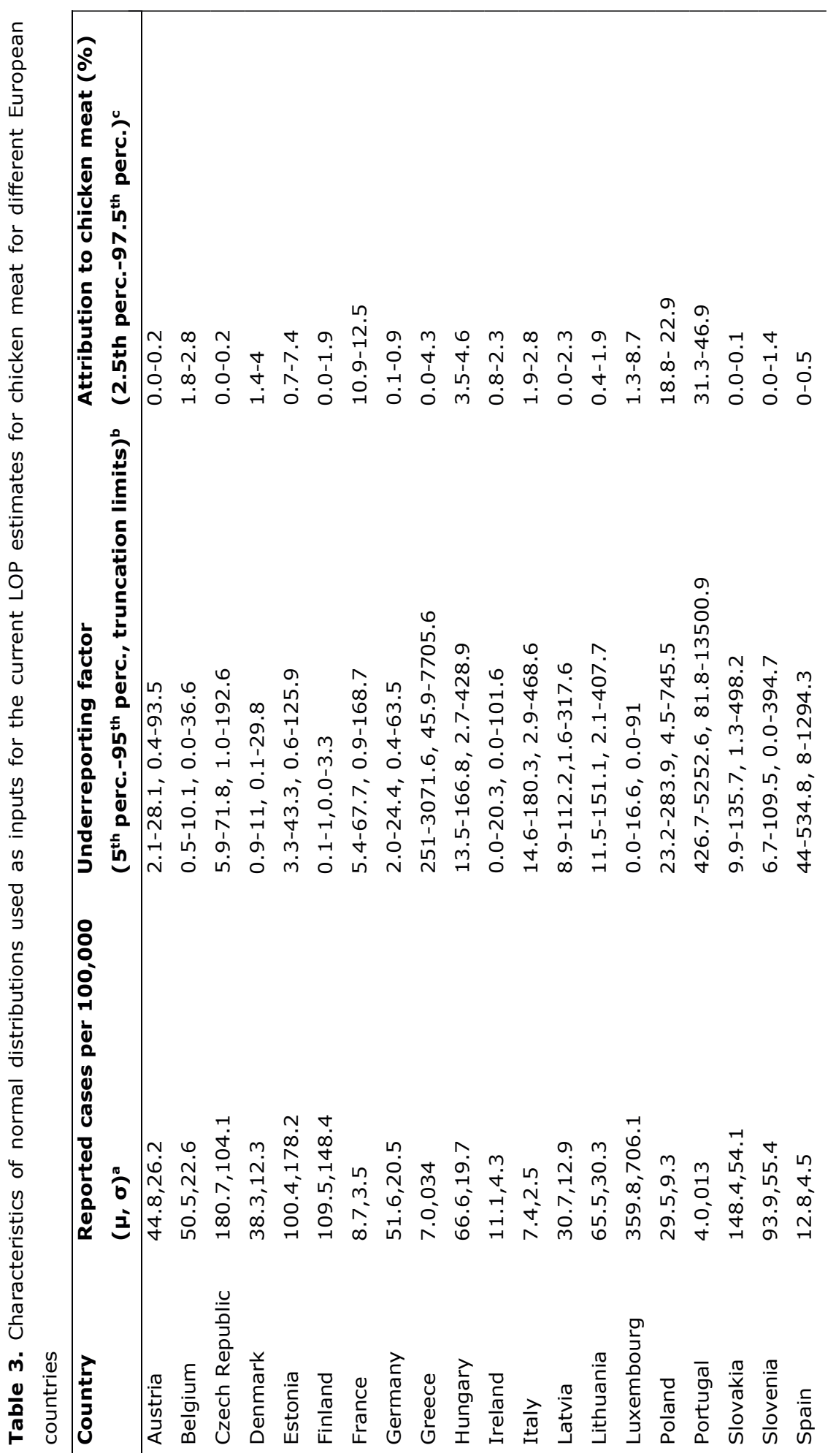




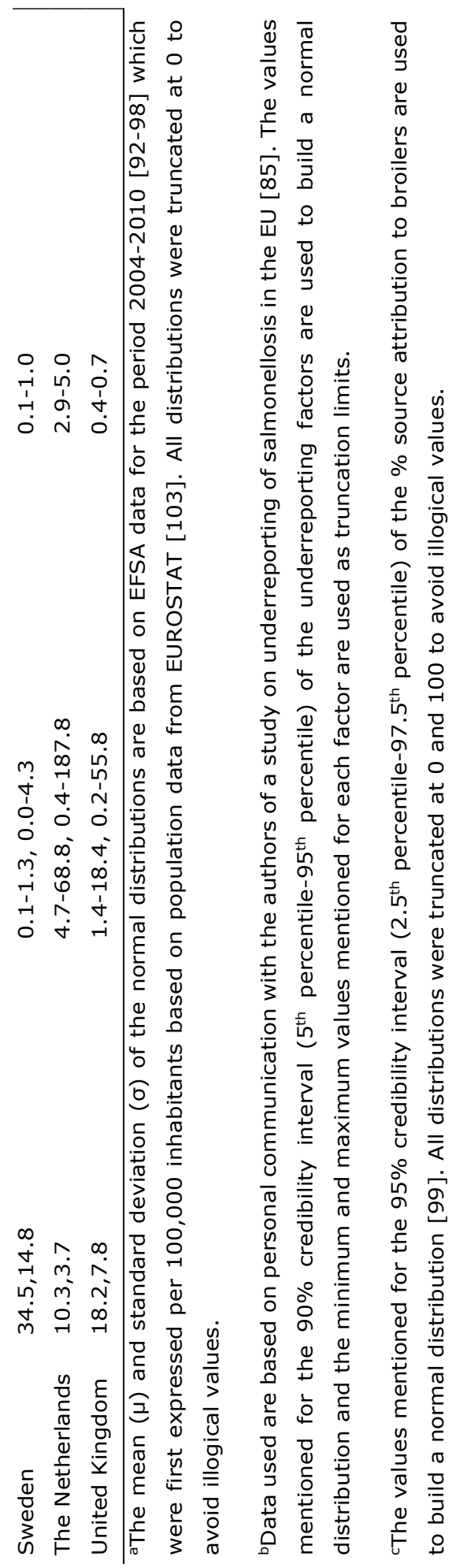


A more detailed comparison of the characteristics of the output distributions obtained with these models can be seen in Figure 3. Although the mean LOP estimates obtained with the two approaches were found to be very similar, they were associated with considerable variance mainly because of the underreporting factor in the top-down approach and the Salmonella concentration in the bottom-up approach (see Figure 4). Depending on the lower and upper percentiles selected for deriving a range for the confidence interval surrounding the mean, the LOP was found to vary up to a factor 36 for estimates derived top-down and even up to a factor $10^{5}$ when estimates were derived bottom-up. The wide range of these confidence intervals is not surprising given the stochastic nature of the risk estimates. In particular, an inherent limitation of the bottom-up model is that it considers many more inputs than the top-down model, each associated with considerable variance that accumulates in the risk characterization step of the risk assessment. Setting an ALOP on the basis of these results would require a risk management decision.

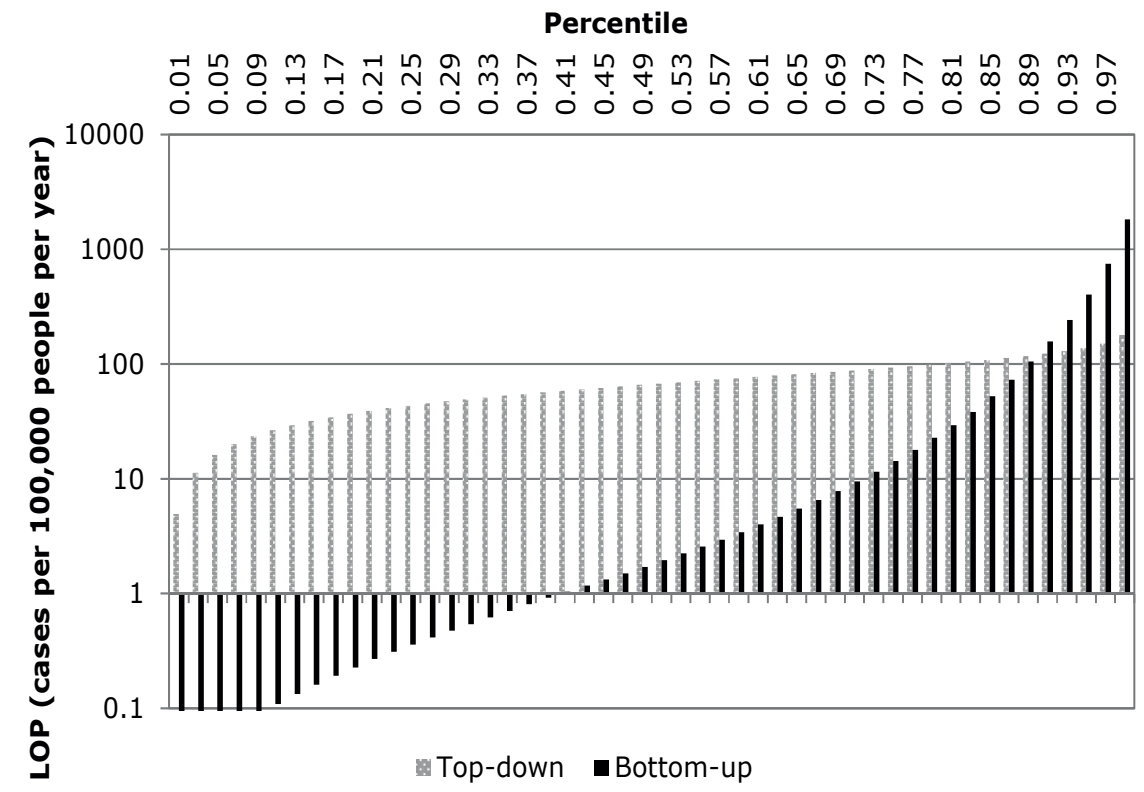

Figure 3. Detailed characteristics of the ALOP output distributions for chicken meat as obtained with the top-down (grey bars) and the bottom-up approach (black bars). Numbers on the $y$-axis are presented on a logarithmic scale to facilitate comparisons.

Since an ALOP expresses the maximum level of illness that is tolerated within a population [19], it requires the governmental risk manager to judge the degree of confidence in a risk 
a

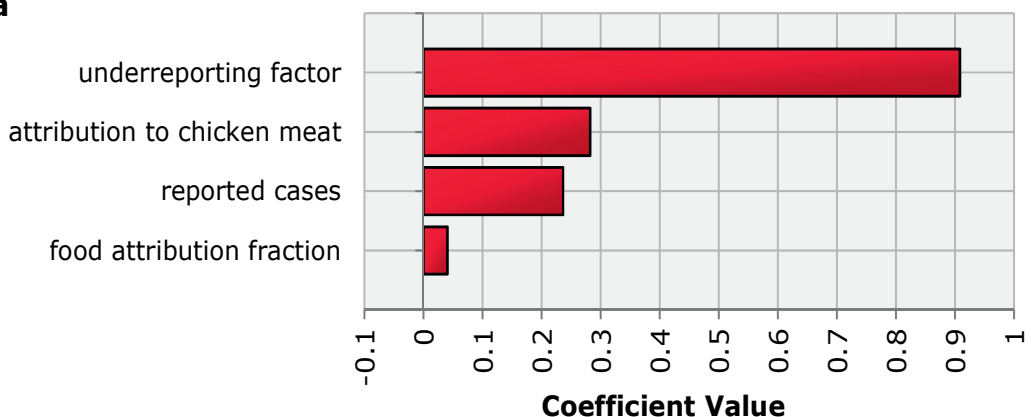

b

concentration of Salmonella in chicken meat at retail LogDref Salmonella transfer rate from hand to salad transfer rate from chicken to hand frequency of undercooking b parameter of Ratkowsky model a parameter of dose response model storage time cooking temperature cooking time storage temperature

$\beta$ parameter of the dose response model prevalence of Salmonella in chicken meat at retail fraction of Salmonella cells in protected areas annual per capita consumption of chicken meat probability of not washing the cutting board and knife
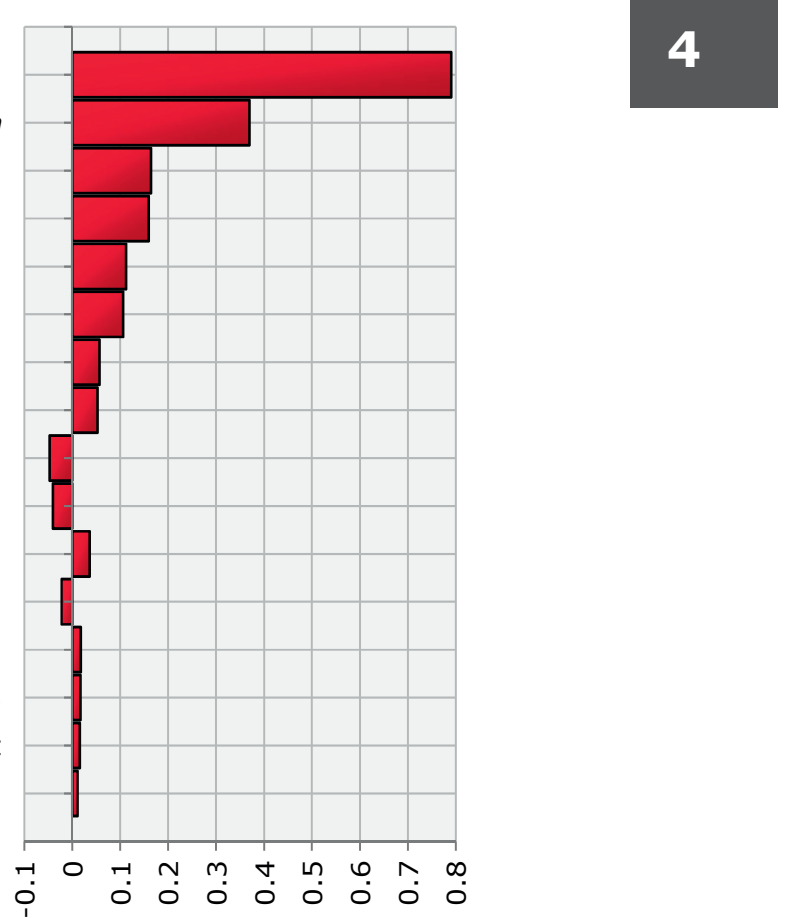

Coefficient Value

Figure 4. Analysis of the impact of the stochastic inputs used in the top-down approach model (a) and the bottom-up approach model (b) on the estimated ALOP for chicken meat, using Spearman's rank correlation coefficients.

estimate derived either via a risk assessment of food supply chain data or on the basis of epidemiological data. This confidence will affect the ability to set a new ALOP, such that this level is not surpassed [12]. An important decision to be made by these risk managers 
is which upper percentile of the stochastic estimates will be used to set the ALOP. The $95^{\text {th }}$ percentile is often suggested for such purposes [12], but other upper percentiles such as the $90^{\text {th }}$ or the $99^{\text {th }}$ may also be options. Figure 3 illustrates that, for the specific case at hand, it may be more straightforward to base the selection of ALOP on the outcomes of the top-down approach, in which the values estimated for the $90^{\text {th }}$ to $99^{\text {th }}$ percentile range differ to a rather small extent, namely less than a factor of 2 when comparing the $90^{\text {th }}$ with the $99^{\text {th }}$ percentile and at maximum $10 \%$ when comparing neighbouring percentiles. The same selection may be less straightforward when basing it on the bottom-up approach, since the upper percentiles can differ in the estimated risk level by a factor of 15 when comparing again the $90^{\text {th }}$ with the $99^{\text {th }}$ percentile and differences between neighbouring percentiles are much greater. The parallel use of both approaches has been recommended so that the estimates can to some extent be validated against each other [26]. Thus, a possible option for setting the ALOP could be the $90^{\text {th }}$ percentile, around which the ALOP estimates of the two models in this study coincide at approximately 119 cases per 100,000 people per year. However, the percentiles at which the values of the two distributions will coincide will vary depending on the risk unit used to derive the population risk. In our case, to illustrate the impact that this selection has on the ALOP we have selected the risk per serving which resulted in great variance (95\% CI: 0.03-904, SD 412). Had we selected the risk per person or the risk per 100,000 people (assuming an annual consumption of 71 servings), the variance surrounding the estimates would have been narrower and the coinciding percentiles different. In particular using the central limit theorem to estimate the population risk as a normal distribution using our risk per serving simulation data, the top down ALOP would have been 96 cases per 100,000 people (95\% CI: 15-185, SD 44) on the basis of the risk per person and 93 cases per 100,000 people (95\% CI: 92.8-93.0, SD 0.047 ) on the basis of 100,000 people.

At this point it should be emphasized that care needs to be taken that the severity of the illness estimated is the same when using both approaches in parallel. For the purpose of our study, we have chosen to express the ALOP as cases of salmonellosis per 100,000 people per year according to the recommendations of the ICMSF [83]. In both models, salmonellosis refers to gastroenteritis caused by the ingestion of Salmonella, but there may be important differences in the way gastroenteritis is defined resulting in outcomes that are not fully comparable. For the input data used in the top-down model, gastroenteritis was defined as three or more loose stools in a period of $24 \mathrm{~h}$ or the occurrence of three different gastrointestinal symptoms preceded by a two week period without symptoms $[85,104]$, but in the bottom-up model it is defined as "any degree of gastroenteritis" [46]. Although the latter definition of gastroenteritis encompasses the former and they both account for the total number of cases of gastroenteritis in the general population, it may be that the severity of the endpoint of the disease is different between 
the two ALOP estimates. It is, for instance possible, that some very mild cases of gastroenteritis have been missed with the top-down approach, leading to an underestimation of the actual public health status in this case. With the information available to us, it is not possible to estimate how significant this difference may be, although it has been reported elsewhere that differences in the definition of gastroenteritis can influence disease incidence estimates 1.5-2.1 times in a given country [105].

To determine the influence of stochastic inputs on the outputs of a model and to investigate if the model is behaving as expected, a sensitivity analysis was performed [102]. Tornado charts, using Spearman's rank correlation coefficients, were built to assess the impact of the stochastic inputs on ALOP estimates for both approaches followed in our study (Figure 4). For the ALOP estimated top-down, by far the most important input is the underreporting factor (0.91), followed by the percentage of cases attributed to chicken meat consumption (0.28) and the number of reported cases (0.24). In the bottom-up model, the concentration of Salmonella in chicken at retail $(0.79)$ is the most influential input, followed by the logarithm of the reference decimal reduction time (0.37). The various other inputs were more weakly correlated with the ALOP, either negatively or positively.

\subsection{Estimated FSO values for chicken meat in the Netherlands.}

The estimated arithmetic mean value for the FSO for chicken meat derived by the topdown approach and the bottom-up approach was found to be $-4.6 \log \mathrm{CFU} / \mathrm{g}$ (95\% CI: 5.4 to -4.1, SD 0.32 ) and $-6.0 \log \mathrm{CFU} / \mathrm{g}$ (95\% CI: -8.1 to -2.9 , SD 1.3 ), respectively. This FSO can be considered to be the pooled concentration of Salmonella from several different types of cross-contaminated or undercooked servings at the time of consumption. A more detailed comparison of the characteristics of the output distributions obtained with these models is shown in Figure 5. The two approaches resulted in very different FSO estimates, both in terms of the mean estimate and the confidence interval, reflecting major differences in the way the FSO was derived. The top-down approach resulted in a leptokurtic, negatively skewed FSO distribution, with a very narrow confidence interval of about $1 \log$ CFU/g surrounding the mean. Conversely, the bottom-up approach resulted in a very platykurtic distribution that was positively skewed, with a very broad confidence interval of about $5 \log \mathrm{CFU} / \mathrm{g}$. The two distributions coincided around the $90^{\text {th }}$ percentile at $-4.3 \log \mathrm{CFU} / \mathrm{g}$. Following the rationale suggested above for the ALOP, an upper percentile where both approaches yield comparable outcomes may possibly be chosen to set the FSO. If the $90^{\text {th }}$ percentile is chosen for this purpose, then this would mean that for contaminated servings of meat or salad with Salmonella at the time of consumption their pooled concentration can only $10 \%$ of the time exceed $-4.3 \log \mathrm{CFU} / \mathrm{g}$ so that the overall health burden does not exceed 119 cases per 100,000 people. 


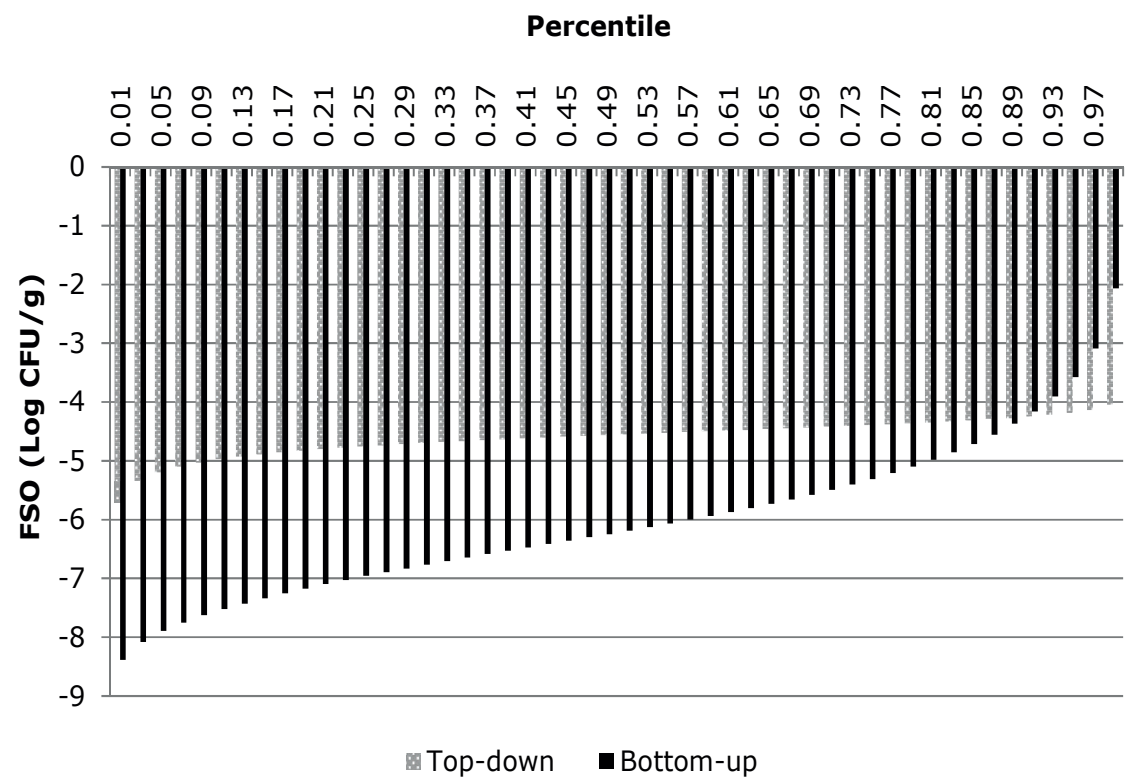

Figure 5. Detailed characteristics of the FSO output distributions for chicken meat as obtained with the top-down model (grey bars) and the bottom-up model approach (black bars).

Notably, estimating an FSO with either of the two models is subject to considerable limitations. Regarding the FSO estimated top-down in our study, the main issue is that it was estimated by reverse engineering the dose-response equation. Therefore it is only one of an infinite number of plausible solutions for this parameter, given the stochastic nature of the model [19]. In reality, while different types of distributions of the hazard concentration at the point of consumption could lead to the same or similar estimate for the ALOP, they could generate many different FSO values. Regarding the FSO estimated top-down, the most important limitation is the fact that it was calculated simplifying reality by assuming that undercooking and two specific cross-contamination pathways would be the only events impacting on pathogen levels at consumption. Obviously, more sources of cross-contamination may have an impact, such as the external packaging of raw meat [106], the water tap [107] or reusable shopping bags [108]. Also, ready-to-eat items other than salad may be involved in cross-contamination in households at the point of consumption. These were not modelled here because they were either recognized as less significant routes than hands, or utensils such as cutting boards and knives [75] or because of a lack of pertinent data to incorporate in the model. These and other important assumptions of the bottom-up model are summarized in Table 4 . The availability of 
knowledge and data for realistic modelling in this regard remains a challenge. Given that the setting of the benchmark is not optimal with either approach, a solution would be to use both approaches in parallel which would require a conscious decision on the side of the risk manager on which of the upper percentiles, where the two distributions tend to coincide, could be used to set the FSO. Such a decision would be better defendable than selecting only one of the two approaches and even more so when the comparison of upper percentiles involves multiple distributions from each approach based on alternative combinations of inputs or different scenarios.

Table 4. Assumptions behind the bottom-up model that could lead in over- or underpredictions

\begin{tabular}{|l}
\hline Over-predictions \\
- $\quad$ The cross-contaminated salads are not washed and consumed as such. \\
- that did not receive appropriate training on how to handle raw meat. \\
- Direct hand contact leads to cross-contamination; in reality cross-contamination \\
- $\quad$ to the salad. \\
Under-predictions \\
- $\quad$ The undercooked meat is safe after reheating. \\
- $\quad$ Hands are not considered a risk for cross-contamination after washing. \\
- $\quad$ Salad is the only item that can be cross-contaminated. \\
- Recent data regarding the heat resistance of pathogens on the surface of chicken \\
meat when fried or boiled suggest that D-values may be higher than what is so \\
far known when estimated under conditions that simulate handling by the \\
consumer (Bergsma et al, 2007 ; de Jong et al. 2012). \\
Either way
\end{tabular}

A sensitivity analysis of the impact of stochastic inputs on FSO estimates can be found in Figure 6 . The inputs of the top-down model most strongly influencing the estimates were the underreporting factor (0.86), the percentage of cases attributed to chicken meat $(0.27)$ and the a parameter of the dose response model $(-0.26)$. For the bottom-up approach, the most strongly correlated input was the concentration of Salmonella in chicken meat at retail $(0.77)$, followed by the logarithm of the reference decimal reduction time $(0.42)$. The remainder of the inputs of the model were less strongly influential on the FSO estimates. 
a

underreporting factor

attribution to chicken meat

a parameter of dose response model

reported cases

$\beta$ parameter of the dose response model annual per capita consumption of chicken meat

food attribution fraction mass per serving of raw chicken meat frequency of undercooking

prevalence of Salmonella in chicken meat at retail probability of not washing the cutting board and knife

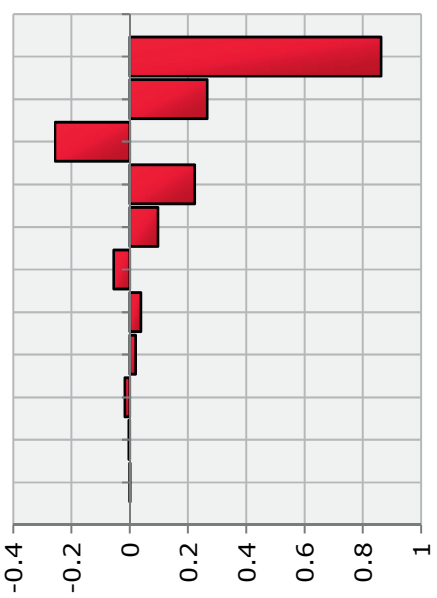

Coefficient Value

b

concentration of Salmonella in chicken meat at retail LogDref Salmonella transfer rate from hand to salad transfer rate from chicken to hand frequency of undercooking b parameter of Ratkowsky model mass per serving of raw chicken meat cooking temperature storage time mass per serving of vegetables cooking time storage temperature

fraction of Salmonella cells in protected areas prevalence of Salmonella in chicken meat at retail probability of not washing the cutting board and knife transfer rate from unwashed cutting board and knife to salad

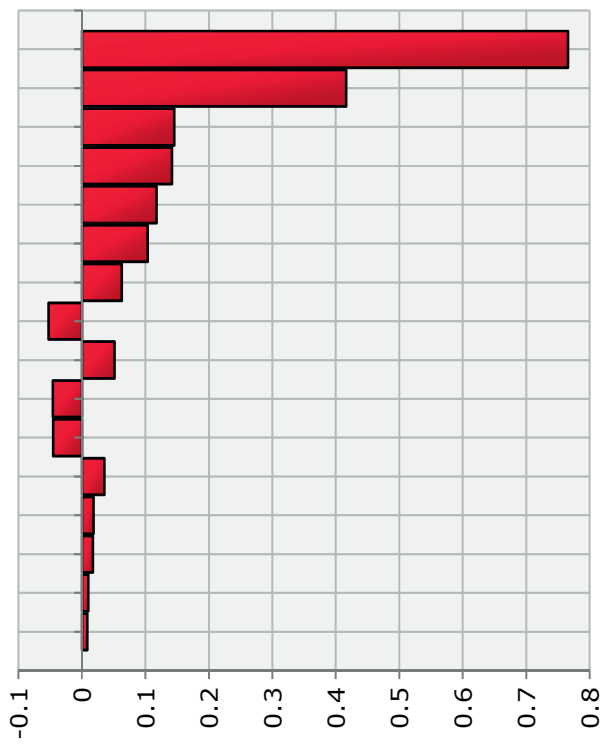

Coefficient Value

Figure 6. Analysis of the impact of the stochastic inputs used in of the top-down approach model (a) and the bottom-up approach model (b) on the estimated FSO for chicken meat, using Spearman's rank correlation coefficients. 
3.3. Comparison of current LOPs for salmonellosis due to chicken meat between EU countries

An overview of the current LOP values for salmonellosis transferred via chicken meat obtained with the top-down model for different European Union member states (including $95 \%$ confidence intervals) on the basis of data from annual Community reports are shown in Figure 7. The calculated mean LOPs span a surprisingly wide range. For some countries (i.e Portugal, Poland, Luxemburg, Greece, Hungary and Estonia) estimates are well above 100 cases per 100,000 people per year. For other countries (i.e. Sweden, Austria, Finland, United Kingdom, Ireland and Germany) these estimates are well below 5 cases per 100,000 people per year. For the remainder of countries, estimates fall between 5 and 100 cases per 100,000 people per year. Unfortunately, it was not possible to establish correlations between the number of cases and the prevalence of Salmonella in chicken meat for different countries in detail, such as reported in studies for laying hen flocks [85], as data on the prevalence of the pathogen in fresh broiler meat at retail reported to EFSA [92-98] was either poor or completely lacking, such as in the case of Finland, Ireland, Poland and Portugal.

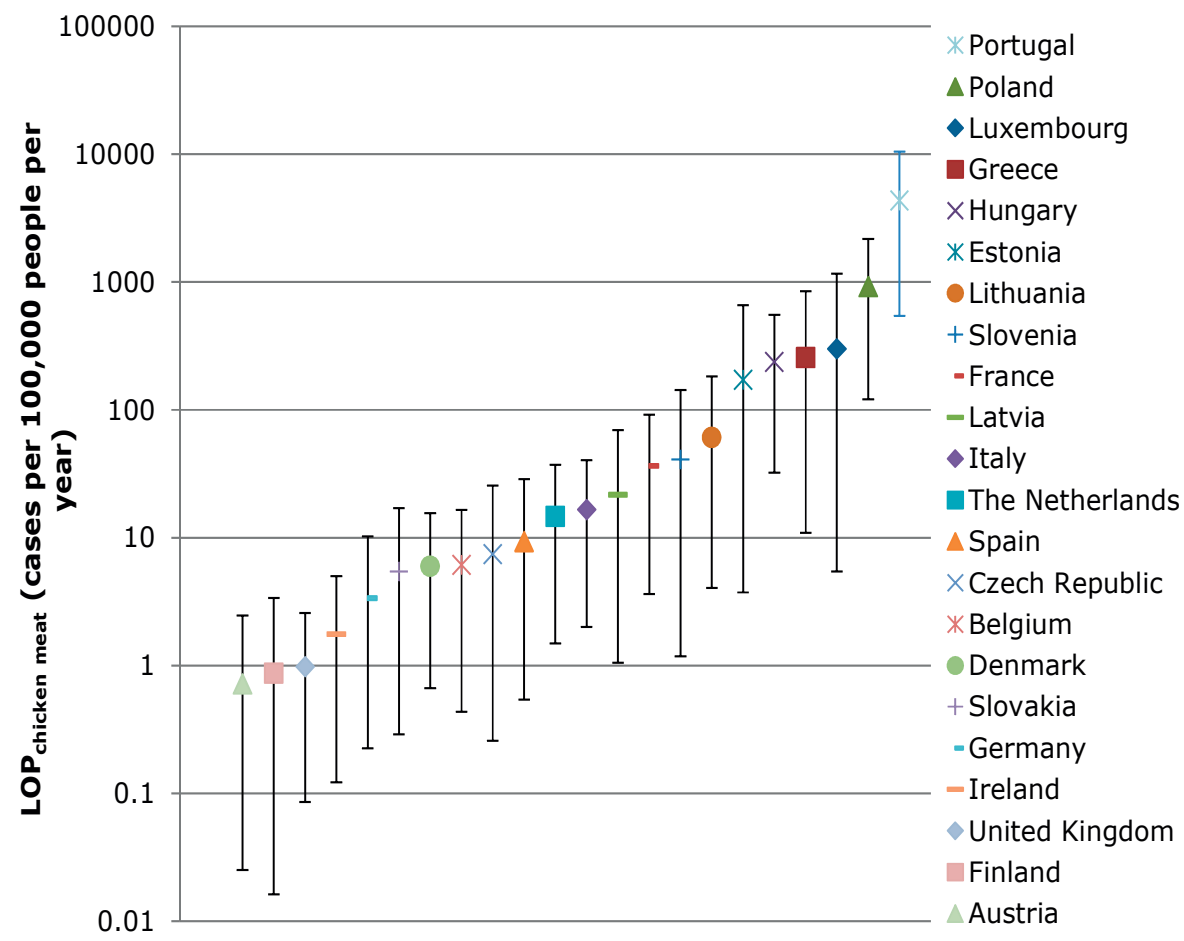

Figure 7. Estimates of current LOP for 23 European Union member states using the topdown model. Numbers on the $y$-axis are presented on a logarithmic scale to facilitate comparisons. Whiskers show the $95 \%$ confidence interval. 
Estimates presented here for current LOPs across different countries in Europe need to be interpreted with due care as they are the result of the specific input data chosen in our top-down model which in turn are influenced by the methodology used to collect them. For instance, the number of cases reported by countries may be subject to particular biases related to differences in the sensitivity of surveillance systems, case definition of salmonellosis and differences between national and international datasets regarding incidence. Although in our model potential differences in LOP estimates related to the first two considerations may be somewhat normalized through the use of underreporting factors that are based on tourist data to estimate total cases in the community, this is not the case for potential disagreements between national and international data for case rates in a given country. Moreover, differences in choices of available datasets concerning other inputs such as source attribution estimates are possible and may lead to different LOP values being estimated for a particular country. This was evident when attempting to compare the LOP distribution that we derived for the Netherlands on the basis of national data with the one we derived using data reported at the EU level (Figure 8a). In this case, the two distributions were markedly different with the national LOP estimate was much higher than the one obtained with EU level data. Interestingly, this phenomenon was not observed when attempting a similar comparison between LOPs for pork in the Netherlands using the same national and international literature sources (Figure 8b). Here the use of different datasets led to only slight deviations between the two output distributions that still coincide at their upper percentiles. The huge deviations observed in the case of LOP estimates for chicken meat possibly may be mainly due to differences in source attribution data for this product and to a far less extent due to differences in incidence data (see Tables 2 and 3 for the actual distributions) considering that the other inputs used for the estimation were the same. It has been reported elsewhere that variations in the methodology used to derive the percentage of cases attributed to a specific food source can lead to different estimates for this parameter [109] and could be responsible for the large differences we observed using either the data reported at EU level or data we retrieved from sources in the Netherlands. It should be noted that the same applies to underreporting factors estimated using tourist studies, despite the obvious advantage of these for expressing risks on a common basis $[85,110]$. With regards to our case-study, the most important drawback of using underreporting factors based on tourist studies is the fact that they do not take into account potential differences in the endemicity of specific Salmonella serotypes and strains or acquired immunity between tourists and local residents [85]. Considering that the factors we used were based on tourists from the North of Europe, it would be interesting to see if similar results would occur when tourists from the South or East of Europe are used to derive the estimates. A comparative study using tourists 
from other regions would be crucial before using such underreporting factors for international comparisons of ALOPS in the context of the SPS Agreement.

a

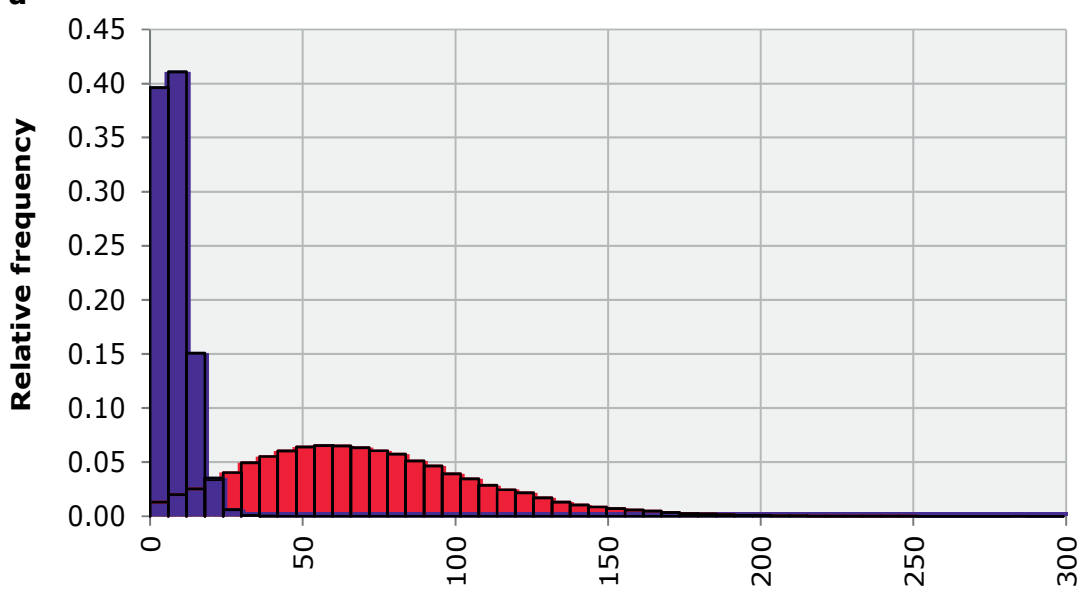

Cases per 100,000 people per year

- ALOPchicken meat - National data

-ALOPchicken meat - International data

b

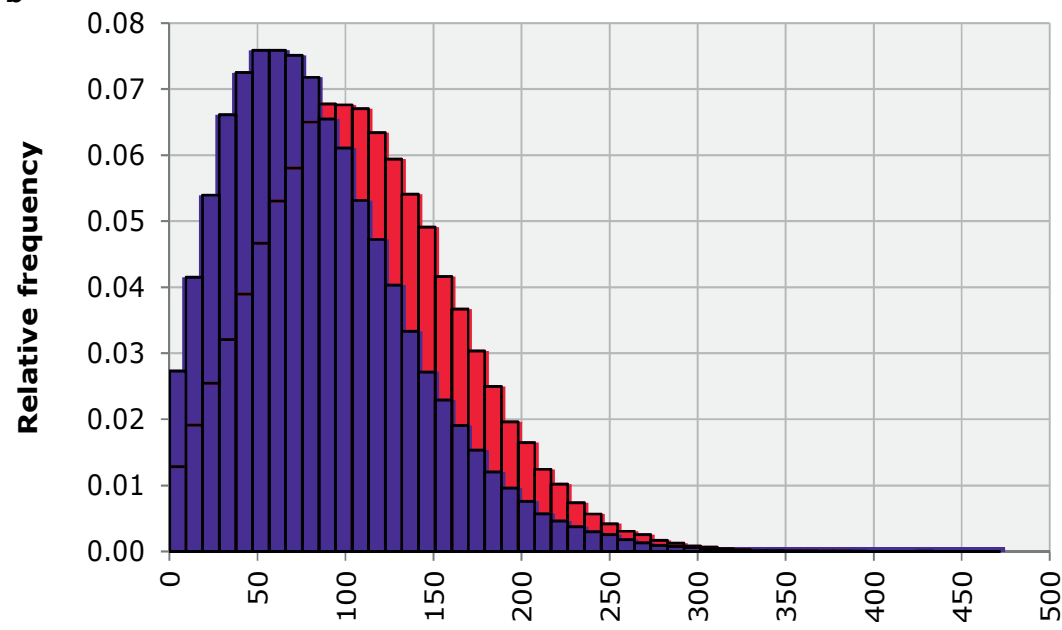

Cases per 100,000 people per year

- ALOP pork - National data

— ALOP pork - International data

Figure 8. Effect of using only national datasets or only international datasets reported at the EU level on the estimated current LOP for chicken meat (a) and pork (b) in the Netherlands. 


\subsection{Issues in the implementation of the concepts}

\subsubsection{FSO definition}

Throughout the development of the FSO concept in Codex and deliberations in other fora, a major issue highlighted was implementation of an FSO for raw products, such as chicken meat. The majority of delegates at a workshop on the application of the FSO concept in food safety management [21] agreed that ideally the FSO should apply at the point of consumption but that, for products involving handling by the consumer, it would better be set at the start of the preparation of the meal or at the point of purchase. In our study it was considered that the FSO applies at the point of consumption according to its current definition [111] and that a PO could be set at the point of retail or even closer to the point of consumption, where relevant. Indeed, estimating an FSO based on the Codex definition proved to be quite challenging, as more than one food product in our models may ultimately contribute to illness and very few data on consumer handling are available. We chose to use two different products to estimate the likely concentration of the pathogen at consumption bottom-up (undercooked chicken and cross-contaminated salad) and simplified the top-down estimates using only chicken meat. In reality, the situation can be more complicated since exposure will depend on the number and type of items involved in cross-contamination events and some routes starting from the chicken meat such as hands to mouth either directly from the meat or indirectly from contaminated surfaces do not involve ingestion of a product but of cells directly. Since it is the number of cells ingested that defines the risk, it might be more appropriate to establish a maximum for the dose instead of the concentration and/or prevalence of the pathogen in the food that relates to an ALOP. This would be in agreement with suggestions from other authors to use a prevalence - dose curve ( $P-D$ curve) to set the FSO [19]. However, as the FSO has been developed as a metric to guide operational food safety management, it is valid to consider aspects of pathogen levels that may be controlled by the industry to an extent as specified by competent authorities in terms of concentration and prevalence.

\subsubsection{Level of complexity in the models used to derive ALOP/FSO values}

While it is evident that when establishing ALOP and FSO values specific to certain types of food based on epidemiological data, issues can be the source attribution and the sensitivity of surveillance systems, a specific issue related to using food supply chain data is the level of complexity of the risk assessment models used for this purpose [26]. In the case of raw products that involve preparation and handling by consumers prior to consumption, the level of illness in the population may be heavily influenced by phenomena such as undercooking and cross-contamination, which are highly uncertain and variable events and can be incorporated in a model in many different ways. Although these two phenomena 
are considered in most risk assessments published elsewhere $[37,40,41,46,112]$, in some only undercooking [113] or only cross-contamination [76] are modelled. Notably, which events are included as contributing to these phenomena, whether their probabilities are independent or not and whether they are incorporated as point estimates or stochastic inputs into a particular model all vary considerably. It may also often be considered that incorporating parameters in a stochastic way instead of point estimates increases the mean risk estimate [114] and the associated variance. As a good practice guideline, it has been recommended to use a rather simple model for validating results and a more complex one for providing additional insight [115], such as used here deploying a top-down and bottomup modelling approach differing in modelling complexity.

3.4.3. Considerations regarding establishing current LOPs to evaluate equivalence of phytosanitary measures between countries

In the context of the SPS agreement [7], the ALOP is a means of evaluating the equivalence of specific phytosanitary measures between different countries. In our study, it seemed that a top-down approach may be easier to apply for this purpose, given the international data available to us, than the bottom-up approach. This method allowed for a rather straightforward estimation of the risk associated with the consumption of chicken meat in different countries, even considering the substantial variance in the estimates. Neither the top-down nor the bottom-up model deployed in our study allowed for an equally straightforward estimation of FSOs with the current level of detail in international data.

\subsection{Improving the estimates}

Many authors before us have mentioned that the availability of better data would help improve predictions through risk assessment $[37,47,112]$ and that for establishing values for ALOP/FSO, important data gaps need to be addressed through targeted research [21]. In this study we noted several research areas where future work could be targeted to further improve data.

As discussed before, decisions regarding the way exposure to Salmonella through for instance undercooking and cross-contamination is modelled can have a profound impact on the estimated risk. Relatively few studies exist on consumer practices related with these phenomena and for but a handful of countries. Most of these are based on questionnaires or telephone interviews concerning food safety $[116,117]$, which also applies for the study that we used to estimate the incidence of undercooking and cross-contamination events for the Netherlands [44]. Only very few studies concern actual observations of consumer behaviour $[118,119]$. Since awareness of food safety issues does not necessarily translate into safe food handling practices [120], more carefully designed observational studies 
involving a statistically significant number of participants would be invaluable in reducing uncertainties in the way cross-contamination and undercooking are currently modelled.

The FAO/WHO dose-response model used in the present study does not discriminate between the healthy and the susceptible part of the population (young, old, pregnant or immune-compromised individuals) as the level of detail in the outbreak data it is based on does not allow for this kind of separation. Nonetheless, it is known that among susceptible individuals, the elderly are proven to be more likely to contract the disease, in which case the associated morbidity and mortality is also expected to be higher than in the normal population [121]. It would be important to attempt to separately estimate the risk associated with these two different sub-populations because this would facilitate the provision of specific recommendations to protect particularly vulnerable consumers and enable policy makers to better estimate the impact of changing demographics (increasing elderly population) on the risk. An additional issue for consideration relating to our casestudy but relevant more generally is a more specific definition of the endpoint (gastroenteritis) so that it is compatible with epidemiological observations. Finally, collecting more quantitative data where there is low pathogen concentration, is another area where more work is needed to improve the precision of model predictions [122].

While working through our case-study, a lack of information was observed for modelling additional cross-contamination pathways only recently acknowledged as potentially significant such as external packaging of meat and reusable shopping bags $[106,108]$. To model these additional pathways new data related with consumer practices and the transfer of microorganisms between surfaces would be necessary. Regarding the latter it is important to estimate the transfer rates using strains of Salmonella instead of surrogate microorganisms, since significant differences between the two have been observed [123].

\section{Conclusions}

Available data have allowed us to derive a current LOP and suggest ALOP and FSO values for chicken meat for the Netherlands, although with sometimes considerable variance. Decisions would have to be made by risk managers intending to establish such values in practice. These decisions primarily concern the choice of the percentile of the output distributions to be used for this purpose, taking into consideration variance in the inputs as well as potential bias. Using the top-down and the bottom-up approach in parallel was found to be of great value as a means of validating results and gaining additional insights on input parameters influencing the modelling results. The top-down approach showed somewhat more promise in the context of international comparisons when using readily available international data. It is important to note though that significant differences were 
observed between estimates resulting from the top-down approach for the Netherlands, based on the available datasets from national sources as compared to international sources. Estimates can be refined with better quality data but they will never be perfect and ultimately the selection of an ALOP/FSO would be a management decision on the basis of the best insight the current situation allows with the accompanying uncertainty.

\section{Acknowledgements}

We wish to thank Unilever for sponsoring the Ph.D. project of Elissavet Gkogka. We would also like to acknowledge Heidy den Besten for assisting with the meta-analysis of Salmonella growth rates, Arie Havelaar for providing us with detailed estimates of underreporting factors for salmonellosis for different EU countries, Sara Monteiro Pires for clarifications regarding the source attribution values we used and Richard $\mathrm{Hol}$ and colleagues of the Product Boards for Livestock, Meat and Eggs (PVE) for providing us with consumption data for chicken meat and pork in the Netherlands. 


\section{Technical Appendix A.}

General information and data used from the study of the Dutch Centre for Nutrition on hygiene in private households [44]. Results are based on individual "face-to-face" interviews based on structured questionnaires. Participants are consumers who are responsible for the housekeeping activities.

Table 1A. General information on participants of the study

\begin{tabular}{|lc|}
\hline & \% of Total sample (n=302) \\
\hline Social class* & 11 \\
A & 28 \\
B-above & 18 \\
B-below & 35 \\
C & 8 \\
D & \\
\hline Gender & 7 \\
Male & 93 \\
Female & \\
\hline Age & 32 \\
Up to and including 34 & 36 \\
35 up to and including 49 & 32 \\
50 or older & 10 \\
\hline Family status & 16 \\
Single (<35 years) & 11 \\
Single (35+ years) & 31 \\
Only adults (<35 years) & 23 \\
With children up to and including 17 years & 9 \\
2 persons, housewife 35+ & \\
Two or one parent family with only young & \\
adults (18+ kids living with the parents) & 19 \\
\hline Region & 25 \\
3 big cities + surrounding areas & 13 \\
Remainder Western Netherlands & 18 \\
Northern Netherlands & 24 \\
Eastern Netherlands & \\
Southern Netherlands & \\
\hline Where A is the highest socia class and D is the lowest & \\
\hline
\end{tabular}

*where $\mathrm{A}$ is the highest social class and $\mathrm{D}$ is the lowest

Table 2A. Time needed to transport fresh meat from the retail shop home among consumers representative of the Dutch population, who recently bought fresh meat

\begin{tabular}{|lc|}
\hline Time to arrival home & \% of responders $(\mathbf{n = 2 9 1 )}$ \\
After \pm 5 minutes & 47 \\
After \pm 10 minutes & 29 \\
After \pm 15 minutes & 16 \\
After \pm 30 minutes & 7 \\
After \pm 60 minutes & 1 \\
After more than 60 minutes & 0 \\
\hline
\end{tabular}


Table 3A. Time needed to unpack fresh meat and store refrigerated upon arrival at home among consumers who recently bought fresh meat

\begin{tabular}{|lc|}
\hline Time to unpacking & \% of responders $(\mathbf{n}=\mathbf{2 9 1})$ \\
\hline Directly upon arrival* & 93 \\
After \pm 5 minutes & 5 \\
After \pm 10 minutes & 0 \\
After \pm 15 minutes & 1 \\
After \pm 30 minutes & 0 \\
After more than 30 minutes & - \\
\hline
\end{tabular}

*For the purpose of our study we considered this to be one minute when building the tunpacking distribution.

Voedingscentrum. 1999. Hygiëne privé-huishouding Voedingscentrum, Den Haag.

\section{Technical Appendix B}

Table 1B. Overview of the dataset underlying the meta-analysis of Salmonella growth rates for different types of raw chicken meat

\begin{tabular}{|c|c|c|c|c|c|}
\hline Strain & Product & Inoculum & $\begin{array}{l}\text { Temperature } \\
\left({ }^{\circ} \mathrm{C}\right)\end{array}$ & $\begin{array}{l}\text { Specific } \\
\text { growth } \\
\text { rate } \\
\left(\log _{10} / h\right)\end{array}$ & Source \\
\hline \multirow{18}{*}{$\begin{array}{l}\text { S. Typhimurium } \\
\text { DT104 (ATCC } \\
700408 \text { ) }\end{array}$} & \multirow{18}{*}{$\begin{array}{l}\text { raw } \\
\text { ground } \\
\text { chicken }\end{array}$} & \multirow{9}{*}{$1.12 \log _{10} \mathrm{MPN} \mathrm{g}^{-1}$} & 10 & 0.011 & \multirow[t]{18}{*}{ [64] } \\
\hline & & & 12 & 0.026 & \\
\hline & & & 14 & 0.031 & \\
\hline & & & 18 & 0.048 & \\
\hline & & & 22 & 0.132 & \\
\hline & & & 26 & 0.202 & \\
\hline & & & 30 & 0.296 & \\
\hline & & & 34 & 0.361 & \\
\hline & & & 40 & 0.445 & \\
\hline & & \multirow{9}{*}{$3.7 \log _{10} \mathrm{CFU} \mathrm{g}^{-1}$} & 10 & 0.013 & \\
\hline & & & 12 & 0.020 & \\
\hline & & & 14 & 0.033 & \\
\hline & & & 18 & 0.052 & \\
\hline & & & 22 & 0.117 & \\
\hline & & & 26 & 0.185 & \\
\hline & & & 30 & 0.262 & \\
\hline & & & 34 & 0.314 & \\
\hline & & & 40 & 0.338 & \\
\hline \multirow{10}{*}{$\begin{array}{l}\text { S. Typhimurium } \\
\text { DT104 (ATCC } \\
700408 \text { ) }\end{array}$} & raw & \multirow[t]{10}{*}{$0.6 \log$ MPN g${ }^{-1}$} & 10 & 0.020 & \multirow[t]{10}{*}[65]{} \\
\hline & ground & & 11 & 0.220 & \\
\hline & chicken & & 12 & 0.024 & \\
\hline & breast & & 14 & 0.018 & \\
\hline & & & 18 & 0.035 & \\
\hline & & & 22 & 0.062 & \\
\hline & & & 26 & 0.099 & \\
\hline & & & 30 & 0.134 & \\
\hline & & & 34 & 0.146 & \\
\hline & & & 40 & 0.171 & \\
\hline
\end{tabular}




\begin{tabular}{|c|c|c|c|c|c|}
\hline \multirow[t]{10}{*}{ S. Rochester } & raw & $0.98 \log$ CFU g ${ }^{-1}$ (air) & 13 & 0.033 & \multirow[t]{10}{*}{ [66] } \\
\hline & \multirow{9}{*}{$\begin{array}{l}\text { minced } \\
\text { chicken }\end{array}$} & $1.0 \log _{\text {CFU g}}^{-1}$ (air) & 13 & 0.024 & \\
\hline & & $1.48 \log _{\text {CFU g}}{ }^{-1}$ (air) & 13 & 0.007 & \\
\hline & & $1.01 \log C^{\prime} g^{-1}$ (air) & 13 & 0.019 & \\
\hline & & $0.99 \log$ CFU g-1 (air) & 13 & 0.021 & \\
\hline & & $1.29 \log C F U g^{-1}(M A)^{a}$ & 13 & 0.009 & \\
\hline & & $1.46 \log C F U g^{-1}(\mathrm{MA})$ & 13 & 0.009 & \\
\hline & & $1.5 \log \mathrm{CFU} \mathrm{g}^{-1}(\mathrm{MA})$ & 13 & 0.011 & \\
\hline & & $1.7 \log \mathrm{CFU} \mathrm{g}^{-1}(\mathrm{MA})$ & 13 & 0.01 & \\
\hline & & $1.58 \log C F U g^{-1}(M A)$ & 13 & 0.01 & \\
\hline \multirow[t]{2}{*}{ S. Enteritidis } & \multirow{2}{*}{$\begin{array}{l}\text { raw } \\
\text { chicken } \\
\text { breast } \\
\text { with skin }\end{array}$} & $\begin{array}{l}4 \times 10^{3} \mathrm{CFU} \text { per } \mathrm{cm}^{2} \\
\text { (untreated meat) }\end{array}$ & 10 & 0.036 & \multirow[t]{2}{*}[67]{} \\
\hline & & $\begin{array}{l}4 \times 10^{3} \text { CFU per } \mathrm{cm}^{2} \\
\text { (decontaminated } \\
\text { meat) }\end{array}$ & 10 & 0.029 & \\
\hline \multirow{2}{*}{$\begin{array}{l}\text { S. Stanley, S. } \\
\text { Thompson }^{\mathrm{b}}\end{array}$} & \multirow{2}{*}{$\begin{array}{l}\text { raw } \\
\text { minced } \\
\text { chicken }\end{array}$} & $10^{2} \mathrm{CFU} \mathrm{g}^{-1}$ & 10.7 & 0.024 & \multirow[t]{2}{*}[68]{} \\
\hline & & $10^{2} \mathrm{CFU} \mathrm{g}$ & 30 & 0.450 & \\
\hline \multirow{5}{*}{$\begin{array}{l}\text { S. Typhimurium } \\
\text { DT104 (ATCC } \\
700408)\end{array}$} & & & 25 & 0.469 & \multirow[t]{5}{*}[69]{} \\
\hline & \multirow{4}{*}{$\begin{array}{l}\text { chicken } \\
\text { skin }\end{array}$} & & 30 & 0.6 & \\
\hline & & & 35 & 0.928 & \\
\hline & & & 40 & 1.118 & \\
\hline & & & 45 & 0.904 & \\
\hline S. Kentucky & \multirow{4}{*}{$\begin{array}{l}\text { chicken } \\
\text { skin }\end{array}$} & $0.47 \log$ CFU per $\mathrm{cm}^{2}$ & 11 & 0.011 & \multirow[t]{4}{*}{ [70] } \\
\hline \multirow{3}{*}{$\begin{array}{l}\text { S. Typhimurium } \\
\text { DT104 }\end{array}$} & & $0.57 \log$ CFU per $\mathrm{cm}^{2}$ & 10 & 0.019 & \\
\hline & & & 12 & 0.017 & \\
\hline & & & 9 & 0.0042 & \\
\hline \multirow[t]{5}{*}{ S. Hadar } & \multirow{10}{*}{$\begin{array}{l}\text { chicken } \\
\text { skin }\end{array}$} & $0.58 \log$ CFU per $\mathrm{cm}^{2}$ & 25 & 0.328 & \multirow[t]{10}{*}{ [71] } \\
\hline & & & 30 & 0.852 & \\
\hline & & & 35 & 0.861 & \\
\hline & & & 40 & 0.894 & \\
\hline & & & 45 & 0.806 & \\
\hline \multirow[t]{5}{*}{ S. Kentucky } & & $0.45 \log$ CFU per $\mathrm{cm}^{2}$ & 25 & 0.210 & \\
\hline & & & 30 & 0.470 & \\
\hline & & & 35 & 0.57 & \\
\hline & & & 40 & 0.83 & \\
\hline & & & 45 & 1.03 & \\
\hline
\end{tabular}

aModified atmosphere

${ }^{b} 1: 1$ mixture of the two strains is used 


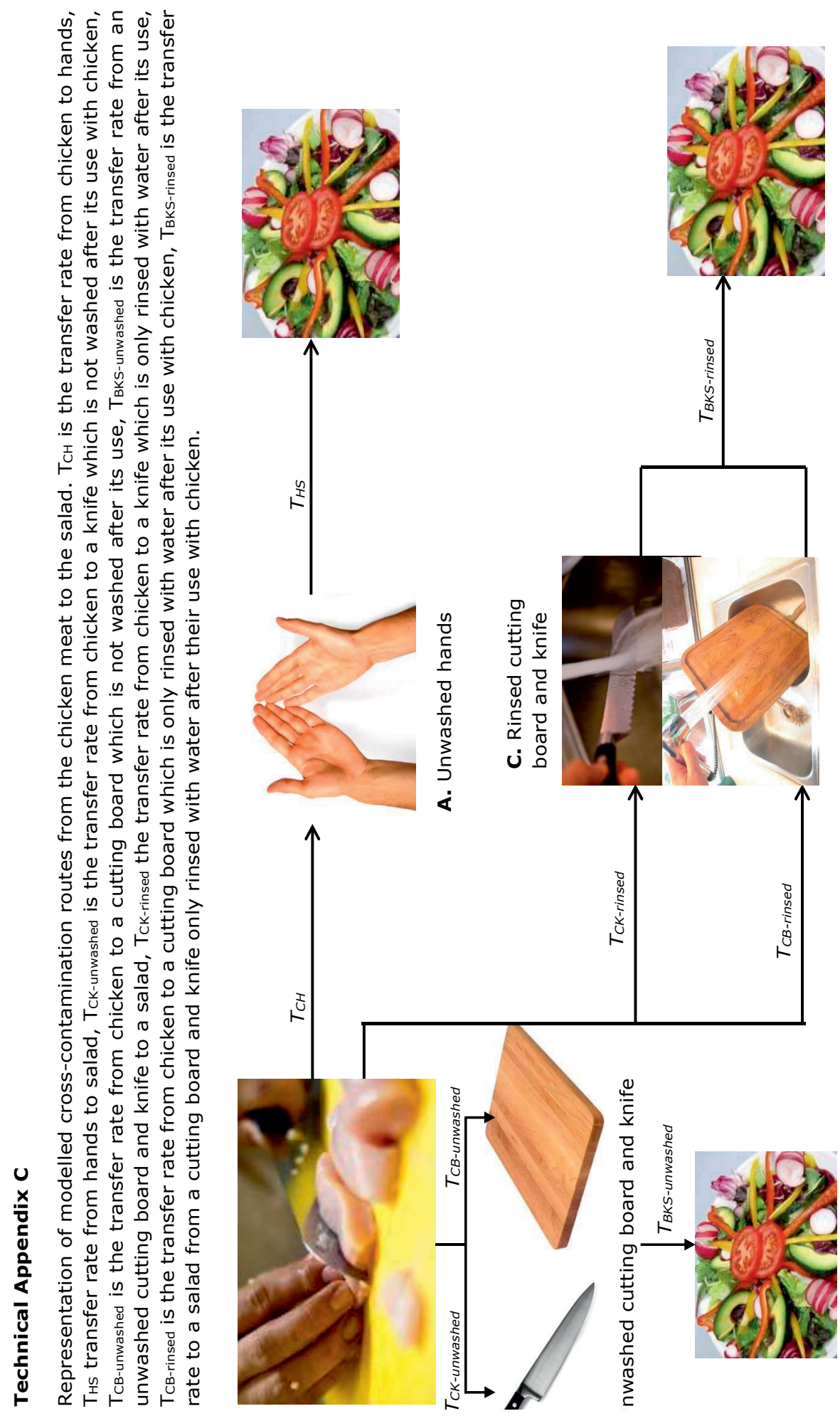




\section{References}

1. Havelaar, A.H., J.A. Haagsma, M.-J.J. Mangen, J.M. Kemmeren, L.P.B. Verhoef, S.M.C. Vijgen, M. Wilson, I.H.M. Friesema, L.M. Kortbeek, Y.T.H.P. van Duynhoven, and W. van Pelt. Disease burden of foodborne pathogens in the Netherlands, 2009 International Journal of Food Microbiology. 2012; 156: p. 231-238.

2. Scallan, E., P.M. Griffin, F.J. Angulo, R.V. Tauxe, and R.M. Hoekstra. Foodborne illness acquired in the United States-Unspecified agents. Emerging Infectious Diseases. 2011; 17: p. 17-22.

3. Todd, E.C.D. Costs of acute bacterial foodborne disease in Canada and the United States. International Journal of Food Microbiology. 1989; 9: p. 313-326.

4. European Community. (2002). European Parliament and Council of the European Union. Regulation (EC) No 178/2002 of the European Parliament and of the Council of 28 January 2002 laying down the general principles and requirements of food law, establishing the European Food Safety Authority and laying down procedures in matters of food safety. Available from: http://eur-lex.europa.eu/LexUriServ LLexUriServ.do?uri=0J:L:2002:031:0001:0024:EN:PDF

5. FAO/WHO. (2006). Food safety risk analysis. A guide for national food safety authorities. ISBN: 978-92-5-105604. Food and Agriculture Organization of the United Nations/World Health Organization: Rome/Geneva. Available from: http://www.who.int/foodsafety/publications/micro/riskanalysis06.pdf

6. ILSI. (2007). Using Microbiological Risk Assessment (MRA) in Food Safety Management. Summary report of a workshop held in October 2005 in Prague, Czech Republic. International Life Sciences Institute: Brussels. Available from: http://ilsi.org/mexico/wp-content/uploads/sites/29/2016/09/Using-Microbiological-

Risk-Assessment-MRA-in-Food-Safety-Management.pdf

7. WTO. (1995). World Trade Organization. Agreement on the application of sanitary and phytosanitary measures (SPS Agreement). Available from: http://www.wto.org Lenglish/docs e/legal e/15-sps.pdf

8. WTO. (2000). World Trade Organization. Committee on Sanitary and Phytosanitary Measures. Guidelines to further the practical implementation of Article 5.5. Available from: http://www.wto.org/english/tratop e/sps e/decisions06 e.htm

9. FAO/WHO. (1995). Application of risk analysis to food standards issues. Report of the Joint FAO/WHO Expert Consultation. Food and Agriculture Organization/World Health Organization: Rome/Geneva. Available from: http://www.fao.org/3/ae922e Lae922e00.htm

10. Codex Alimentarius. (1999). Principles and guidelines for the conduct of microbiological risk assessment. CAC/GL-30 Available from: http://www.fao.org /3/y1579e/y1579e05.htm 
11. Codex Alimentarius. (2007). Principles and guidelines for the conduct of microbiological risk management (MRM), CAC/GL 63-2007. Available from: www.fao.org/input/download/standards/10741/CXG 063e.pdf

12. FAO/WHO. (2002). Principles and guidelines for incorporating microbiological risk assessment in the development of food safety standards, guidelines and related texts. Report of a Joint FAO/WHO Consultation, Kiel, Germany, 18-22 March 2002. ISBN: 92-5-104845-2. Food and Agriculture Organization of the United Nations/World Health Organization: Rome/Geneva. Available from: http://www.fao.org/3/a-y4302e.pdf

13. Codex Alimentarius. (2007). Working principles for risk analysis for food safety for application by governments. CAC/GL 62-2007. Available from: http://www.fao.org /3/a-a1550t.pdf

14. ICMSF. International Commission on Microbiological Specifications for Foods. Book 7. Microbiological testing in food safety management (2nd edition). 2002. International Commission on Microbiological Specifications for Foods (eds). Springer International Publishing AG: Cham, Switzerland

15. Codex Alimentarius. (2004). C. Alimentarius. Codex Alimentarius Commission. Procedural Manual. Fourteenth Edition. Available from: http://www.codexalimentarius.net/web/procedural manual.jsp

16. Gorris, L.G.M. Food safety objective: An integral part of food chain management. Food Control. 2005; 16: p. 801-809.

17. Zwietering, M. Practical considerations on food safety objectives. Food Control. 2005; 16: p. 817-823.

18. Feld, N.C., L. Ekeroth, K.O. Gradel, S. Kabell, and M. Madsen. Evaluation of a serological Salmonella Mix-ELISA for poultry used in a national surveillance programme. Epidemiology and Infection. 2000; 125: p. 263-268.

19. Havelaar, A.H., M.J. Nauta, and J.T. Jansen. Fine-tuning food safety objectives and risk assessment. International Journal of Food Microbiology. 2004; 93: p. 11-29.

20. Rieu, E., K. Duhem, E. Vindel, and M. Sanaa. Food safety objectives should integrate the variability of the concentration of pathogen. Risk Analysis. 2007; 27: p. 373-386.

21. Stringer, M. Food safety objectives - role in microbiological food safety management. Food Control. 2005; 16: p. 775-794.

22. Buchanan, R., R. Whiting, and T. Ross. (2006). Background paper for the joint FAO/WHO expert consultation on development of practical risk management strategies based on microbiological risk assessment outputs. Kiel, Germany, 3-7 April 2006. Case study: Listeria monocytogenes in smoked fish. "Development of Risk Management Metrics for Food Safety". Food and Agriculture Organization of the 
United Nations/World Health Organization: Rome/Geneva. Available from: http://www.fao.org/3/a-au625e.pdf

23. Butler, F., G. Duffy, D. Engeljohn, A.M. Lammerding, and R.B. Tompkin. (2006). Background paper for the joint FAO/WHO expert consultation on the development of practical risk management strategies based on microbiological risk assessment outputs. Kiel, Germany, 3-7 April 2006. Case study: Escherichia coli 0157:H7 in fresh ground beef. Food and Agriculture Organization of the United Nations/World Health Organization: Rome/Geneva. Available from: http://www.fao.org/3/a-au624e.pdf

24. DePaola, A., R. Lee, D. Mahoney, I. Rivera, and M. Tamplin. (2006). Background paper for the joint FAO/WHO expert consultation on the development of practical risk management strategies based on microbiological risk assessment outputs. Kiel, Germany, 3-7 April 2006. Case study: Vibrio vulnificus in oysters. Food and Agriculture Organization of the United Nations/World Health Organization: Rome/Geneva. Available from: http://www.fao.org/3/a-au626e.pdf

25. FAO/WHO. (2006). The use of microbiological risk assessment outputs to develop practical risk management strategies. Food and Agricultural Organization of the United Nations/World Health Organization: Rome/Geneva. Available from: https://www.who.int/foodsafety/publications/micro/MRA Outputs.pdf

26. Gkogka, E., M.W. Reij, L.G.M. Gorris, and M.H. Zwietering. The application of the Appropriate Level of Protection (ALOP) and Food Safety Objective (FSO) concepts in food safety management, using Listeria monocytogenes in deli meats as a case study. Food Control. 2013; 29: p. 382-393.

27. Pouillot, R., V. Goulet, M.L. Delignette-Muller, A. Mahé, and M. Cornu. Quantitative risk assessment of Listeria monocytogenes in French cold-smoked salmon: II. Risk characterization. Risk Analysis. 2009; 29: p. 806-819.

28. Tromp, S.O., E. Franz, H. Rijgersberg, E. Van Asselt, and I. Van Der Fels-Klerx. A model for setting performance objectives for Salmonella in the broiler supply chain. Risk Analysis. 2010; 30: p. 945-951.

29. Tuominen, P., J. Ranta, and R. Maijala. Studying the effects of POs and MCs on the Salmonella ALOP with a quantitative risk assessment model for beef production. International Journal of Food Microbiology. 2007; 118: p. 35-51.

30. Anderson, N.M., J.W. Larkin, M.B. Cole, G.E. Skinner, R.C. Whiting, L.G.M. Gorris, A. Rodriquez, R. Buchanan, C.M. Stewart, J.H. Hanlin, L. Keener, and P.A. Hall. Food safety objective approach for controlling Clostridium botulinum growth and toxin production in commercially sterile foods. Journal of Food Protection. 2011; 74: p. 1956-1989.

31. Crouch, E.A., D. LaBarre, N.J. Golden, J.R. Kause, and K.L. Dearfield. Application of quantitative microbial risk assessments for estimation of risk management metrics: 
Clostridium perfringens in ready-to-eat and partially cooked meat and poultry products as an example. Journal of Food Protection. 2009; 72: p. 2151-2161.

32. Membré, J.M., J. Bassett, and L.G.M. Gorris. Applying the food safety objective and related standards to thermal inactivation of Salmonella in poultry meat. Journal of Food Protection. 2007; 70: p. 2036-2044.

33. Sosa Mejia, Z., R.R. Beumer, and M.H. Zwietering. Risk evaluation and management to reaching a suggested FSO in a steam meal. Food Microbiology. 2011; 28: p. 631638.

34. Stewart, C.M., M.B. Cole, and D.W. Schaffner. Managing the risk of staphylococcal food poisoning from cream-filled baked goods to meet a food safety objective. Journal of Food Protection. 2003; 66: p. 1310-1325.

35. Redmond, E.C. and C.J. Griffith. Consumer food handling in the home: A review of food safety studies. Journal of Food Protection. 2003; 66: p. 130-161.

36. Zwietering, M.H. and S.J.C. van Gerwen. Sensitivity analysis in quatitative microbial risk assessment. International Journal of Food Microbiology. 2000; 58: p. 213-221.

37. Uyttendaele, M., K. Baert, K. Grijspeerdt, L. De Zutter, B. Horion, F. Devlieghere, M. Heyndrickx, and J. Debevere. Comparing the effect of various contamination levels for Salmonella in chicken meat preparations on the probability of illness in Belgium. Journal of Food Protection. 2009; 72: p. 2093-2105.

38. Mead, G., A.M. Lammerding, N. Cox, M.P. Doyle, F. Humbert, A. Kulikovskiy, A. Panin, V. Pinheiro do Nascimento, M. Wierup, and Salmonella on raw poultry writing committee. Scientific and technical factors affecting the setting of Salmonella criteria for raw poultry: a global perspective. Journal of Food Protection. 2010; 73: p. 15661590.

39. Hansen, T.B., B.B. Christensen, and S. Aabo. Salmonella in pork cuttings in supermarkets and butchers' shops in Denmark in 2002 and 2006. Zoonoses and Public Health. 2010; 57: p. 23-29.

40. Bollaerts, K.E., W. Messens, L. Delhalle, M. Aerts, Y. Van der Stede, J. Dewulf, S. Quoilin, D. Maes, K. Mintiens, and K. Grijspeerdt. Development of a quantitative microbial risk assessment for human salmonellosis through household consumption of fresh minced pork meat in Belgium. Risk Analysis. 2009; 29: p. 820-840.

41. Delhalle, L., C. Saegerman, W. Messens, F. Farnir, N. Korsak, Y. Van der Stede, and G. Daube. Assessing interventions by quantitative risk assessment tools to reduce the risk of human salmonellosis from fresh minced pork meat in Belgium. Journal of Food Protection. 2009; 72: p. 2252-2263.

42. De Sadeleer, L., J. Dewulf, L. De Zutter, Y. Van der Stede, S. Ribbens, E. De Busser, S. Quoilin, K. Houf, L. Delhalle, K. Grijspeerdt, and D. Maes. A qualitative risk 
assessment for human salmonellosis due to the consumption of fresh pork in Belgium. Vlaams Diergeneeskundig Tijdschrift. 2008; 78: p. 34-41.

43. Straver, J.M., A.F.W. Janssen, A.R. Linneman, M.A.J.S. van Boekel, R.R. Beumer, and M.H. Zwietering. Number of Salmonella on chicken breast fillet at retail level and its implications for public health risk. Journal of Food Protection. 2007; 70: p. 20452055.

44. Voedingscentrum. (1999). Hygiëne privé-huishouding Voedingscentrum: Den Haag. Available from: http://www.voedingscentrum.nl/nl.aspx

45. Nauta, M.J., S. Litman, G.C. Barker, and F. Carlin. A retail and consumer phase model for exposure assessment of Bacillus cereus. International Journal of Food Microbiology. 2003; 83: p. 205-218.

46. FAO/WHO. (2002). Risk assessments of Salmonella in eggs and broiler chickens. Food and Agriculture Organization of the United Nations/World Health Organization: Rome/Geneva. Available from: http://www.fao.org/3/a-y4392e.pdf

47. Notermans, S., J. Dufrenne, P. Teunis, R. Beumer, M. te Giffel, and P.P. Weem. A risk assessment of Bacillus cereus present in pasteurized milk. Food Microbiology. 1997; 14: p. 143-151.

48. Van Asselt, E.D. and M.H. Zwietering. A systematic approach to determine global thermal inactivation parameters for various food pathogens. International Journal of Food Microbiology. 2006; 107: p. 73-82.

49. Rossum, C.T.M., H.P. Fransen, J. Verkaik-Kloosterman, E.J.M. Buurma-Rethans, and M.C. Ocké. (2011). Dutch National Food Consumption Survey 2007-2010. Diet of children and adults aged 7 to 69 years. National Institute for Public Health and the Environment: Bilthoven. Available from: http://www.rivm.nl/vcp en/Images L02788 Dutch\%20National\%20Food\%20Consumption\%20Survey\%2020072010 def tcm81-74475.pdf

50. PVE. Productschap Vee en Vlees - Productschap Pluimvee en Eieren [cited 2012 December 11]. Available from: http://www.pve.nl/pve?waxtrapp=teGsHsuOnbPTE

51. Aalten, M., O. Stenvers, W. van Pelt, M. Braks, B. Schimmer, and M. Langelaar. (2010). Staat van zoönosen 2009. Rijksinstituut voor Volksgezondheid en Milieu (RIVM): Bilthoven. Available from: http://www.rivm.nl/bibliotheek/rapporten /330131002.html

52. Aalten, M., A. de Jong, O. Stenvers, M. Braks, I. Friesema, K. Maassen, W. Van Pelt, B. Schimmer, and P. Geenen. (2011). Staat van zoönosen 2010. National Institute of Public Health and the Environment: Bilthoven. Available from: http://www.rivm.nl/bibliotheek/rapporten/330291007.html

53. Nauta, M.J., W.F. Jacobs-Reitsma, E.G. Evers, W. Van Pelt, and A.H. Havelaar. (2005). Risk assessment of Campylobacter in the Netherlands via broiler meat and 
other routes. National Institute for Public Health and the Environment: Bilthoven. Available from: http://www.rivm.nl/bibliotheek/rapporten/250911006.html

54. Montville, R., Y. Chen, and D.W. Schaffner. Glove barriers to bacterial crosscontamination between hands to food. Journal of Food Protection. 2001; 64: p. 845849.

55. Ravishankar, S., L. Zhu, and D. Jaroni. Assessing the cross-contamination and trasfer rates of Salmonella enterica from chicken to lettuce under different food handling scenarios. Food Microbiology. 2010; 27: p. 791-794.

56. Dufrenne, J., W. Ritmeester, E. Delfgou-van Asch, F. van Leusden, and R. de Jonge. Quantification of the contamination of chicken and chicken products in the Netherlands with Salmonella and Campylobacter. Journal of Food Protection. 2001; 64: p. 538-541.

57. van der Fels-Klerx, H.J., W.F. Jacobs-Reitsma, R. van Brakel, H. van der Voet, and E.D. Van Asselt. Prevalence of Salmonella in the broiler supply chain in the Netherlands. Journal of Food Protection. 2008; 71: p. 1974-1980.

58. Adams, M.R. and M.O. Moss. Food Microbiology (2nd edition). 2006. The Royal Society of Chemistry: Cambridge

59. den Besten, H.M.W. and M.H. Zwietering. Meta-analysis for quantitative microbial risk assessments and benchmarking data Trends in Food Science and Technology. 2012; 25: p. 34-39.

60. IFR/USDA - ARS/FSC. ComBase, 2011, Institute of Food Research/United States Department of Agriculture - Agricultural Research Service/Food Safety Centre.

61. D'Aoust, J.Y. Psychrotrophy and foodborne Salmonella. International Journal of Food Microbiology. 1991; 13: p. 207-216.

62. ICMSF. International Commission on Microbiological Specifications for Foods. Microorganisms in Foods 5. Characteristics of microbial pathogens. edition). 1996. T.A. Roberts, A.C. Baird-Parker, and R.B. Tompkin (eds). Blackie Academic and Professional: London

63. ICMSF. International Commission on Microbiological Specifications for Foods. MicroOrganisms in Foods 6 : Microbial Ecology of Food Commodities edition). 2005. Kluwer Academic/Plenum Publishers: Boston, MA

64. Oscar, T.P. Predictive models for growth of Salmonella Typhimurium DT104 from low and high initial density on ground chicken with a natural microflora. Food Microbiology. 2007; 24: p. 640-651.

65. Oscar, T.P. Validation of a tertiary model for predicting variation of Salmonella Typhimurium DT104 (ATCC 700408) growth from a low initial density of ground chicken breast meat with a competitive flora Journal of Food Protection. 2006; 69: p. 2048-2057. 
66. Langston, S.W., N.S. Altman, and J.H. Hotchkiss. Within and between sample comparisons of Gompertz parameters for Salmonella enteritidis and aerobic plate counts in chicken stored in air and modified atmosphere. International Journal of Food Microbiology. 1993; 18: p. 43-52.

67. Nissen, H., T. Maugesten, and P. Lea. Survival and growth of Escherichia coli 0157:H7, Yersinia enterocolitica and Salmonella Enteritidis on decontaminated and untreated meat. Meat Science 2001; 57: p. 291-298.

68. Bovill, R., J. Bew, N. Cook, M. D'Agostino, N. Wilkinson, and J. Baranyi. Predictions of growth for Listeria monocytogenes and Salmonella during fluctuating temperature. International Journal of Food Microbiology. 2000; 59: p. 157-165.

69. Oscar, T.P. Predictive model for survival and growth of Salmonella Typhimurium DT104 on chicken skin during temperature abuse. Journal of Food Protection. 2009; 72: p. 304-314.

70. Oscar, T.P. Development and validation of a predictive microbiology model for survival and growth of Salmonella on chicken stored at 4 to $12{ }^{\circ} \mathrm{C}$. Journal of Food Protection. 2011; 74: p. 279-284.

71. Oscar, T.P. General regression neural network and Monte Carlo simulation model for survival and growth of Salmonella on raw chicken skin as a function of serotype, temperature, and time for use in risk assessment. Journal of Food Protection. 2009; 72: p. 2078-2087.

72. Ratkowsky, D.A., J. Olley, T.A. McMeekin, and A. Ball. Relationship between temperature and growth rate of bacterial cultures. Journal of Bacteriology. 1982; 149: p. 1-5.

73. Terpstra, M.J., L.P.A. Steenbekkers, N.C.M. de Maertelaere, and S. Nijhuis. Food storage and disposal: consumer practices and knowledge. British Food Journal. 2006; 107: p. 526-533.

74. Buchanan, R.L., M.H. Golden, R.C. Whiting, J.G. Phillips, and J.L. Smith. Non-thermal inactivation models for Listeria monocytogenes. Journal of Food Science. 1994; 59: p. $179-188$.

75. Mylius, S.D., M.J. Nauta, and A.H. Havelaar. Cross-contamination during food preparation: a mechanistic model applied to chicken-borne Campylobacter. Risk Analysis. 2007; 27: p. 803-813.

76. Nauta, M., A. Hill, H. Rosenquist, S. Brynestad, A. Fetsch, P. Van der Logt, A. Fazil, B. Christensen, E. Katsma, B. Borck, and A. Havelaar. A comparison of risk assessments on Campylobacter in broiler meat. International Journal of Food Microbiology. 2009; 129: p. 107-123.

77. RIVM. Dutch National Food Consumption Surveys (DNFCS) [cited 2010 May 27]. Available from: http://www.rivm.nl/vcp en/overview/ 
78. Hogeweg, L. The meaning and interpretation of the Dutch particle wel. Journal of Pragmatics. 2009; 41: p. 519-539.

79. Anonymous. ESL: English Study and Learning materials [cited 201216 December]. Available from: http://www.eslgold.com/grammar/frequency adverbs.html

80. EUROSTAT. Consumption of certain foodstuffs per inhabitant [cited 2011 November 10]. Available from: http://epp.eurostat.ec.europa.eu/tgm /refreshTableAction. do?tab=table\&plugin $=1 \&$ pcode $=$ tsdpc330\&language $=$ en

81. CBS. Statistics Netherlands [cited 2009 September 30]. Available from: http://www.cbs.nl/en-GB/menu/home/default.htm

82. EFSA. Opinion of the Scientific Panel on Biological Hazards on microbiological criteria and targets based on risk analysis (Question No EFSA-Q-2005-296). EFSA Journal. 2007; 5: 462.

83. ICMSF. (2006). A simplified guide to understanding and using Food Safety Objectives and Performance Objectives. International Commission on Microbiological Specifications for Foods: Available from: http://www.icmsf.org/publications/guide/

84. Rocourt, J., G. Moy, K. Vierk, and J. Schlundt. (2003). The present state of foodborne disease in OECD countries. World Heath Organization: Geneva. Available from: http://www.who.int/foodsafety/publications/foodborne disease/en/OECD\%20Final \%20for\%20WEB.pdf

85. Havelaar, A.H., S. Ivarsson, M. Löfdahl, and M.J. Nauta. Estimating the true incidence of campylobacteriosis and salmonellosis in the EU, 2009 Epidemiology and Infection. 2013; 141: p. 293-302.

86. RIVM. (2006). Our food our health. Healthy diet and safe food in the Netherlands. RIVM report number 270555009. National Institute for Public Health and the Environment: Bilthoven. Available from: http://www.rivm.nl/bibliotheek/rapporten 2270555009.pdf

87. Havelaar, A.H., E.G. Evers, and M.J. Nauta. Challenges in quantitative microbial risk assessment at EU level. Trends in Food Science and Technology. 2008; 19: p. S26S33.

88. Havelaar, A.H., A.V. Galindo, D. Kurowicka, and R.M. Cooke. Attribution of foodborne pathogens using structured expert elicitation. Foodborne Pathogens and Disease. 2008; 5: p. 649-659.

89. Scallan, E., R.M. Hoekstra, F.J. Angulo, R.V. Tauxe, M.A. Widdowson, S.L. Roy, J.L. Jones, and M.P. Griffin. Foodborne illness acquired in the United States - Major pathogens. Emerging Infectious Diseases. 2011; 17: p. 7-15.

90. Hall, G., D.M. Kirk, N. Becker, E.J. Gregory, L. Unicomb, G. Millard, R. Stafford, K. Lalor, and O.W. Group. Estimating foodborne gastroenteritis, Australia. Emerging Infectious Diseases. 2005; 11: p. 1257-1264. 
91. Mead, P.S., L. Slutsker, V. Dietz, L.F. McCaig, J.S. Breese, C. Shapiro, P.M. Griffin, and R.V. Tauxe. Food-related illness and death in the United States. Emerging Infectious Diseases. 1999; 5: p. 607-625.

92. EFSA. The Community summary report on trends and sources of zoonoses, zoonotic agents and antimicrobial resistance in the European Union in 2004. EFSA Journal. 2005; 3: 310ar.

93. EFSA/ECDC. The Community summary report on trends and sources of zoonoses, zoonotic agents, antimicrobial resistance and foodborne outbreaks in the European Union in 2005. EFSA Journal. 2006; 4: 94r.

94. EFSA/ECDC. The Community summary report on trends and sources of zoonoses, zoonotic agents, antimicrobial resistance and foodborne outbreaks in the European Union in 2006. EFSA Journal. 2007; 5: 130r.

95. EFSA/ECDC. The Community summary report on trends and sources of zoonoses and zoonotic agents in the European Union in 2007. EFSA Journal. 2009; 7: 223r.

96. EFSA/ECDC. The Community summary report on trends and sources of zoonoses, zoonotic agents and food-borne outbreaks in the European Union in 2008. EFSA Journal. 2010; 8: 1496.

97. EFSA/ECDC. The European Union summary report on trends and sources of zoonoses, zoonotic agents and food-borne outbreaks in 2009. EFSA Journal. 2011; 9: 2090.

98. EFSA/ECDC. The European Union summary report on trends and sources of zoonoses, zoonotic agents and foodborne outbreaks in 2010. EFSA Journal. 2012; 10: 2597.

99. Pires, S.M., L. de Knegt, and T. Hald. (2011). Scientific/Technical report submitted to EFSA. Estimation of the relative contribution of different food and animal sources to human Salmonella infections in the European Union. European Food Safety Authority: Parma. Available from: http://www.efsa.europa.eu/en/supporting $\angle$ pub/184e.htm

100. Adak, G.K., S.M. Long, and S.J. O'Brien. Trends in indigenous foodborne disease and deaths, England and Wales: 1992 to 2000. Gut. 2002; 51: p. 832-841.

101. Vaillant, V., H. De Valk, E. Baron, T. Ancelle, P. Colin, M.-C. Delmas, B. Dufour, R. Pouillot, Y. Le Strat, P. Weinbreck, E. Jougla, and J.C. Desenclos. Foodborne infections in France. Foodborne Pathogens and Disease. 2005; 2: p. 221-232.

102. Vose, D. Risk analysis: a quantitative guide (Third edition). 2008. John Wiley and Sons, Ltd: Chichester, West Sussex

103. Eurostat. Population on 1 January by age and sex [cited 2012 April 25]. Available from: http://appsso.eurostat.ec.europa.eu/nui Lshow.do?dataset $=$ demo pjan\&lang=en 
104. de Wit, A.S.M., P.G.M. Koopmans, M.L. Kortbeek, N.J. van Leeuwen, A.I.M. Bartelds, and T.H.P.Y. van Duynhoven. Gastroenteritis in sentinel general practices, the Netherlands. Emerging Infectious Diseases. 2001; 7: p. 82-91.

105. Majowicz, S.E., G. Hall, E. Scallan, G.K. Adak, C. Gauci, T.F. Jones, S. O'Brien, O. Henao, and P.N. Sockett. A common, symptom-based case definition for gastroenteritis. Epidemiology and Infection. 2007; 136: p. 886-894.

106. Burgess, F., C.L. Little, G. Allen, K. Williamson, and R.T. Mitchell. Prevalence of Campylobacter, Salmonella, and Escherichia coli on the external packaging of raw meat. Journal of Food Protection. 2005; 68: p. 469-475.

107. Chen, Y., K.M. Jackson, F.P. Chea, and D.W. Schaffner. Quantification and variability analysis of bacterial cross-contamination rates in common food service tasks. Journal of Food Protection. 2001; 64: p. 72-80.

108. Gerba, C.P., D. Williams, and R.G. Sinclair. Assessment of the potential for crosscontamination of food products by reusable shopping bags. Food Protection Trends. 2011; 31: p. 508-513.

109. Batz, M.B., M.P. Doyle, J.G. Morris, J. Painter, R. Singh, R.V. Tauxe, M.R. Taylor, and D.M.A. Lo Fo Wong. Attributing illness to food. Emerging Infectious Diseases. 2005; 11: p. 993-999.

110. Ekdahl, K. and J. Giesecke. Travellers returning to Sweden as sentinels for comparative disease incidence in other European countries, Campylobacter and Giardia infection as examples. Eurosurveillance. 2004; 9: p. 6-9

111. Codex Alimentarius. (2011). F.a.A.O.o.t.U. Nations. Joint FAO/WHO Food Standards Programme. Codex Alimentarius Commission. Procedural Manual. Twentieth edition. Available from: ftp://ftp.fao.org/codex/Publications/ProcManuals/Manual 20e.pdf

112. Oscar, T.P. A quantitative risk assessment model for Salmonella and whole chickens. International Journal of Food Microbiology. 2004; 93: p. 231-247.

113. Gonzales-Barron, U.A., G. Redmond, and F. Butler. A consumer-phase exposure assessment of Salmonella Typhimurium from Irish fresh pork sausages: II. Cooking and consumption modules. Food Control. 2010; 21: p. 1693-1702.

114. Pouillot, R. and M.B. Lubran. Predictive microbiology models vs. modeling microbial growth within Listeria monocytogenes risk assessment: What parameters matter and why. Food Microbiology. 2011; 28: p. 720-726.

115. Zwietering, M.H. Quantitative risk assessment: Is more complex always better? Simple is not stupid and complex is not always more correct. International Journal of Food Microbiology. 2009; 134: p. 57-62.

116. Gilbert, S.E., R. Whyte, G. Bayne, S.M. Paulin, R.J. Lake, and P. van der Logt. Survey of domestic food handling practices in New Zealand. International Journal of Food Microbiology. 2007; 117: p. 306-311. 
117. Jevšnik, M., V. Hlebec, and P. Raspor. Consumers' awareness of food safety from shopping to eating. Food Control. 2008; 19: p. 737-745.

118. Fischer, A.R.H., A.E.I. De Jong, E.D. Van Asselt, R. De Jonge, L.J. Frewer, and M.J. Nauta. Food safety in the domestic environment: an interdisciplinary investigation of microbial hazards during food preparation. Risk Analysis. 2007; 27: p. 1065-1082.

119. Worsfold, D. and C.J. Griffith. Assessment of the standard of consumer food safety behaviour. Journal of Food Protection. 1997; 60: p. 399-406.

120. Abbot, J.M., C. Byrd-Bredbenner, D. Schaffner, C.M. Bruhn, and L. Blalock. Comparison of food safety cognitions and self-reported food-handling behaviors with observed food safety behaviors of young adults. European Journal of Clinical Nutrition. 2009; 63: p. 572-579.

121. Smith, J.L. Foodborne illness in the elderly. Journal of Food Protection. 1998; 61: p. 1229-1239.

122. Gonzales-Barron, U.A., G. Redmond, and F. Butler. A risk characterization model of Salmonella Typhimurium in Irish fresh pork sausages. Food Research International. 2012; 45: p. 1184-1193.

123. Kusumaningrum, H.D., E.D. van Asselt, R.R. Beumer, and M.H. Zwietering. A quantitative analysis of cross-contamination of Salmonella and Campylobacter spp. via domestic kitchen surfaces. Journal of Food Protection. 2004; 67: p. 1892-1903. 


\section{Chapter 5}

Risk assessment of Clostridium perfringens in Cornish pasties in the UK

Elissavet Gkogka, Martine W. Reij, Leon G.M. Gorris and Marcel H. Zwietering

Accepted for publication in Food Control 


\section{Abstract}

To assess the risk of Clostridium perfringens toxico-infections related to the consumption of Cornish pasties in the United Kingdom, a stochastic risk assessment model was created. Exposure to the pathogen was modelled as the result of contamination of different ingredients (i.e. beef and pepper), application of different cooling scenarios at room temperature and considering pasties of a number of common sizes. The model predicted a mean of 213 cases of gastroenteritis per million people in the UK per year (95\% CI: 128 317), which might explain a significant proportion of annual C. perfringens toxico-infections according to epidemiological data. Major factors influencing this estimate and possible targets for interventions were the time to consumption and the concentration of the pathogen in contaminated ingredients, the impact of which in reducing the risk was tested in different intervention scenarios. The results of the model together with a number of possible risk mitigation measures are used as a basis to discuss the potential of setting of risk-based metrics as a risk management option in the context of food safety decisionmaking. 


\section{Introduction}

Clostridium perfringens is a common cause of foodborne gastrointestinal illness in developed countries [1-3]. The disease usually manifests itself with abdominal pain, nausea and diarrhoea 6-24 $\mathrm{h}$ after the consumption of contaminated food and lasts for about 24h. Though in the vast majority of cases it is self-limiting, in the vulnerable population (elderly, very young patients) deaths can occur due to dehydration [4]. The microorganism is widely distributed in nature and can be considered a foodborne pathogen of importance to public health because of its abilities to produce heat resistant spores, grow very rapidly in food and produce toxins [5].

C. perfringens is mainly associated with meat dishes such as stews, meat gravies, roast joints and meat pies [6] because of its inability to synthesize essential amino acids that can be found in meat [7] but also because of the mode of preparation and consumption of these products [6]. Typically, a large number of vegetative cells need to be ingested to cause illness which is due to the release of enterotoxin during the sporulation of toxigenic strains of the microorganism (cpe+ strains) in the intestine and for this reason is referred to as a toxico-infection. This large number of vegetative cells may be reached when food has been temperature-abused after cooking, either during cooling or during unrefrigerated storage, processes which would allow the germination of spores being present in the product and the multiplication of vegetative cells of the pathogen [8].

Meat pies and pasties are food items traditionally consumed in large quantities in the United Kingdom where the incidence of $C$. perfringens toxico-infections is high, with most recent estimates suggesting it is the third most common cause of bacterial gastroenteritis [3]. However, the extent of their contribution to the total number of cases in the country is unknown. Though in comparison with stews and roast joints they are less often reported to be the vehicle of outbreaks (Adedoyin Awofisayo, personal communication), deciding on the proportion of cases that are due to meat pies and pasties on the basis of available outbreak data is very difficult. The main reasons for this are that reported and investigated outbreaks represent only part of all outbreaks occurring and do not include sporadic cases while the implicated food vehicle is not always identified or described in enough detail [9] to be classified as a meat pie or a pasty. In view of the lack of epidemiological data regarding this product group, risk assessment could be another way to put the risk due to meat pies and pasties into perspective by investigating their potential contribution in the total number of cases of $C$. perfringens toxico-infections in the country.

Performing a risk assessment for $C$. perfringens in meat pies and pasties can be relatively complicated as: 1) there is substantial variation in their recipes, both in terms of ingredients and preparation mode, 2) more than one ingredients (meat, spices, vegetables) can lead to the introduction of the pathogen to the product, 3) they vary considerably in size and shape, factors that can affect the cooling time which in turn is 
related to the risk of the pathogen multiplying to significantly high levels in the product to cause illness, 4) they may be frozen, refrigerated, held hot or stored at ambient temperatures following baking.

The goal of this study was to develop a stochastic risk assessment model for $C$. perfringens that could easily be adapted for different types of meat pies and pasties using product specific data on the prevalence of the pathogen in the raw ingredients and the time and temperature of baking, cooling and storage steps. The model is here described for Cornish pasties, a Protected Geographical Indication (PGI) meat pie consumed in large quantities in the UK which is not evidently associated with C. perfringens and serves as an example of building a risk assessment model with limited input. Our aims were: to quantify the current level of risk associated with the consumption of Cornish pasties in the country, to identify factors contributing to risk, to evaluate the efficiency of different approaches in mitigating the risk for this product on the basis of our model and to relate control measures to risk-based metrics for food safety decision-making $[10,11]$.

\section{Materials and Methods}

\subsection{Product description}

The focus of this risk assessment is on Cornish pasties, i.e. D-shaped meat pies of various sizes that have gained in recent years the status of Protected Geographical Indication (PGI) products [12]. Cornish pasties are consisted of pastry dough used to encase a filling consisted traditionally of potato, swede, onion, uncooked beef, salt and pepper. They contain no artificial colours, flavours or preservatives and they are characterized by joining the edges of the dough (crimping) always on one side of the pasty. From a legal point of view, for marketed pasties to bear the indication Cornish they need to be assembled in Cornwall although ingredients can originate from different areas and the baking can also take place elsewhere [13]. For the purpose of this study, the production of Cornish pasties was mimicked following a traditional recipe [14] and using locally available ingredients.

\subsection{Design of the risk assessment model}

To estimate the risk associated with the consumption of pasties, a stochastic risk assessment model was built from the time point that the pasties enter the oven for baking until the moment of consumption (Figure 1 ). In short, exposure to $C$. perfringens was estimated taking into account contamination of recipe ingredients with spores of the pathogen (pepper, beef or both), spore inactivation during baking and spore germination/growth as a result of inappropriate cooling at room temperature. The probability of acquiring a toxico-infection was estimated by coupling estimations on dose of vegetative cells per contaminated serving with an exponential dose response model derived from a combination of feeding trial and outbreak data [15-17]. 


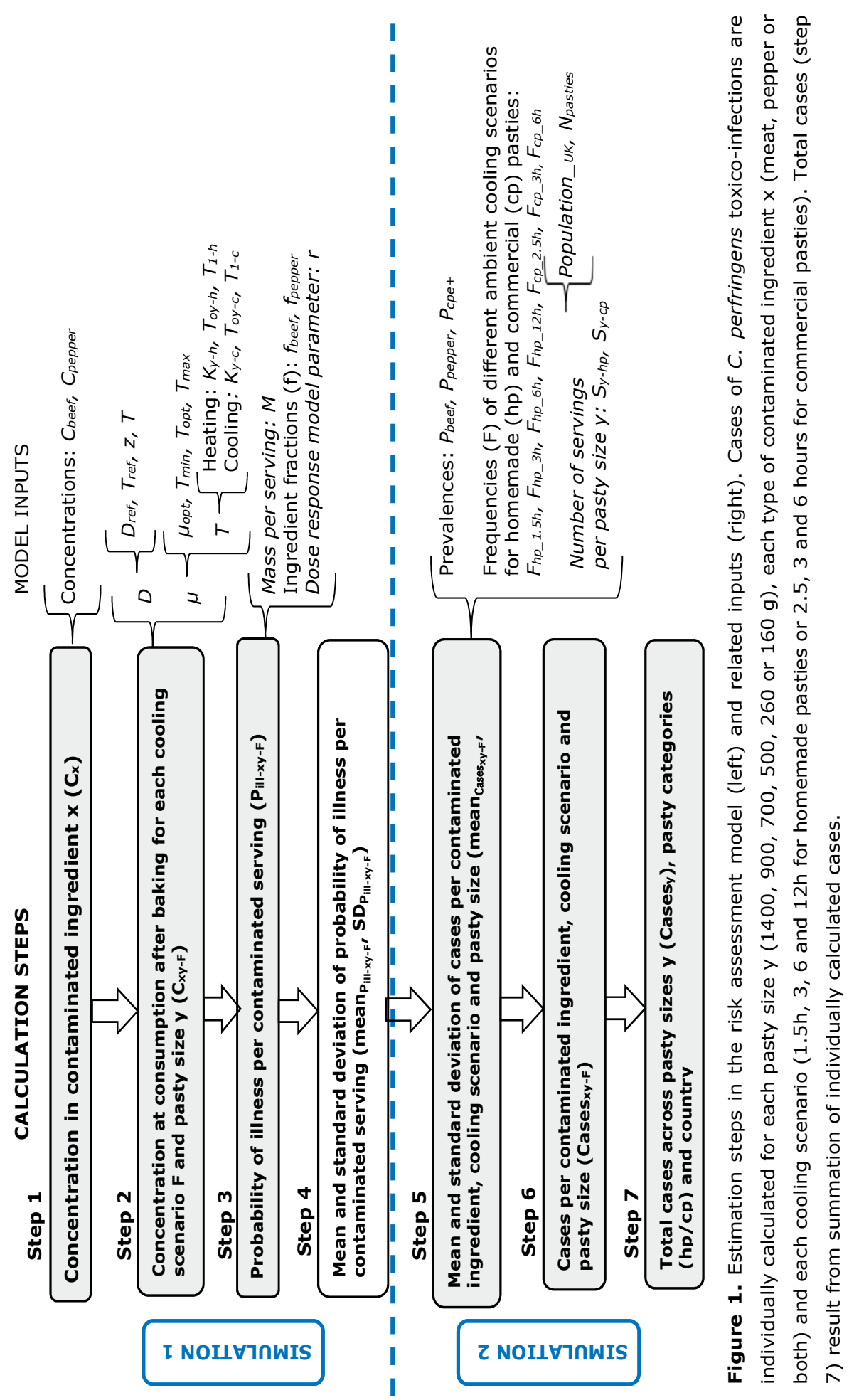


To calculate cases due to contaminated pasties, the Central Limit Theorem (CLT) was applied to first calculate the mean and standard deviation of the probability of toxicoinfection distribution and then to calculate the number of cases using the number of contaminated servings [18]. Basic calculation steps presented in flow diagram of Figure 1 were repeated for pasties of six different sizes and two different cooling scenarios based on consumer practices for homemade pasties [19] or assumptions regarding commercial cooling and time to consumption following purchase for commercial pasties. Cooling for both homemade and commercial pasties was assumed to take place at ambient temperatures $\left(20.5 \pm 0.5{ }^{\circ} \mathrm{C}\right)$. To acquire a time-temperature profile necessary for estimating inactivation during baking and growth during cooling, pasties of different sizes $(160,260,500,700,900$ and $1400 \mathrm{~g})$ were baked in a fan assisted oven at $165^{\circ} \mathrm{C}$ and the temperature at the core of the products was monitored using either iButtons (DS1922T, MAXIM) or a thermocouple data logger (Eltek, 851). Selection of product sizes was based on data available regarding traditional recipes $[14,20,21]$ for homemade pasties, UK retail data for commercial pasties [22, 23] and trends in portion sizes for pasties [24]. The risk associated with the consumption of Cornish pasties was expressed as cases per million people per year. A summary of the inputs and outputs of the model is given in Table 1 and a more detailed description of the estimation steps is provided below.

\subsection{Estimation steps in the risk assessment model}

Step 1 - Concentration of $C$. perfringens in contaminated ingredient $x\left(C_{x}\right)$. Ingredients that were considered to be potentially contaminated with $C$. perfringens were beef and black pepper based on what is generally known about meat being commonly implicated in outbreaks of the disease [25] and spices being considered a potential route of introducing the pathogen to foods [26]. C. perfringens given its presence in soil [5] could also be a contaminant of the vegetables (swede, potatoes) used in the preparation of pasties but these ingredients were not considered to be a source of contamination since their contribution in outbreaks is low [25] while in this particular product they are peeled, a process which would remove most of the microbial load. The concentration of $C$. perfringens in beef was based on swab data from the Food Standards Agency (FSA) collected from 3,249 fresh retail samples (whole cuts of various sizes: mean $511 \mathrm{~g}$, SD 307g) [27]. Of the 489 swab samples found to be positive in this study, only 3 had a concentration $>0 \log \mathrm{CFU} / \mathrm{g}$ and 268 had a concentration $<-2.5 \log \mathrm{CFU} / \mathrm{g}$. The cumulative probabilities of these concentrations were used to build a normal distribution in @RISK which was assumed to be representative of the concentration of spores in contaminated beef, as studies from other countries show that spore levels in meat are similarly low [28]. 


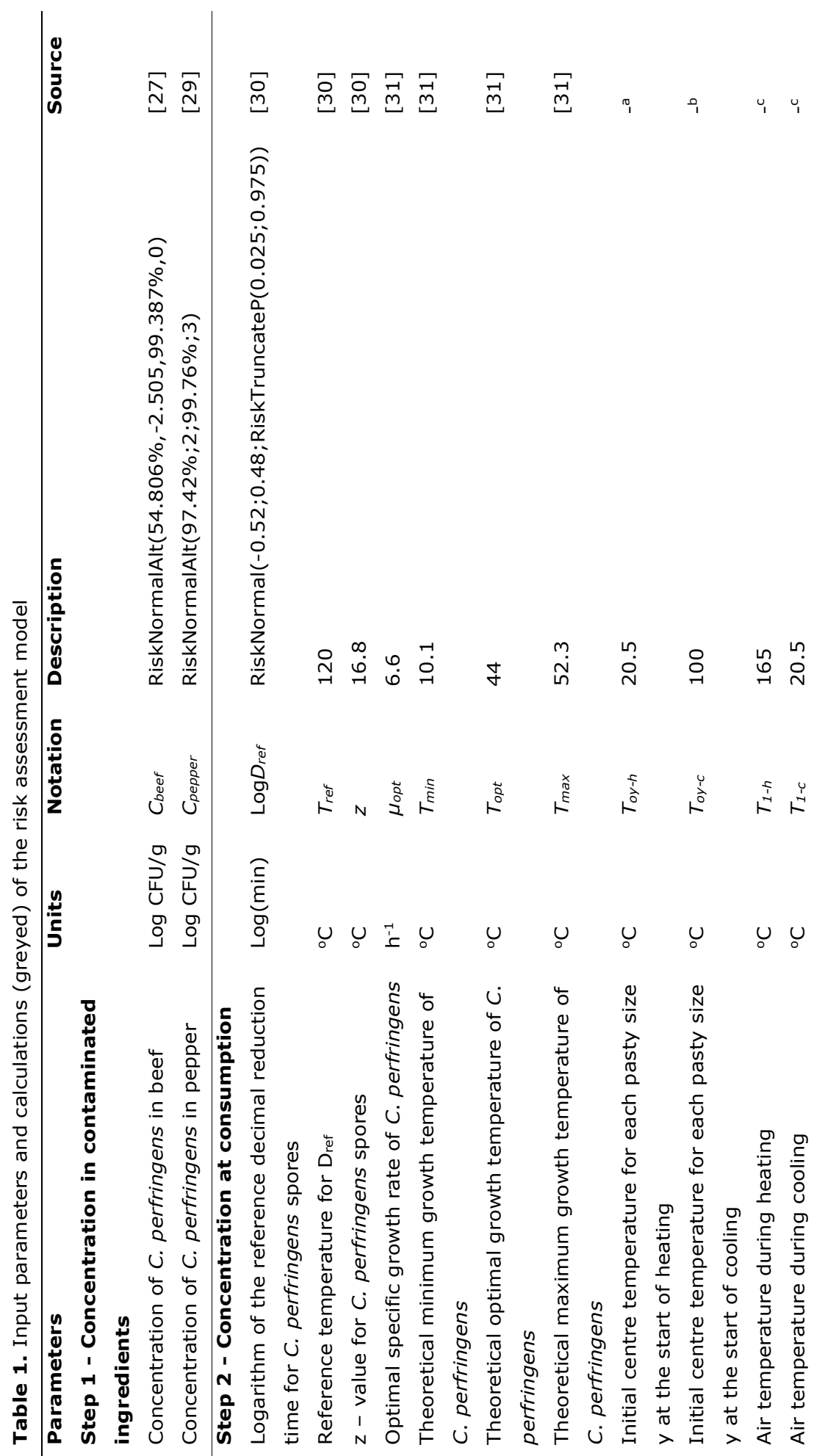




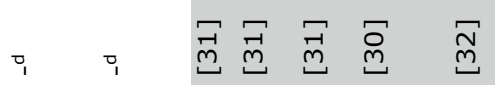

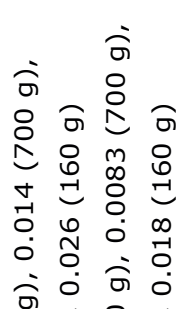

ชิ ธิ ถั่

o 000

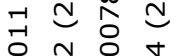

:

जें कें

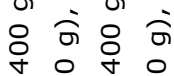

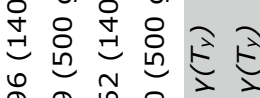

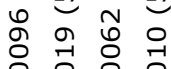

落

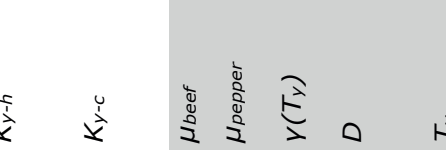

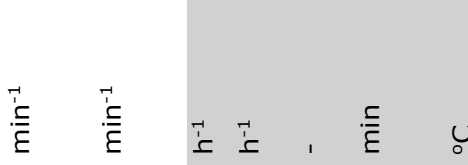

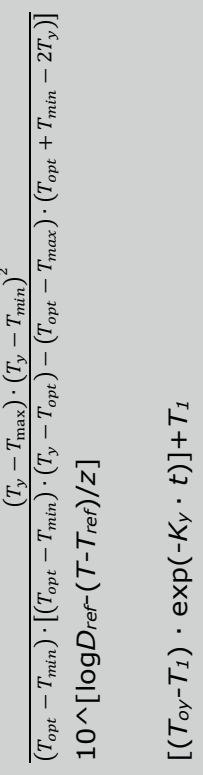

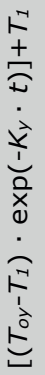

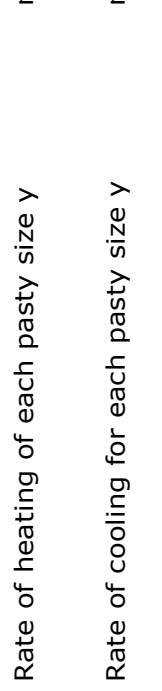

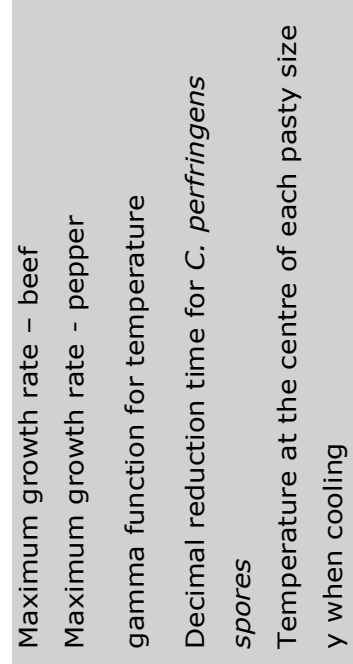

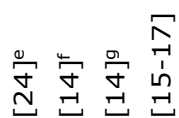

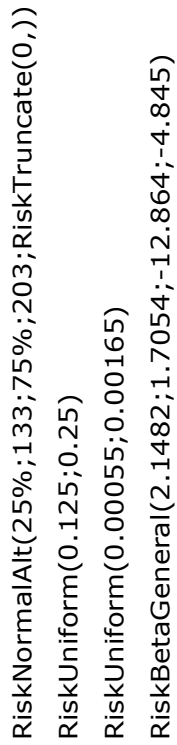

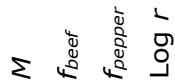

밀

옹 व

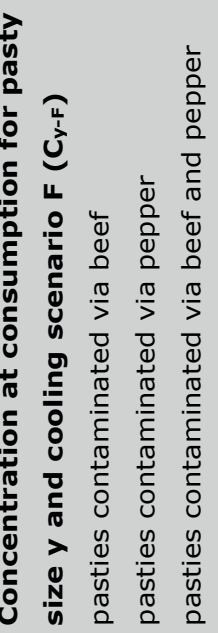

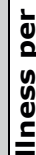

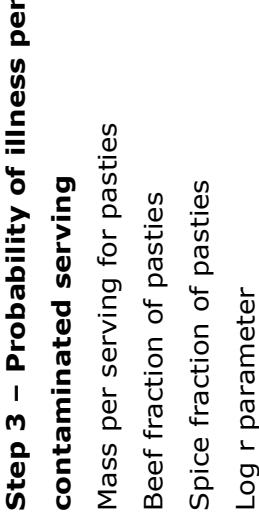




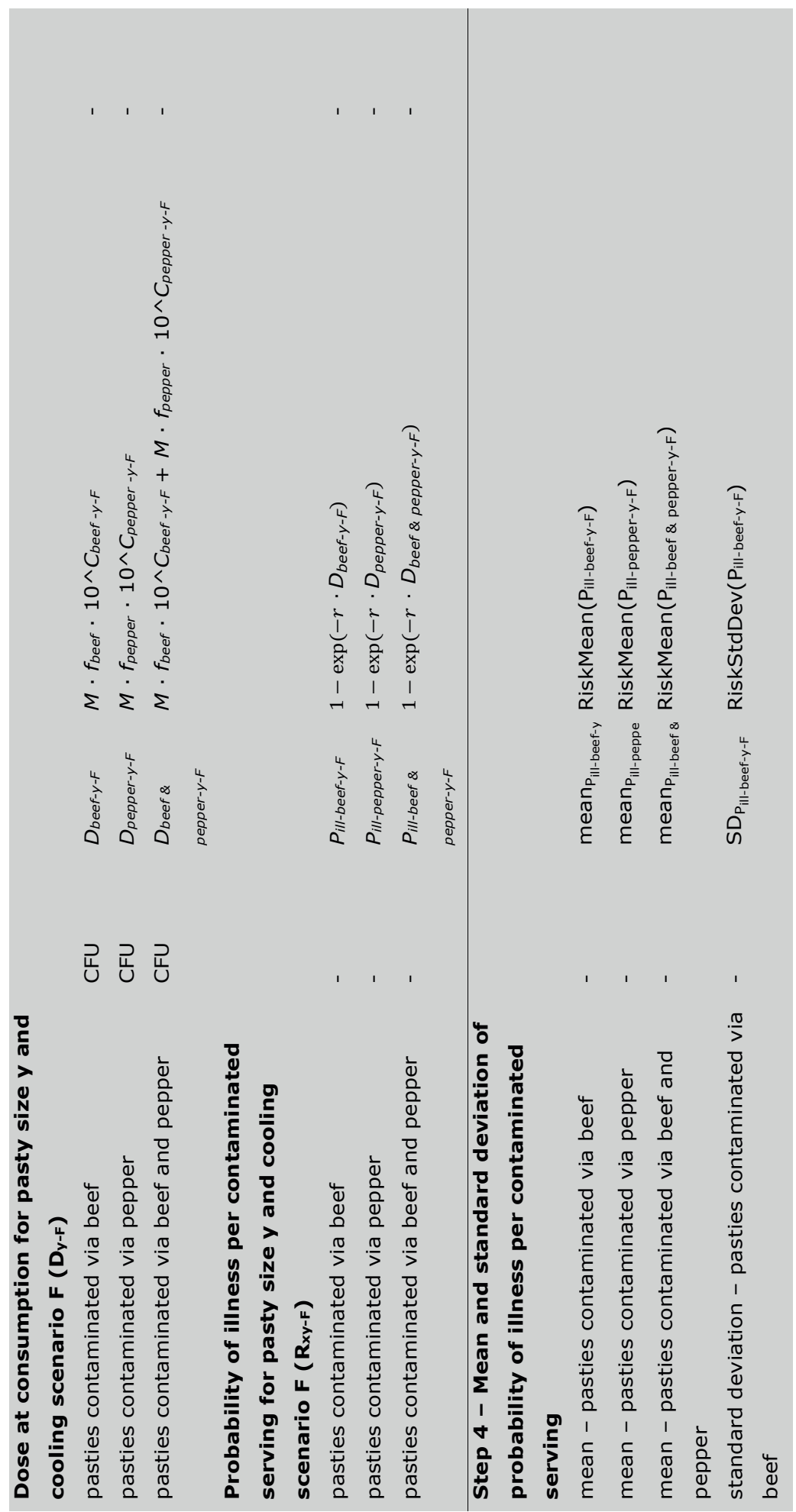



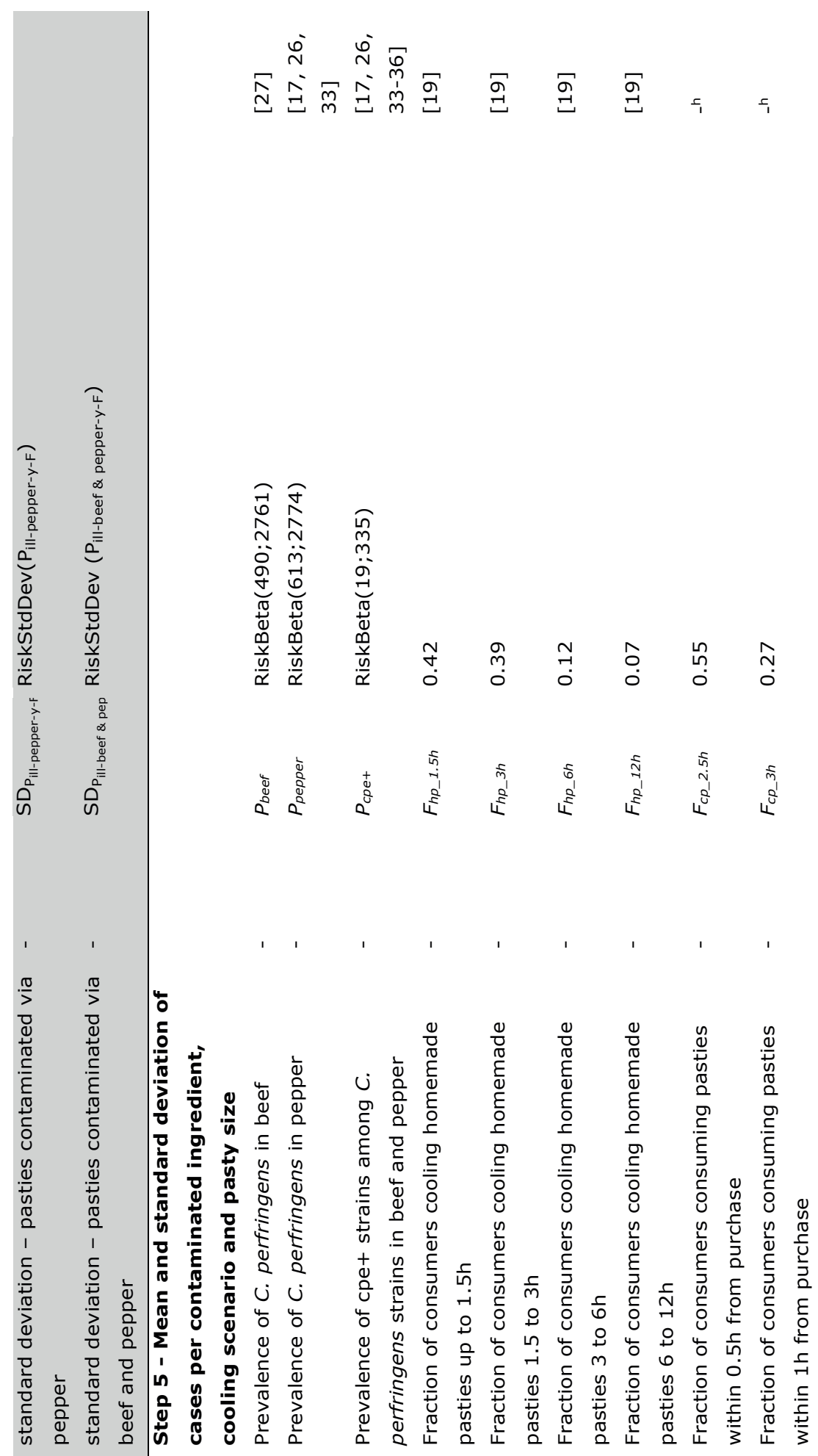


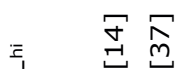

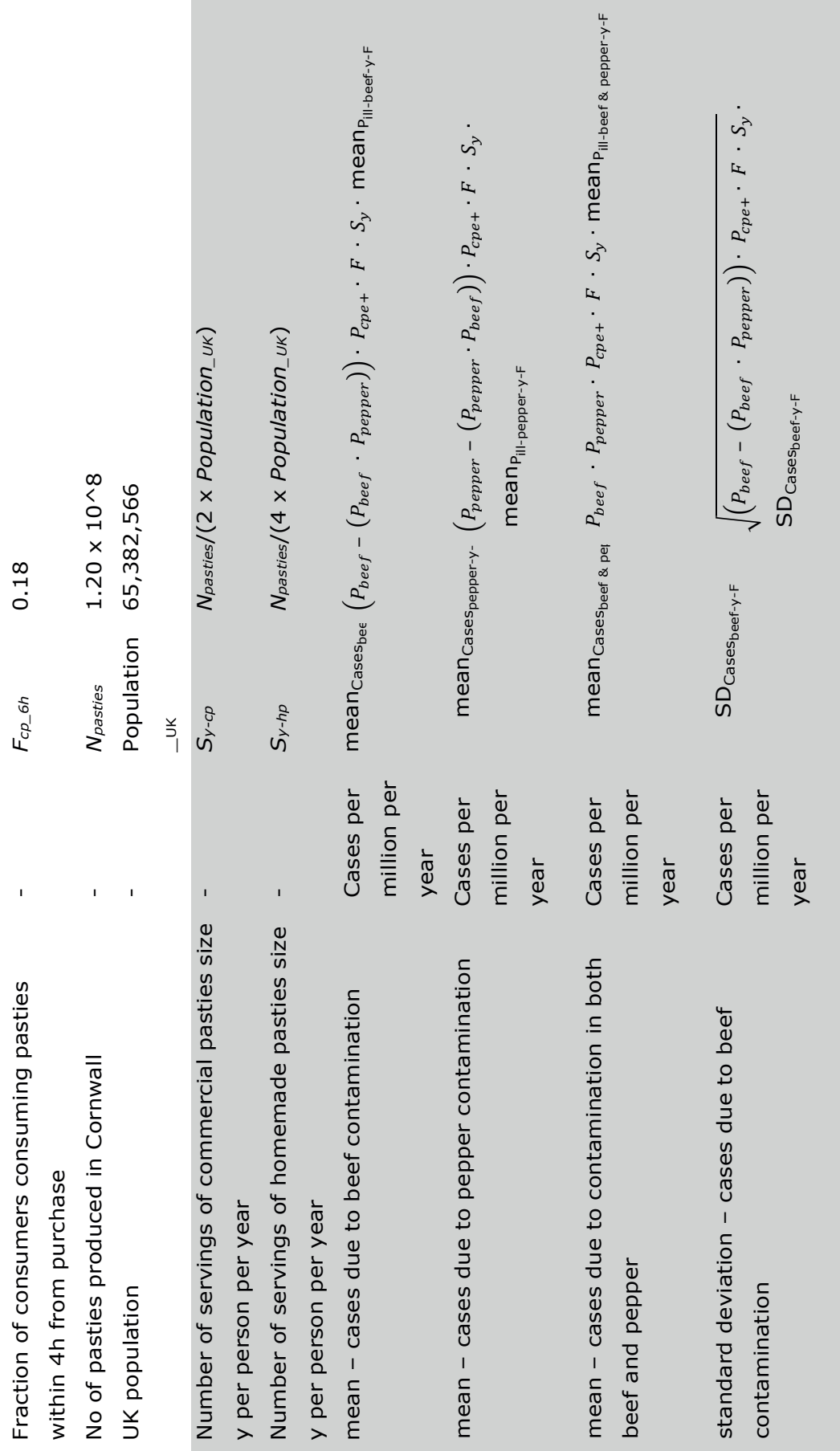




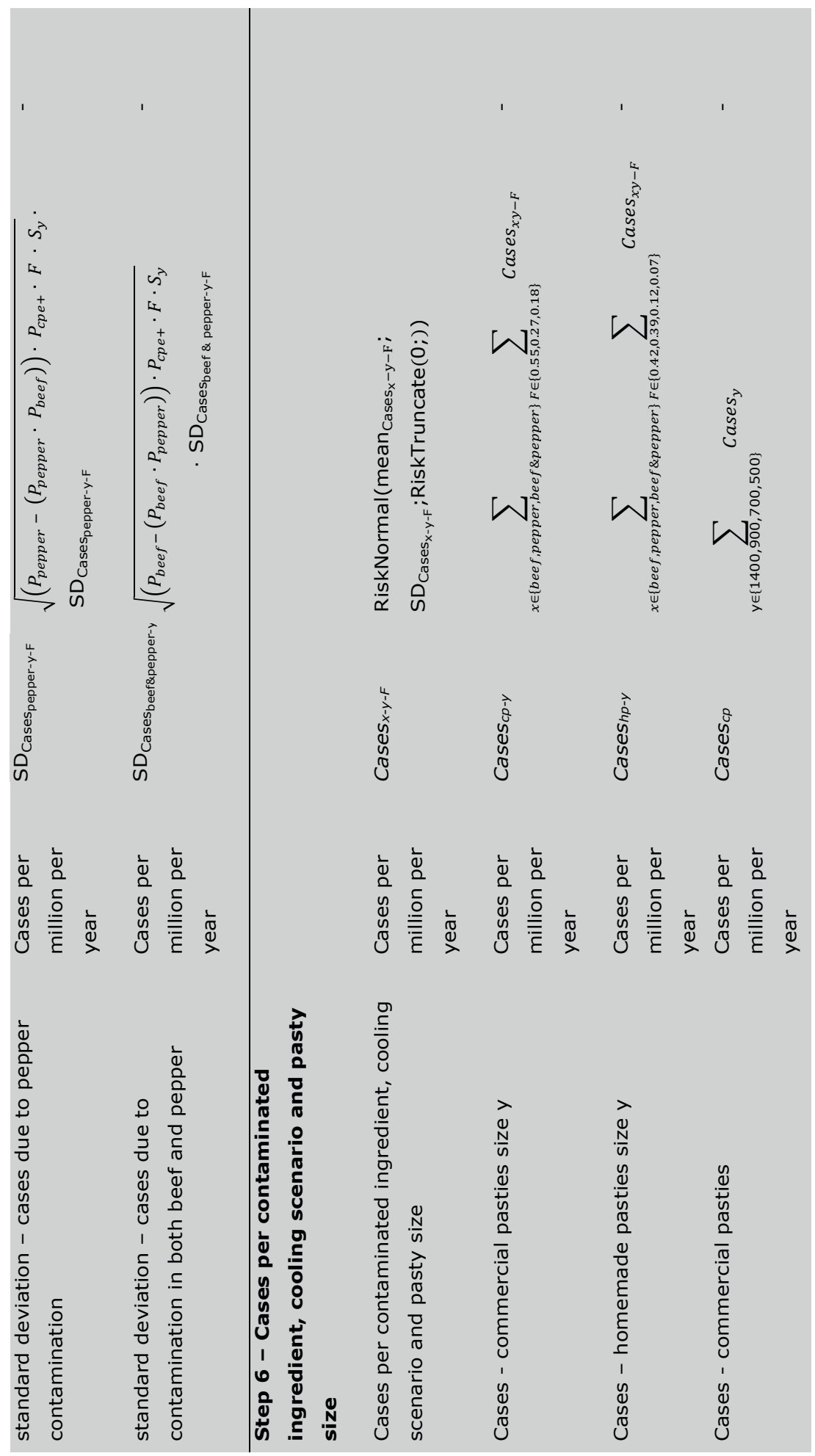




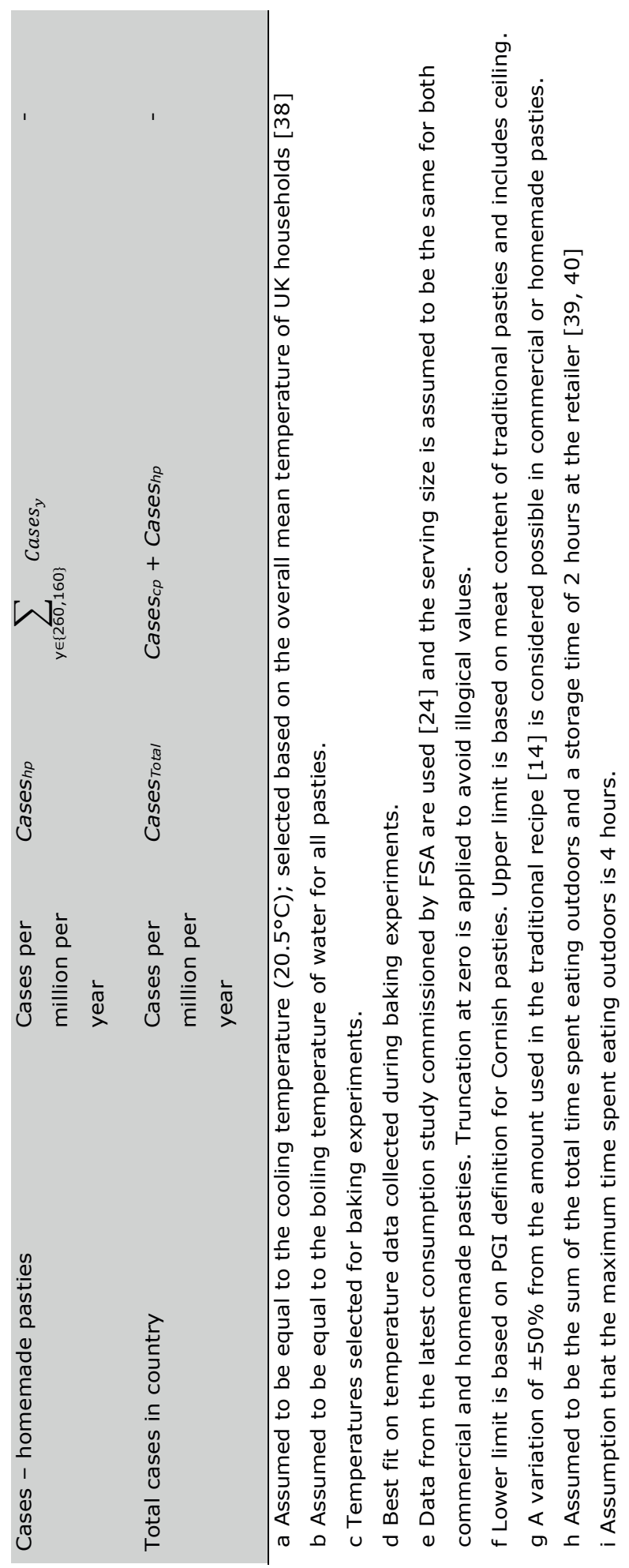


The concentration of C. perfringens in pepper was based on a UK study categorizing 2090 samples of spices at the retail level on the basis of their microbiological quality as satisfactory $(<2 \log$ CFU/g), acceptable $(2-3 \log \mathrm{CFU} / \mathrm{g}$ ) and unsatisfactory ( $>3 \log$ CFU/g) [29]. The cumulative probabilities of the samples being of satisfactory $(0.974)$ and acceptable (0.998) qualities were selected to build a normal distribution to describe the concentration using the RiskNormalAlt function. Concentration data for spices were considered to be representative of spores as vegetative cells are not likely to survive production steps involving exposure to air or chemical decontamination [15].

Step 2 - Concentration at consumption after cooling $\left(C_{x y-F}\right)$. The concentration at consumption was estimated separately for beef and pepper taking into account the total inactivation and growth of $C$. perfringens spores during different cooling scenarios $F$ for pasties of different sizes y. For homemade pasties $(500,700,900$ or $1400 \mathrm{~g})$, four different cooling scenarios were considered $(0-1.5 \mathrm{~h}, 1.5 \mathrm{~h}-3 \mathrm{~h}, 3-6 \mathrm{~h}$ and $6-12 \mathrm{~h})$ based on consumer storage time intervals following baking [19]. For commercial pasties $(160,260 \mathrm{~g})$, three different cooling scenarios were assumed (0-2.5h, 2.5-3.0h and 3-6h) on the basis of available information about recommended storage times of pies in shops [39] and consumer eating out times [41]. Concentration at consumption following each cooling scenario was based on the following equation:

$C_{x y-F}=C_{x}-\Sigma R_{x y-F}+\Sigma I_{x y-F}$

where:

$C_{x}$ is the initial concentration of the pathogen in contaminated ingredient $x$ (beef, black pepper) in log $\mathrm{CFU} / \mathrm{g}$

$\sum R_{x y-F}$ is the total inactivation observed during heating and cooling. Inactivation was estimated for temperatures $\geq 80^{\circ} \mathrm{C}$ since lower temperatures (used for pasteurization) are generally regarded not to have an effect on bacterial spores. Estimations were based on time increments $(\Delta t)$ of 5 min using a linear primary model without lag [42] and a decimal reduction time $(D, \mathrm{~min})$ as a function of temperature derived from a meta-analysis of literature data [30]:

$C_{t}=C_{t-1}-\Delta t / D$

$\sum I_{x y-F}$ is the total growth observed for different cooling scenarios $F$ involving pasties of different sizes y. Growth was estimated for temperatures lower than $52.3^{\circ} \mathrm{C}$ and for time increments $(\Delta t)$ of 5 min using a simple exponential model without lag [31]:

$C_{t}=C_{t-1}+\mu \cdot \Delta t /(60 \cdot \ln 10)$

In this model the maximum specific growth rate $\left(\mu_{\max }, \mathrm{h}^{-1}\right)$ is temperature $(\mathrm{T})$ dependant and modelled with a cardinal parameter gamma function using the formulas [31]:

$\mu_{\max }=\mu_{o p t} \cdot \gamma\left(T_{y}\right) \quad$ and 
$\gamma\left(T_{y}\right)=\frac{\left(T_{\mathrm{y}}-T_{\max }\right) \cdot\left(T_{\mathrm{y}}-T_{\min }\right)^{2}}{\left(T_{o p t}-T_{\min }\right) \cdot\left[\left(T_{o p t}-T_{\min }\right) \cdot\left(T_{\mathrm{y}}-T_{o p t}\right)-\left(T_{o p t}-T_{\max }\right)\left(T_{o p t}+T_{\min }-2 T_{\mathrm{y}}\right)\right]}$

where: $T_{\min }, T_{\text {opt }}$ and $T_{\max }$ are the minimum, optimum and maximum growth temperature of $C$. perfringens and $T_{y}$ the temperature of the core of the pasty $y$.

In both the inactivation and the growth model the temperature refers to the temperature of the core of each pasty size $y$. This was assumed to be homogeneous within the product and was modelled as a function of time using Newton's law of cooling or heating $[32,43]$ : $T_{y}=\left[\left(T_{o y}-T_{1}\right) \cdot \exp \left(-K_{y} \cdot t\right)\right]+T_{1}$

where:

$T_{y}=$ the temperature of the core of a pasty of size $y$ at time $t$

$T_{\text {oy }}$ the initial core temperature of a pasty of size $y\left({ }^{\circ} \mathrm{C}\right)$, equal to $100^{\circ} \mathrm{C}$ when cooling starts and equal to $20.5^{\circ} \mathrm{C}$ when heating starts

$T_{1}$ the air temperature, $20.5^{\circ} \mathrm{C}$ for cooling and $165^{\circ} \mathrm{C}$ for heating

$t$ is the cooling or heating time (min)

$K_{y}$ the rate of temperature change; the cooling $\left(K_{y-c}\right)$ or heating $\left(K_{y-h}\right)$ rate for pasties of different sizes $\left(\mathrm{min}^{-1}\right)$ was estimated by fitting the temperature data collected from the sensors to equation 6 using the least sum of squares method and the Solver add-in of Microsoft@ Excel 2010.

Baking was assumed to last until the core temperature of the pasties reached $100^{\circ} \mathrm{C}$. This resulted in heating times varying from approximately 83 minutes for the largest pasties $(1400 \mathrm{~g})$ to 35 minutes for the smallest ones $(160 \mathrm{~g})$ which were similar to the actual baking times determined empirically by observation and within ranges of baking times mentioned in recipes for different pasty sizes.

Step 3 - Probability of illness per contaminated serving $\left(P_{i l l-x y-F}\right)$.

$P_{\text {ill-beef-y-F}}, P_{\text {ill-pepper-y-F, }}, P_{\text {ill-beef }}$ \& pepper-y-F are the probabilities of illness for pasties contaminated through beef, pepper or both beef and pepper respectively. Three dose response models are available in literature to estimate these probabilities: an exponential model based on human feeding trials in the US [15] and two Bayesian binomial models: one based on feeding trials and another based on outbreak data collected from literature or investigated in the region of Paris [16]. For the purpose of our study the datasets used in the abovementioned models were combined and supplemented with additional outbreak data summarized in a Dutch qualitative risk assessment for $C$. perfringens [17] to build an exponential dose-response model [44] as follows. The resulting dataset was used to estimate $r$-parameters from each individual feeding trial and outbreak. For the outbreak data for which no information on the mass of the product consumed was available to estimate the dose, we assumed that the mean mass was $100 \mathrm{~g}$ with a range between 30 and $300 \mathrm{~g}$ given what is known about consumption levels for most food items [45]. To take 
this uncertainty regarding the dose into account, three $r$-parameters were estimated from each outbreak and were given equal weight when further analysing the data. All $r$ parameters estimated from feeding trials and outbreaks that were $>0$ and $<1$ were log transformed (Table 2) and were best fitted by a beta distribution using the AndersonDarling statistic in @RISK to give equal importance to the tails and the main body of the distribution during fitting [46]. The resulting model had a wide enough credible interval of predictions to describe both outbreak and human trial data (Figure 2).

When using this exponential model to estimate the probability of illness per contaminated serving, the dose was estimated on the basis of the beef $\left(f_{\text {beef }}\right)$ and pepper $\left(f_{\text {pepper }}\right)$ content of the pasties and the mass per serving (Table 1). For both commercial and homemade pasties the mass per serving was considered to be the same and equal to what is mentioned in UK studies regarding portion sizes for pasties [24].

Step 4 - Mean and standard deviation of probability of illness per contaminated serving (mean $_{\mathrm{P}_{\mathrm{ill}-\mathrm{xy}-\mathrm{F}}}, \mathrm{SD}_{\mathrm{P}_{\mathrm{ill}-\mathrm{xy}-\mathrm{F}}}$ ). The mean and standard deviation were estimated for $P_{\text {ill-beef-y-F, }} P_{\text {ill- }}$

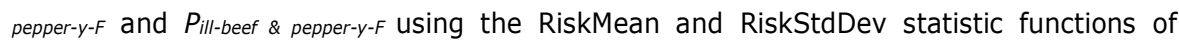
@RISK.

Step 5 - Mean and standard deviation of cases per contaminated ingredient $\mathrm{x}$, cooling scenario $\mathrm{F}$ and pasty size y $\left(\operatorname{mean}_{\text {Cases }_{\mathrm{xy}-\mathrm{F}}}, \mathrm{SD}_{\text {Cases }_{\mathrm{xy}-\mathrm{F}}}\right.$ ). These are calculated as follows for pasties contaminated through beef, pepper or both ingredients:

$$
\begin{aligned}
& \text { mean }_{\text {Cases beef }-\mathrm{y}-\mathrm{F}}=\left(P_{\text {beef }}-\left(P_{\text {beef }} \cdot P_{\text {pepper }}\right)\right) \cdot P_{c p e+} \cdot F \cdot S_{y} \cdot \text { mean }_{\mathrm{P}_{\text {ill-beef }-\mathrm{y}-\mathrm{F}}} \\
& \mathrm{SD}_{\text {Cases beef-y-F }_{\text {F }}}=\sqrt{\left(P_{\text {beef }}-\left(P_{\text {beef }} \cdot P_{\text {pepper }}\right)\right) \cdot P_{\text {cpe }} \cdot F \cdot S_{y}} \cdot \mathrm{SD}_{\mathrm{P}_{\text {ill-beef-y-F}}}
\end{aligned}
$$

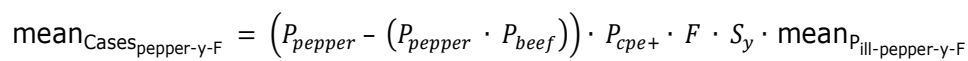

$$
\begin{aligned}
& \mathrm{SD}_{\text {Cases }_{\text {pepper-y-F }}}=\sqrt{\left(P_{\text {pepper }}-\left(P_{\text {pepper }} \cdot P_{\text {beef }}\right)\right) \cdot P_{\text {cpet }} \cdot F \cdot S_{y}} \cdot \mathrm{SD}_{\mathrm{P}_{\text {ill-pepper-y-F}}} \\
& \text { mean }_{\text {Cases }_{\text {beef \& pepper-y-F }}}=P_{\text {beef }} \cdot P_{\text {pepper }} \cdot P_{c p e+} \cdot F \cdot S_{y} \cdot \text { mean }_{\mathrm{P}_{\text {ill-beef \& pepper-y-F }}} \\
& \mathrm{SD}_{\text {Cases }_{\text {beef \& pepper-y-F }}}=\sqrt{\left(P_{\text {beef }}-\left(P_{\text {beef }} \cdot P_{\text {pepper }}\right)\right) \cdot P_{\text {cpet }} \cdot F \cdot S_{y}} \cdot \mathrm{SD}_{\mathrm{P}_{\text {ill-beef \& pepper-y-F }}}
\end{aligned}
$$




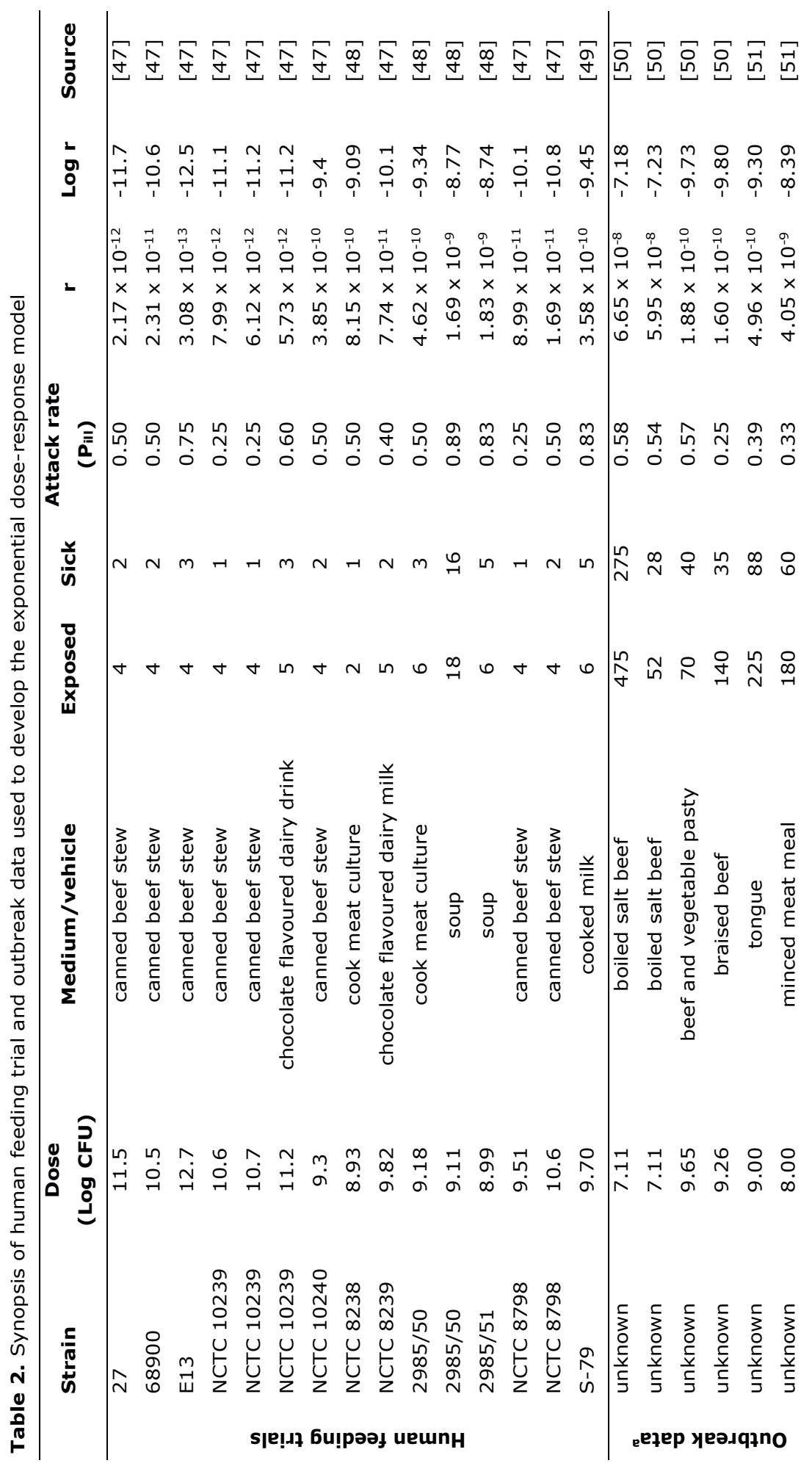




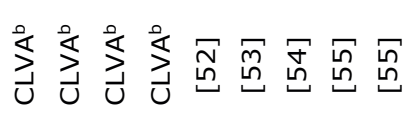

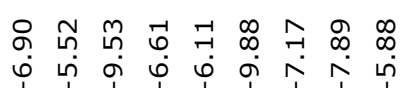

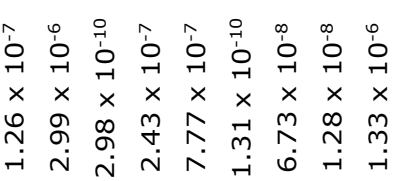

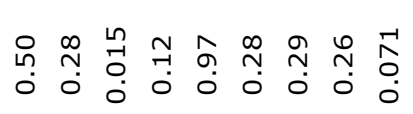

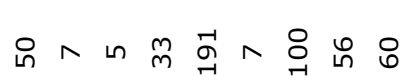

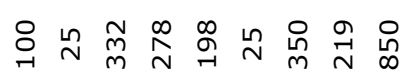

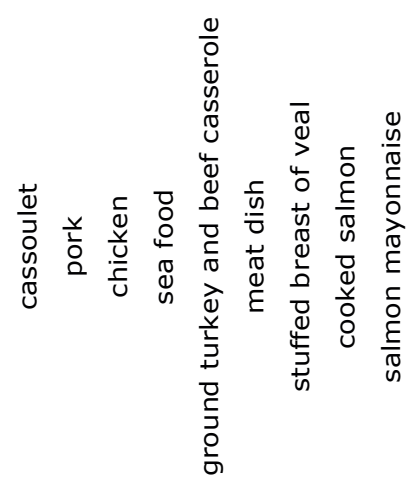

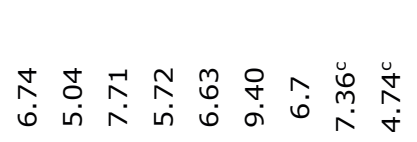

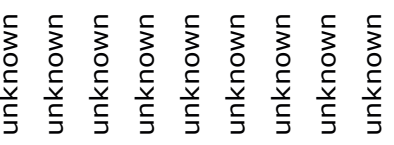

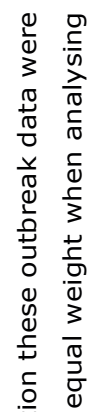

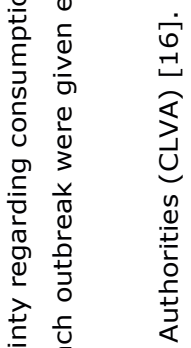

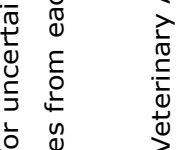

窎

$\circ$

守

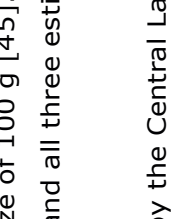

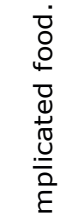

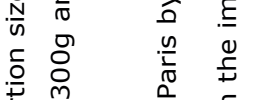

to

ॠ్

ग

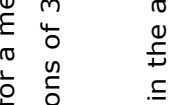

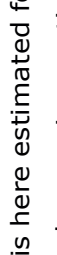

वे क्ष

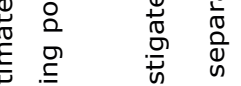

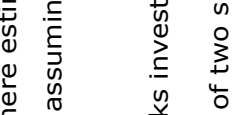

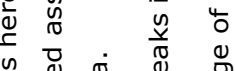

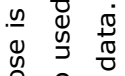

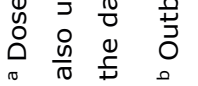




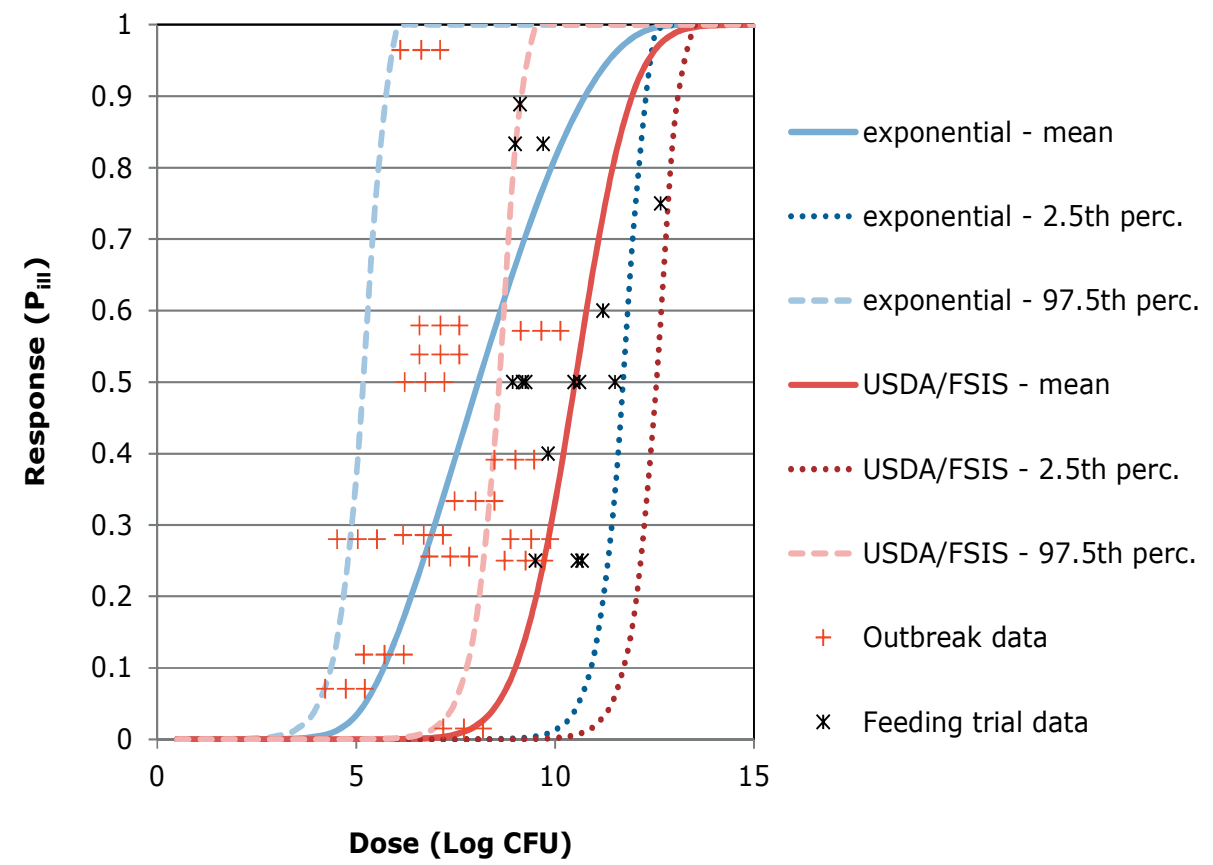

Figure 2. Mean predictions (solid lines) and $95 \%$ confidence intervals (dotted lines) for the dose response model of this study (exponential) and the one of the study of Crouch and Golden (USDA-FSIS) [15]. The range of predictions is compared to observed data from outbreaks $[16,17]$ and feeding trials [47-49].

where:

$P_{\text {beef }}, P_{\text {pepper }}$ the prevalence of the pathogen in the beef and pepper respectively, estimated on the basis of available literature $[17,26,27,33]$ and treated as independent and not mutually exclusive events [46].

$P_{\text {cpe+ }}$ the prevalence of cpe+ strains among $C$. perfringens isolates, estimated on the basis of a literature review for beef and spices $[17,26,33-36]$.

$F$ the frequency of cooling (time period from the end of baking until consumption). For homemade pasties, the frequencies of cooling were $F_{h p_{-} 1.5 h,} F_{h p_{-} 3 h,} F_{h p_{-} 6 h,} F_{h p_{-} 12 h}$ based on a survey of consumer food handling practices [19]. For commercial pasties, the

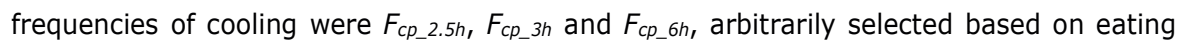
times out of home $[40,41]$ and assuming as a worst case scenario an initial storage of the pasties for two hours at the retailer [39]. 
$\mathrm{S}_{\mathrm{y}}$ is the number of pasty servings of size y consumed annually per person. Information on the number of servings or the total mass of pasties consumed in the UK was not available. Thus for commercial pasties, the number of servings $\left(S_{c p}\right)$ was assumed to be equal to the number of product units produced in Cornwall [14] and considered to be spread evenly over different sizes y. For homemade pasties, it was assumed that the same number of servings as for commercial pasties is consumed ( $\left.S_{h p}\right)$ and that it is again spread evenly over different product sizes $y$.

Step 6 - Cases per contaminated ingredient, cooling scenario and pasty size (Cases $x y-F)$.

The number of cases of $C$. perfringens food poisoning per million people per year due to pasties of size $y$, contaminated through ingredient(s) $x$ and cooled under scenario $F$ was estimated on the basis of the CLT:

Cases $_{x y-F}=\operatorname{RiskNormal}\left(\right.$ mean $_{\text {Cases }_{x y-F}} ; \mathrm{SD}_{\text {Cases }_{\mathrm{xy}-\mathrm{F}} \text {; }}$ RiskTruncate $\left.(0 ;)\right)$

To avoid negative values, the normal distribution was truncated at zero.

Step 7 - Total cases across pasty sizes, across product categories (homemade versus commercial) and in the country. The total number of cases for each pasty size $y$ was estimated by summing cases for pasties contaminated through different ingredients and different cooling scenarios.

For commercial pasties:

Cases $_{y}=\sum_{x \in\{\text { beef,pepper, beef\&pepper }\}} \sum_{F \in\{0.55,0.27,0.18\}}$ Cases $_{x y-F}$

For homemade pasties:

Cases $=\sum_{x \in\{\text { beef,pepper,beef\&pepper }\}} \sum_{F \in\{0.42,0.39,0.12,0.07\}}$ Cases $_{x y-F}$

The total number of cases (Casestotal) in the country due to commercial (Cases ${ }_{c p}$ ) and homemade pasties (Caseshp) was estimated by summing cases across different sizes $y$ :

Cases $_{\text {Total }}=$ Cases $_{c p}+$ Cases $_{h p}$

where:

Cases $_{c p}=\sum_{\mathrm{y} \in\{260,160\}}$ Cases $_{y-F}$

CaseS $_{h p}=\sum_{y \in\{1400,900,700,500\}}$ Cases $_{y-F}$

\subsection{Software and simulation settings}

The model was built in Microsoft Excel 2016 (Microsoft, Redmond, WA, USA) using the @RISK 7.5 software (Palisade Corporation, Ithaca, NY) and run in two simulations of 100,000 iterations each based on Latin Hypercube sampling. A fixed seed value of one was selected using a Mersenne Twister random number generator to prevent variations in the sensitivity analysis and "what if" scenarios due to the effect of random sampling and to allow the repetition of our results by others [46]. 


\section{Results and discussion}

\subsection{Risk estimates for Cornish pasties}

The model predicted a mean of 213 (95\% CI: 128-317) cases of C. perfringens toxicoinfections per million inhabitants each year due to the consumption of Cornish pasties, whose contribution varied with mean estimates ranging from 4.1 to 61 cases per million inhabitants for different pasty sizes and from 0-182 cases for different times to consumption (Table 3 and Figure 3). Major contributors to risk was time to consumption with homemade pasties consumed within 6 to $12 \mathrm{~h}$ being representative of about $86 \%$ of total cases. Homemade pasties and commercial pasties consumed within 3 to 6 hours contributed to the risk to a less extent with 8.8 and $4.7 \%$ of total cases respectively. The contribution of homemade and commercial pasties consumed up to $3 \mathrm{~h}$ after baking was negligible and represented less than $1 \%$ of total cases (Figure 3). The individual contribution of commercial pasties when consumed within up to $1 \mathrm{~h}$ after purchase, assuming a prior maximum display period of 2 hours based on current temperature control regulations in the UK [39], was slightly less than 2 cases per million inhabitants. These findings highlight the importance of short storage times in keeping the risk of $C$. perfringens in relation to Cornish pasties low.

Table 3. Mean risk estimates and $95 \%$ confidence intervals $\left(2.5^{\text {th }}-97.5^{\text {th }}\right.$ percentile) for different sizes of Cornish pasties expressed as cases per million people per year. Values have been rounded to include significant digits

\begin{tabular}{|c|c|}
\hline Pasty size (g) & Cases per million people per year \\
\hline 160 & $4.1(1.9-6.9)$ \\
\hline 260 & $7.7(3.7-13)$ \\
\hline 500 & $39(22-61)$ \\
\hline 700 & $51(29-78)$ \\
\hline 900 & $50(28-77)$ \\
\hline 1400 & $61(35-94)$ \\
\hline Total & $213(128-317)$ \\
\hline
\end{tabular}




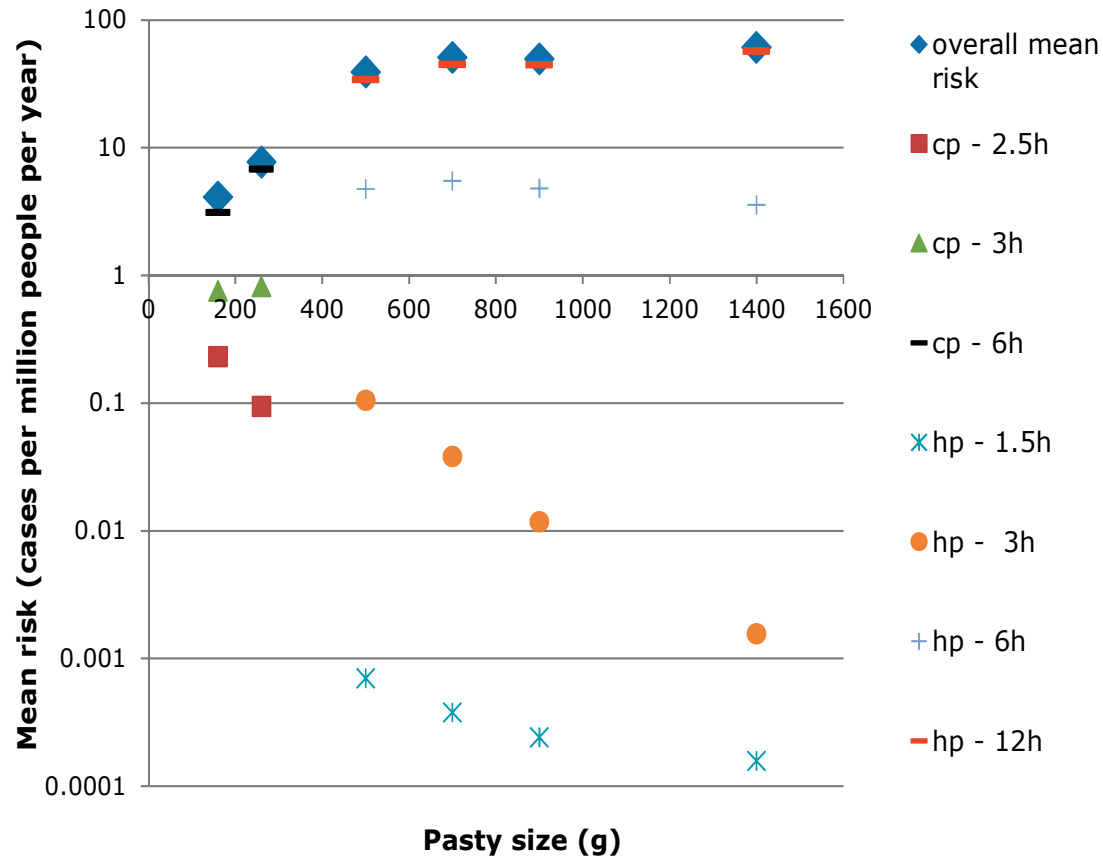

Figure 3. Mean risk estimates (cases per million people per year) for different pasty sizes and times to consumption. Numbers on the $y$-axis are presented on a logarithmic scale. Larger commercial pasty sizes were generally found to be related to higher risk in the case of times to consumption in excess of $3 \mathrm{~h}$, as a consequence of pasties staying for slightly longer times at temperatures permitting growth of $C$. perfringens. However, this was not the case for shorter times to consumption $(<3 \mathrm{~h})$ due to the faster cooling rate of smaller sizes. In the case of homemade pasties, larger sizes were related to relatively lower risk for times to consumption up to $3 \mathrm{~h}$. This was due to pasties staying at core temperatures unfavourable for the growth of $C$. perfringens for slightly longer times during heating and cooling down, causing higher estimated spore inactivation. All in all, this resulted in an extremely low risk for homemade pasties consumed $<1.5 \mathrm{~h}$ (mean value being less than 2 cases per billion inhabitants). For times to consumption of homemade pasties in excess of $3 \mathrm{~h}$, the effect of higher core temperature and greater spore inactivation for larger sizes was outweighed by that of more favourable growth temperatures for larger pasties.

Pasties contaminated through black pepper were found to be responsible for relatively (slightly) more cases (mean 100, 95\% CI: 58-151) than pasties contaminated through beef (mean 84, 95\% CI: 49 - 127) or through both ingredients at the same time (mean $29,95 \% \mathrm{CI}: 16-46)$. Despite that black pepper is being added in much lower amounts to 
pasties than beef, the prevalence and concentration levels of $C$. perfringens spores in pepper used in our model were considerably higher than in beef (Table 1), which explains this relatively higher risk contribution of black pepper. This finding also shows that spices can be an important source of introducing spores of $C$. perfringens to pasties and similar products, which when abused allow the pathogen to multiply and reach sufficient numbers to cause illness. The rationale for the number of cases resulting from pasties contaminated through both ingredients being relatively lower despite the higher initial concentration of spores in the product, is that the probability of the occurrence of double contamination ( $P_{\text {pepper }} \times P_{\text {beef }}$ ) is much lower than contamination through individual ingredients ( $P_{\text {pepper }}$ or Pbeef).

All risk estimates were surrounded by considerable variance, due to variability of inputs such as for instance the r-parameter of the dose response model, the $D_{\text {ref }}$ value or the concentration of the pathogen in the raw ingredients (pepper, beef) that accumulated in the risk characterization step of the risk assessment [45]. Advanced sensitivity analysis results on the basis of 10,000 iterations showing the impact of different inputs on the total number of cases can be seen in Figure 4. Bars of the tornado graph represent the range of impact of different percentiles of stochastic inputs $\left(1^{\text {st }}-99^{\text {th }}\right)$ on the mean total number of toxico-infections (mean 213 cases per million people) and show that impact of the variability of $r-$, Dref, $C_{\text {beef }}$ and $\mathrm{C}_{\text {pepper }}$ is more significant in comparison to that of other inputs such as the prevalence of cpe+ strains, the portion size or the spice and meat content. A limitation of this sensitivity analysis technique is that it does not evaluate the impact of non-stochastic inputs on the output, most importantly the variation in time to consumption that was captured in this model by using deterministic inputs (frequencies of different times to consumption following baking), which was already shown to have a significant impact on the risk estimates (Figure 3). All variable inputs identified to contribute the most to risk and that can be the subject of interventions (time to consumption, $C_{\text {beef }}$ and $\mathrm{C}_{\text {pepper}}$ ) are discussed further in section 3.2 .

Our annual estimate of total cases due to Cornish pasties seems to be within the range of recent epidemiological predictions regarding the total incidence of $C$. perfringens cases in UK (mean 1278 cases per million, 95\% CI 493-3,933) [56, 57]. At a mean of 213 cases per million per annum, our estimate possible explains a significant proportion (about 15\%) of the total UK burden of illness due to $C$. perfringens toxico-infections. Although pasties could play an important role as a vehicle of the disease, it is not possible to conclude with more certainty what their relative contribution is in the total number of cases in comparison with other products. To attribute the total burden of $C$. perfringens toxico-infections due to specific different food products, a comparative exposure assessment approach would be needed that, coupled with the hazard characterization step, would allow for the estimation 
of cases from different sources [58]. However, this was beyond the scope of our risk assessment. Nonetheless, our model shows that pasties may be a potential source of risk that justifies further study and can be used to decide on risk mitigation strategies for this pathogen which are discussed in the following section.

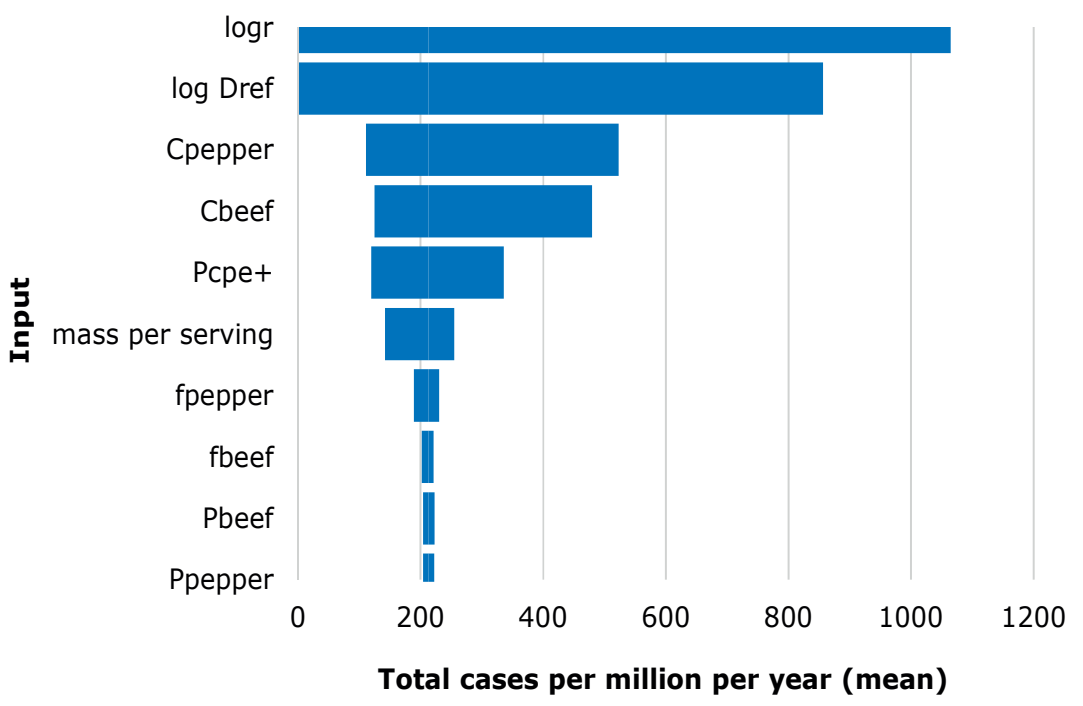

Figure 4. Advanced sensitivity analysis of the impact of stochastic inputs on the mean total number of estimated $C$. perfringens toxico-infections per million people.

\subsection{Risk management options}

Considering that the presence of $C$. perfringens in both beef and pepper is unavoidable, although it can be reduced to low levels when good hygienic practices are applied throughout their production [59], possible interventions for mitigating the risk could be decontaminating the raw ingredients and/or changing consumer attitudes through education campaigns. In view of this, reducing the levels of the pathogen in pepper and beef by different treatments, and preventing its growth to dangerous levels by reducing time to consumption or applying hot-holding were investigated as possible risk reduction strategies. Other options such as reheating or cold storage in the consumer phase were not taken into consideration as risk management measures since their deployment depends on consumer knowledge and practices of correct reheating and fridge temperatures. An overview of the alternative risk reduction scenarios that we examined 
and their impact on the mean risk estimates of the risk assessment model can be seen in Table 4.

Table 4. Effect of different intervention scenarios in mitigating the risk of $C$. perfringens toxico-infections due to pasties

\begin{tabular}{lcc}
\hline Scenario & $\begin{array}{c}\text { Mean risk } \\
\text { (cases per million } \\
\text { per year) }\end{array}$ & $\begin{array}{c}\text { Risk reduction in } \\
\text { comparison to baseline } \\
\text { (\%) }\end{array}$ \\
\hline Baseline & 213 & - \\
Consumption up to 3h & 2.5 & 99 \\
Consumption up to 6h & 34 & 84 \\
Correct hot-holding (retail) & 207 & 3 \\
Correct hot-holding (consumers) & 12 & 94 \\
Correct hot-holding (all) & 7.0 & 97 \\
Irradiation (pepper) & 130 & 39 \\
Steam treatment (pepper) & 183 & 14 \\
Ozone treatment (pepper) & 161 & 24 \\
Ozone treatment (beef) & 164 & 23 \\
Ozone treatment (beef and pepper) & 111 & 48 \\
Hot water decontamination (beef) & 131 & 39 \\
\hline
\end{tabular}

In short, four methods currently available for decontamination of raw materials were investigated: steam treatment being extensively used by the European spice industry [60], irradiation being more efficient for spices than steam treatment $[61,62]$ though less accepted by consumers [59], ozone treatment considered by some researchers as an alternative approach especially for spices [63] and hot water decontamination of meat carcasses advocated by some as most effective among surface decontamination treatments [64]. Other methods were rejected, either because they are forbidden in the European Union (fumigation with ethylene oxide) [60] or the UK (irradiation of beef) [65] or because they are less practical such as high temperature short time (HTST) requiring the spices to be frozen after treatment [66]. To investigate the impact of the selected decontamination methods on the population of $C$. perfringens spores in beef and pepper, a literature search was performed. Regarding irradiation, for black pepper, for which this method can be used in the UK up to a maximum dose of $10 \mathrm{kGy}$ [65], a $2 \log$ CFU/g reduction was considered possible [67]. In the case of ozone, a reduction of $1 \log \mathrm{CFU} / \mathrm{g}$ was regarded feasible for beef surfaces [68]. Similar data could not be found for black pepper for which it was considered safe to assume a similar reduction of $1 \log \mathrm{CFU} / \mathrm{g}$, on 
the basis of the efficiency of ozone treatment on the reduction of spores of $B$. cereus in red pepper [69] and in view of the fact that these spores are particularly resistant to ozone [70]. For steam treatment, in the absence of data specific to spores, it was estimated to result in a reduction of $0.5 \mathrm{log} \mathrm{CFU} / \mathrm{g}$ on the basis of thermal inactivation conditions applied to black pepper $\left(98^{\circ} \mathrm{C}, 3 \mathrm{~min}\right)$ and the $T_{\text {ref, }}$ mean $D_{\text {ref }}$ and $z$-values for $C$. perfringens used in our risk assessment model [61]. Finally, for hot water decontamination, no data were found specific to beef and $C$. perfringens while a wide variation of the efficiency of this process was observed depending on parameters of the selected methodology and carcass characteristics. Therefore as a best case scenario a reduction of $2.5 \mathrm{log} \mathrm{CFU} / \mathrm{g}$ was assumed on the basis of the range of efficiencies of this process and available data for other sporeformers ( $C$. sporogenes) on beef carcasses [64]. When comparing the above risk reduction scenarios to our baseline model, it was evident that the most efficient ones in reducing the risk were the ones associated with changes in consumer practices (reducing time to consumption and applying hot-holding). Provided these changes are adopted by all consumers, the risk associated with the consumption of pasties can be reduced almost completely (84-99\%). Among decontamination scenarios, it was found that the greatest reduction in risk can be achieved by treating both beef and pepper with ozone (48\% reduction). This was followed by irradiation of pepper and hot water decontamination of beef carcasses, each resulting in an approximately $39 \%$ risk reduction. Steam treatment of pepper resulted in a much lower risk reduction (14\%) since it had only a minor impact on spore inactivation.

\subsection{Use of risk-based metrics}

The use of risk-based metrics has been promoted in the past two decades by international bodies [71, 72] as a means of making food safety management transparent and quantifiable [73]. Such metrics have the potential of linking governmental policy regarding acceptable levels of illness because of a particular hazard in a product (Appropriate Level of Protection, ALOP), with specific guidelines to the industry in the form of maximum permitted frequency/concentration level of the same hazard in the product at a specified step in the food chain, before (Performance Objective, PO) or at the moment (Food Safety Objective, FSO) of consumption [74]. While an ALOP and an FSO can only be set by governments, a PO can also be set by the industry who is allowed to decide on the required performance criteria (PC) and control measures (CM) it needs to meet this target [75]. The application of these risk-based metrics has been the subject of a number of case studies dealing with products in the market [76-82]. Although a niche food product even in the UK, the risk of $C$. perfringens in Cornish pasties also constitutes an interesting case study 
because the moment of consumption for this product group varies considerably, while it is one of the most important factors influencing risk.

Using the risk assessment model developed in our study, an assessment was done of the current public health burden related to this food/pathogen combination, i.e. 213 (95\% CI: 128-317) cases of $C$. perfringens toxico-infection in the UK per year, which in essence represents the current Level of Protection (LOP) in the UK. Based on the SPS Agreement [72] this risk level could be considered by the competent authorities as an ALOP level that can be tolerated further. To more clearly specify the actual level of risk accepted, the ALOP could be set on the basis of one of the upper percentiles of the output distribution of total cases per million per year. Which percentile can be selected for this purpose will depend on how confident the risk manager needs to be that this safety target is achieved, and although the $95^{\text {th }}$ percentile is often selected for this purpose [83] corresponding here to 298 cases, other percentiles such as for instance the $97.5^{\text {th }}$ or the $99^{\text {th }}$ are also an option corresponding to 317 and 340 cases respectively. In this case, this ALOP would represent accepting a status quo regarding public health protection. Alternatively, in the context of continuous improvement of food safety, the ALOP could also be set on the basis of an intervention to reduce risk, taking again into account the degree of confidence that needs to be placed on the risk estimate [83]. Interventions may either target industrial or consumer practices. For instance, looking at the comparison of different intervention scenarios that the industry could apply with our baseline (Figure 5) it may be decided that for practical reasons, the easiest option for reducing the risk could be introducing an irradiation step for pepper. In this case, if the risk manager needs to be certain that this safety target is reached $95 \%$ of the time, the ALOP could then correspond to the $95^{\text {th }}$ percentile and be set at 183 cases per million people per year. Similarly, among interventions targeting consumer practices, the introduction of a hot holding step by $60 \%$ of consumers (e.g. as a result of an education campaign) could be an alternative target, in which case assuming again $95 \%$ confidence in the risk estimate the ALOP could be set at 130 cases per million people per year. Based on the above, the setting of the ALOP will depend heavily on the interpretation of the target (current or future level of protection) and the level of confidence on the risk estimate.

Having an ALOP specified, an FSO and PO values, as considered appropriate, can be decided on by the competent authorities, using our purpose built risk-assessment and hazard-characterization information to define what pathogen levels at consumption or at earlier stages in the value chain could be tolerated. Given the complexity of the risk assessment model, the available data and various assumptions made, setting these riskbased metrics may require particular skills and expertise for decision-making. As per the Codex Alimentarius definition [71, 84], FSO and PO values can be expressed as a 
concentration, a prevalence or a combination of both. Given that concentrations and prevalences of spores and cpe+ strains vary in raw materials, in pasties of different sizes, in pasties treated with different methods, and in the ready-to-eat food at the time of consumption, setting FSO and PO values is not necessarily straightforward. Although it is still theoretically possible to define an FSO for $C$. perfringens in pasties, PO values might be more relevant but then it is up to the commercial producers and home producers of pasties to choose and correctly implement the measures that assure meeting the PO. In this situation, it is most likely more useful to communicate hazard reduction targets (Performance Criteria) associated with the different mitigation scenarios we examined as means of achieving an ALOP. For instance, if the current level of protection is not accepted and a decision has been made that a risk reduction of $39 \%$ would result in an acceptable level of protection, then it can be communicated to the industry that either pepper or beef need to be decontaminated having as a target a 2 and $2.5 \log$ CFU/g reduction respectively (Performance Objectives). Naturally, if the current level of risk is accepted, it is not required to communicate any other risk-based metrics to the industry.

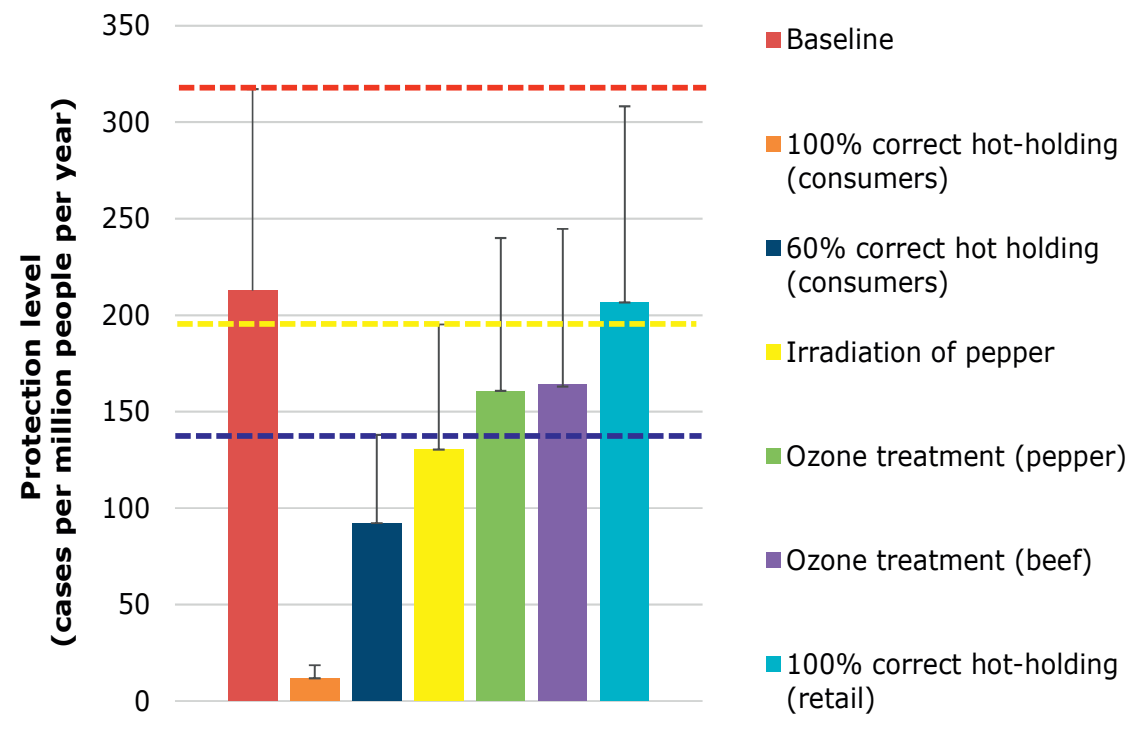

Figure 5. Levels of protection achieved for different intervention scenarios in comparison to the baseline. Whiskers show the $95^{\text {th }}$ percentile of estimates. Potential ALOPs could be set on the basis of the current level of protection (red dotted line) or future levels of protections on the basis of interventions targeting consumers (dark blue dotted line) or industrial practices (yellow dotted line). 


\subsection{Assumptions and limitations of the model}

Any model is a simplification of reality and ours is no exception to this rule. When building the skeleton of the model all major factors influencing risk were taken into consideration and incorporated into the different estimation steps to the best of our ability and to the extent that existing literature allowed. Unavoidably though simplifications and assumptions needed to be made that could lead in either over- or under-predictions. When possible, these were made on the conservative side and they are summarized in Table 5 . The impact of each assumption on the model is discussed in more detail in Technical Appendix I. More research on the type of $C$. perfringens contamination of carcasses (spores/vegetative cells), consumer and store practices regarding the preparation of this product (cooling, hot-holding, re-heating, formulating) could significantly help in reducing the number of assumptions and in further refining our estimates.

\section{Conclusions}

A stochastic risk assessment model was built for Cornish pasties that can be used by companies and government authorities for estimating the risk of $C$. perfringens toxicoinfections associated with this product group, when not held hot in retail outlets, a practice that may become more common given discussions for increase in their price when held hot or reheated before purchase [85]. The model may provide a basis to estimate the risk of the domestic preparation of Cornish pasties, which is also of interest since homemade food has the potential to contribute to outbreaks though not to the same extent as food from commercial establishments $[25,86]$. The predictions were within the range of existing epidemiological data and showed that this product group may be an important source of C. perfringens toxico-infections. Use of the model for food safety decision-making indicated that reducing time to consumption, correct application of hot-holding and decontaminating the raw ingredients (beef, pepper) were all viable options for reducing the risk, with changes in consumer practices having the greatest impact on risk. These risk reduction interventions could also serve as a basis for setting risk-based metrics for this product group when using the model.

\section{Acknowledgments}

We would like to thank Unilever's Safety \& Environmental Assurance Centre for fully funding this project. We are grateful to Sofia Arapaki for performing the baking experiments that formed the basis of this risk assessment model and the Onasis Foundation for sponsoring her MSc study. We also wish to acknowledge Alejandro Amezquita and Peter McClure for their valuable feedback in earlier forms of this manuscript. 
Table 5. Model assumptions and their impact on the risk estimates

\begin{tabular}{|c|c|}
\hline Over-predictions & Impact on risk \\
\hline $\begin{array}{l}\text { All ingredient contamination is due to } \\
\text { spores }\end{array}$ & Significant \\
\hline $\begin{array}{l}\text { No forced cooling/chilled storage/re- } \\
\text { heating of Cornish pasties at shops after } \\
\text { baking }\end{array}$ & Potentially significant for commercial pasties \\
\hline $\begin{array}{l}\text { No GOL phase (Germination - Outgrowth } \\
\text { - Lag) for spores }\end{array}$ & Unknown, cannot be modeled \\
\hline No lag due to shifts in temperature & Unknown, cannot be modeled \\
\hline $\begin{array}{l}\text { Commercial pasties formulated to } \\
\text { prevent pathogen growth }\end{array}$ & Potentially significant for commercial pasties \\
\hline \multicolumn{2}{|l|}{ Under-predictions } \\
\hline $\begin{array}{l}\text { No contamination from flour and } \\
\text { vegetables }\end{array}$ & Negligible \\
\hline No contamination from food handler & Unknown, insufficient data to model \\
\hline $\begin{array}{l}\text { Cpe+ strains only cause of } C \text {. } \\
\text { perfringens gastroenteritis }\end{array}$ & Unknown, insufficient data to model \\
\hline $\begin{array}{l}\text { Prevalence and concentration based on } \\
\text { data for spices rather than black pepper }\end{array}$ & $\begin{array}{l}\text { Unknown, impact on risk depends on whether } \\
\text { or not black pepper vs other peppers is used }\end{array}$ \\
\hline \multicolumn{2}{|l|}{ Either way } \\
\hline No hot-holding & Potentially significant \\
\hline No re-heating & Potentially significant \\
\hline Cooling temperature & $\begin{array}{l}\text { Potentially significant for commercial pasties } \\
\text { consumed outdoors. }\end{array}$ \\
\hline Recipe variation & $\begin{array}{l}\text { Potentially significant depending on variations } \\
\text { in size, ingredients and baking times. }\end{array}$ \\
\hline
\end{tabular}




\section{Technical Appendix I}

Assumptions and limitations of the model

\section{Assumptions that could lead to over-predictions}

All ingredient contamination is due to spores. In practice contamination with vegetative cells is also possible though less likely for spices. In the case of beef, $C$. perfringens contamination has been mentioned to be mainly due to vegetative cells [64] but no data on the relative contribution of spores/vegetative cells could be found. This means that our risk estimate is likely to be an over-estimation of the actual situation by more than $20 \%$ if we accept that less than half of the contamination is due to spores.

All commercial pasties were assumed to be let to cool at ambient temperatures while in practice some may be held refrigerated prior to sale. In the event of refrigerated storage, the risk in relation to commercial pasties would be even lower than what is currently estimated but the overall risk which is mainly due to homemade pasties would remain mostly unaffected.

Absence of germination-outgrowth-lag time (GOL time) for bacterial spores. The GOL time for bacterial spores is dependent on the conditions the vegetative cells from which they originated from, have experienced. These conditions should ideally also be considered when modelling this growth phase for spores [87] which is not possible for pasties unless additional assumptions are made that all spores present in the product are produced under uniform conditions regardless of the raw ingredient they are found. Therefore for simplicity reasons the GOL time was not taken into consideration in the estimations.

Absence of additional lag due to shifts in temperature. When modelling growth for time increments of $5 \mathrm{~min}$, temperature was assumed to be constant for the duration of this time period and no additional lag due to a shift in temperature was used. Though this is not likely to have had an impact for cells in the exponential phase, for which temperature shifts can be assumed not to result in a lag phase, for cells already within the lag phase a temperature shift is expected to prolong this phase [88] as cells are then less efficient in growing [89]. Considering that the same uncertainties as with the GOL time of spores apply here (pre-history of vegetative cells) and that even under controlled experimental conditions, measurements of lag time are much less repeatable than those for growth rate [90] and more difficult to predict for shifts of temperature around the boundaries for growth [88] this factor was left out of the estimations.

No refrigerated storage before consumption. The population of vegetative cells of $C$. perfringens would either remain stable or die during this step [28] depending on duration 
and temperature. Although refrigerated storage can last up to one week for products such as cold pies [91], because pasties are usually consumed warm, this step was considered less relevant for this type of product and left out of the model.

Accuracy of standard methods. The detection protocols for $C$. perfringens in the prevalence studies that we used $[17,26,27,29,33]$ were all assumed to be the same and equally accurate. In a recent study nevertheless it was pointed out that standard methods for the detection of this pathogen based on the isolation of sulphite reducing colonies which are subsequently confirmed with biochemical tests may result in false positive results [92]. Adjusting our estimates for this phenomenon is not possible without additional studies quantifying differences between standard detection protocols currently in place.

\section{Assumptions that could lead to under-predictions}

Absence of $C$. perfringens spores in other ingredients. Although the spores, being ubiquitous in nature [5], can be found in both the vegetables and the flour used for making pasties, they were not considered a source of introducing the pathogen to the product. Bearing in mind that for vegetables the contaminated part (skin) is removed, while the dough is the part of the product that comes partly into contact with air and unlike meat is not a good substrate for the microorganism, the impact of this assumption is likely to be negligible.

Food handler not a source of contamination. Recent studies have identified healthy humans handling foods as a potential source of product contamination [5]. The impact of this assumption is likely to be negligible for commercial pasties made by professionally trained staff wearing gloves. However, it is uncertain how significant this assumption is for homemade pasties in the absence of data on contamination levels in human carriers and spore transfer rates between surfaces.

Only cpe+ strains cause gastroenteritis. Recently it has been shown that other enterotoxin producing strains (BEC, binary enterotoxin of $C$. perfringens) can also cause acute gastroenteritis in humans [93]. It is currently unknown what is the relative contribution of BEC strains in comparison to cpe+ strains in cases of $C$. perfringens gastroenteritis.

Selecting data for the prevalence and concentration of $C$. perfringens in spices instead of black pepper. Black pepper is a spice that because of the way it is produced it has a high chance of being contaminated with pathogenic microorganisms [63] and in a recent study on the microbiological quality of spices in the UK it was found to be relatively more often of unacceptable quality in comparison with other spices [29]. Data for black pepper were limited and taking into account that the pepper used in some recipes might also be white 
(which is less heavily contaminated because the hull is removed) general data for spices were considered to be more relevant.

\section{Assumptions having an unforeseeable effect on the estimates}

Hot holding. Although correct application of hot-holding would completely eliminate the risk, in reality a certain percentage of consumers can be expected to improperly hold hot food [94]. This percentage in combination with data regarding the frequencies with which pasties are held at different incorrect temperatures would be necessary to model this step. Because of the absence of this kind of information and because assumptions for different hot-holding temperatures can result in over- or under-predictions in comparison to our baseline model (results not shown), this step was left out altogether.

Reheating. If this step is performed efficiently then the risk can be completely eliminated, similar to applying hot-holding. However, when this step is carried out inadequately, as in the case of certain outbreaks of $C$. perfringens, it can also promote the growth of vegetative cells [17]. Given the absence of data necessary to model this step and because it has been suggested that reheating temperatures are usually not high enough to destroy pathogenic bacteria potentially present in food [95] it was decided to leave it out of the estimations.

Cooling temperature. Current assumption on cooling temperature is based on average temperatures in consumer households [19]. Commercial pasties consumed outdoors may be exposed to significantly higher or lower temperatures than this depending on the season.

Cornish pasty recipe. We have assumed that all pasties are made with the same traditional recipe though many different recipes exist and it is likely that each recipe is executed in different ways, especially in the case of homemade pasties. Variations in pasty sizes, baking times and ingredients are possible and they may impact the risk both ways. 


\section{References}

1. Havelaar, A.H., J.A. Haagsma, M.-J.J. Mangen, J.M. Kemmeren, L.P.B. Verhoef, S.M.C. Vijgen, M. Wilson, I.H.M. Friesema, L.M. Kortbeek, Y.T.H.P. van Duynhoven, and W. van Pelt. Disease burden of foodborne pathogens in the Netherlands, 2009 International Journal of Food Microbiology. 2012; 156: p. 231-238.

2. Scallan, E., R.M. Hoekstra, F.J. Angulo, R.V. Tauxe, M.A. Widdowson, S.L. Roy, J.L. Jones, and M.P. Griffin. Foodborne illness acquired in the United States - Major pathogens. Emerging Infectious Diseases. 2011; 17: p. 7-15.

3. Tam, C.C., L.C. Rodrigues, L. Viviani, J.P. Dodds, M.R. Evans, P.R. Hunter, J.J. Gray, L.H. Letley, G. Rait, D.S. Tompkins, and S.J. O'Brien. Longitudinal study of infectious intestinal disease in the UK (IID2 study): incidence in the community and presenting to general practice. Gut. 2012; 61: p. 69-77.

4. Brynestad, S. and P.E. Granum. Clostridium perfringens and foodborne infections. International Journal of Food Microbiology. 2002; 74: p. 195-202.

5. Lindström, M., A. Heikinheimo, P. Lahti, and H. Korkeala. Novel insights into the epidemiology of Clostridium perfringens type A food poisoning. Food Microbiology. 2011; 28: p. 192-198.

6. Adams, M.R. and M.O. Moss. Food Microbiology (2nd edition). 2006. The Royal Society of Chemistry: Cambridge

7. Novak, J.S. and V.K. Juneja. Clostridium perfringens: hazards in new generation foods. Innovative Food Science \& Emerging Technologies. 2002; 3: p. 127-132.

8. EFSA. Opinion of the Scientific Panel on Biological Hazards on the request from the Commission related to Clostridium spp. in foodstuffs (Question No EFSA-Q-2004009). The EFSA Journal. 2005; 3: 199.

9. Batz, M.B., M.P. Doyle, J.G. Morris, J. Painter, R. Singh, R.V. Tauxe, M.R. Taylor, and D.M.A. Lo Fo Wong. Attributing illness to food. Emerging Infectious Diseases. 2005; 11: p. 993-999.

10. Gkogka, E., M.W. Reij, L.G.M. Gorris, and M.H. Zwietering. The application of the Appropriate Level of Protection (ALOP) and Food Safety Objective (FSO) concepts in food safety management, using Listeria monocytogenes in deli meats as a case study. Food Control. 2013; 29: p. 382-393.

11. Gkogka, E., M.W. Reij, L.G.M. Gorris, and M.H. Zwietering. Risk assessment strategies as a tool in the application of the Appropriate Level of Protection (ALOP) and Food Safety Objective (FSO) by risk managers. International Journal of Food Microbiology. 2013; 167: p. 8-28.

12. EC. (2011). Commission implementing regulation (EU) No 717/2011 of 20 July 2011 entering a name in the register of protected designations of origin and protected 
geographical indications (Cornish Pasty (PGI)). European Commission: Official Journal of the European Union. Available from: http://eurlex.europa.eu/LexUriServ/LexUriServ.do?uri=OJ:L:2011:193:0013:0014:EN:PDF

13. EC. (2010). Publication of an application pursuant to Article 6(2) of Council Regulation (EC) No 510/2006 on the protection of geographical indications and designations of origin for agricultural products and foodstuffs (2010/C 190/07). European Commission: Official Journal of European Union. Available from: http://eurlex.europa.eu/LexUriServ/LexUriServ.do?uri=0J:C:2010:190:0033:0036:EN:PDF

14. CPA. Cornish pasty association [cited 2012 August 7]. Available from: http://www.cornishpastyassociation.co.uk/

15. Crouch, E. and N.J. Golden. (2005). A risk assessment for Clostridium perfringens in ready to eat and partially cooked meat and poultry products. USDA-Food Safety Inspection Service: Washington DC. Available from: http://www.fsis.usda.gov /PDF/CPerfringens Risk Assess Sep2005.pdf

16. Jaloustre, S. (2011). Appréciation quantitative des risques pour l'évaluation de mesures de maîtrise sanitaire dans une filière agro alimentaire. Application à Clostridium perfringens en restauration hospitalière (Doctorat ParisTech thèse). AgroParisTech-Institut des sciences et industries du vivant et de l'énvironnement: Paris. Available from: https://pastel.archives-ouvertes.fr/pastel-00781728 Ldocument

17. Wijnands, L.M., A. van der Mey-Florijn, and E. Delfgou-van Asch. (2011). Clostridium perfringens associated food borne disease. National Institute for Public Health and the Environment: Bilthoven. Available from: http://www.rivm.nl /bibliotheek/rapporten/330371005.pdf

18. Pérez-Rodríguez, F. and M.H. Zwietering. Application of the central limit theorem in microbial risk assessment: High number of servings reduces the Coefficient of Variation of food-borne burden-of-illness. International Journal of Food Microbiology. 2012; 153: p. 413-419.

19. Worsfold, D. and C.J. Griffith. Assessment of the standard of consumer food safety behaviour. Journal of Food Protection. 1997; 60: p. 399-406.

20. BBC. Cornish pasty [cited 2012 August 9]. Available from: http://www.bbc.co.uk/food/recipes/cornishpasty 89627

21. Food.com. Pendarvis House Cornish Pasty [cited 2012 August 9]. Available from: http://www.food.com/recipeprint.do?rid $=372458$

22. Anonymous. TESCO [cited 2017 February 23]. Available from: http://www.tesco.com/?DCBOB=AWS1

23. Anonymous. Sainsbury's [cited 2017 February 23]. Available from: http://www.sainsburys.co.uk/shop/gb/groceries 
24. Church, S. (2008). Trends in portion sizes in the UK - A preliminary review of published information. Food Standards Agency: London. Available from: http://tna.europarchive.org/20111116080332/http://www.food.gov.uk/news/press releases/2008/jun/portionsize

25. Gormley, F.J., C.L. Little, N. Rawal, I.A. Gillespie, S. Lebaigue, and G.K. Adak. A 17year review of foodborne outbreaks: describing the continuing decline in England and Wales (1992-2008). Epidemiology and Infection. 2011; 139: p. 688-699.

26. Rodríguez-Romo, L.A., N.L. Heredia, R.G. Labbé, and J.S. García-Alvarado. Detection of enterotoxigenic Clostridium perfringens in spices used in Mexico by dot blotting using a DNA probe. Journal of Food Protection. 1998; 61: p. 201-204.

27. FSA. (2010). A UK-wide survey of microbiological contamination of fresh red meats on retail sale. FSA Project B18018. Technical report. Food Standards Agency: London. Available from: http://www.food.gov.uk/science/research/surveillance /fsisbranch2010/fsis0210

28. Kalinowski, R.M., R.B. Tompkin, P.W. Bodnaruk, and W.P. Pruett. Impact of cooking, cooling, and subsequent refrigeration on the growth or survival of Clostridium perfringens in cooked meat and poultry products. Journal of Food Protection. 2003; 66: p. 1227-1232.

29. Sagoo, S.K., C.L. Little, M. Greenwood, V. Mithani, K.A. Grant, J. McLauchlin, E. de Pinna, and E.J. Threlfall. Assessment of the microbial safety of dried spices and herbs from production and retail premises in the United Kingdom. Food Microbiology. 2009; 26: p. 39-43.

30. Van Asselt, E.D. and M.H. Zwietering. A systematic approach to determine global thermal inactivation parameters for various food pathogens. International Journal of Food Microbiology. 2006; 107: p. 73-82.

31. De Jong, A.E.I., R.R. Beumer, and M.H. Zwietering. Modeling growth of Clostridium perfringens in pea soup during cooling. Risk Analysis. 2005; 25: p. 61-73.

32. Snyder, O.P.J. The basics of cooling food [cited 2012 August 9]. Available from: http://www.hi-tm.com/Documents/Basic-cool.html

33. Aguilera, M.O., P.V. Stagnitta, B. Micalizzi, and A.M. Stefanini de Guzmán. Prevalence and characterization of Clostridium perfringens from spices in Argentina. Anaerobe. 2005; 11: p. 327-334.

34. Miki, Y., K. Miyamoto, I. Kaneko-Hirano, K. Fujiuchi, and S. Akimoto. Prevalence and characterization of enterotoxin gene-carrying Clostridium perfringens isolates from retail meat products in Japan. Applied and Environmental Microbiology. 2008; 74: p. 5366-5372. 
35. Miwa, N., T. Nishina, S. Kubo, M. Atsumi, and H. Honda. Amount of enterotoxigenic Clostridium perfringens in meat detected by nested PCR. International Journal of Food Microbiology. 1998; 42: p. 195-200.

36. Wen, Q. and B.A. McClane. Detection of enterotoxigenic Clostridium perfringens type A isolates in American retail foods. Applied and Environmental Microbiology. 2004; 70: p. 2685-2691.

37. Eurostat. Population on 1 January [cited 2017 February 25]. Available from: http://ec.europa.eu/eurostat/tgm/table.do?tab=table\&init=1\&language=en\&pcode =tps00001\&plugin $=1$

38. James, S.J. and J. Evans. Consumer handling of chilled foods: Temperature performance. International Journal of Refrigeration. 1992; 15: p. 299-306.

39. Anonymous. (2006). The Food Hygiene (England) Regulations 2006. The Stationery Office: London, UK. Available from:

http://www.legislation.gov.uk/uksi/2006/14/contents/made

40. Cheng, S.-L., W. Olsen, D. Southerton, and A. Warde. The changing practice of eating: evidence from UK time diaries, 1975 and 2000. The British Journal of Sociology. 2007; 58: p. 39-61.

41. UK Cabinet Office - The Strategy Unit. (2008). Food: An analysis of the issues. Cabinet Office of the UK London. Available from: http://webarchive.nationalarchives.gov.uk/20090504050602/http://www.cabinetoff ice.gov.uk/media/cabinetoffice/strategy/assets/food/food analysis.pdf

42. Buchanan, R.L., M.H. Golden, R.C. Whiting, J.G. Phillips, and J.L. Smith. Non-thermal inactivation models for Listeria monocytogenes. Journal of Food Science. 1994; 59: p. $179-188$.

43. Lindeburg, M.R. Chemical engineering reference manual for the PE Exam (7th edition). 2013. Professional Publications, Inc.: Belmont, CA

44. Zwietering, M.H. and A.H. Havelaar. (2006). Dose-response relationships and foodborne disease, in "Food consumption and disease risk. Consumer-pathogen interactions". Woodhead Publishing Limited: Cambridge

45. Zwietering, M.H. and S.J.C. van Gerwen. Sensitivity analysis in quatitative microbial risk assessment. International Journal of Food Microbiology. 2000; 58: p. 213-221.

46. Vose, D. Risk analysis: a quantitative guide (3rd edition). 2008. John Wiley and Sons, Ltd: Chichester, West Sussex

47. Strong, D.H., C.L. Duncan, and G. Perna. Clostridium perfringens type A food poisoning II. Response of the rabbit ileum as an indication of enteropathogenicity of strains of Clostridium perfringens in human beings. Infection and Immunity. 1971; 3: p. $171-178$. 
48. Dische, F.E. and S.D. Elek. Experimental food poisoning by Clostridium welchii. The Lancet. 1957; 273: p. 71-74.

49. Hauschild, A.H.W. and F.S. Thatcher. Experimental food poisoning with heat susceptible Clostridium perfringens type A. Journal of Food Science. 1967; 32: p. 467-469.

50. Hobbs, B.C., M.E. Smith, C.L. Oakley, G.H. Warrack, and J.C. Cruickshank. Clostridium welchii food poisoning. Journal of Hygiene. 1953; 51: p. 75-101.

51. Sutton, R.G.A. and B.C. Hobbs. Food poisoning caused by heat-sensitive Clostridium welchii. A report of five recent outbreaks. The Journal of Hygiene. 1968; 66: p. 135146.

52. Hsieh, H., J. Archer, R. Heffernan, J.P. Davis, and C.F. Nielsen. Clostridium perfringens infection among inmates at a county jail-Wisconsin, August 2008. Morbidity and Mortality Weekly Report. 2009; 58: p. 138-141.

53. Young, M.K., P. Smith, J. Holloway, and R.P. Davison. An outbreak of Clostridium perfringens and the enforcement of food safety standards. Communicable Diseases Intelligence Quaterly Report. 2008; 32: p. 462-465.

54. Mol, H. and H.M. Vincentie. A case of food poisoning caused by Clostridium perfringens (in Dutch). Netherlands Journal of Veterinary Science. 1988; 113: p. 1135-1138.

55. Hewitt, J.H., N. Begg, J. Hewish, S. Rawaf, M. Stringer, and B. Theodore-Gandi. Large outbreaks of Clostridium perfringens food poisoning associated with the consumption of boiled salmon. Epidemiology and Infection. 1986; 97: p. 71-80.

56. Anonymous. (2013). Revised annual mid-year population estimates, UK: 2001 to 2010. Office for National Statistics: London, UK. Available from: https://www.ons.gov.uk/peoplepopulationandcommunity/populationandmigration/p opulationestimates/bulletins/annualmidyearpopulationestimates/2013-12-17\#mid2001-to-mid-2010-uk-population-estimates

57. O'Brien, S.J., T.L. Larose, G.K. Adak, M.R. Evans, and C.C. Tam. Modelling study to estimate the health burden of foodborne diseases: Cases, general practice consultations and hospitalisations in the UK, 2009. BMJ Open. 2016; 6: p.

58. Pires, S.M., E.G. Evers, W. van Pelt, T. Ayers, E. Scallan, F.J. Angulo, A. Havelaar, T. Hald, and Med-Vet-Net Workpackage 28 Working Group. Attributing the human disease burden of foodborne infections to specific sources. Foodborne Pathogens and Disease. 2009; 6: p. 417-424.

59. Farkas, J. Irradiation as a method for decontaminating food. A review. International Journal of Food Microbiology. 1998; 44: p. 189-204. 
60. Schweiggert, U., R. Carle, and A. Schieber. Conventional and alternative processes for spice production - a review. Trends in Food Science \& Technology. 2007; 18: p. 260-268.

61. Sádecká, J. Influence of two sterilisation ways, gamma-irradiation and heat treatment, on the volatiles of black pepper (Piper nigrum L.). Czech Journal of Food Sciences. 2010; 28: p. 44-52.

62. Waje, C.K., H.-K. Kim, K.-S. Kim, S. Todoriki, and J.-H. Kwon. Physicochemical and microbiological qualities of steamed and irradiated ground black pepper (Piper nigrum L.). Journal of Agricultural and Food Chemistry. 2008; 56: p. 4592-4596.

63. Zhao, J. and P.M. Cranston. Microbial decontamination of black pepper by ozone and the effect of the treatment on volatile oil constituents of the spice. Journal of the Science of Food and Agriculture. 1995; 68: p. 11-18.

64. EFSA. Scientific opinion on the safety and efficacy of using recycled hot water as a decontamination technique for meat surfaces. EFSA Journal. 2010; 8: 1827.

65. FSA. Food Standards Agency. Irradiated food [cited 2012 December 30]. Available from: http://www.food.gov.uk/policy-advice/irradfoodqa/

66. Almela, L., J.M. Nieto-Sandoval, and J.A. Fernández López. Microbial inactivation of paprika by a high-temperature short-X time treatment. Influence on color properties. Journal of Agricultural and Food Chemistry. 2002; 50: p. 1435-1440.

67. Zaied, S.E.A.F., N.H. Aziz, and A.M. Ali. Comparing effects of washing, thermal treatments and gamma irradiation on quality of spieces. Food / Nahrung. 1996; 40: p. 32-36.

68. Novak, J.S. and J.T.C. Yuan. The fate of Clostridium perfringens spores exposed to ozone and/or mild heat pretreatment on beef surfaces followed by modified atmosphere packaging. Food Microbiology. 2004; 21: p. 667-673.

69. Akbas, M.Y. and M. Ozdemir. Effect of gaseous ozone on microbial inactivation and sensory of flaked red peppers. International Journal of Food Science \& Technology. 2008; 43: p. 1657-1662.

70. Mahfoudh, A., M. Moisan, J. Séguin, J. Barbeau, Y. Kabouzi, and D. Kéroack. Inactivation of vegetative and sporulated bacteria by dry gaseous ozone. Ozone: Science \& Engineering. 2010; 32: p. 180-198.

71. ICMSF. International Commission on Microbiological Specifications for Foods. Book 7. Microbiological testing in food safety management (2nd edition). 2002. International Commission on Microbiological Specifications for Foods (eds). Springer International Publishing AG: Cham, Switzerland

72. WTO. (1995). Agreement on the application of sanitary and phytosanitary measures (SPS Agreement). World Trade Organization: Geneva. Available from: http://www.wto.org/english/docs e/legal e/15-sps.pdf 
73. Zwietering, M. Practical considerations on food safety objectives. Food Control. 2005; 16: p. 817-823.

74. ICMSF. (2006). A simplified guide to understanding and using Food Safety Objectives and Performance Objectives. International Commission on Microbiological Specifications for Foods: Available from: http://www.icmsf.org/publications/guide/

75. Gorris, L.G.M. Food safety objective: An integral part of food chain management. Food Control. 2005; 16: p. 801-809.

76. Anderson, N.M., J.W. Larkin, M.B. Cole, G.E. Skinner, R.C. Whiting, L.G.M. Gorris, A. Rodriquez, R. Buchanan, C.M. Stewart, J.H. Hanlin, L. Keener, and P.A. Hall. Food safety objective approach for controlling Clostridium botulinum growth and toxin production in commercially sterile foods. Journal of Food Protection. 2011; 74: p. 1956-1989.

77. Crouch, E.A., D. LaBarre, N.J. Golden, J.R. Kause, and K.L. Dearfield. Application of quantitative microbial risk assessments for estimation of risk management metrics: Clostridium perfringens in ready-to-eat and partially cooked meat and poultry products as an example. Journal of Food Protection. 2009; 72: p. 2151-2161.

78. Membré, J.M., J. Bassett, and L.G.M. Gorris. Applying the food safety objective and related standards to thermal inactivation of Salmonella in poultry meat. Journal of Food Protection. 2007; 70: p. 2036-2044.

79. Rieu, E., K. Duhem, E. Vindel, and M. Sanaa. Food safety objectives should integrate the variability of the concentration of pathogen. Risk Analysis. 2007; 27: p. 373-386.

80. Sosa Mejia, Z., R.R. Beumer, and M.H. Zwietering. Risk evaluation and management to reaching a suggested FSO in a steam meal. Food Microbiology. 2011; 28: p. 631638.

81. Stewart, C.M., M.B. Cole, and D.W. Schaffner. Managing the risk of staphylococcal food poisoning from cream-filled baked goods to meet a food safety objective. Journal of Food Protection. 2003; 66: p. 1310-1325.

82. Membré, J.M., M. Diao, C. Thorin, G. Cordier, F. Zuber, and S. André. Risk assessment of proteolytic Clostridium botulinum in canned foie gras. International Journal of Food Microbiology. 2015; 210: p. 62-72.

83. FAO/WHO. (2002). Principles and guidelines for incorporating microbiological risk assessment in the development of food safety standards, guidelines and related texts. Report of a Joint FAO/WHO Consultation, Kiel, Germany, 18-22 March 2002. ISBN: 92-5-104845-2. Food and Agriculture Organization of the United Nations/World Health Organization: Rome/Geneva. Available from: http://www.fao.org/3/a-y4302e.pdf

84. CAC. (2015). Codex Alimentarius Commission. Procedural Manual. Twenty-third edition. World Health Organization/Food and Agriculture Organization of the United 
Nations: Geneva/Rome. Available from: $\mathrm{ftp} / / / \mathrm{ftp}$. fao.org/codex/Publications ProcManuals/Manual 23e.pdf

85. Robinson, M. MailOnline 2012. P-Day! Victory for pasty eaters everywhere as U-turn ends threat of 50p VAT increase (as long as you eat at Greggs or don't mind a lukewarm one). Available from: http://www.dailymail.co.uk/news/article-2151287 Pasty-tax-U-turn-ends-threat-50p-VAT-increase-long-eat-Greggs-dont-mindlukewarm-one.html

86. Jones, T.F. and F.J. Angulo. Eating in restaurants: A risk factor for foodborne disease? Clinical Infectious Diseases. 2006; 43: p. 1324-1328.

87. Smelt, J.P.P.M. and S. Brul. (2007). Modelling lag-time in predictive microbiology with special reference to lag phase of bacterial spores, in "Modelling microorganisms in food". Woodhead Publishing Limited: Cambridge

88. Zwietering, M.H., J.C. de Wit, H.G.A.M. Cuppers, and K. van't Riet. Modeling of bacterial growth with shifts in temperature. Applied and Environmental Microbiology. 1994; 60: p. 204-213.

89. Taormina, P.J. and W.J. Dorsa. Growth potential of Clostridium perfringens during cooling of cooked meats Journal of Food Protection. 2004; 67: p. 1537-1547.

90. McClure, P.J., C. de W. Blackburn, M.B. Cole, P.S. Curtis, J.E. Jones, J.D. Legan, I.D. Ogden, M.W. Peck, T.A. Roberts, J.P. Sutherland, and S.J. Walker. Modelling the growth, survival and death of microorganisms in foods: the UK Food Micromodel approach. International Journal of Food Microbiology. 1994; 23: p. 265-275.

91. Evans, J. Consumer handling of chilled foods: Perception and practice. International Journal of Refrigeration. 1992; 15: p. 290-298.

92. Xiao, Y., A. Wagendorp, R. Moezelaar, T. Abee, and M.H.J. Wells-Bennik. A wide variety of Clostridium perfringens type $A$ food-borne isolates that carry a chromosomal cpe gene belong to one multilocus sequence typing cluster. Applied and Environmental Microbiology. 2012; 78: p. 7060-7068.

93. Yonogi, S., S. Matsuda, T. Kawai, T. Yoda, T. Harada, Y. Kumeda, K. Gotoh, H. Hiyoshi, S. Nakamura, T. Kodama, and T. Iida. BEC, a novel enterotoxin of Clostridium perfringens found in human clinical isolates from acute gastroenteritis outbreaks. Infection and Immunity. 2014; 82: p. 2390-2399.

94. Albrecht, J.A. Food safety knowledge and practices of consumers in the U.S.A. Journal of Consumer Studies and Home Economics. 1995; 19: p. 119-134.

95. Anonymous. (2009). Microbiological quality of filled savoury pastries. A survey to determine the safety of ready-to-eat filled savoury pastries sold in NSW. NSW Food Authority: Newington NSW. Available from: http://www.foodauthority.nsw.gov.au $\angle$ Documents/science/Microbiological quality of filled savoury pastries.pdf 
Chapter 5 


\title{
Chapter 6
}

\author{
General discussion
}




\section{Need for risk-based food safety metrics}

With the world's population exceeding 7 billion at the time this thesis is being written [1] and projections for the coming decades showing that it may probably reach 9 billion by 2050 [2], achieving global food security is going to be one of humanity's great challenges in the years to come [3]. Food safety is undoubtedly a key feature of the envisioned food security which has been defined as the right of "all people at all times to have physical and economic access to sufficient, safe and nutritious food to meet their dietary needs and food preferences for an active and healthy life" [4]. So the safety of food is recognized as a vital part of a sustainable and secure food system [5], which is only natural considering the impact of unsafe food on public health, the economy and society as we have demonstrated in more detail in chapter 1.

However, managing food safety is becoming a more and more complex issue. To catch up with increased food demands, food production has grown tremendously since the green revolution and food exports have increased almost exponentially with a rising number of countries depending on international long-distance trade and a shift of traded products from raw ingredients to processed foods [5]. As a result, markets have become international and more versatile than ever, including myriads of products that may vary greatly in their origin, manufacture, production standards and target groups. Practices surrounding the consumption of food have also shifted towards more and more people eating outdoors, relying on ready-to-eat products or introducing ethnic food into their diet. This is an enormous difference in comparison with the situation about a century ago when food supply chains were mainly short, with most meals being prepared at home using ingredients that were in their vast majority locally produced and placing the blame in case of mishaps relatively straightforward. Because of the international nature and complexity of markets, the use of new, transparent and generally accepted targets for managing food safety has become necessary [6]. Such targets would help governmental agencies in better controlling the safety of food on a national level but also in food trade situations, to avoid arbitrary or unjustifiable measures set by trading countries in the context of public health protection.

In this direction, in the last two decades, risk-based approaches for managing food safety have been acknowledged as a way of ensuring access to an adequate food supply, facilitating trade and, above all, protecting public health [7]. To make this risk-based food safety management system a reality, new targets were designed. Firstly, the Appropriate Level of Protection (ALOP) was accepted by WTO member states as an expression of the "acceptable level of risk" in a country in relation to foodborne illnesses [8]. Secondly, in order to translate the ALOP into meaningful targets for the industry, the Food Safety Objective (FSO) and its associated targets (Performance Objective, PO; Performance 
Criterion, PC) were adopted a few years later by Codex Alimentarius [9, 10]. These new risk-based targets have several benefits that can be summarized as follows:

- Clear connection between government public health targets (ALOPs) and appropriate food safety measures in the food chain $[11,12]$. The ALOPs can here be viewed as the current level of foodborne illness in a country, given that the country apparently accepts that level of risk, although the country may wish to reduce the current level and set targets for a future ALOP [13]. This link is highly desirable because it offers a food chain approach to food safety and has the potential to make it transparent and quantifiable [14]. In chapters 3-4 of this thesis we have shown how a connection could be made between an ALOP and an FSO. In chapter 5 we demonstrated how a link can be established between future reduced levels of foodborne illness or future Levels of Protection (LOPs) and alternative reduction targets $(P C)$.

- Facilitation of international trade. According to the SPS agreement, each WTO member has to accept the potentially different sanitary or phytosanitary measures of other Member State as equivalent, if it is objectively demonstrated that the measures achieve its "appropriate level of sanitary or phytosanitary protection" i.e. the ALOP. This ALOP is required to be based on a scientific assessment of risk to human health in order to avoid arbitrary or unjustifiable measures that could serve as a disguised restriction on international trade [8]. In chapter 4 we have demonstrated how current levels of protection can be estimated and compared for different European countries for Salmonella in poultry meat.

- Flexibility in their application. The FSO concept provides a concise statement of the required safety level of a food product at the point of consumption which can be communicated to the industry but it leaves open how the latter is going to meet this target $[15,16]$. Therefore it allows for considerable flexibility in the way equivalent food safety levels are achieved by different food chains [15]. The model developed in chapter 4 can be used to decide on alternative ways of meeting a target FSO (Box 1) based on the conceptual equation of ICMSF (Ho - $\Sigma \mathrm{R}+\Sigma \mathrm{I} \leq$ FSO) and serves as proof of this flexibility. However, an FSO may in practice also be too complicated to communicate to small scale industries that lack the technical resources to interpret it into a more meaningful intervention target for the step in the food chain that they are responsible for (i.e. PO, PC) and in that case the competent authority in a country may propose or require a "default" or safe heaven value for such metrics [17]. In instances where the consumer preparing meals at home from raw ingredients is the main factor contributing to the ALOP, countries may have to find ways to educate/inform those that prepare the meals to adopt 
practices that help meeting the ALOP. In the latter case, alternative targets to the FSO may be used by governments so that the flexibility of communicating a risk reduction target is maintained. For instance, in the case of Cornish pasties discussed in chapter 5, where neither the small-scale industry nor the consumer are expected to have the technical skills to decide themselves on a PO or a PC, the government can recommend a number of specific interventions that can help meet a target Level of Protection (LOP) considering interventions shown in Figures $1 \mathrm{a}$ and $1 \mathrm{~b}$. The recommended interventions may differ in their efficiency or may result in the same risk reduction as long as the LOP is met.

- Promoting technological developments in the food industry. The introduction of an ALOP-FSO policy might encourage industry innovation through the setting of public health goals that are oriented towards a continuous risk reduction [12]. Moreover the implementation of these targets is likely to promote a shift from qualitative to quantitative approaches for evaluating risk, which would be preferable for the setting of their intermediate targets in the food chain (PO, PC, CM) and would offer additional insights into the factors that contribute towards product safety. This would overall improve our understanding and managing of safety. For instance, the quantitative risk assessments of chapters 3-5 could be used by stakeholders in the food supply chain to evaluate and decide on control measures for Listeria, Salmonella and C. perfringens in deli meats, poultry meat and Cornish pasties respectively.

Despite the potential advantages of the ALOP-FSO framework listed above, approximately 10 years since its introduction no country explicitly applies the FSO concept for local regulated targets and there is ongoing debate and disagreement about the use of the ALOP concept as a current or future public health protection target. Possible reasons for this could be that there is little guidance on how to establish the concepts [16] or how to implement them in practice linked to each other $[6,18]$. An overlooked reason could also be the political courage it takes to set an acceptable level of risk and communicate it to the general public. However, considering the historical evolution of food safety management, the implementation of similarly new concepts also took a considerable amount of time e.g. for HACCP it took more than 30 years from the moment it was available for use to the industry until it became obligatory by law in the EU $[19,20]$. The steps in the implementation of the concepts and potential bottlenecks $s$ experienced through chapters 2-5 of this thesis and available literature are discussed in the following sections. 
Baseline

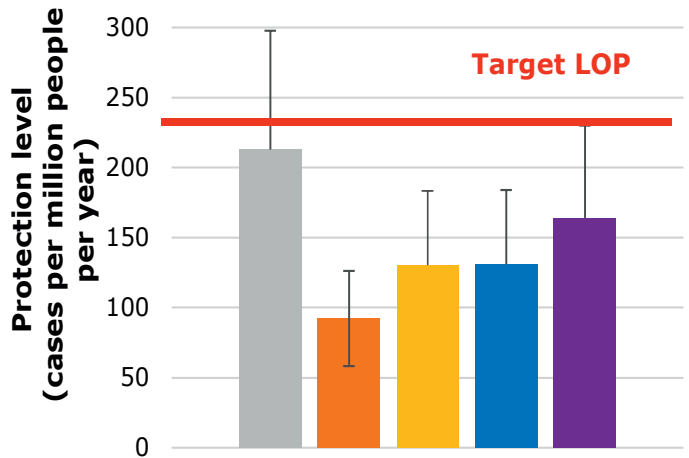

$60 \%$ correct hot holding (consumers)

Irradiation of pepper

- Hot water decontamination (beef)

- Ozone treatment (beef)

Figure 1a. Efficiency of different interventions in meeting a target future LOP for $C$. perfringens in Cornish pasties (230 cases per million people, $23 \%$ risk reduction from baseline) based on the model described in chapter 5 . Whiskers show the $95^{\text {th }}$ percentile of estimates. Hot holding refers to storing pasties at temperatures $\geq 63^{\circ} \mathrm{C}$ after baking; $60 \%$ of consumers comply to this practice. Irradiation has as a target $a \geq 2 \log \mathrm{CFU} / \mathrm{g}$ reduction of spores in pepper. Hot water decontamination aims for $a \geq 2.5 \mathrm{log}$ reduction of spores on beef carcasses while ozone treatment aims for $a \geq 1 \log$ reduction of spores on beef. Compliance is assumed to be $100 \%$ for irradiation, ozone treatment and hot water decontamination.

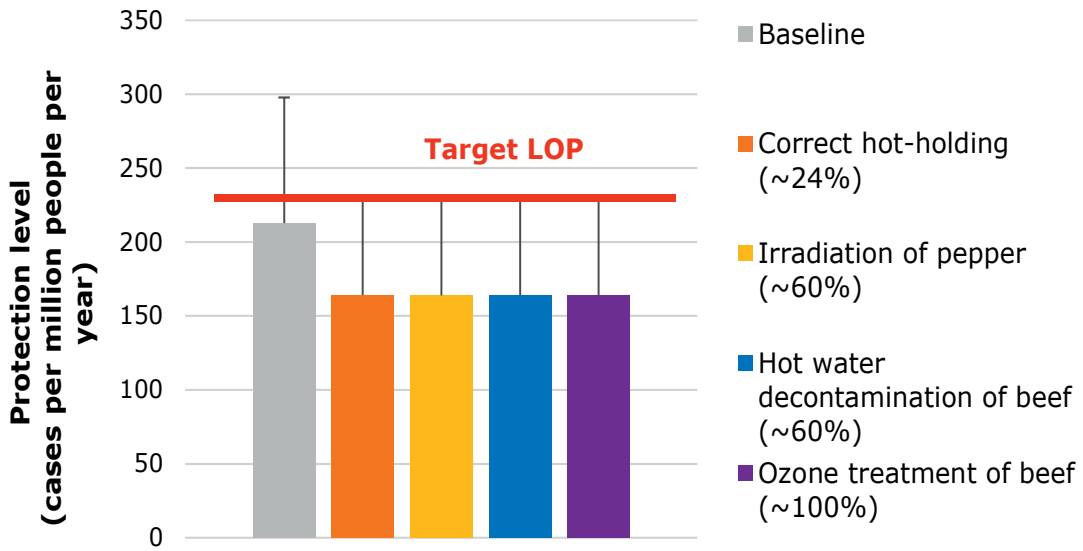

Figure 1b. Effect of same interventions in meeting the same LOP as in Figure 1a for $C$. perfringens in Cornish pasties but for different compliance percentages (values between brackets). 
Box 1. Combinations of factors that may result in the same FSO value for Salmonella in poultry based on use of factors 3-5 in the model described in chapter 4. All figures refer to mean values.

Scenario 1: Greater initial concentration of Salmonella by $0.5 \mathrm{log}$ CFU/g due to accidental post slaughter increase which is mitigated by consumer education campaign resulting in $60 \%$ reduction in undercooking and the probability of preparing a salad after handling chicken.

Scenario 2: Even greater initial concentration of Salmonella with is mitigated by a more intensive consumer education campaign resulting in $80 \%$ reduction for the same practices.

Scenario 3. High initial concentration of Salmonella which is mitigated by improvements in the decontamination process (change from hot water to steam decontamination)

\begin{tabular}{|c|c|c|c|c|c|c|}
\hline & \multicolumn{5}{|c|}{ Factors } & \multirow[b]{2}{*}{$\begin{array}{c}\mathrm{FSO} \\
(\log \\
\mathrm{CFU} / \mathrm{g})\end{array}$} \\
\hline & $\begin{array}{c}\mathbf{1 .} \\
\text { Carcass } \\
\text { concentration } \\
(\log C F U / g)\end{array}$ & $\begin{array}{c}\mathbf{2 .} \\
\text { Decontamination } \\
\text { reduction (log } \\
\text { CFU)* }\end{array}$ & $\begin{array}{c}\mathbf{3 .} \\
\text { Retail } \\
\text { concentration } \\
(\log C F U / g)\end{array}$ & $\begin{array}{c}\mathbf{4 .} \\
\text { Probability of } \\
\text { making salad } \\
\text { after chicken }\end{array}$ & $\begin{array}{c}\mathbf{5} . \\
\text { Frequency } \\
\text { of } \\
\text { undercooking }\end{array}$ & \\
\hline Baseline & 0.5 & -1.5 & -1 & 0.5 & 0.2 & -6 \\
\hline $\begin{array}{l}\text { Scenario } \\
1\end{array}$ & 1 & -1.5 & -0.5 & 0.2 & 0.082 & -6 \\
\hline $\begin{array}{l}\text { Scenario } \\
2\end{array}$ & 1.25 & -1.5 & -0.25 & 0.1 & 0.041 & -6 \\
\hline $\begin{array}{l}\text { Scenario } \\
3\end{array}$ & 2 & -3 & -1 & 0.5 & 0.2 & -6 \\
\hline
\end{tabular}

*It is assumed that in the baseline and scenarios 1-2 decontamination is based on hot water and results in an average reduction of $1.5 \mathrm{log}$ CFU while in the scenario 3 it is assumed that decontamination is based on steam which has double the efficiency [21].

\section{Steps in the implementation of ALOP, FSO and associated targets}

The steps taken when implementing an ALOP-FSO framework are listed and described in detail below.

\subsection{Risk ranking}

Foodborne risks should logically be identified and quantified before deciding whether they can be tolerated or need to be reduced; in other words before setting an ALOP [13]. This is done through a process known as risk or hazard ranking which may be considered to lie at the interface of risk assessment and risk management. Risk ranking is part of the preliminary activities of risk management $[22,23]$ but it is also mentioned to be a risk assessment tool [24]. Risk ranking may be done on the basis of risk profiles [17] established for various food pathogen combinations in scope of the risk management activity, where these profiles are not full-blown risk assessments but contain sufficient information to understand the magnitude of risk impact associated to different hazards/foods. Van der Fels-Klerx et al. have shown in a recent review that there is a wide variety of risk ranking methodologies [25]. Though most studies follow the risk assessment method using metrics suitable for quantifying the probability and severity of the risks, 
some studies follow methods that quantify societal preferences for risk reduction using more subjective metrics such as for instance willingness to pay.

In chapter 3, a risk ranking study was performed for Greece, using the Disability Adjusted Life Year (DALY) which is a risk metric recommended by the WHO for use in burden of disease studies [26] and is increasingly used in describing the public health impact of foodborne illnesses on a national and international level [27-30]. DALY is a time based health indicator that is calculated as the number of healthy years of life lost due to death and disability [26]. Therefore, it has an advantage over incidence in that it can quantify the public health effect of diseases that vary in their associated morbidity and mortality in a unified way using time as a unit and also including health effect weighing, which allows comparison over illnesses that have different outcomes. Such estimates can be used by governments for consultation and agreement on ALOPs with the general public or by risk managers or policy makers to order/rank risk assessments [29] but most importantly to make rational decisions about whether or not resources should be allocated for increased management or regulation of one hazard over another [31]. In that regard, the risk ranking estimates for Greece showed that four illnesses, brucellosis, salmonellosis, echinococcosis and toxoplasmosis were responsible for approximately $70 \%$ of the annual DALY in the country and may thus be considered a priority for food safety management measures. Such measures could be taken after commissioning a risk assessment to evaluate the impact of different interventions on reducing the risk of each illness but they could also be taken immediately when control measures for an illness are already well known from other risk assessments and/or there are examples of their successful application in other countries. In this particular case, because risk factors for all four illnesses have been identified and their management has been successful in other countries, control measures could be selected among what is already mentioned in literature. More specifically:

- For the control of brucellosis, standard prevention measures may involve eradication of the disease in animals (by vaccinations and testing of herds), special precautions by individuals that might be exposed as a result of their occupation and inactivation of the pathogen in dairy and other potentially contaminated products by heating [32]. As the urban population is not exposed to any significant risk of acquiring the infection since all commercially available dairy products in Greece are produced from pasteurized milk [33], these measures should be focused on the rural areas of the country. Considering also that the consumption of unpasteurized dairy products is the main cause of childhood brucellosis where the manifestation of the disease can be more severe $[34,35]$, and a cause of outbreaks that can affect a large number of persons [36] a program of health education of people at risk in these areas was also considered to be necessary for the incidence of the disease to decrease [33]. 
- For the control of salmonellosis, the use of new epidemiological methods [37] but also existing information regarding the most commonly implicated foodstuff in salmonellosis outbreaks [38, 39] and existing risk assessments [40] can be put to use for the prevention and control of the disease for which a coordinated multidisciplinary effort from public health, veterinary and food safety experts is required [41].

- In the case of echinococcosis, preventive measures could include disinfecting carriers of the parasite, prohibiting unauthorized slaughtering of animals, incinerating infected organs and improving cooperation between physicians and veterinarians with the aim to inform people who either because of their occupation or because of their residence in rural areas are at particular risk of contracting the disease [42].

- Finally, to reduce the risk of congenital toxoplasmosis, efforts should be targeted in educating pregnant women on risk factors for contracting the disease, i.e. eating raw or undercooked meat, travelling in developing countries and having contact with soil [43]. Interestingly, cat ownership is not found to be a major risk factor for infection with Toxoplasma [43-46] although domesticated and feral cat populations are a recognized risk factor for seropositivity $[47,48]$.

The selection of appropriate control measures could be based on multi-criteria decision analysis tools that allow the optimal evaluation of different interventions and selection of one over others on the basis of multiple criteria such as weight of evidence, effectiveness, cost and practicality [49].

\subsection{Selection of a risk assessment method}

When there is insufficient information to manage the risks that constitute a priority in terms of public health burden, a risk assessment can be commissioned by risk managers to evaluate interventions [7]. Another use of risk assessment is to provide a scientific link between the ALOP and the sanitary or phytosanitary measure [8], which in this case can be the FSO, PO or PC, that can then be used as a basis for selecting the necessary control measures (CM). The development of such a risk assessment is dependent on the needs of the risk managers, existing data and resource limitations [7]. Depending on data availability a risk assessment may be quantitative, when its individual components are linked by models, or qualitative when this is not the case [50]. Furthermore, depending on the level of detail in the available data, a risk assessment may be deterministic when inputs are point estimates, or stochastic when inputs are incorporated in the form of distributions to include variability and uncertainty [31]. In general, there are two different methodologies for performing a risk assessment, an epidemiological approach, having the risk of illness as a starting point and a supply chain approach having the hazard as a 
starting point [51]. In chapters 3 and 4, both of these approaches were followed with the epidemiological one, estimating first an ALOP and then an FSO being referred to as "topdown" and the supply chain approach, estimating first an FSO and then an ALOP being referred to as "bottom-up". A general overview of the estimation steps and data needs for each risk assessment approach can be seen in Figures 2 and 3 .

It would be recommended to use both approaches when implementing the ALOP-FSO benchmarks. First applying the top-down approach so that the current situation in relation to food safety can be evaluated on the basis of disease surveillance and a target for reduction can be set, and then the bottom-up approach so that the efficiency of different intervention measures in achieving the desired risk reduction can be weighed. Given that the responsibility for deciding on ALOP and FSO values is with governments, they would need the resources and capabilities to conduct the necessary risk assessment(s) as well as have access to relevant epidemiological data and supply chain data. Naturally the application of both approaches in this context would also require an integrated food and disease surveillance system to verify compliance with the FSO and ALOP benchmarks [52]. Such a system would also need to be stable over time so that changes in the observed disease incidence or prevalence of microorganisms cannot be attributed to changes in surveillance methods or isolation and detection protocols respectively. Finally, care should be taken that the end-point of the bottom-up approach is the same as the starting point of the top-down approach. In other words, the cases of

illness estimated through the use of a dose-response model should be of the same severity as the cases estimated through epidemiological data to allow for comparisons between the two approaches. A way to overcome this problem could be to introduce the use of DALY $[53,54]$ as a metric to express the ALOP. DALYs provide the means to express public health burden in a consistent way by summing up the years of human life that are lost in a population due to a specific illness that may manifest in symptoms varying considerably in terms of their severity. Thus the metric can serve as a means of normalizing the outputs of different kinds of risk assessment models [55].

In general, both types of assessments may result in valuable interventions for reducing risk though not of the same kind. It is also important to note that new knowledge from one type of risk assessment can help improve the other type and vice versa. For instance, epidemiological data from outbreak investigations used in top down risk assessments may help identify high risk product-pathogen combinations or contamination scenarios for which a bottom-up risk assessment is needed to identify interventions in the food chain. Similarly, a knowledge gap with regards to dose-response modelling in bottom-up risk assessments may be narrowed by better quality epidemiological data from outbreaks collected in a topdown risk assessment. 
However, both the top-down and the bottom-up approach are quite demanding in terms of data and particularly in the case of the former, an integrated food chain surveillance system would be needed for the results to be suitable for model validation [56]. At present, very few countries hold this type of surveillance system and not for all pathogens. This means that in practice it may only be possible to apply one approach to setting risk based metrics, as has been the case in chapter 5 where only a bottom-up risk assessment model could be developed for a niche product. Though using only one risk assessment approach is not optimal, this may still allow for risk-based interventions connected to an ALOP or a LOP as shown before in Figure 1. An overview of the differences between top-down and bottom-up risk assessments can be seen in Table 1.

Table 1. Overview of similarities and differences between top-down and bottom-up risk assessments

\begin{tabular}{|c|c|c|}
\hline & Bottom-up risk assessment & Top-down risk assessment \\
\hline \multirow{5}{*}{ 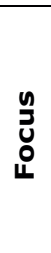 } & Single hazard-food combination & Single hazard-multiple foods \\
\hline & More on interventions than on risk & More on risk than on interventions \\
\hline & Targeted more towards the & Targeted more towards public health \\
\hline & industry and food chain safety & authorities and governmental food safety \\
\hline & managers. & managers. \\
\hline \multirow{12}{*}{$\begin{array}{l}\stackrel{+}{\vec{z}} \\
\stackrel{0}{0} \\
\stackrel{2}{z}\end{array}$} & Interventions based on the effect & Interventions based on risk factors, \\
\hline & of processing/consumer practices & frequently implicated vehicles in outbreaks \\
\hline & on risk. E.g. irradiation in & and high-risk product-pathogen \\
\hline & combination with MAP can reduce & combinations. E.g. guidelines on how to \\
\hline & the mean risk of listeriosis per & manage risk of viral product \\
\hline & serving of baby spinach by $65.6 \%$ & contamination from food handlers [58] \\
\hline & {$[57]$} & following outbreak investigations \\
\hline & & $\begin{array}{l}\text { identifying asymptomatic food handlers in } \\
\text { contact with sick household members as a } \\
\text { major cause of Norovirus outbreaks [59]. }\end{array}$ \\
\hline & Risk estimate based on standard & Risk estimate also includes incidental \\
\hline & industrial/household practices. & contamination during non-standard \\
\hline & $\begin{array}{l}\text { E.g risk estimate for Salmonella in } \\
\text { poultry based on retail data and }\end{array}$ & $\begin{array}{l}\text { industrial/consumer practices (outbreaks, } \\
\text { sporadic cases). }\end{array}$ \\
\hline & $\begin{array}{l}\text { common consumer mishandling } \\
\text { practices described in chapter } 4 \text {. }\end{array}$ & $\begin{array}{l}\text { E.g. top-down risk estimate for Listeria in } \\
\text { deli meats in chapter } 3 \text {. }\end{array}$ \\
\hline
\end{tabular}




\begin{tabular}{|c|c|}
\hline Estimation steps & Inputs \\
\hline Reported cases of illness & $\begin{array}{l}\text { Surveillance data on laboratory confirmed } \\
\text { cases, population statistics }\end{array}$ \\
\hline Total cases of illness & $\begin{array}{l}\text { Underreporting factor, under-notification } \\
\text { factor }\end{array}$ \\
\hline Total cases of illness due to food & $\%$ cases transmitted through food \\
\hline $\begin{array}{l}\text { Appropriate level of Protection: } \\
\text { Total cases of illness due to food product }\end{array}$ & $\%$ cases due to food product \\
\hline Dose consumed & Dose response model, number of servings \\
\hline Concentration at consumption & Mass per serving, concentration \\
\hline Food Safety Objective & Prevalence in food product \\
\hline
\end{tabular}

Figure 2. General outline of the estimation steps and input requirements in the "topdown" risk assessment methodology for the determination of ALOP and FSO. 


\begin{tabular}{|c|c|}
\hline Estimation steps & Inputs \\
\hline $\begin{array}{l}\text { Appropriate Level of Protection: } \\
\text { Total cases of illness due to food } \\
\text { product }\end{array}$ & $\begin{array}{l}\text { Dose response model, number of servings, } \\
\text { prevalence }\end{array}$ \\
\hline Food Safety Objective & Mass per serving Prevalence \\
\hline Concentration at consumption & $\begin{array}{l}\text { Frequency of consumer practices resulting } \\
\text { in growth, reduction and/or recontamination }\end{array}$ \\
\hline Recontamination (if applicable) & $\begin{array}{l}\text { Transfer rates between surfaces, } \\
\text { concentration levels in source of } \\
\text { recontamination }\end{array}$ \\
\hline Reduction (if applicable) & D-value, $z$-value, time, temperature \\
\hline Growth (if applicable) & $\begin{array}{l}\text { Growth rate, time, temperature, primary } \\
\text { growth model, secondary growth model } \\
\text { parameters }\end{array}$ \\
\hline Initial concentration in the product & Sampling data \\
\hline
\end{tabular}

Figure 3. General outline of the steps in the "bottom-up" risk assessment methodology for the estimation of ALOP and FSO. Examples of input requirements are given in the second column.

\subsection{Considerations on the targets}

Once the risk assessment has been set and a link has been established between the risk of illness and the prevalence and concentration of the hazard in the food chain, the ALOP and FSO (or other risk-based targets) can be set. However, a series of decisions need to 
made, sometimes prior to the completion of the risk assessment. These decisions are summarized in the paragraphs below.

\subsubsection{Interpretation of definitions and agreement on units for expressing the metrics.}

Though it is generally agreed that an ALOP is an expression of risk in relation to a hazard in food in a country, not all WTO members may agree that their current LOP represents an "acceptable risk" and they may wish to link their sanitary measures to a future LOP. So in practice, a LOP may either be linked to a current of future public health protection level. Furthermore, considering that data gathering for risk assessment purposes takes time and typically includes studies from different years, both top-down and bottom-up risk assessments would inevitably provide risk estimates for recent past years and not the current situation. For instance, in chapter 4 , in the case of the top-down LOPs for salmonellosis, estimates were based on data from a 7-year period prior to the time of the assessment while in the case of the bottom-up LOP data were based on a 14-year period. Considering that it is inevitable to exclude data from past studies, an agreement has to be made prior to the start of a risk assessment on the timeframe from which relevant data can be extracted for building the model and that this can be considered an approximation of the current situation or a basis for discussing future LOPs.

The selection of the units for expressing risk is also important. Both the risk per serving and the population risk would fulfil the criteria for defining risk (probability and severity of the adverse effect in relation to the hazard in food). However, the selection of one over the other would influence the communication of the risk, particularly when targets for the same pathogen in multiple foods are to be set. Population risk (especially when expressed as DALYs instead of incidence), gives a more accurate picture of the disease burden that is accepted (ALOP) or is a target for future interventions (public health goal LOP) and therefore is better for communication to food safety managers and the general public. The risk per serving may be preferable for communicating risk to consumers, food handlers or the industry but it does not give on its own a clear picture of the disease burden it represents unless combined with population consumption data. This is because a high risk per serving means that the concentration/prevalence of the hazard is high or the consumer is particularly sensitive to the hazard (and therefore a target for interventions by consumers, food handlers or the industry) but when it is very infrequently consumed and/or by a small part of the population, the food product does not necessarily contribute significantly to the disease burden in the whole population. This difference between population risk and risk per serving has already been observed during the FDA/FSIS Listeria monocytogenes risk assessment in ready-to-eat foods where products with relatively low risk per serving (pasteurized milk) were found to be linked with a high population risk and products with a high risk per serving (pâté and meat spreads) were linked to moderate 
population risk (Figure 4). It is therefore recommended to express risk both on population level (risk per population unit) and on consumer level (risk per serving) when designing risk communication to stakeholders.

With regards to the FSO units, in the case studies of chapters 3 and 4, it was selected to use $\log \mathrm{CFU} / \mathrm{g}$ as this would allow for the incorporation of the concentration, prevalence and frequency of events leading to the hazard being introduced in the food (unwashed hands, unwashed or only rinsed cutting board and knife) in the FSO equation as the definition of this target would require.

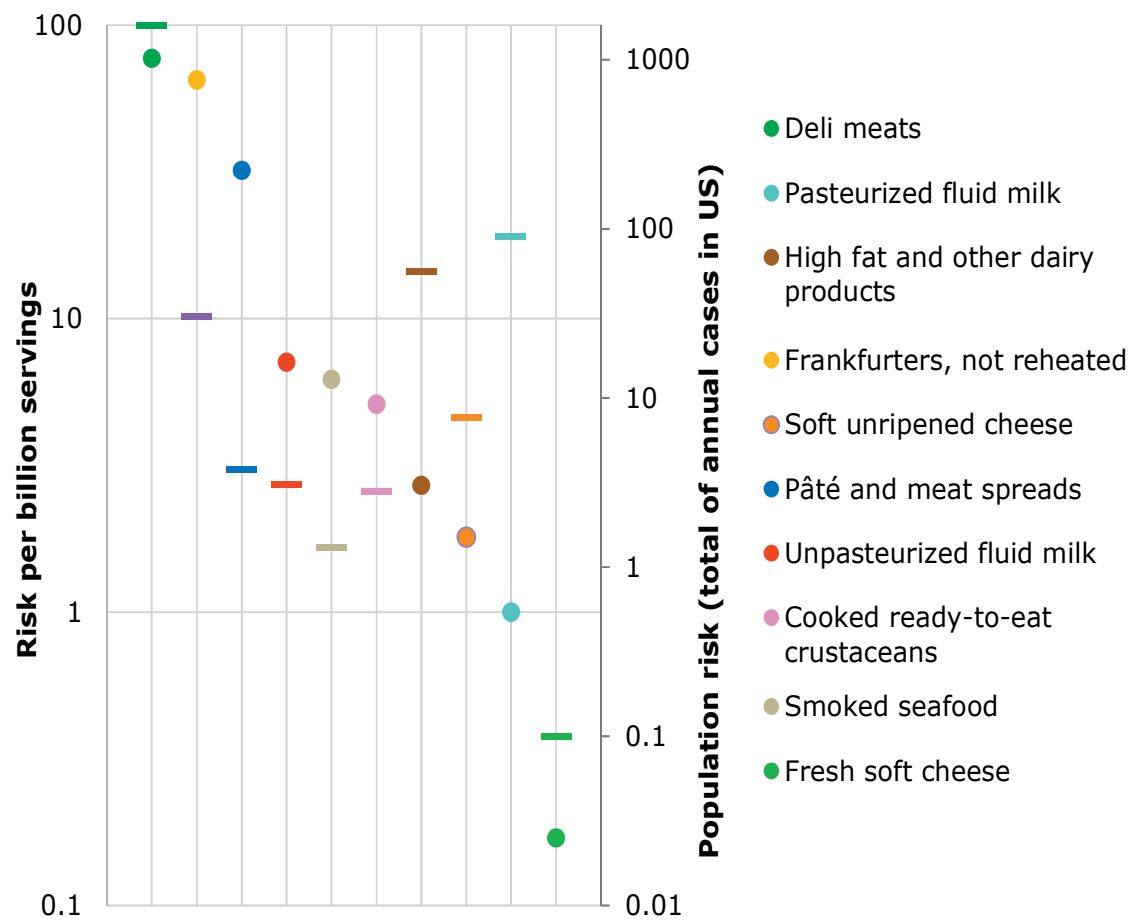

Figure 4. Top-10 of riskiest ready-to-eat products for Listeria in terms of risk per serving (bullets) and their correspondent population risk (dashes of same colour as the bullets) in the US. Risk per serving is the risk of listeriosis per single serving of each ready-to-eat food for the individual consumer. Risk per serving is considered high when the product contributes to $>5$ cases per billion servings, moderate for $1-5$ cases per billion servings and low for $<1$ case per billion servings. Population risk is the annual number of listeriosis cases for the entire US population. Population risk is considered very high for $>100$ cases per annum, high for $>10$ cases per annum, moderate for 1-10 cases per annum and low for $<1$ case per annum [60]. 
However, a complication of selecting concentration is that exposure to a pathogen may not only be the result of consuming the food item it originated from (e.g. chicken meat) but also a number of other products that may have incidentally been contaminated from this item during the preparation of a meal (e.g. salad). Furthermore, in the case of multiingredient foods like Cornish pasties, concentration of more than one contaminated ingredients may contribute to exposure. For these reasons it has been suggested to use the dose instead of the concentration at consumption as a means of defining an FSO. This can be done by building a prevalence-dose curve (P-D curve) [16]. An example of this approach is shown in Figure 5 where the P-D curve is built by solving the LOP formulas of the bottom-up model of chapter 3 for the prevalence, using fixed values for the LOP ( $99^{\text {th }}$ percentile values for yopi and healthy population) and dose (5-10 log CFU). The outer part of each curve corresponds to combinations of prevalence and dose at consumption that result in meeting a target LOP.

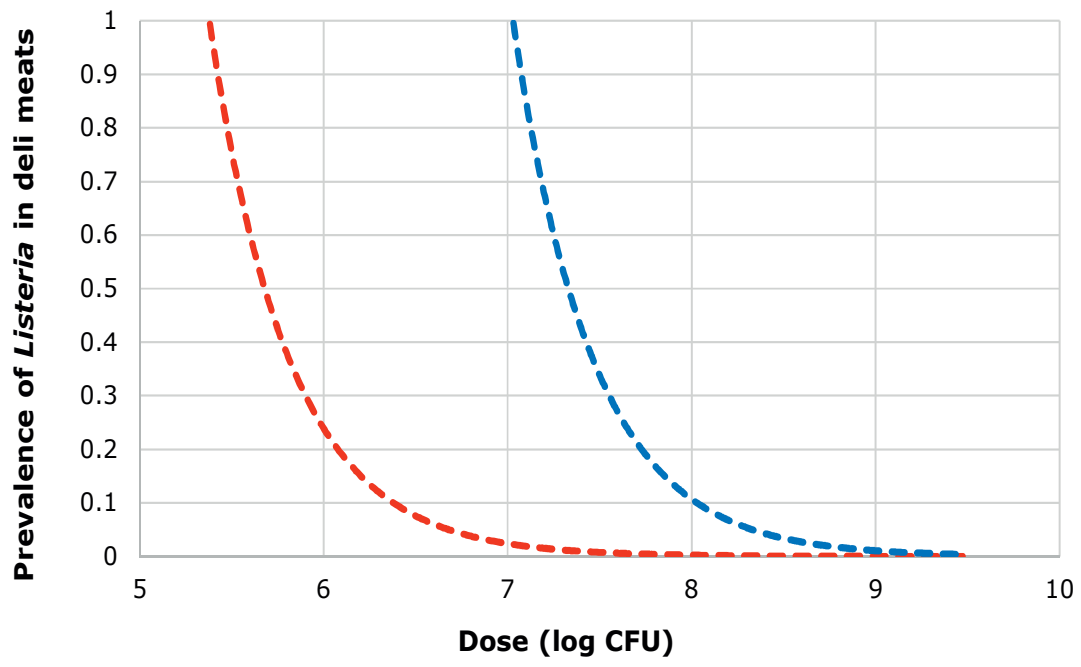

Figure 5. Combinations of prevalence $(P)$ and dose $(D)$ that result in a target Level of Protection (LOP) for Listeria in deli meats in the Netherlands for the susceptible (red dashed line) and the healthy population (blue dashed line). Target protection levels correspond to the $9^{\text {th }}$ percentile of calculated LOPs for these two population groups based on the bottomup risk assessment model of chapter 3 ( $\sim 80$ cases per million susceptible individuals and $\sim 2$ cases per million healthy individuals). 


\subsubsection{Interpretation of probability distributions (percentile selection for setting risk based} targets)

Considering the stochastic nature of many risk assessments, another major decision is how to set a risk-based target, that for all intents and purposes needs to be a numerical threshold, on the basis of a distribution that is a continuous range of values. This is not a real issue for deterministic risk assessments since their outputs are by definition numerical (point estimates) or for qualitative risk assessments that by definition do not result in numerical outputs. For stochastic risk assessments, this decision depends on the interpretation of the "maximum frequency and/or concentration of the hazard" that is part of the FSO definition and thus affects all its related targets. Currently there is no uniform agreement among experts on how to relate this "maximum" to the outputs of a stochastic risk assessment (probability distributions) [7]. In chapters 3 and 4 it was suggested that the interpretation of maximum may relate to the selection of an upper percentile of the probability distribution of the risk estimate (ALOP/FSO) that covers for both uncertainty and variability. Which percentile is selected depends on the level of confidence the food safety manager wishes to have on the risk estimate so that it is not surpassed. When both a top-down and bottom-up approach are used, then the selected percentile could be one of the upper percentiles after the median for which both outputs are aligned, e.g. with this approach the $90^{\text {th }}$ percentile could be a good selection for setting a LOP for Salmonella in chicken based on the risk assessments of chapter 4 . In general, looking at risk assessments from other fields than food microbiology, the median or percentiles at very different distances from the median may be used to set targets. For instance, Peters et al. selected the $66^{\text {th }}$ percentile to suggest targets for carbon emissions on the basis of temperature increases (global warming) [61]. In toxicological risk assessments, the selection of percentiles may also vary considerably depending on the aim of the assessment. As an example, for estimating chronic dietary exposures to pesticide and veterinary drug residues, the median of the residue distribution is selected. In contrast, for estimating acute dietary exposure, upper percentiles of serving sizes (e.g. 97.5 th $)$ in combination with highest residue concentrations measured in supervised trials are selected [62]. In any case, the selected percentile expresses the probability of reaching the risk based target and is mentioned by different authors in relation to the FSO as the "compliance rate" [63] or the "food safety margin" in meeting this target [64].

\subsubsection{Rate of industrial and consumer compliance in meeting a risk-based metric}

Every risk assessment model is a simplification of the real world and thus may not cover for all pathways leading to exposure to microbial hazards and illness. Failure to cover for all relevant risk pathways may be due to failure to capture certain types of unpredictable human error events (unforeseen malpractices/accidents at the consumer or industry level 
leading to sporadic cases or outbreaks) or the actual variation in production, distribution and consumer use of a specific food commodity. For these reasons it is unrealistic to expect $100 \%$ compliance to a risk-based target and it is advisable to consider the potential failure rates at the consumer and industry level in meeting the target. A way to do this is by allowing for some extra ceiling in the numerical LOP for these unforeseen cases and/or clarifying that the ALOP/LOP target is representative of the main factors identified to contribute to the risk and/or setting separate targets for the percentage of cases due to uncertain human error events.

On the side of the industry, the abovementioned human error events are relatively rare food contamination incidents due to failure to meet HACCP prerequisites or to achieve a safe formulation. Examples of such single events that have affected an exceptionally large number of people are for instance:

- the 1994 US Salmonella outbreak in relation to ice cream that resulted in an increase of about $20 \%$ in the annual reported number of salmonellosis cases ( $>200,000$ cases of gastroenteritis in the general population). The incident originated from tanker trailers of ice cream premix that had been previously used to carry liquid non-pasteurized eggs without being properly washed and sanitized [65]

- the 1989 UK botulism outbreak in relation to hazelnut yoghurt that resulted in 27 cases [66], representing in itself more than a third of all cases reported in the UK in the period 1922-2005 [67]. The source of this outbreak was traced back to a change in the formulation of the hazelnut conserve (replacement of sugar with aspartame) that was made without an assessment of the risk of growth of $C$. botulinum.

On the side of the consumer, human error events could be unforeseen malpractices resulting in sporadic cases or outbreaks. An example of this type of human error is the consumption of raw cookie dough by a large percentage of consumers in the US in 2009, despite package instructions to bake the product, that resulted in 77 illnesses due to $E$. coli 0157:H7 [68].

Non/compliance to risk-based metrics due to unforeseen human error events such as those described above is different to non/compliance due to the variability and uncertainty of risk assessment models discussed in the previous section. It is also important to note that common malpractices are usually part of the risk assessment model (use of contaminated cutting boards or poor food handler hygiene resulting in product contamination $[40,69]$ ) and therefore their impact on the risk based metric should be covered by the selected compliance rate or food safety margin. 


\subsubsection{Social and economic factors}

Other considerations before making a decision on a value for an ALOP/LOP and related risk based targets is the technical and economic feasibility of achieving them and that they should not be more restrictive to trade with other countries than necessary [8]. This allows for different countries to opt for different public health targets due to societal differences or financial reasons, even if they have the same level of technological resources. An example of this are the different public health targets for the reduction of Salmonella between Denmark and the United States. Both countries have intensive broiler/hen farming systems and started Salmonella control programmes at periods when salmonellosis in relation to poultry and eggs was recognized as a major public health issue with comparable incidence rates. However, they opted for very different targets (eradication in Denmark vs reduction in the US) and control approaches (top-down eradication in Denmark vs control measures at/following slaughter in the US) $[70,71]$ (see also Table 2). Suggested reasons for the selection of different control measures is the larger size of the US poultry industry in comparison to the Danish one, willingness to pay for Salmonella free meat and issues with the implementation of uniform control measures across the food chain due the US regulatory framework [72].

Financial and societal reasons such as the eating culture, customs and traditions in a country may also result in the acceptance of relatively high LOPs for some niche products. An example of this is the sale of soft raw milk cheeses in Europe where they are an important part of the economy of many countries despite risk assessments and epidemiological investigations showing that they can be a significant contributor to the incidence of listeriosis [73, 74]. The European approach in controlling products such as these that support the growth of Listeria monocytogenes, is to set a maximum legal threshold for the concentration of the pathogen (i.e. $\leq 100 \mathrm{CFU} / \mathrm{g}$ throughout shelf-life for products placed in the market, absence in $25 \mathrm{~g}$ at the manufacturer; thresholds based on 5 samples in each case) in combination with environmental sampling covering the processing areas and equipment used for their production [75]. In contrast, the US current approach is to prohibit the sale of raw milk cheeses that have been aged for less than 60 days and to have a zero tolerance policy for the presence of the pathogen in ready-to-eat products [76]. Interestingly, the strictness of the latter policy is not necessarily related to a higher level of public health protection, since it has been shown when combining food survey and epidemiological data by means of risk assessment techniques that interventions targeting the concentration of Listeria rather than its prevalence have a greater risk reduction potential [77]. Similar findings have been reported in the EU where it is shown that $\sim 92 \%$ of invasive listeriosis cases due to ready-to-eat foods are caused by ingestion of contaminated servings with concentrations in excess of 2,000 CFU/g [78]. 
Table 2. Background of Salmonella control programs in Denmark and the United States

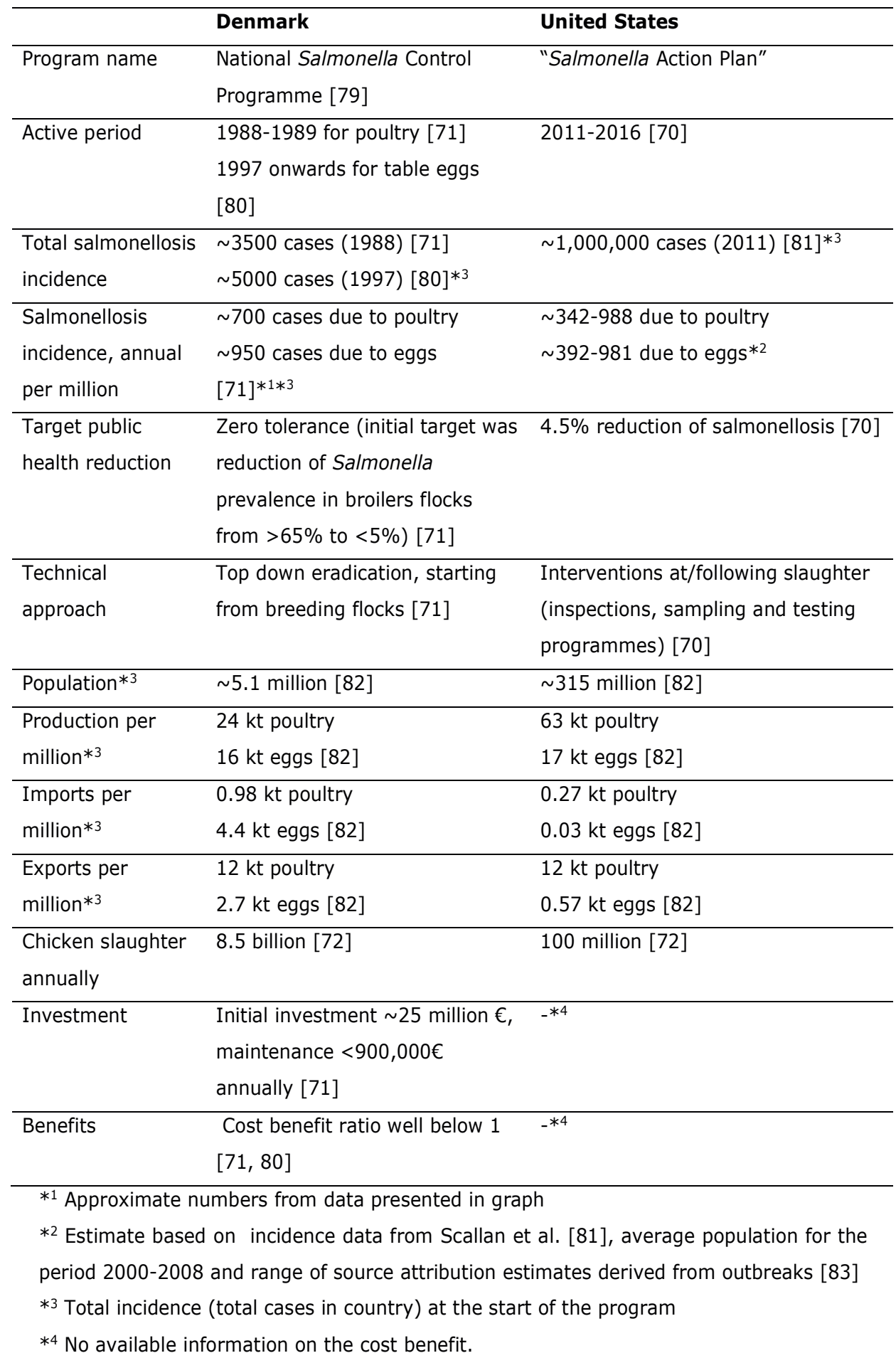




\subsubsection{Risk communication}

Last but not least, both the ALOP and the FSO are to be communicated to different parties and this is perhaps the most challenging part of the whole process as most consumers are likely to have a difficulty in understanding the uncertainty and variability involved in the estimations and the fact that it is not possible to achieve a zero level of risk [84]. For these reasons perhaps, communication in relation to food safety has so far been mainly focused not on the risk itself but on general mitigation strategies as for instance in the World Health Organization's "Five keys to safer food" educational material targeting food handlers and consumers [85]. An exception to this is the Dutch campaign "Ziekmakers zie je niet" ("You cannot see pathogens") where both the risk and the mitigation strategy are communicated to the general population. The campaign that involved YouTube videos and posters published on high traffic public locations such as bus shelters and city information panels aimed to reduce the incidence of foodborne illness in the Netherlands by raising awareness over the most dangerous food handling/preparation behaviours. In each poster, the impact of foodborne illnesses on the population is highlighted (2000 people sick every day in the country) alongside messages on safe practices that can help reduce it [86-88](Figure 6).

It is also important to acknowledge that risk communication has gradually evolved since the time of the first food scandals with the public becoming gradually more involved and in some cases given the opportunity to influence the decision making process [89]. One of the most notable examples of the latter being the debate on genetically modified crops that took place in the United Kingdom in the period 2002-2003 when the general public was given the opportunity to voice their concerns regarding their commercialization in the country [90].

\section{Risk-based food safety management today}

As noted before, no country to this day uses the concepts of ALOP and FSO as risk based benchmarks for guiding food safety management in food supply chains. However, there are several examples of countries establishing links between a future public health goal (target for the reduction of incidence foodborne illnesses) and a control measure in the food chain based on the principles of risk analysis. Creating in these cases a quantitative or qualitative link between the risk and the control measure makes food safety management risk-based and has all the advantages discussed in section 1. A few notable examples of risk-based food safety management linked to LOPs are discussed below.

The Danish Salmonella control programme started after a sharp increase in the incidence of salmonellosis in the country in the second half of the 1980s due the spread of Salmonella in broiler chickens [71]. The program was thus first implemented in poultry and later on in pork and table eggs $[80,91]$. With regards to poultry and eggs several targets were established with the aim of reducing the level of Salmonella in broilers from $>65 \%$ to less 

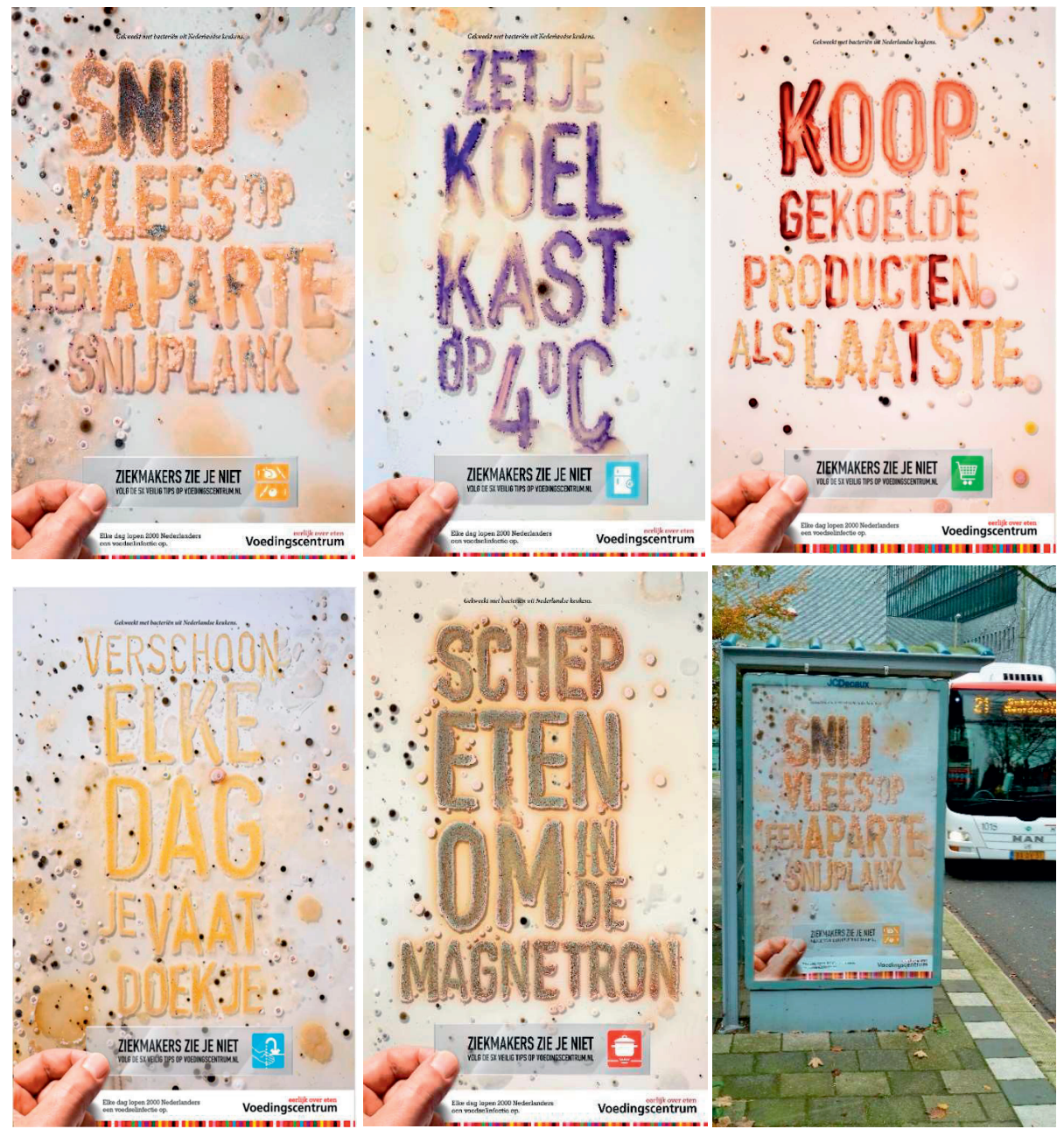

Figure 6. Posters from the Dutch campaign "Ziekmakers zie je niet" ("You cannot see pathogens" or freely translated: "Foodborne pathogens are invisible"). Top left: "Cut meat on a separate cutting board", top middle: "Set your fridge at $4{ }^{\circ} \mathrm{C}$ ", top right: "Buy chilled products last", bottom left: "Clean every day your dish cloth", bottom middle: "Stir microwave heated food", bottom right: poster display at a bus stop. Messages are written on laboratory media using microorganisms that have been isolated from Dutch kitchens as stated in small print on the upper part of each poster.

Source: Voedingscentrum en Lemz (reproduced with permission) [86-88]. 


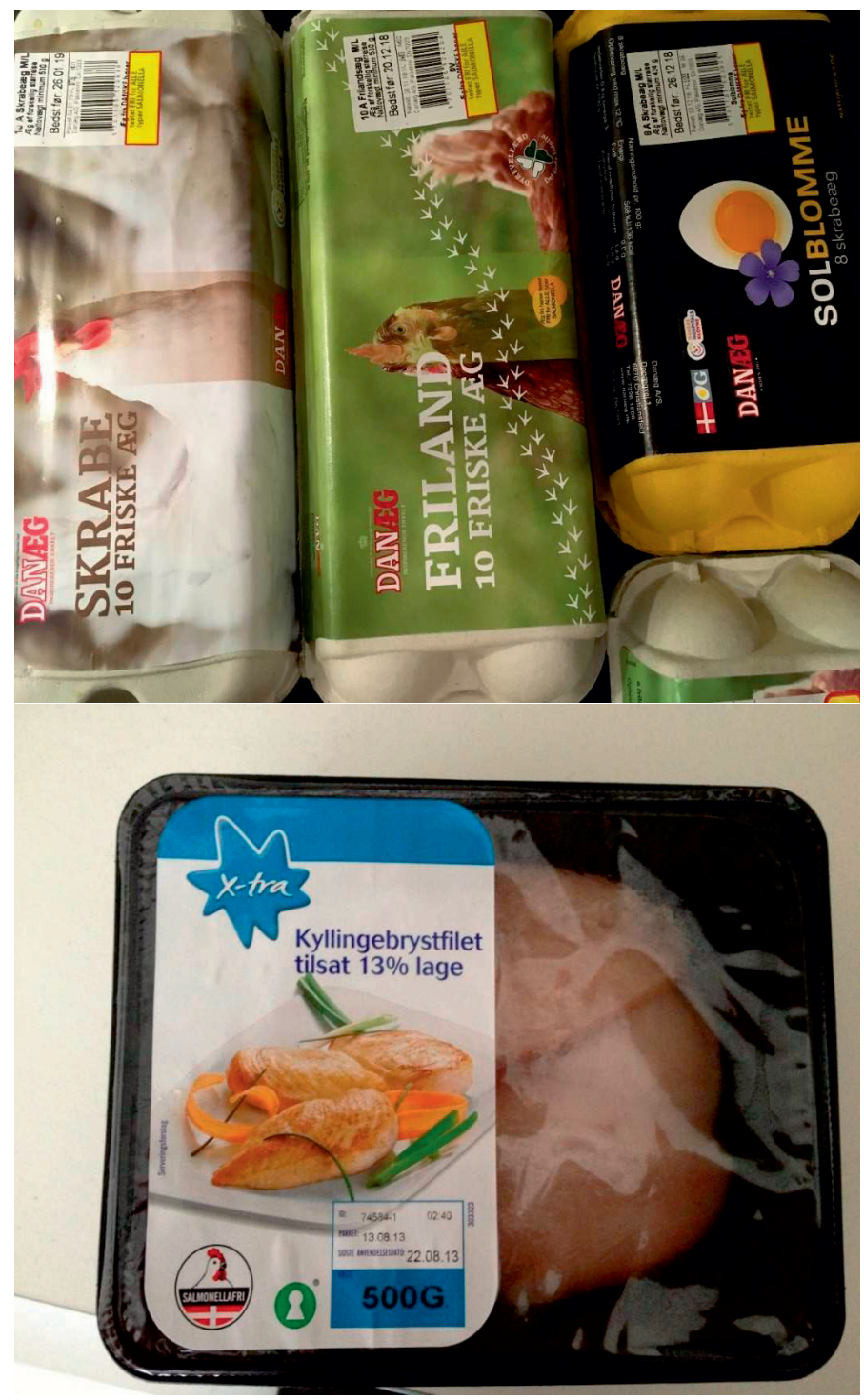

Figure 7. Danish egg cartons and chicken meat package bearing the logos "eggs from Danish hens that tested free from all types of Salmonella (yellow logos in top picture "/Eg fra Danske høner er testet fri for alle typer Salmonella") or "Salmonella free" (circular logo in bottom picture "SALMONELLAFRI").

than $5 \%$. Later on the target was revised as zero tolerance and products complying to state regulations were allowed to bear the logo "Salmonella-free" (Figure 7) [71, 92]. These targets were based on the principle of top-down eradication and involved measures such as intensive serologic and bacteriological testing of broilers and breeding flocks for 
the presence of Salmonella, slaughter of infected animals at separate lines, processing of contaminated products or products suspected of contamination in such a way as to eliminate the pathogen (e.g. pasteurization of eggs), thorough cleaning, disinfection and resting periods for poultry houses [71]. The implementation of these measures resulted in practice in a very low prevalence of Salmonella in animal flocks in Denmark which is mirrored in a very low incidence of salmonellosis due to table eggs and broiler meat. E.g. in $2017<1 \%$ of table egg and broiler flocks were found to be positive for Salmonella and the incidence of salmonellosis due to these products was $<5$ cases per million inhabitants [93]. Similarly, specific targets for the reduction of different foodborne illnesses have been established through the US Healthy People programmes and are accompanied by targets for the improvement of key food safety practices by consumers, food services and retail establishments [94]. The targeted food safety practices are in this case based on the World Health Organization's guidelines for safer food [85] and represent major interventions at the household level for reducing the risk of foodborne illness. In both the Danish and the US programs, measures are based on the assessment of risk factors and are related to public health targets. However, in neither case are the public health targets described as ALOPs or the measures selected to achieve these targets as FSOs, POs and PCs. This demonstrates that perhaps the greater limitation in the implementation of the concepts is not the lack of guidance on how to establish them [16] or link them to each other $[6,18]$, nor the legal constraints, but it could also be due to the political courage that might come from making known to the public that a certain level of risk with regards to foodborne illness is accepted.

The European Drinking Water Directive, aiming to protect public health from microbial and chemical contaminants in water, is another example of risk based guidelines linked with specific control standards [95]. The Directive has as a scientific basis the guidelines of the World Health Organization on drinking water that define a "tolerable level of risk" in relation to drinking water as an upper limit of $10^{-6}$ DALYs per person per year [96] and the opinion of the Commission's Scientific Advisory Committee to determine the toxicity of chemical compounds [95]. When incorporating the Directive's thresholds on microbial and chemical contaminants into their own legislation, EU Member States have the right to aim for higher standards or additional requirements (e.g. regulate more substances or microorganisms relevant for their territory) but it is not possible to set lower standards since the level of protection of human health should be the same within the whole European Union. Nonetheless, Member States are allowed to deviate from the standards of the Directive for a limited period of time, provided that in this period the quality of the water supply cannot be maintained by any reasonable means and it can be demonstrated by means of risk assessment that the deviation does not constitute a danger to human health [97]. Thus it 
can be said that the Directive allows for the setting of sanitary measures in the same way as the SPS agreement [8]: based on a scientific assessment of the risk to the population and giving the freedom to Member States to aim for stricter measures when deemed necessary to protect human health within their territory.

\section{Concluding remarks}

A country study on the impact of foodborne diseases is recommended before deciding on an ALOP to quantify and put risks into perspective before deciding whether they are acceptable or not. In chapter 2 we have shown that such a study is possible for a country with laboratory-based surveillance and that despite uncertainties, results can still be useful for risk ranking. The developed approach for working with limited country specific data for source attribution, under-reporting and case fatalities was presented at the fourth meeting of the Foodborne Disease Epidemiology Reference Group (FERG) of the World Health Organization where it was positively received [98]

ALOPs, FSOs and other risk-based metrics can be used to manage food safety on a national level besides food trading situations but decisions need to be made by competent authorities: definition, risk assessment approach, political courage to make decisions on acceptable risk and communication to the general public. In chapters 2-4 we have shown that setting these metrics is possible in situations that differ as much as possible in terms of the infectivity of the pathogen, the frequency of consumption and mode of preparation of the commodity and the availability of data.

When possible, it is advisable to implement both a top-down and a bottom-up risk assessment approach for setting risk-based metrics. In this chapter and chapters 3-4 we have shown that the top-down approach can be used to decide on a target level of protection and that the bottom-up approach can be used to decide on interventions to meet the target level of protection and set relevant targets in the food chain to guide management decisions. Though ideally the two approaches are recommended since they complement each other, the availability of data and/or complexity of a case may result in only one of the two approaches being implemented as was the case in chapter 5 .

Despite the uncertainty and variability that is inherent to stochastic risk assessments, riskbased metrics can make decision making in relation to food safety transparent by providing a quantitative link between a hazard and the risk it pauses to the population. Furthermore, such metrics provide flexibility to decision makers by allowing for the objective evaluation of alternative public health protection levels and risk mitigation strategies. 


\section{References}

1. Anonymous. Worldometers - real time world statistics [cited 2013 December 30]. Available from: http://www.worldometers.info/

2. Anonymous. (2004). Department of Economic and Social Affairs. Popular Division. World population to 2300. United Nations: New York. Available from: https://warwick.ac.uk/fac/soc/pais/research/researchcentres/csgr/green/foresight/ demography/united nations world population to 2300.pdf

3. Godfray, H.C.J., J.R. Beddington, I.R. Crute, L. Haddad, D. Lawrence, J.F. Muir, J. Pretty, S. Robinson, S.M. Thomas, and C. Toulmin. Food Security: The challenge of feeding 9 billion people. Science. 2010; 327: p. 812-818.

4. FAO. (1996). Rome Declaration on World Food Security and World Food Summit Plan of Action. Food and Agriculture Organization of the United Nations: Rome. Available from: http://www.fao.org/docrep/003/w3613e/w3613e00.htm

5. Anonymous. (2011). Foresight. The Future of food and farming: Challenges and choices for global sustainability. Final Project Report. The Government Office for Science: London. Available from: http://www.bis.gov.uk/assets/foresight/docs/foodand-farming/11-546-future-of-food-and-farming-report.pdf

6. Stringer, M. Food safety objectives - role in microbiological food safety management. Food Control. 2005; 16: p. 775-794.

7. FAO/WHO. (2006). The use of microbiological risk assessment outputs to develop practical risk management strategies. Food and Agricultural Organization of the United Nations/World Health Organization: Rome/Geneva. Available from: https://www.who.int/foodsafety/publications/micro/MRA Outputs.pdf

8. WTO. (1995). Agreement on the application of sanitary and phytosanitary measures (SPS Agreement). World Trade Organization: Geneva. Available from: http://www.wto.org/english/docs e/legal e/15-sps.pdf

9. ICMSF. International Commission on Microbiological Specifications for Foods. Book 7. Microbiological testing in food safety management (2nd edition). 2002. International Commission on Microbiological Specifications for Foods (eds). Springer International Publishing AG: Cham, Switzerland

10. CAC. (2004). Codex Alimentarius. Codex Alimentarius Commission. Procedural Manual. Fourteenth Edition. Available from: http://www.fao.org/3/y5817e $\angle y 5817 \mathrm{e} 00 . \mathrm{htm}$

11. de Swarte, C. and R.A. Donker. Towards an FSO/ALOP based food safety policy. Food Control. 2005; 16: p. 825-830.

12. Todd, C.D.E. Microbiological safety standards and public health goals to reduce foodborne disease. Meat Science. 2003; 66: p. 33-43. 
13. ICMSF. (2006). A simplified guide to understanding and using Food Safety Objectives and Performance Objectives. International Commission on Microbiological Specifications for Foods: Available from: http://www.icmsf.org/publications/quide/

14. Zwietering, M. Practical considerations on food safety objectives. Food Control. 2005; 16: p. 817-823.

15. Gorris, L.G.M. Food safety objective: An integral part of food chain management. Food Control. 2005; 16: p. 801-809.

16. Havelaar, A.H., M.J. Nauta, and J.T. Jansen. Fine-tuning food safety objectives and risk assessment. International Journal of Food Microbiology. 2004; 93: p. 11-29.

17. Codex Alimentarius. (2007). Principles and guidelines for the conduct of microbiological risk management (MRM), CAC/GL 63-2007. Available from: http://www.fao.org/fao-who-codexalimentarius/sh-proxy/en $\angle$ ? Ink=1\&url=https\%253A\%252F\%252Fworkspace.fao.org\%252Fsites\%252Fcodex \%252FStandards\%252FCAC\%2BGL\%2B63-2007\%252FCXG 063e.pdf

18. Rieu, E., K. Duhem, E. Vindel, and M. Sanaa. Food safety objectives should integrate the variability of the concentration of pathogen. Risk Analysis. 2007; 27: p. 373-386.

19. Hulebak, K.L. and W. Schlosser. Hazard analysis and critical control point (HACCP) history and conceptual overview. Risk Analysis. 2002; 22: p. 547-552.

20. European Community. (2004). European Parliament and Council of the European Union. Regulation (EC) No 852/2004 of the European Parliament and of the Council of 29 April 2004 on the hygiene of foodstuffs. Available from: http://eurlex.europa.eu/LexUriServ/LexUriServ.do?uri=0J:L:2004:139:0001:0054:en:PDF

21. Buncic, S. and J. Sofos. Interventions to control Salmonella contamination during poultry, cattle and pig slaughter. Food Research International. 2012; 45: p. 641-655.

22. Codex Alimentarius. (2007). Working principles for risk analysis for food safety for application by governments. CAC/GL 62-2007. Available from: http://www.fao.org 33/a-a1550t.pdf

23. FAO/WHO. (2006). Food safety risk analysis. A guide for national food safety authorities. ISBN: 978-92-5-105604. Food and Agriculture Organization of the United Nations/World Health Organization: Rome/Geneva. Available from: http://www.who.int/foodsafety/publications/micro/riskanalysis06.pdf

24. ILSI. (2007). Using Microbiological Risk Assessment (MRA) in Food Safety Management. Summary report of a workshop held in October 2005 in Prague, Czech Republic. International Life Sciences Institute: Brussels. Available from: http://ilsi.org/mexico/wp-content/uploads/sites/29/2016/09/Using-MicrobiologicalRisk-Assessment-MRA-in-Food-Safety-Management.pdf

25. Van der Fels-Klerx, H.J., E.D. Van Asselt, M. Raley, M. Poulsen, H. Korsgaard, L. Bredsdorff, M. Nauta, M. D'Agostino, D. Coles, H.J.P. Marvin, and L.J. Frewer. Critical 
review of methods for risk ranking of food-related hazards, based on risks for human health. Critical Reviews in Food Science and Nutrition. 2017; p. 1-16.

26. World Health Organization. (2007). The global burden of foodborne disease: taking stock and charting the way forward: WHO consultation to develop a strategy to estimate the global burden of foodborne diseases, Geneva, 25-27 September 2006. The Organization: Geneva. Available from: http://www.who.int/foodsafety /publications/foodborne disease/fbd 2006.pdf

27. Devleesschauwer, B., A. Ale, P. Torgerson, N. Praet, C.M. de Noordhout, B.D. Pandey, S.B. Pun, R. Lake, J. Vercruysse, D.D. Joshi, A.H. Havelaar, L. Duchateau, P. Dorny, and N. Speybroeck. The burden of parasitic zoonoses in Nepal: A systematic review. PLoS Neglected Tropical Diseases. 2014; 8: e2634.

28. Havelaar, A.H., J.A. Haagsma, M.-J.J. Mangen, J.M. Kemmeren, L.P.B. Verhoef, S.M.C. Vijgen, M. Wilson, I.H.M. Friesema, L.M. Kortbeek, Y.T.H.P. van Duynhoven, and W. van Pelt. Disease burden of foodborne pathogens in the Netherlands, 2009 International Journal of Food Microbiology. 2012; 156: p. 231-238.

29. Lake, J.R., J.P. Cressey, M.D. Campbell, and E. Oakley. Risk ranking for foodborne microbial hazards in New Zealand: burden of disease estimates. Risk Analysis. 2010; 30: p. 743-752.

30. Van Lier, E.A. and A.H. Havelaar. (2007). Disease burden of infectious diseases in Europe: a pilot study. National Institute for Public Health and the Environment: Bilthoven. Available from: http://www.rivm.nl/bibliotheek/rapporten/215011001.pdf

31. Lammerding, M.A. and A. Fazil. Hazard identification and exposure assessment for microbial food safety risk assessment. International Journal of Food Microbiology. 2000; 58: p. 147-157.

32. Corbel, M.J. Brucellosis: an Overview. Emerging Infectious Diseases. 1997; 3: p. 213221.

33. Minas, M., A. Minas, K. Gourgulianis, and A. Stournara. Epidemiological and clinical aspects of human brucellosis in Central Greece. Japanese Journal of Infectious Diseases. 2007; 60: p. 362-366.

34. Giannakopoulos, I., N.M. Nikolakopoulou, M. Eliopoulou, A. Ellina, F. Kolonitsiou, and D.A. Papanastasiou. Presentation of childhood brucellosis in Western Greece. Japanese Journal of Infectious Diseases. 2006; 59: p. 160-163.

35. Tsolia, M., S. Drakonaki, A. Messaritaki, T. Farmakakis, M. Kostaki, H. Tsapra, and T. Karpathios. Clinical features, complications and treatment outcome of childhood brucellosis in Central Greece. Journal of Infection. 2002; 44: p. 257-262.

36. Vorou, R., K. Gkolfinapoulou, G. Dougas, K. Mellou, I.N. Pierroutsakos, and T. Papadimitriou. Rapid communications. Local brucellosis outbreak on Thassos, Greece: a preliminary report. Eurosurveillance. 2008; 13: p. 1-2. 
37. Besser, J.M. Salmonella epidemiology: A whirlwind of change. Food Microbiology. 2018; 71: p. 55-59.

38. EFSA/ECDC. The Community summary report on food-borne outbreaks in the European Union in 2007. The EFSA Journal. 2009; 7: 271r.

39. Scuderi, G., M. Fantasia, E. Filetici, and M.P. Anastasio. Foodborne outbreaks caused by Salmonella in Italy. Epidemiology and Infection. 1996; 116: p. 257-265.

40. FAO/WHO. (2002). Risk assessments of Salmonella in eggs and broiler chickens. Food and Agriculture Organization of the United Nations/World Health Organization: Rome/Geneva. Available from: http://www.fao.org/3/a-y4392e.pdf

41. ECDC. (2007). The first European communicable disease epidemiological report. European Centre for Disease prevention and Control: Stockholm. Available from: http://www.ecdc.europa.eu/en/publications/Publications/0706 SUR First \%20Ann ual Epidemiological Report 2007.pdf

42. Verso, M.G., A. Provenzani, S. Sorrentino, S. Caracappa, F. Vitale, G. Vesco, and D. Picciotto. [Case study of a population of subjects in Sicily operated for echinococcosis cysts: correlation with occupational and living environment] in italian. La Medicina del Lavoro. 2000; 91: p. 135-141.

43. Cook, A.J.C., R.E. Gilbert, W. Buffolano, J. Zufferey, E. Petersen, P.A. Jenum, W. Foulon, A.E. Semprini, and D.T. Dunn. Sources of toxoplasma infection in pregnant women: European multicentre case-control study. BMJ. 2000; 321: p. 142-147.

44. Iddawela, D., S.M.P. Vithana, and C. Ratnayake. Seroprevalence of toxoplasmosis and risk factors of Toxoplasma gondii infection among pregnant women in Sri Lanka: a cross sectional study. BMC Public Health. 2017; 17: p. 930.

45. Kapperud, G., P.A. Jenum, B. Stray-Pedersen, K.K. Melby, A. Eskild, and J. Eng. Risk factors for Toxoplasma gondii infection in pregnancy: results of a prospective casecontrol study in Norway. American Journal of Epidemiology. 1996; 144: p. 405-412.

46. Petersen, E., G. Vesco, S. Villari, and W. Buffolano. What do we know about risk factors for infection in humans with Toxoplasma gondii and how can we prevent infections? Zoonoses Public Health. 2010; 57: p. 8-17.

47. de Wit, L.A., D.A. Croll, B. Tershy, D. Correa, H. Luna-Pasten, P. Quadri, and A.M. Kilpatrick. Potential public health benefits from cat eradications on islands. PLOS Neglected Tropical Diseases. 2019; 13: e0007040.

48. Wilking, H., M. Thamm, K. Stark, T. Aebischer, and F. Seeber. Prevalence, incidence estimations, and risk factors of Toxoplasma gondii infection in Germany: a representative, cross-sectional, serological study. Scientific Reports. 2016; 6: p. 22551. 
49. Fazil, A., A. Rajic, J. Sanchez, and S. McEwen. Choices, Choices: The application of multi-criteria decision analysis to a food safety decision-making problem. Journal of Food Protection. 2008; 71: p. 2323-2333.

50. Nauta, M.J. Separation of uncertainty and variability in quantitative microbial risk assessment models. International Journal of Food Microbiology. 2000; 57: p. 9-18.

51. Zwietering, M.H. and S.J.C. van Gerwen. Sensitivity analysis in quatitative microbial risk assessment. International Journal of Food Microbiology. 2000; 58: p. 213-221.

52. Walls, I. and L.R. Buchanan. Use of food safety objectives as a tool for reducing foodborne listeriosis. Food Control. 2005; 16: p. 795-799.

53. Murray, C.J.L. Quantifying the burden of disease: the technical basis for disabilityadjusted life years. Bulletin of the World Health Organization. 1994; 72: p. 429-445.

54. Murray, C.J.L. and K.A. Acharya. Understanding DALYs. Journal of Health Economics. 1997; 16: p. 703-730.

55. FAO/WHO. (2002). Principles and guidelines for incorporating microbiological risk assessment in the development of food safety standards, guidelines and related texts. Report of a Joint FAO/WHO Consultation, Kiel, Germany, 18-22 March 2002. ISBN: 92-5-104845-2. Food and Agriculture Organization of the United Nations/World Health Organization: Rome/Geneva. Available from: http://www.fao.org/3/a-y4302e.pdf

56. World Health Organization. (2002). Methods for Foodborne Disease Surveillance in Selected Sites. Report of a WHO consultation 18-21 March 2002, Leipzig, Germany. The Organization: Geneva. Available from: http://whqlibdoc.who.int/hq/2002 /WHO CDS CSR EPH 2002.22.pdf

57. Omac, B., R.G. Moreira, A.F. Puerta-Gomez, and E. Castell-Perez. Effect of intervention strategies on the risk of infection from Listeria monocytogenes due to consumption of fresh baby spinach leaves: A quantitative approach. LWT - Food Science and Technology. 2017; 80: p. 208-220.

58. Codex Alimentarius. (2012). CAC/GL 79-2012. Guidelines on the application of general principles of food hygiene to the control of viruses in food. World Health Organization/Food and Agriculture Organization of the United Nations: Geneva/Rome. Available from: http://webcache.googleusercontent.com /search?q=cache:OdxHEKTCBhYJ:www.fao.org/input/download/standards/13215/C XG 079e.pdf $+\& c d=1 \& h l=e n \& c t=c \mid n k \& g l=d k$

59. Franck, K.T., M. Lisby, J. Fonager, A.C. Schultz, B. Böttiger, A. Villif, H. Absalonsen, and $\mathrm{S}$. Ethelberg. Sources of calicivirus contamination in foodborne outbreaks in Denmark, 2005-2011-The role of the asymptomatic food handler. The Journal of Infectious Diseases. 2015; 211: p. 563-570. 
60. FDA/FSIS. (2003). Quantitative assessment of relative risk to public health from foodborne Listeria monocytogenes among selected categories of ready-to-eat foods. U.S. Department of Health and Human Services Food and Drug Administration/U.S. Department of Agriculture Food Safety Inspection service, : Washington DC. Available from: https://www.fda.gov/downloads/food/foodscienceresearch/ucm197330.pdf

61. Peters, G.P., R.M. Andrew, S. Solomon, and P. Friedlingstein. Measuring a fair and ambitious climate agreement using cumulative emissions. Environmental Research Letters. 2015; 10: p. 105004.

62. FAO/WHO. (2009). International Programme on Chemical Safety (IPCS). Environmental Health Criteria 240. Principles and methods for the risk assessment of chemicals in food. Chapter 6: Dietary exposure assessment of chemicals in food. World Health Organization, Food and Agriculture Organization of the United Nations: Geneva, Switzerland. Available from: http://apps.who.int/iris/bitstream/10665 444065/9/WHO EHC 2409 eng Chapter6.pdf

63. Membré, J.M., J. Bassett, and L.G.M. Gorris. Applying the food safety objective and related standards to thermal inactivation of Salmonella in poultry meat. Journal of Food Protection. 2007; 70: p. 2036-2044.

64. Doménech, E. and S. Martorell. Definition and usage of food safety margins for verifying compliance of Food Safety Objectives. Food Control. 2016; 59: p. 669-674.

65. Hennessy , T.W., C.W. Hedberg, L. Slutsker, K.E. White, J.M. Besser-Wiek, M.E. Moen , J. Feldman , W.W. Coleman , L.M. Edmonson, K.L. MacDonald , M.T. Osterholm, and and the Investigation Team. A national outbreak of Salmonella enteritidis infections from ice cream. New England Journal of Medicine. 1996; 334: p. $1281-1286$.

66. O'Mahony, M., E. Mitchell, R.J. Gilbert, D.N. Hutchinson, N.T. Begg, J.C. Rodhouse, and J.E. Morris. An outbreak of foodborne botulism associated with contaminated hazelnut yoghurt. Epidemiology and Infection. 2009; 104: p. 389-395.

67. McLauchlin, J., K.A. Grant, and C.L. Little. Food-borne botulism in the United Kingdom. Journal of Public Health. 2006; 28: p. 337-342.

68. Neil, K.P., G. Biggerstaff, J.K. MacDonald, E. Trees, C. Medus, K.A. Musser, S.G. Stroika, D. Zink, and M.J. Sotir. A novel vehicle for transmission of Escherichia coli 0157:H7 to humans: Multistate uutbreak of E. coli 0157:H7 infections associated with consumption of ready-to-bake commercial prepackaged cookie dough-United States, 2009. Clinical Infectious Diseases. 2012; 54: p. 511-518.

69. Bouwknegt, M., K. Verhaelen, A. Rzeżutka, I. Kozyra, L. Maunula, C.-H. von Bonsdorff, A. Vantarakis, P. Kokkinos, T. Petrovic, S. Lazic, I. Pavlik, P. Vasickova, K.A. Willems, A.H. Havelaar, S.A. Rutjes, and A.M. de Roda Husman. Quantitative farm-to-fork risk assessment model for norovirus and hepatitis A virus in European 
leafy green vegetable and berry fruit supply chains. International Journal of Food Microbiology. 2015; 198: p. 50-58.

70. Anonymous. Salmonella Action Plan [cited Available from: https://www.fsis.usda.gov Lwps/portal/fsis/topics/food-safety-education/get-answers/food-safety-fact-sheets /foodborne-illness-and-disease/salmonella/sap

71. Wegener, H.C., T. Hald, D.L.F. Wong, M. Madsen, H. Korsgaard, F. Bager, P. GernerSmidt, and K. Mølbak. Salmonella Control Programs in Denmark. Emerging Infectious Diseases. 2003; 9: p. 775.

72. Terry, L. The Oregonian/OregonLive 2014. Contaminated chicken: USDA says difficult to replicate Denmark and eliminate Salmonella in poultry. Available from: https://www.oregonlive.com/health/index.ssf/2014/03/contaminated chicken usda says.html

73. Condoleo, R., Z. Mezher, S. Marozzi, A. Guzzon, R. Fischetti, M. Senese, S. Sette, and L. Bucchini. Risk assessment of human listeriosis from semisoft cheeses made from raw sheep's milk in Lazio and Tuscany (Italy). Risk Analysis. 2017; 37: p. 661676.

74. Girard, D., A. Leclercq, E. Laurent, M. Lecuit, H. de Valk, and V. Goulet. Pregnancyrelated listeriosis in France, 1984 to 2011, with a focus on 606 cases from 1999 to 2011. Eurosurveillance. 2014; 19: p. 20909.

75. European Community. (2005). European Parliament and Council of the European Union. Commission Regulation (EC) No 2073/2005 of November 2005 on microbiological criteria for foodstuffs. Available from: http://eurlex.europa.eu/LexUriServ/LexUriServ.do?uri=0J:L:2005:338:0001:0026:EN:PDF

76. Anonymous. (2018). e - CFR. Electronic Code of Federal Regulations (21 C.F.R. $\S$ 109.4, §133). Office of the Federal Register (OFR)/Government Publishing Office: USA. Available from: https://www.ecfr.gov/cgi-bin/text-idx?SID=3ee286332416 f26a91d9e6d786a604ab\&mc=true\&tpl=/ecfrbrowse/Title21/21tab 02.tpl

77. Chen, Y., W.H. Ross, V.N. Scott, and D.E. Gombas. Listeria monocytogenes: low levels equal low risk. Journal of Food Protection. 2003; 66: p. 570-7.

78. Ricci, A., A. Allende, D. Bolton, M. Chemaly, R. Davies, Fernandez Escamez PS, R. Girones, L. Herman, K. Koutsoumanis, B. Nørrung, L. Robertson, G. Ru, M. Sanaa, M. Simmons, P. Skandamis, E. Snary, N. Speybroeck, B. Ter Kuile, J. Threlfall, H. Wahlstrom, J. Takkinen, M. Wagner, D. Arcella, Da Silva Felicio MT, M. Georgiadis, W. Messens, and R. Lindqvist. Listeria monocytogenes contamination of ready-to-eat foods and the risk for human health in the EU. EFSA Journal. 2018; 16: e05134.

79. Terry, L. The Oregonian/OregonLive 2014. Contaminated chicken: How Denmark solved its Salmonella problem. Available from: https://www.oregonlive.com Lhealth/index.ssf/2014/03/contaminated chicken denmark.html 
80. Hald, T., S.M. Pires, H. Korsgaard, N.C. Feld, J. Mygind, and M. Madsen. The effects, costs and benefits of Salmonella surveillance in the Danish table-egg sector. in 11th International Symposium on Veterinary Epidemiology and Economics. 2006.

81. Scallan, E., R.M. Hoekstra, F.J. Angulo, R.V. Tauxe, M.A. Widdowson, S.L. Roy, J.L. Jones, and M.P. Griffin. Foodborne illness acquired in the United States - Major pathogens. Emerging Infectious Diseases. 2011; 17: p. 7-15.

82. FAO. FAOSTAT - FAO's corporate database [cited 2019 May 3rd]. Available from: http://www.fao.org/faostat/en/\#home

83. Painter, J.A., R.M. Hoekstra, T. Ayers, R.V. Tauxe, B.C. R., F.J. Angulo, and P.M. Griffin. Attribution of foodborne illnesses, hospitalizations, and deaths to food commodities by using outbreak data, United States, 1998-2008. Emerging Infectious Disease Journal. 2013; 19: p. 407.

84. Buchanan, R.L. Understanding and managing food safety risks, in Food Safety Magazine, Issue: December 2010/January 2011. Available from: http://www.foodsafetymagazine.com/magazine-archive1/december-2010january2011/understanding-and-managing-food-safety-risks/

85. WHO. Five keys to safer food [cited 2013 January 10]. Available from: http://www.who.int/foodsafety/publications/consumer/en/5keys en.pdf

86. Havas Lemz. The invisible made visible - The Food and Nutrition Centre (Voedingscentrum) [cited 2019 January 20th]. Available from: http://havaslemz.com/cases/voedingscentrum/

87. Anonymous. (2014). Foodborne pathogens are invisible. Voedingscentrum: Den Haag. Available from: https://www.voedingscentrum.nl/Assets/Uploads Lvoedingscentrum/Documents/Professionals/Overig/VC Flyers Advancing\%20Food \%20Safety.pdf

88. Anonymous. Campagne hygiëne in de keuken van start [cited 2019 April 7th]. Available from: https://www.evmi.nl/nieuws/voedselveiligheid-kwaliteit/campagnehygiene-de-keuken-van-start/

89. Covello, V. and P.M. Sandman. (2001). Risk communication: evolution and revolution, in "Solutions to an environment in peril". John Hopkins University Press: Baltimore, Maryland

90. Horlick-Jones, T., J. Walls, and G. Rowe. On Evaluating the GM Nation? Public Debate about the Commercialisation of Transgenic Crops in Britain. New Genetics and Society. 2006; 25: p. 265-288.

91. Hurd, H.S., C. Enøe, L. Sørensen, H. Wachmann, S.M. Corns, K.M. Bryden, and M. Greiner. Risk-Based analysis of the Danish pork Salmonella program: past and future. Risk Analysis. 2008; 28: p. 341-351. 
92. Feld, N.C., L. Ekeroth, K.O. Gradel, S. Kabell, and M. Madsen. Evaluation of a serological Salmonella Mix-ELISA for poultry used in a national surveillance programme. Epidemiology and Infection. 2000; 125: p. 263-268.

93. Anonymous. (2018). Annual report on zoonoses in Denmark 2017. National Food Institute, Technical University of Denmark, the Danish Veterinary and Food Administration and Statens Serum Institute: Copenhagen. Available from: https://www.food.dtu.dk/Publikationer/Sygdomsfremkaldende-mikroorganismer Zoonoser-aarlige-rapporter

94. Anonymous. HealthyPeople.gov - Food Safety [cited 2019 April 8]. Available from: https://www.healthypeople.gov/2020/topics-objectives/topic/food-safety/objectives

95. European Community. (1998). European Parliament and Council of the European Union. Council Directive 98/83/EC of 3 November 1998 on the quality of water intended for human consumption. Available from: https://eur-lex.europa.eu/legalcontent/EN/TXT/?uri=CELEX:31998L0083

96. WHO. (2017). Guidelines for drinking-water quality. Fourth edition incorporating the first addendum. World Health Organization: Geneva. Available from: http://apps.who.int/iris/bitstream/handle/10665/254637/9789241549950eng.pdf; jsessionid =EB5055B5D64FA3E20AEEB6FE3844CADD? sequence $=1$

97. EC. European Commission. Environment. Water. Drinking water. Drinking water Directive. The Directive overview [cited 2019 January 14]. Available from: http://ec.europa.eu/environment/water/water-drink/legislation en.html

98. WHO. (2014). WHO Initiative to estimate the global burden of foodborne diseases. Fourth formal meeting of the Foodborne Disease Burden Epidemiology Reference Group (FERG): sharing new results, making future plans, and preparing ground for the countries. World Health Organization: Geneva. Available from: https://apps.who.int/iris/bitstream/handle/10665/159844/9789241507950 eng.pdf ?sequence $=1$ 


\section{Summary}

Foodborne illnesses are a significant cause of morbidity and mortality worldwide and are therefore important to manage for the protection of public health. In the course of the last half century, when it comes to prioritizing resources for their management, there has been a gradual shift of focus from the hazards that cause the illnesses (microorganisms, chemical and physical agents) to the actual risk that these hazards pose to the population (probability and severity of adverse health effects in relation to hazards in food) and their impact on public health. To accommodate these different schools of thought, new health metrics could be operationalized (DALY, Disability Adjusted Life Year) but also new benchmarks were created for the control of foodborne hazards in food supply chains (ALOP, Appropriate Level of Protection; FSO, Food Safety Objective). These risk-based metrics have been proposed by international organizations as a means of establishing a link between governmental public health policy and the management of hazards in the food supply chain.

The aim of this thesis was to develop four different case studies on the operationalization of these risk-based metrics (DALY, ALOP, FSO). Cases were selected so as to deal with different microbial hazards, food products and population groups as well as addressing a number of different real life settings faced by competent authorities in various countries.

The first case study used a range of publicly available data to rank all foodborne risks in Greece on the basis of DALYs, in order to set national priorities for food safety management. The use of the results of this study for setting ALOPs is part of the general discussion of the thesis.

The second case study dealt with setting of ALOP and FSO targets for Listeria monocytogenes in deli meats in the Netherlands. Here the focus was on a severe, low incidence disease, mainly relevant for susceptible subpopulations, usually associated with medium to high doses of the pathogen in contaminated products consumed on a regular basis by the vast majority of the Dutch population.

The third case study concerned the implementation of risk-based targets for Salmonella in poultry meat in the Netherlands and in 22 other EU Member States. Here the focus was on a mostly mild but, on occasion, severe disease, due to longer term sequelae, usually associated with ingestion of low doses of the pathogen through contaminated or undercooked products consumed frequently by the vast majority of the European population.

The last case study addressed the application of the targets for Clostridium perfringens in Cornish pasties in the United Kingdom. Here the focus was on a mostly self-limiting, rarely fatal illness, usually associated with very high doses of the pathogen in a Protected Geographical Indication product, infrequently consumed by the British population. 
The developed case studies showed that the operationalization of the new metrics is feasible and valuable in creating insight and for making food safety more transparent and quantifiable despite data scarcities, inherent uncertainty and variability in the risk estimates and the need for decisions to be made on the interpretation of the metric definitions and their communication to the public. 


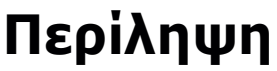

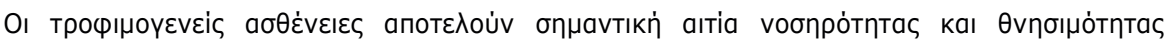

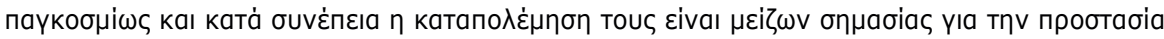

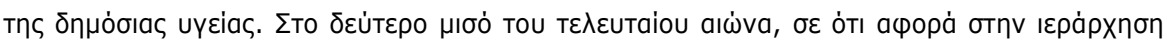

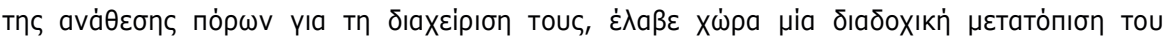

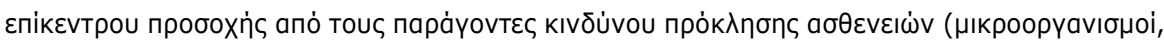

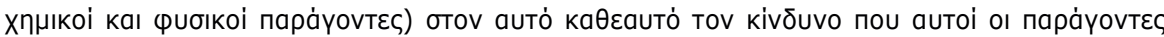

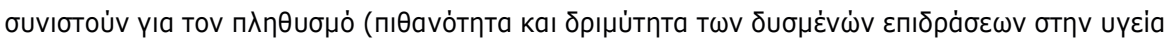

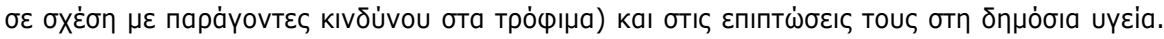

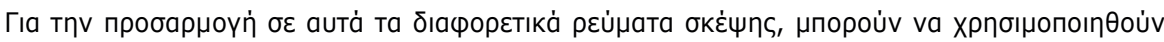

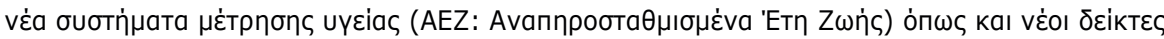

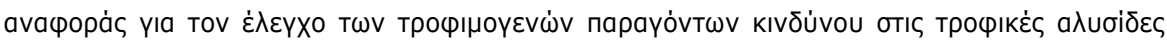

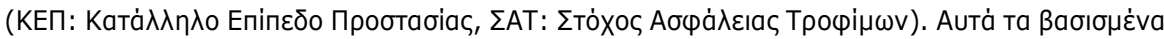

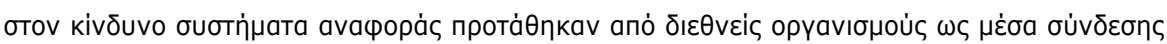

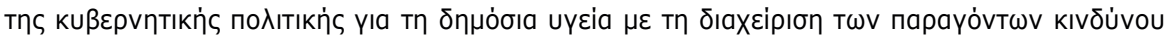

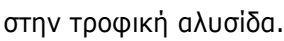

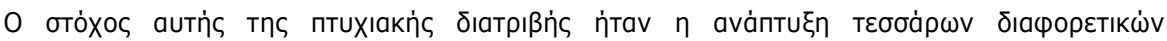

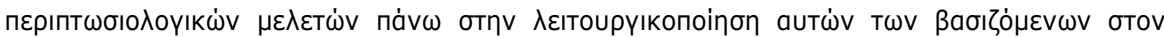

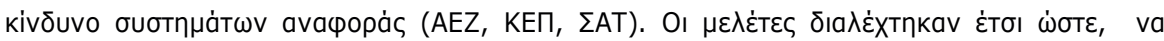

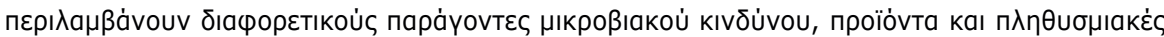

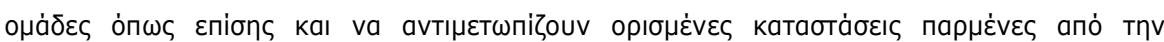

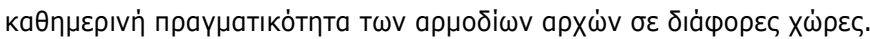

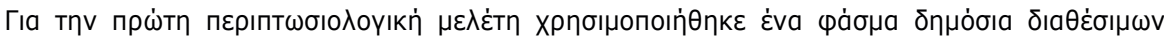

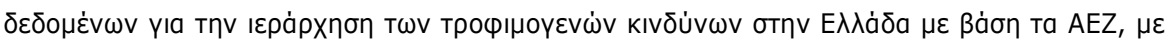

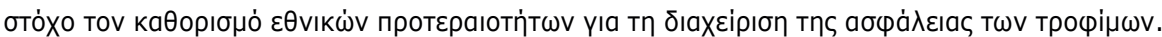

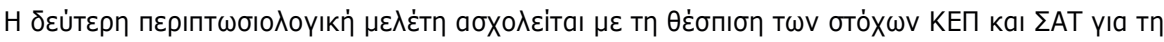

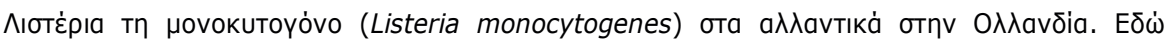

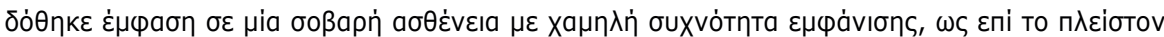

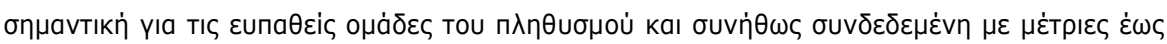

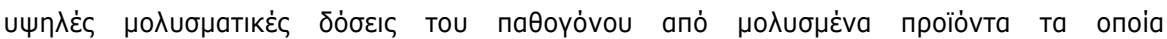

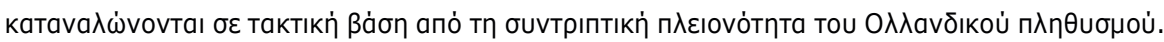

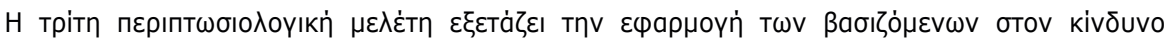

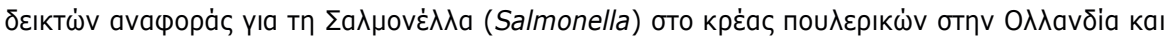

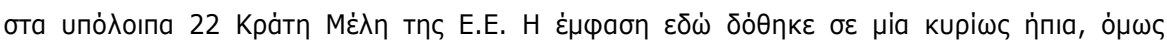

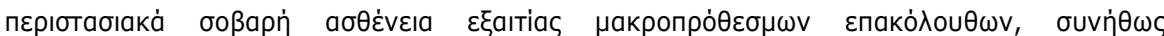




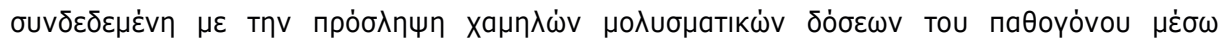

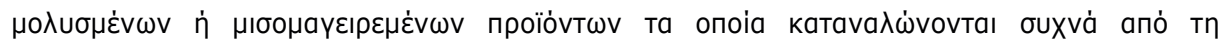

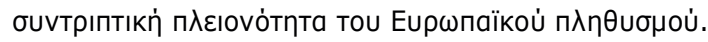

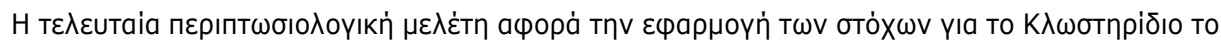

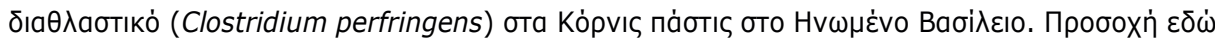

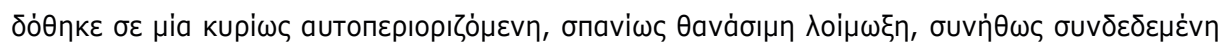

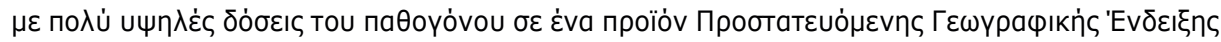

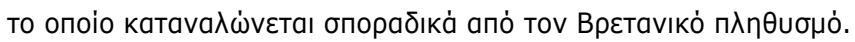

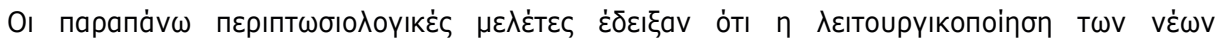

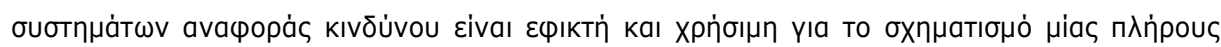

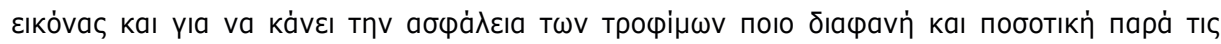

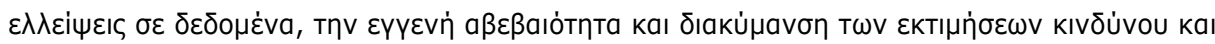

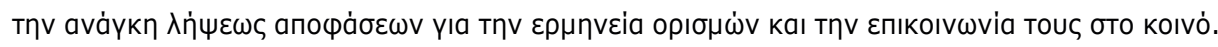




\section{VLAG graduate school}

Overview of completed training activities

\section{Discipline specific activities}

Courses

Management of microbiological hazards in foods, VLAG, Wageningen NL, 2008

Genetics \& physiology of food associated microorganisms, VLAG, Wageningen, NL, 2010

Reaction kinetics in food, VLAG, Wageningen, NL, 2009

Food risk analysis, MGS, Wageningen, NL, 2009

Summer school QMRA, Delft, NL, 2010

Conferences and meetings

Food Micro 2008 (poster presentation), ICFMH, Aberdeen, UK, 2008

Food Micro 2010 (poster presentation), ICFMH, Copenhagen, DK, 2010

Food Micro 2012 (oral presentation), ICFMH, Istanbul, TU, 2012

ICPMF 7 (oral presentation), ICPMF, Dublin, IE, 2011

FERG meeting (oral presentation), WHO, Geneva, CH, 2010

ICPMF 8 (oral presentation), ICPMF, Paris, FR, 2013

\section{General courses}

VLAG PhD week, VLAG, Bilthoven, NL, 2009

PhD competence assessment, WGS, Wageningen, NL, 2009

Teaching and supervising thesis students, WGS, Wageningen, NL, 2011

Information literacy, including introduction Endnote, WGS, Wageningen, NL, 2010

Techniques for writing and presenting a scientific paper, WGS, Wageningen, NL, 2009

Basic statistics, C.T. de Wit Graduate School, Wageningen, NL, 2008

Project and time management, WGS, Wageningen, NL, 2009

Philosophy and ethics of food science and technology, WGS, Wageningen, NL, 2009

Career perspectives, WGS, Wageningen, NL, 2011

\section{Optional activities}

Preparation of research proposal, FHM, Wageningen, NL

FHM PhD trip, Switzerland 2010, including organization

FHM PhD trip, Japan 2012 
Addenda

\section{Supervision of WUR courses and practicals}

FHM-20306 Food Microbiology practical, 2008 and 2009

FHM-30306 Food Safety practical, 2010 and 2011

Discipline Integrated Product Practical, 2009 and 2010 


\section{List of publications}

\section{This thesis}

Gkogka, E., M.W. Reij, A.H. Havelaar, M.H. Zwietering, and L.G.M. Gorris. Risk-based estimate of effect of foodborne diseases on public health, Greece. Emerging Infectious Diseases. 2011; 17: p. 1581-1590.

Gkogka, E., M.W. Reij, L.G.M. Gorris, and M.H. Zwietering. The application of the Appropriate Level of Protection (ALOP) and Food Safety Objective (FSO) concepts in food safety management, using Listeria monocytogenes in deli meats as a case study. Food Control. 2013; 29: p. 382-393.

Gkogka, E., M.W. Reij, L.G.M. Gorris, and M.H. Zwietering. Risk assessment strategies as a tool in the application of the Appropriate Level of Protection (ALOP) and Food Safety Objective (FSO) by risk managers. International Journal of Food Microbiology. 2013; 167: p. 8-28.

Gkogka, E., M.W. Reij, L.G.M. Gorris, and M.H. Zwietering. Risk assessment of Clostridium perfringens in Cornish pasties in the UK. Submitted for publication in Food Control.

\section{Other}

Reij, M.W., I. Jongenburger, E. Gkogka, L.G.M. Gorris, and M.H. Zwietering. Perspective on the risk to infants in the Netherlands associated with Cronobacter spp. occurring in powdered infant formula. International Journal of Food Microbiology. 2009; 136: p. 232-237.

Gkogka, E., W.C. Hazeleger, M.A. Posthumus, and R.R. Beumer. The antimicrobial activity of the essential oil of Pistacia lentiscus var. Chia. Journal of Essential Oil Bearing Plants. 2013; 16: p. 714-729.

Martinez-Rios, V., N.B. Østergaard, E. Gkogka, P.S. Rosshaug, and P. Dalgaard. Modelling and predicting growth of psychrotolerant pseudomonads in milk and cottage cheese. International Journal of Food Microbiology. 2016; 216: p. 110-120.

Bosch, A., E. Gkogka, F.S. Le Guyader, F. Loisy-Hamon, A. Lee, L. van Lieshout, B. Marthi, M. Myrmel, A. Sansom, A.C. Schultz, A. Winkler, S. Zuber, and T. Phister. Foodborne viruses: Detection, risk assessment, and control options in food processing. International Journal of Food Microbiology. 2018; 285: p. 110-128.

Martinez-Rios, V., Gkogka, E. and P. Dalgaard. New term to quantify the effect of temperature on pHmin-values used in cardinal parameter growth models for Listeria monocytogenes. Frontiers in Microbiology. 2019; 10:1510.

Martinez-Rios, V., Jørgensen, Ø. M., Koukou I., Gkogka, E. and P. Dalgaard. Growth and growth boundary model with terms for melting salts to predict growth responses of Listeria monocytogenes in spreadable processed cheese. Food Microbiology. 2019; (article in press). 


\section{List of presentations}

\section{This thesis}

Gkogka, E., Reij, M.W., Zwietering, M.H., Havelaar, A.H., \& Gorris, L.G.M. (2010). Health burden of foodborne illnesses in Greece. Poster presentation at the FOOD MICRO 2010 Symposium in Copenhagen, Denmark, 30 August-3 September 2010.

Gkogka, E., Reij, M.W., Havelaar, A.H., Zwietering, M.H., \& Gorris, L.G.M. (2010). Ranking microbial foodborne risks on a national level using Greece as a case study. Oral presentation at the $4^{\text {th }}$ Formal Meeting of the Foodborne Disease Burden Epidemiology Reference Group (FERG) of the World Health Organization in Geneva, Switzerland, 8-12 November 2010.

Gkogka, E., Reij, M W., Gorris, L.G.M., \& Zwietering, M.H. (2011). The application of the Appropriate Level of Protection (ALOP) and Food Safety Objective (FSO) concepts in food safety management, using Listeria monocytogenes in deli meats as a case study. Oral presentation at the $7^{\text {th }}$ International Conference on Predictive Modelling of Food Quality and Safety in Dublin, Ireland, 12-15 September 2011.

Gkogka, E., Reij, M.W., Gorris, L.G.M., \& Zwietering, M.H. (2012). Testing the application of the appropriate level of protection (ALOP) and food safety objective (FSO) benchmarks in the case of Salmonella in chicken meat. Oral presentation at the FOOD MICRO 2012 Symposium in Istanbul, Turkey, 3-7 September 2012.

Gkogka E., van de Wardt, L.C, de Wildt, N., Vranken, E., Bouwman, L.I., Reij, M.W. (2013). Refrigerated storage and handling practices of deli meats by Dutch elderly consumers. Oral presentation at the $5^{\text {th }}$ International Cold Chain Management Workshop, Bonn, Germany

Gkogka, E., Reij, M.W., Gorris, L.G.M., Zwietering, M.H. (2013). Risk assessment of Clostridium perfringens in Cornish pasties in the UK. Oral presentation at the $8^{\text {th }}$ International Conference on Predictive Modeling in Foods, Paris, France.

Gkogka, E., Aryani,D.C., Metz, A,. Telgmann,S. Reij, M.W., Zwietering. M.H. (2014) Levels of Salmonella and Campylobacter in organic and conventional chicken fillets in the Netherlands. Poster presentation at the FOOD MICRO 2014 Symposium in Nantes, France.

Gkogka, E., Gorris, L.G.M. (2015). The application of the Appropriate Level of Protection (ALOP) and Food Safety Objective (FSO) risk-based metrics in food safety management. Oral presentation at International Association of Food Protection Webinar: http://www.foodprotection.org/events/webinars/

Gkogka, E. (2018). Application of risk based and other food safety management metrics by the industry. Oral presentation. DTU Food meeting on food safety metrics, Copenhagen, Denmark, March $20^{\text {th }} 2018$. 
Other

Gkogka E., Hazeleger, W.C., Beumer, R.R. (2008). Antimicrobial activity of the essential oil of mastic gum (Pistacia lentiscus var. Chia). Poster presentation at the FOOD MICRO 2008 Symposium in Aberdeen, Scotland, 1-5 September 2008.

Gkogka, E., Eklöw, A. (2014). Predictive modelling of dairy products - Experiences of Arla Foods. Oral presentation at Prædiktiv mikrobiologi DTU temadag, Copenhagen, Denmark, 27 February 2014.

Gkogka, E., Zhang, Y., Abee, T., Xiao, Y. Quantifying the growth variability of pathogenic and spoilage sporeforming microorganisms of interest for chilled foods using meta-analysis techniques. Poster presentation at the the $9^{\text {th }}$ International Conference on Predictive Modelling of Food Quality and Safety in Rio de Janeiro, Brazil, 8-12 September 2015.

Krogsgaard Warming, M.B., Nørgaard Bundesen, T., Bank Nielsen, M., Gkogka, E. (2016). Minimum Inhibitory Concentrations (MICs) of nisin against Bacillus and Clostridium spp. of relevance for the safety or quality of dairy products. Poster presentation at the $30^{\text {th }}$ EFFoST International Conference, Vienna, Austria, 28-30 November 2016.

Zhang, Y., Gkogka, E., Abee, T., Xiao, Y. (2016). Heat Resistance and Growth Potential of Spore-formers of Interest for Chilled Dairy Products. Poster presentation at the $7^{\text {th }}$ European Spores Conference, Royal Holloway, University of London, United Kingdom, 18-20th April 2016.

Gkogka, E. (2017). Translating risk assessment of viruses in foods into practice. Oral presentation at the European Symposium of the International Association of Food Protection, Brussels, Belgium, 29-31 March, 2017.

Krogsgaard Warming, M.B., Nørtoft Kristensen, M., Gkogka, E. Effect of temperature on the growth potential of selected yeast contaminants in fresh fermented dairy. Poster presentation at the $10^{\text {th }}$ International Conference on Predictive Modelling in Foods, Cordoba, Spain, 26-29 September 2017.

Valderrama García, E., Nitzan, N., Segal, E., Gezer, S., Gkogka, E. Effect of active packaging in extending the shelf-life of bread and Cheddar cheese. Poster presentation at the European Symposium of the International Association of Food Protection, Nantes, France, 24-26 April 2019. 


\section{Acknowledgements}

"The true delight is in the finding out rather than in the knowing." - Isaac Asimov

This PhD project has given me a lot of joy by discovering how to build predictive models, risk assessments and epidemiological studies. It also helped me to learn more about myself, what I am capable of doing and my limitations. I hope that this work will promote the use of riskbased metrics and that the developed models may in the future be of further use for deciding on interventions for the control of the studied pathogens and/or for building similar studies. A number of people have contributed to the completion of this project whom I would like to thank and mention here.

First of all, I would like to thank my supervisors Marcel Zwietering, Martine Reij and Leon Gorris for giving me the opportunity to work on this topic and their continuous support throughout the project. Marcel, I really appreciate you introducing me into the field of predictive microbiology; undoubtedly the quality of the work would not have been the same without your critical reflections and push for higher standards. Martine, thank you for all the troubleshooting attempts, guiding me through the various practicalities of the PhD and planning of the work. Leon, your experience in the international management of food safety was invaluable and greatly influenced all manuscripts and the discussion of the case-studies.

I would also like to give a special thanks to my co-author Arie Havelaar for guiding me into the field of foodborne disease epidemiology and enabling me to present the first case study at the $4^{\text {th }}$ formal meeting of the Foodborne Disease and Epidemiology Reference Group of the World Health Organization.

Peter McClure and Alejandro Amezquita are gratefully acknowledged for their valuable comments in the thesis manuscripts.

Ik wil ook mijn collega's in het levensmiddelenmicrobiologie laboratorium bedanken voor een gezellig werkomgeving! Rijkelt en Wilma, jullie passie voor microbiologie was een belangrijke reden voor mij om een carrière in dit gebied te kiezen. Judith thank you for all the emotional support and positive thinking since my first days of work in the department and for being a great friend throughout the years. Lidia thank you for all the nice memories from our trips to the UK, Portugal and Greece. Ingrid and Martina thank you for all the enjoyable breaks that took my mind of work! My fellow PhD students and colleagues, you made everyday life more pleasurable through coffee breaks, lively discussions, outings, dinners and $\mathrm{PhD} / \mathrm{lab}$ trips and excursions. Special thanks goes to Sachin, Greetje, Clint and Xiao, not only for being fantastic team players when organizing the PhD trip to Switzerland but also for our fun gatherings outside the lab.

Many thanks are also due to my students for their hard work on side topics in relation to the case studies on Listeria and Salmonella, baking experiments for the $C$. perfringens manuscript 
and risk mitigation strategies for drinking water. Pauline, Diah, Emelie, Nicky, Eline, Amrei, Sabrina, Laura and Sofia, it has been my pleasure working with you!

Halfway through my studies I made the decision to transgress from dorm to adult apartment life in Wageningen. I would like to thank all my friends that made this move possible and helped in many ways by carpooling to IKEA, Gamma and whitegoods stores, lending tools, carrying or providing furniture, tips for repairs and managing paperwork. Reiko, Tjibbe, Wasma, Ahmad, Martine, Sachin, Ingrid, Judith, Clint, Ralf, Martina and Marion: thank you for helping me to settle down in Salverdaplein and have a home away from home!

To my dear friends Reiko and Wasma, I feel so lucky that you were the first friends I made in the Netherlands and I am happy that we have not lost contact although I moved to Denmark. Thank you for being who you are and for allowing to be who I am when we are together. I treasure the unique moments we have together!

To my friends outside of food microbiology in Wageningen: Sahar, Arwa, Natasa, Nadia, Milkha, Pradnya and Anisha. Thank you for all the great discussions, encounters, outings and dinners we had together and for taking my mind of work!

Transitioning to a new life with an unfinished PhD is not easy. I would like to thank here my dear friend Sander for helping me adjust to life in Aarhus, move to my new apartment and being a link between the PhD world of the Netherlands and Denmark. Sander thank you for your support all these years! I would also like to acknowledge all my new friends and colleagues in Scandinavia that helped me forget my worries through fun dinners, movie nights, board game nights, philosophical discussions and escapades to Denmark, Sweden, Norway, Poland, the Czech Republic, France, Israel, Germany and the UK: the fellow pioneers Sander and Sirina, the Mønsgade gang (Priscila, Emilien, and Ellen), Leticia, Xiao, Yin, Lukas, Trine, Annelie, Marcin, Anna, Julia and Vittoria.

Ellen and Xiao, I really appreciate our deep discussions in food microbiology, safety and quality systems but also our fun interactions outside of work.

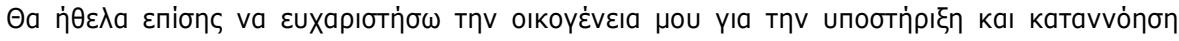

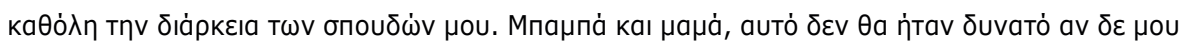

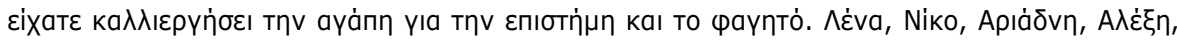

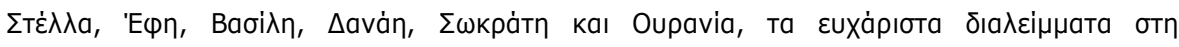

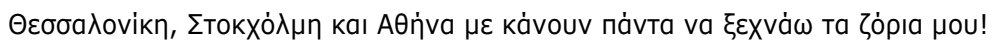

Towards the end, I would also like to acknowledge here my Arla colleagues Simon, Rodrigo and Grith for their understanding and push in finishing my PhD.

Sidst men ikke mindst, min kæreste Jonas, dette ville ikke være muligt uden din kærlighed, støtte og forståelse. Lykke er at finde en der er lige så mærkelig som sig selv og jeg glæder mig til vores fremtid sammen. 


\section{About the author}

Elissavet Gkogka was born in 1980 in Thessaloniki, Greece. From a very young age she had a love for science, nature and food which she tried to pursue by studying Agronomy with a specialization in Food Science and Technology in Aristotle University. After obtaining her degree (2005), she briefly taught pastry-making in her home town at the Institute of Vocational Training before continuing her studies in the Netherlands with an MSc in Food Safety from Wageningen University (2008). During her MSc thesis at the Food Microbiology Laboratory, she worked on the food preservation potential of mastic oil, the essential oil of Pistacia lentiscus var Chia, a tree native to her homeland. Following her MSc studies she received an award for her thesis by the Dutch NVVL Network for Food Experts and started a Unilever funded PhD on risk-based metrics in the Food Microbiology laboratory of Wageningen University. Half-way through her PhD studies she was invited as a technical advisor by the Foodborne Disease Epidemiology Reference Group (FERG) of the World Health Organization to present her study on the burden of foodborne illnesses in Greece and especially her approach for correcting for uncertainty in key multipliers (food attribution, underreporting and case fatality). Since 2013 she is based in Aarhus, Denmark where she works as a Research Microbiologist at the Innovation Centre of Arla Foods in the areas of product safety and shelf life, risk assessment, predictive modeling and challenge test design. 
The research described in this thesis was financially supported by Unilever's Safety \& Environmental Assurance Centre, Colworth Science Park, Sharnbrook, United Kingdom.

Financial support from Wageningen University for printing this thesis is gratefully acknowledged.

Cover design by Dennis Hendriks, inspired by the work of Piet Mondrian Printed by Digiforce (proefschriftmaken.nl) 